\title{
An Examination of the Desistance and Risk Paradigms in Correctional Service Canada Policies
}

\author{
By
}

Olivia Lynn Stavretis

A thesis submitted to the Faculty of Graduate and Postdoctoral Affairs in partial fulfillment of the requirements for the degree of

\author{
Master of Arts \\ in \\ Sociology \\ Carleton University \\ Ottawa, Ontario \\ (C) 2020
}

Olivia Stavretis 


\begin{abstract}
This thesis explores the concepts of desistance and risk and examines whether these aspects are present in Correctional Service Canada policies. This thesis uses thematic analysis, constructivist grounded theory and critical discourse analysis to examine four Correctional Service Canada policies: Commissioner's Directives: 705-6, 715-1, 715-2, and 715-3. Focused codes developed for each policy are as follows; $C D$ 705-6: Relationships and Thoughts, Legitimate Pathways, Criminal Experiences and Connections to Society. For CD 715-1: Connections to Society, Deviant Behaviours and Comprehension of Realities. Furthermore $C D$ 715-2 only had primary codes as it was a smaller policy, and they included History/Offence History, Relationships/Support/Community and Responses to Interventions Including Situations. Finally, CD 715-3 focused codes included Acceptance and Understanding and Connections to Society. Suggestions are made throughout this paper as to where and how aspects of the desistance paradigm could be further represented in these policies, while also providing a commentary on where risk paradigm aspects are present within them. For example, in relation to the codes, the ones that relate to offence history more fully fit within the risk paradigm, whereas the codes that relate to community and society relate more to the desistance paradigm. This paper also looks at aspects of sex offender desistance. This thesis concludes that the risk and desistance paradigms co-exist in Correctional Service Canada policy, which is beneficial for not only parole officers, but also for offenders. This is because the fact that these two paradigms are simultaneously present means they can account for parole officer style, while also allowing offenders to see where they are within their correctional program.
\end{abstract}




\section{Acknowledgements}

There are a lot of people to which I owe thanks and gratitude to that helped me get through this thesis writing process.

First, to my co-supervisor Dr. Leslie-Anne Keown. Thank you for always being there and for always being present to talk about this paper. Your insights were always incredibly valuable. Thank you for also always being around just to chat about things other than this paper, especially when I needed a break from school talk. It was always appreciated and made this process a lot easier. Thanks for being a friend and a mentor. I could not have done this without you.

Second, to my other co-supervisor, Dr. Aaron Doyle. I also owe you thanks for reading many drafts and adding many valuable contributions to this project. Your insights were also always appreciated.

I also want to extend thanks to my external examiner Dr. Shelley Brown. Thank you for taking the time to read my thesis, and for offering valuable insights at my defense. You made one of the most nerve-wracking parts of the thesis process pleasant, and for that I am grateful.

I am also really fortunate to have friends who have always been supportive of my school journey, but more importantly of me. Special shoutout goes out to my lovely friends Jackie and Kim, for answering every Facebook message and always being there when I was stressed (regardless of if I wanted to talk to anyone about it or not). You guys are amazing, and I am incredibly thankful. Another special shoutout goes out to Natalia. Thanks for being there always, and for understanding me and my feelings towards this intense journey we call grad school. You are the best.

Connor. Thank you for everything, from being there to hear me talk about this paper for a year and always listening, to making dinner on all the late nights spent working on this paper, and for reminding me to take breaks when I needed it. It was extremely appreciated more than you will ever know.

Dad. You rock! There is a lot I could say, but really it boils down to you always supporting me, and for that I am grateful. 


\section{Table of Contents}

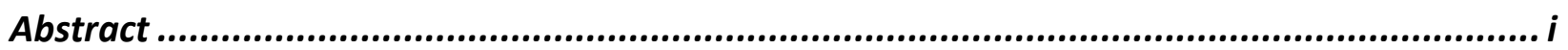

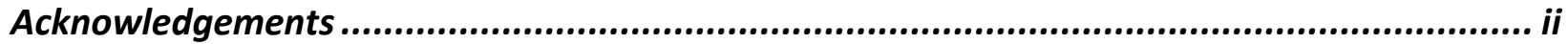

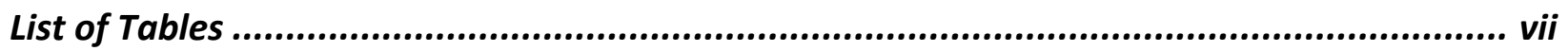

List of Abbreviations ..............................................................................................

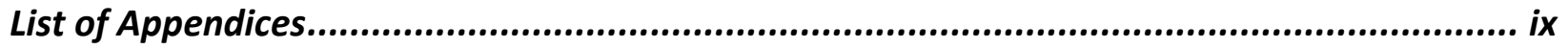

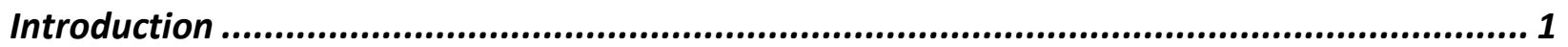

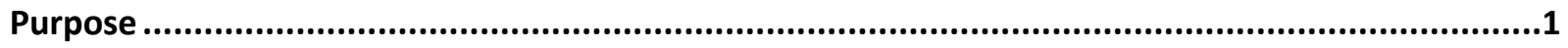

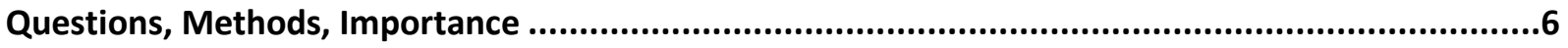

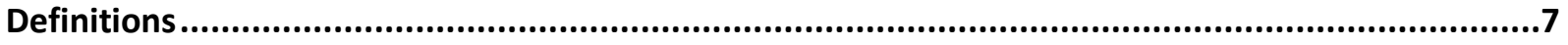

Policies

$C D$ 705-6

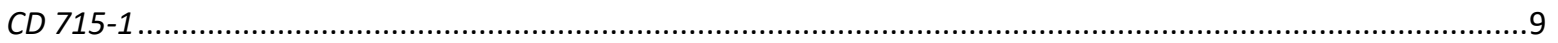

$C D$ 715-2

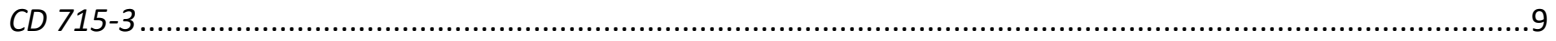

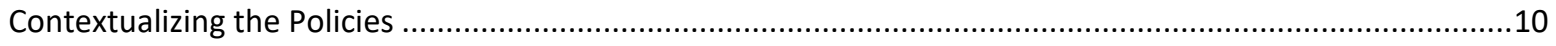

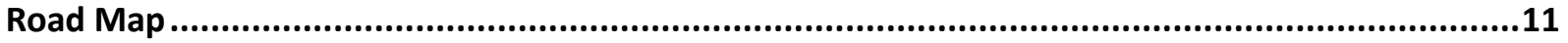

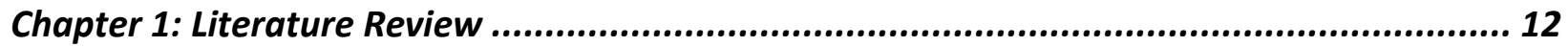

Risk Assessment Tools for Sexual Offenders, and Recidivism ................................................15

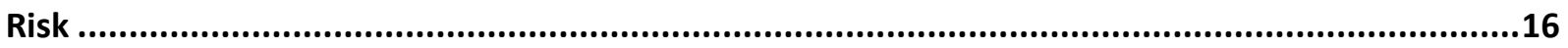

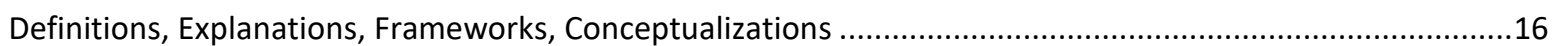

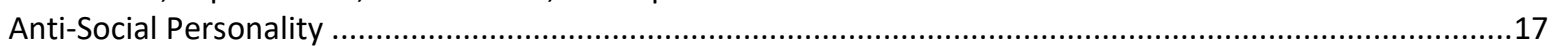

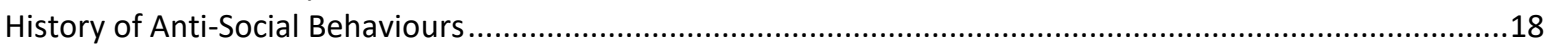

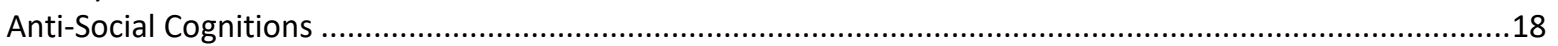

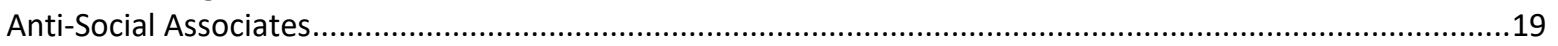

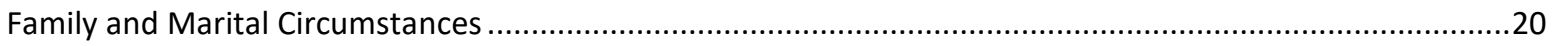

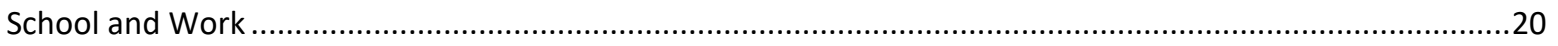

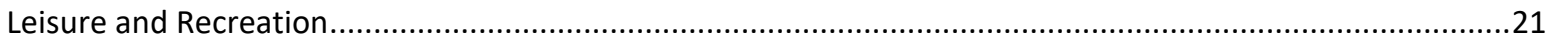

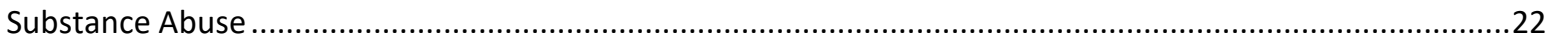

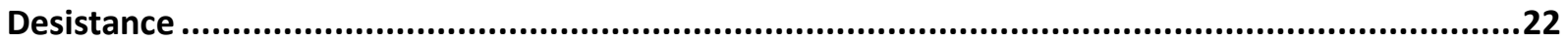

Definitions, Explanations, Frameworks, Conceptualizations ….................................................................22

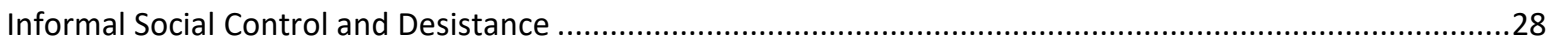

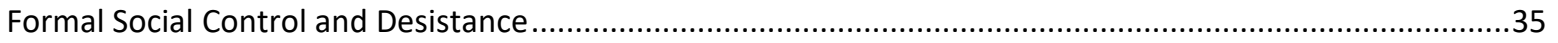

The Relationship Between Risk and Desistance .....................................................................40

Reintegration of Offenders in the Community: Perceptions, Support and Realities .......................43

Sexual Offender Reintegration: Circles of Support and Accountability .....................................................45

Government Reports: Sexual Offending and Parole...................................................................48

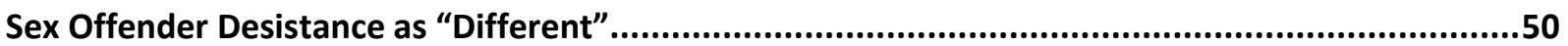

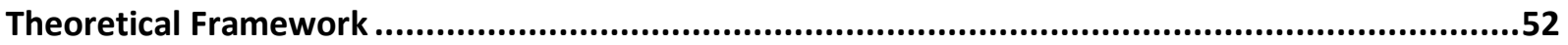




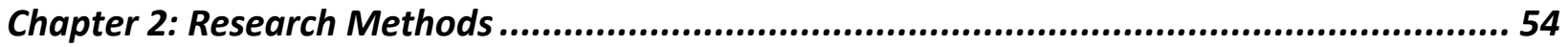

Choosing Qualitative Research .................................................................................................54

Evolution of the Research Project.............................................................................................5

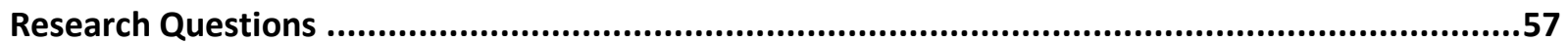

Researcher Positionality and Reflexivity .....................................................................................58

Data Type and Data Collection ...................................................................................................60

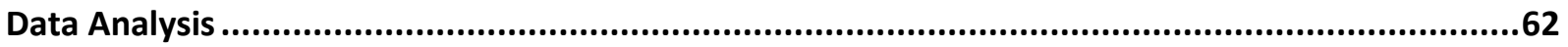

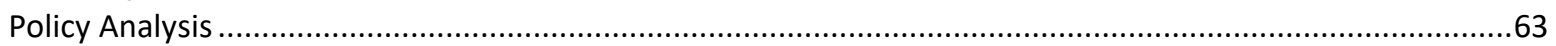

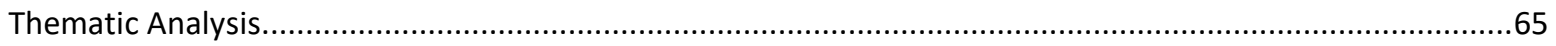

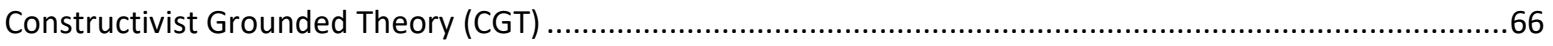

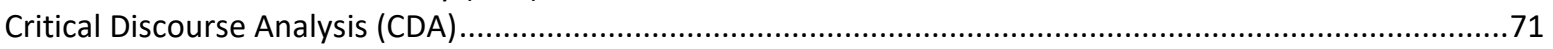

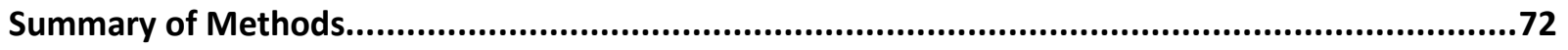

Ethical Considerations...............................................................................................................74

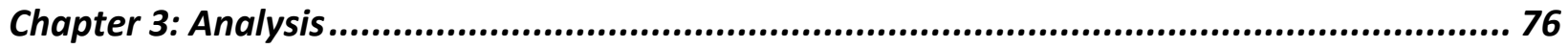

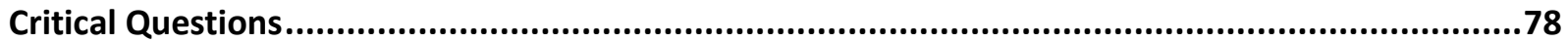

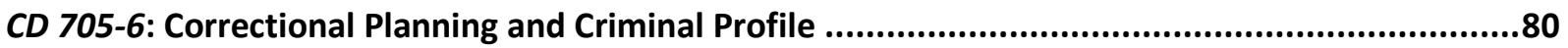

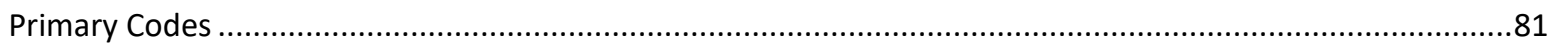

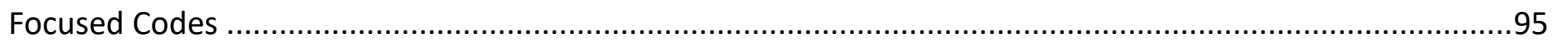

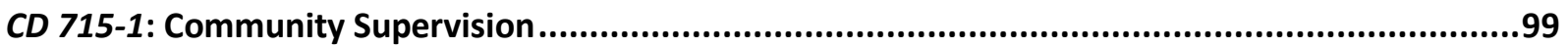

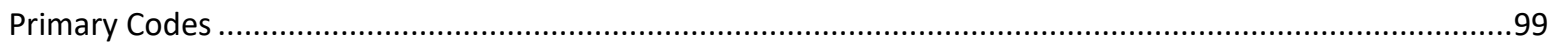

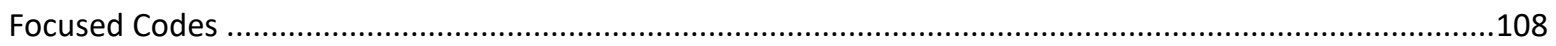

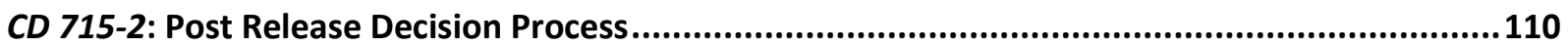

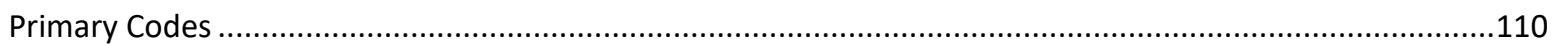

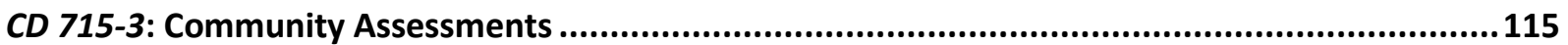

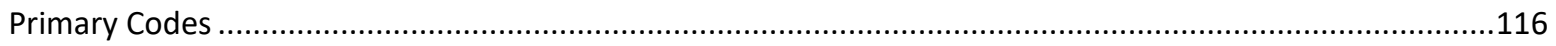

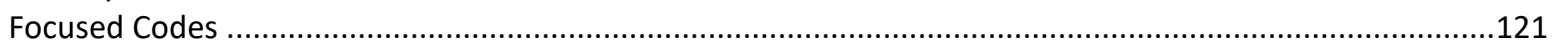

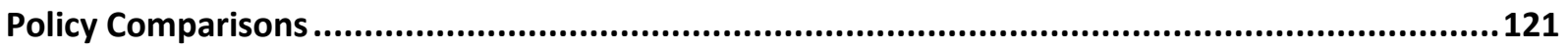

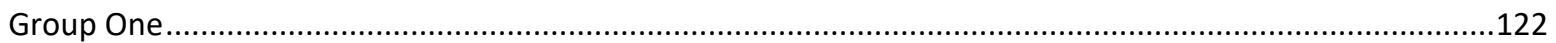

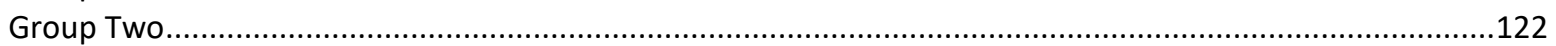

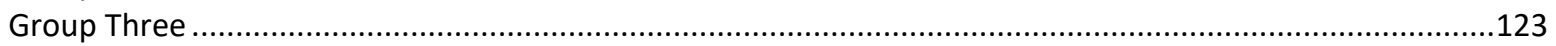

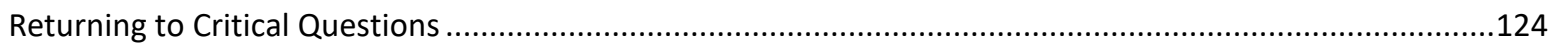

Chapter 4: Discussion.................................................................................. 127

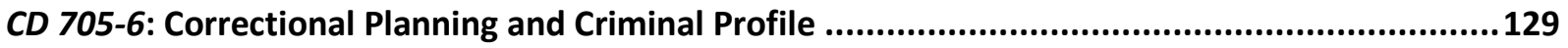

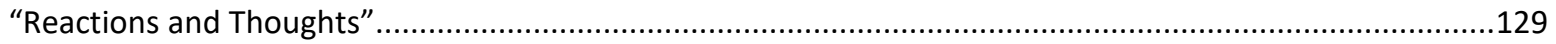

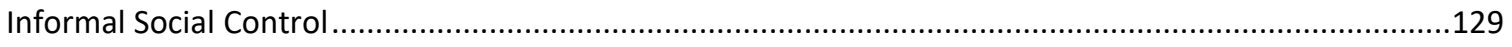

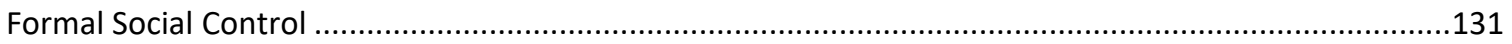

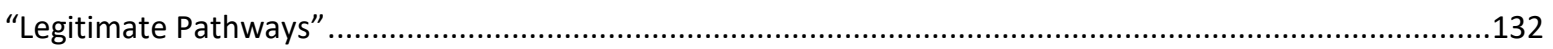

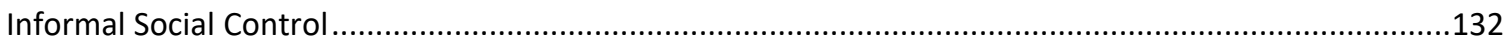

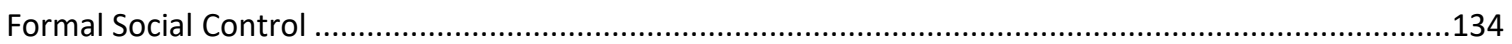

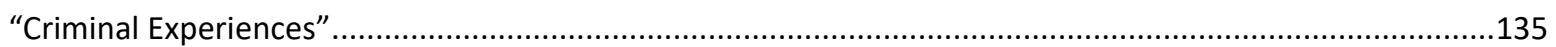

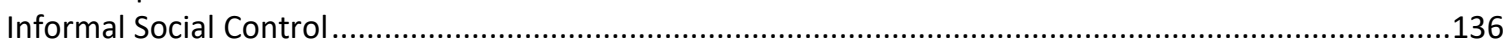

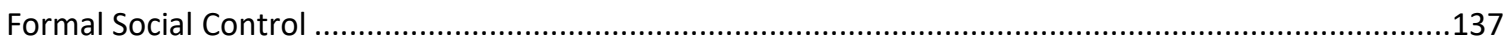




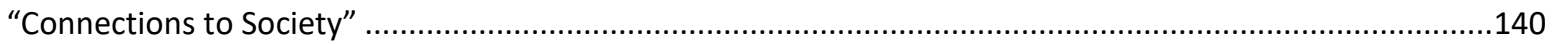

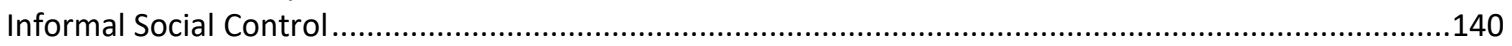

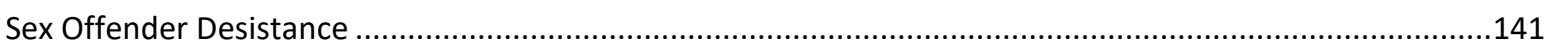

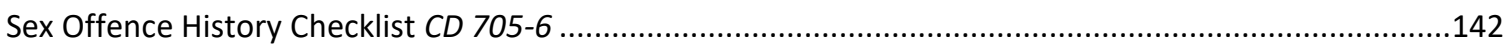

Other Aspects of Sex Offender Desistance.................................................................................... 143

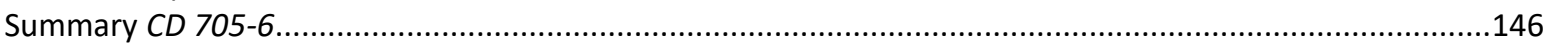

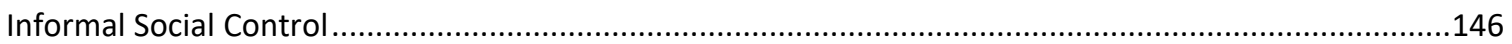

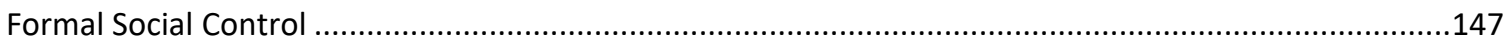

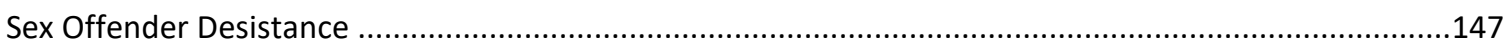

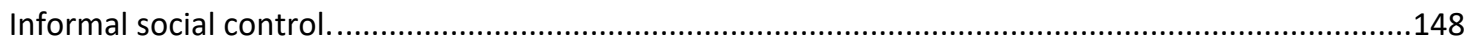

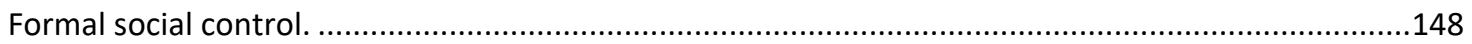

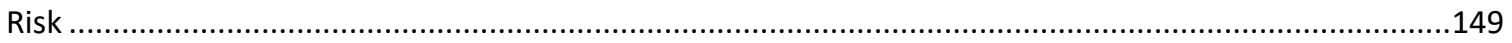

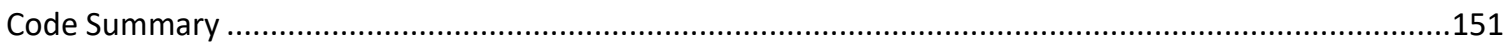

CD 715-1: Community Supervision ...................................................................153

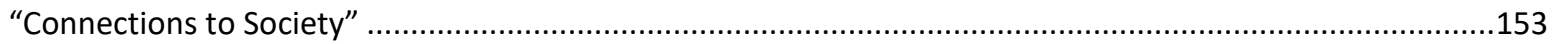

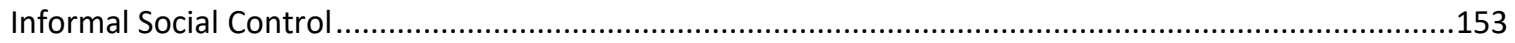

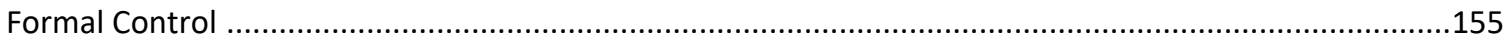

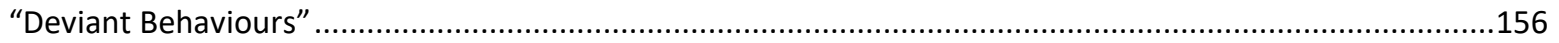

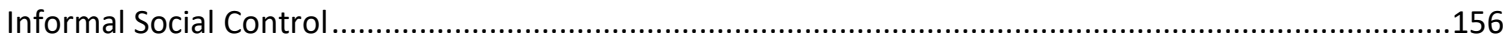

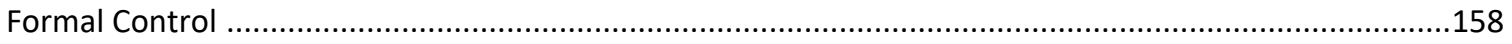

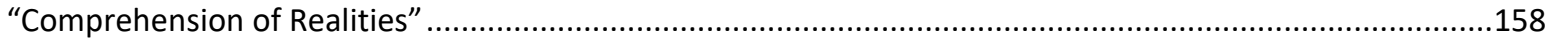

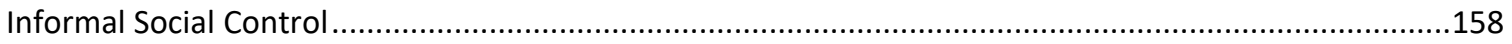

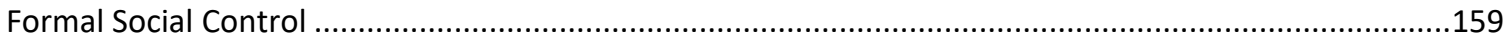

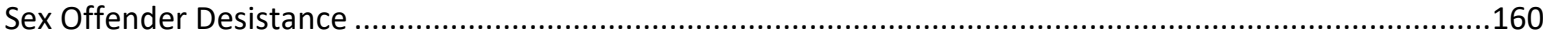

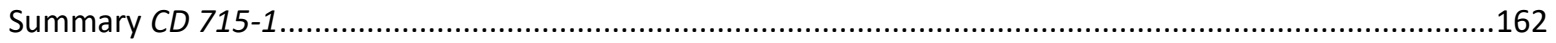

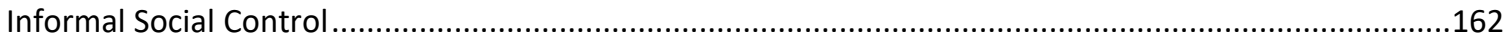

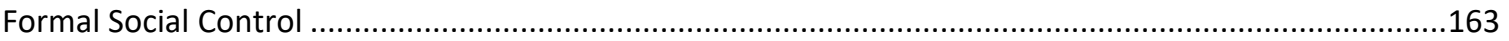

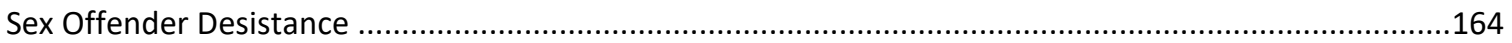

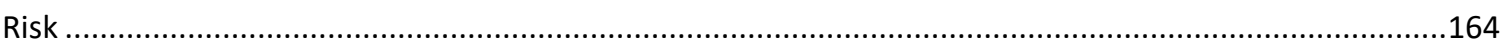

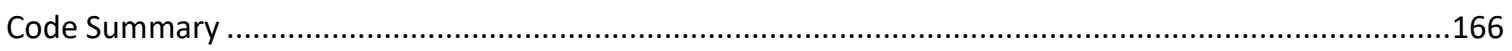

CD 715-2: Post-Release Decision Process ........................................................................168

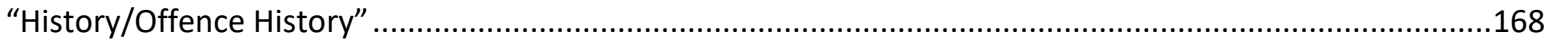

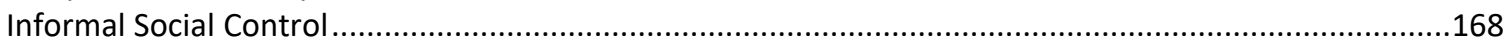

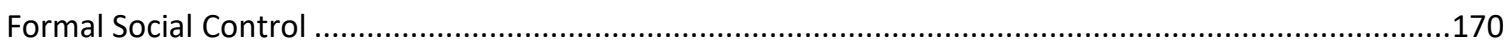

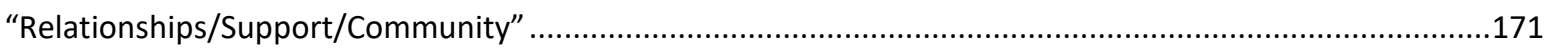

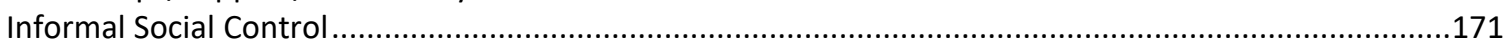

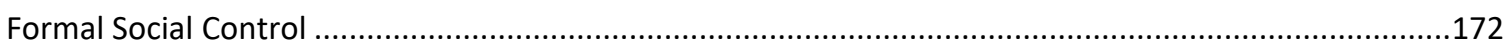

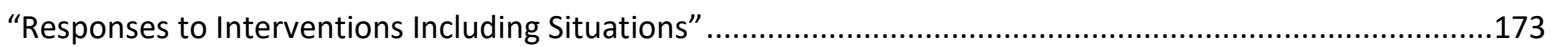

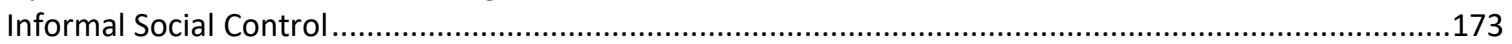

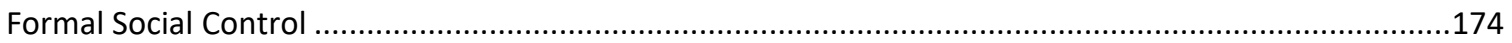

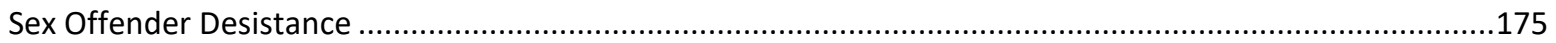

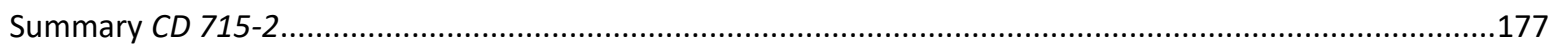

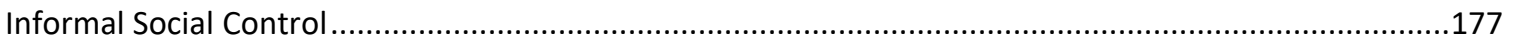

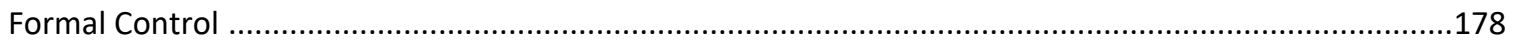

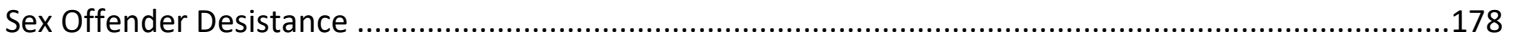

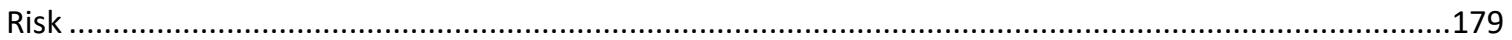

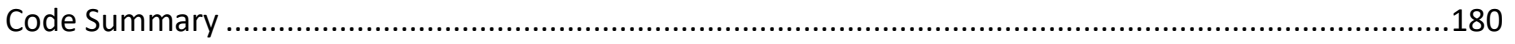

CD 715-3: Community Assessments ........................................................................181

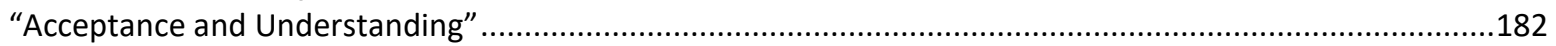

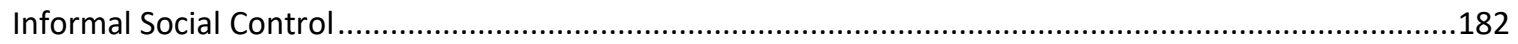

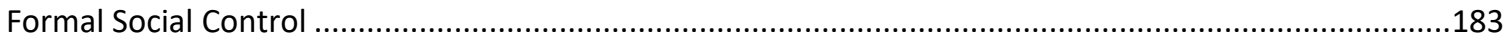




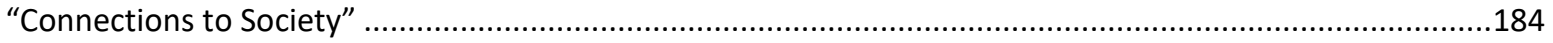

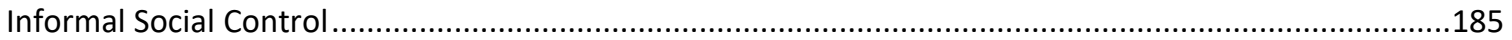

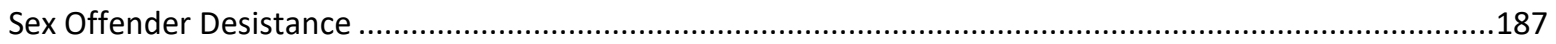

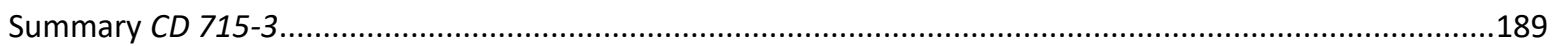

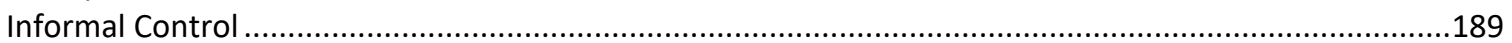

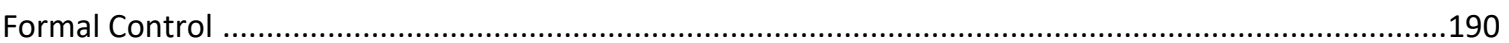

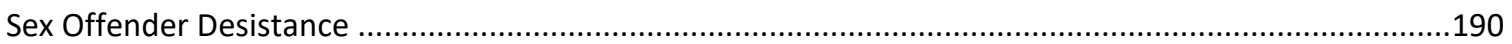

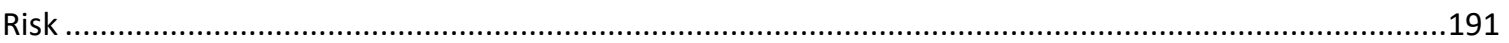

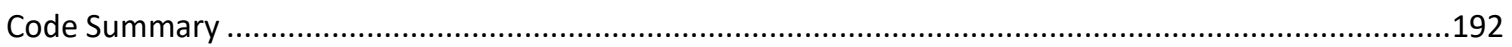

Policy Comparisons in Relation to Desistance .............................................................193

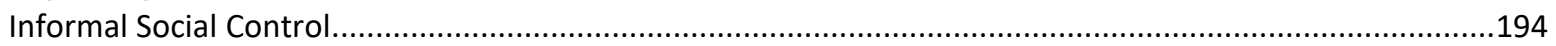

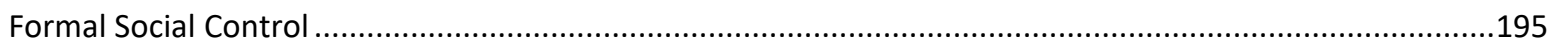

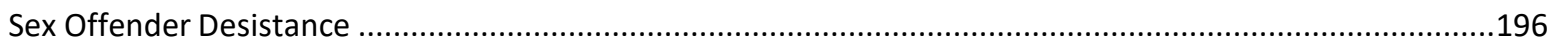

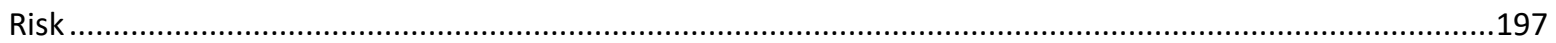

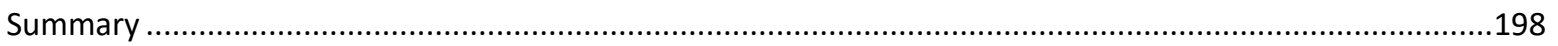

Final Thoughts: Desistance versus Risk .................................................................................198

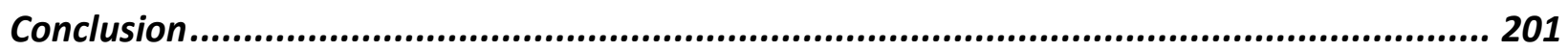

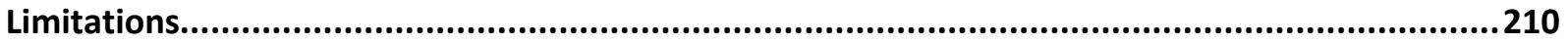

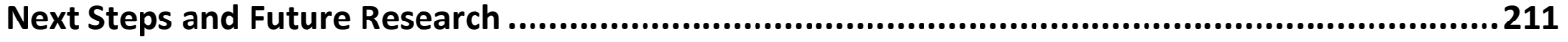

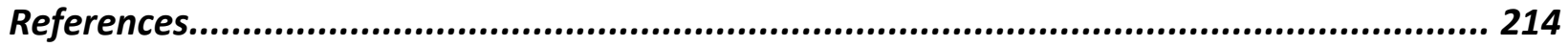

Appendix A: CD 705-6- Correctional Planning and Criminal Profile.................................... 233

Appendix B: CD 715-1- Community Supervision ............................................................... 292

Appendix C: CD 715-2- Post-Release Decision Process....................................................... 311

Appendix D: CD 715-3- Community Assessments ........................................................... 332 


\section{List of Tables}

Table 1: Risk and Desistance Paradigm Comparison Table

Table 2: $C D$ 705-6 Primary Codes

Table 3: $C D$ 705-6 Focused Codes

Table 4: $C D$ 715-1 Primary Codes

Table 5: $C D$ 715-1 Focused Codes

Table 6: $C D$ 715-2 Primary Codes

Table 7: $C D$ 715-3 Primary Codes

Table 8: $C D$ 715-3 Focused Codes

Table 9: All Primary and Focused Codes Per Policy

Table 10: $C D$ 705-6 Code Summary

Table 11: $C D$ 715-1 Code Summary

Table 12: $C D$ 715-2 Code Summary

Table 13: $C D$ 715-3 Code Summary 


\section{List of Abbreviations}

CCRSO- Corrections and Conditional Release Overview

CD- Commissioner's Directive

CDA- Critical Discourse Analysis

CGT-Constructivist Grounded Theory

CoSA-Circles of Support and Accountability

CSC- Correctional Service Canada

PBC- Parole Board of Canada

PSC- Public Safety Canada

RNR- Risk, Needs, Responsivity (Principles) 


\section{List of Appendices}

Appendix A: CD 705-6-Correctional Planning and Criminal Profile Appendix B: CD 715-1- Community Supervision Appendix C: CD 715-2- Post-Release Decision Process

Appendix D: CD 715-3-Community Assessments 


\section{Introduction}

This thesis will examine desistance and parole by looking at Correctional Service Canada (CSC) policies that outline the assessments that parole officers must complete for their clients before, during, and after their release. This is a Master's thesis in Sociology. However, the contributions I am making are to the interdisciplinary field of Criminology, which is why certain areas of this paper will make reference to the field of Criminology.

\section{Purpose}

The purpose of this qualitative study is to investigate CSC policy to examine if the policy includes aspects of the desistance paradigm. This paper will also examine if aspects of the desistance paradigm are included in relation to sex offenders. Although criminogenic needs (factors that relate to an offender's likelihood to recidivate) are valid within criminological literature as they relate to recidivism, offenders, and sexual offenders (Andrews and Bonta 1998; Hanson et al. 2009; Hanson 2005; Serin and Mailloux 2003), the purpose of this paper is to investigate if CSC mobilizes the desistance paradigm in their policies. This project will still discuss aspects of the risk paradigm, as they are both often talked about in the criminological realm in relation to offending or re-offending. To note, when I am discussing risk and desistance, I am actually talking about desistance and risk as paradigms as they relate to offending. This project will analyze the assessment portions of: Commissioner's Directive 705-6 (CD 705-6), Correctional Planning and Criminal Profile (Appendix A), CD 715-1, Community Supervision (Appendix B), CD 715-2, Post-Release Decision Process (Appendix C), and $C D$ 715-3, Community Assessments (Appendix D).

Further, understanding the risk paradigm can also play a role in understanding aspects of the desistance paradigm (see Maruna and LeBel 2003, or Nee and Vernham 2016, for 
example). With this discussion of risk also comes the discussion of the aspects of the risk, needs, and responsivity (RNR) principles (Andrews and Bonta 2010). The risk principle has two components: "use of a reliable and validated risk assessment to predict criminal behaviour, and appropriately matching level of service to the assessed level of risk" (Viglione 2019, 656). In other words, programming should be matched to an offender's risk level (Viglione 2019; Andrews and Bonta 2010). Research shows that programming and treatment intensity that matches risk level is effective, especially when looking at correctional programming for high risk offenders (Andrews and Bonta 2010; Andrews, Bonta, and Hoge 1990; Bonta, Wallace-Capretta, and Rooney 2000). According to Andrews and Bonta (2010) the needs principle is the idea that programming should focus on criminogenic needs. Since some of these factors can change, it makes them easy to target for treatment purposes (Andrews and Bonta 2010). These factors are explained further as they relate to offending in the literature review. Research has shown that treatment programs that specifically take into account the needs principle are more effective at providing treatment to offenders (Smith, Gendreau, and Swartz 2009).

The responsivity principle dictates how to give treatment to offenders. General responsivity encompasses the idea that individuals should consider the offender's learning style when trying to assess how to provide them with treatment, whereas specific responsivity goes a step further and dictates that treatment should be personalized to the characteristics of the offender (psychological etc.) (Andrews and Bonta 2010; Viglione 2019). There have been several meta-analyses done that indicate that targeting an offender's learning and life characteristics in relation to treatment has a significant effect on recidivism reductions (Gendreau, Smith, and French 2006; Andrews, Bonta, and Wormith 2010; Prendergast et al. 
2013).

It is important to note, however, that the RNR principles have been criticized by several scholars for different reasons. For example, desistance scholars such as Ward and Maruna (2007) discuss how the model of RNR does not engage with an offender in a meaningful way, because the programs do not focus on skill building in a way that an offender could understand their abilities. Mann et al. (2004) comment that because the RNR model focuses on reducing risks, it does not do a good job at motivating offenders. As will be referenced later in my literature review, many desistance scholars talk about the importance of desistance being about a change in identity (Maruna 2001). This is important because scholars such as Maruna (2001) believe that the RNR model does not account for the offender's identity change, and does not make much of an effort to see the offender as someone who has individual agency. Lastly, Ward and Stewart (2003) comment that this model does not take into account the goods that human beings require to be satisfied in life (i.e. has a narrow idea of what humans need).

Another criticism of RNR is the fact that the principles were developed using a majority male sample, which begs the question of whether they can be generalizable to women (Salisbury, Boppre, and Kelly 2016; Voorhis 2012). Hannah-Moffat (2008) also notes how research supporting the RNR principles often used white males as their sample, and thus, people of colour and women are not used as the basis for RNR research, even though these principles are used on them. Of the research that is available that looks at gender in the context of RNR, there is a tendency to refer to gender as binary, without considering other gender identities (Hannah-Moffat 2008). For example, Pollack (2000) examined women's experiences in treatment programs within a Canadian correctional institution and found that women of colour (specifically Black women) felt as though they could not relate to the program the same way 
their female white counterparts could. This situation highlights how using the RNR principles may not take women of colour into account. I come back to this discussion specifically in relation to RNR and gender at the end of the introduction when highlighting how this thesis is talking specifically about non-Indigenous men. Despite the criticisms, the RNR principles are important to keep in mind, because aspects of the RNR such as programming, learning styles, and dynamic risk factors are mentioned in the policies that this project is examining (see $C D$ 705-6 for example).

It is also important to understand the concept of desistance. In the opening of Laub and Sampson's (2001) article titled Understanding Desistance from Crime, these scholars ask the question "why do they stop?", while also making it clear that desistance "is not well understood" (1). Maruna (2001) defines desistance as a process and says that it relates to an offender ceasing from a life of crime and committing criminal activities. Furthermore, de Vries Robbé et al. (2015) distinguishes between risk and desistance by explaining that desistance research focuses on why some offenders "go straight" instead of why they "fail" (23). In this context, failing would mean a return to prison, whereas "going straight" means the stopping of offending behaviour (de Vries Robbé et al. 2015, 23).

Since this thesis is going to talk about both the risk and desistance paradigms, I think that Serin and Lloyd (2017) summarize the main differences quite well. They state that risk "targets criminal thinking and peers in a way that increases prosocial skills and manages risk situations", whereas desistance "enhances social supports to increase agency and reinforce effort which, with success, leads to identity change" (8). Furthermore, it is important to discuss protective factors; that is, "those factors that might reduce rather than increase the likelihood of an individual reoffending" (Nee and Vernham 2016, 38). As outlined in Nee 
and Vernham (2016), desistance literature outlines how it is important to look at offenders' strengths, especially in relation to desistance, and thus, looking at why an offender stops offending (which often takes into account protective factors), versus why they do re-offended (risk factors) is important (de Vries Robbé et al. 2015, also see Maruna and LeBel 2003). Nee and Vernham (2016) also mention how risk inherently focuses on the offender's "problems" (39).

The characteristics of the risk and desistance paradigms are further expanded on in my literature review (see Table 1) where I outline what are known as the central eight risk factors that relate to offenders and aspects that put them at risk to offend (Andrews and Bonta 2010). These include anti-social personality, history of anti-social behaviours, anti-social cognitions, anti-social associates, family and marital circumstances, school and work, leisure and recreation, and substance abuse (Andrews and Bonta 2010). I also discuss factors that are said to impact desistance such as employment, marriage, education and treatment (see Craig and Foster 2013; Laub and Sampson 2003; Abeling-Judge 2019 and Farmer, McAlinden and Maruna 2015, for example). These are important aspects to keep in mind throughout this thesis as they will come together in the analysis and discussion sections.

If the themes from the policies that are analyzed for this project are similar to the literature as it relates to desistance, then CSC is fostering an approach consistent with that of the desistance paradigm, which could be vital given how more individuals are on federal parole in the community in the last 10 years according to Public Safety Canada (Corrections and Conditional Release Overview (CCRSO) 2017). At the same time, however, within the policies there could be more of a focus on the risk paradigm. Furthermore, sexual offenders are stigmatized in the community (Griffiths 2015), yet there are many on federal parole, and 
their rate of re-offense while on parole is minimal. Therefore, discussing reintegration as it relates to sex offenders is important especially within the discussion around desistance and risk (CCRSO 2018).

Questions, Methods, Importance

This project will ask several questions such as: Do Correctional Service Canada (CSC) policies encompass aspects pertinent to reducing recidivism, and what does this look like? How is desistance incorporated into CSC policy around community supervision and parole? Are specific desistance factors related to sex offenders considered in these policies? How could they be included in these policies? Or, more specifically, how do the assessment portions of CSC Commissioner's Directive (CD) 705-6 (Correctional Planning and Criminal Profile), CD 715-1 (Community Supervision), $C D$ 715-2 (Post-Release Decision Process), and CD 715-3 (Community Assessments) discuss desistance? Are aspects of sex offender desistance present within these policies? How could they be incorporated into these policies?

Data for this project was collected by gathering the policy documents on CSC's website. This thesis analyzes these documents by using thematic analysis coupled with a critical discourse analysis approach (CDA) (Fairclough 2013), and a constructivist grounded theory approach (CGT) (Charmaz 2006; 2008) to interrogate and examine CSC policies on reintegration. Specifically, thematic analysis was used in order to investigate how, and in which ways the risk and desistance paradigms were included in CSC policies, along with examining if sex offender desistance was an aspect included in these policies as well.

This project is important because it could help CSC in developing a more revised and current policy that can be better targeted to highlight the needs of sexual offenders while focusing $C D s$ 705-6, 715-1, 715-2, and 715-3 on factors of desistance instead of risk. According 
to the CCRSO, between 2016 and 2017, approximately 33\% of releases from federal institutions were granted day parole, increasing in the past ten years by approximately 5\% (CCRSO 2017). Between 2017 and 2018, “36.1\% of all releases from federal institutions were on day parole and $2.9 \%$ were on full parole" (CCRSO 2018, 81). This act defines the successful completion of parole as not being "returned to prison for a breach of conditions of for a new offence" (CCRSO 2017 (96), CCRSO 2018 (96)). As cited in the CCRSO (2018), in the past 9 years federal day parole had a completion rate of over $85 \%$. Lastly, offenders who are on day parole for a violent offense only reoffend, on average, $0.1 \%$ of the time (violent offences include sex offences) (CCRSO 2018). Thus, one can infer that federally there are more offenders in the community on parole, and fewer offenders are returning to penitentiaries for sexual reoffences. Furthermore, as the CCRSO looks at corrections on a national scale, the examination of federal policy is important as it can contribute to the national trends seen in corrections (CCRSO 2017, 2018).

\section{Definitions}

Although my questions are policy specific, I realize that I could have narrowed down my questions more in order to take into consideration specific sexual offence types. I decided against this as it narrows down my already specific population parameters. More importantly, policy is often written in a more general sense, thus, examining policy on the parameters of a specific "type" of sex offender would not be indicative of how policy is presented. The literature on desistance is not often specific on the type of sexual offender that is studied, therefore in this case it would make sense to approach the policy analysis in the same way (see Kras and Blasko 2016; King 2013; Laub and Sampson 2001, for example).

However, it is important to include Parole Board of Canada (PBC) definitions in this section as the policies analyzed for this project discuss different aspects of parole. To start, 
temporary absences are releases wherein offenders are allowed to leave their facility for certain reasons such as personal development or work (Parole Board of Canada Website 2018). They can either be escorted, or unescorted depending on sentence length; for escorted temporary absences one can apply at any time through CSC, however if one has a life sentence one "must be approved by the Parole Board", and for unescorted temporary absences offenders are eligible to apply if their sentence is three years or more, and they have served one sixth of that sentence (Parole Board of Canada Website 2018). If an offender has a life sentence, they can still apply for an unescorted temporary absence three years before they are eligible for full parole (Parole Board of Canada Website 2018).

Furthermore, day parole "allows an offender to participate in community-based activities in preparation for full parole or statutory release", and they usually have to return to halfway houses or community-based residential facilities at night (Parole Board of Canada Website 2018). Full parole "allows an offender to serve part of their sentence under supervision in the community under specific conditions" (Parole Board of Canada Website 2018). Lastly, statutory release is when CSC releases offenders under supervision conditions after they have completed two thirds of their sentence (Parole Board of Canada Website 2018).

\section{Policies}

Given that I am discussing four policies and their assessment frameworks it is vital to understand the importance of these policies and what they are intended for.

\section{705-6}

This policy is entitled Correctional Planning and Criminal Profile. The main purpose of this policy is for parole officers, to discuss and assess aspects of an offender's life in order 
to accurately understand what kind of plans need to be in place for the offender to be released in the community safely and effectively (CSC Website, $C D$ 705-6). This includes assessing many different items such as the offender's motivation to change, their engagement with their supervision plan, and their accountability (CSC Website, CD-705-6).

\section{715-1}

This policy is the Community Supervision policy and applies to CSC staff who are supervising offenders in the community (CSC Website, $C D$ 715-1). In this policy, staff are to assess offenders based on their engagement, reintegration potential and if factors in their life have changed indicating they may need a reassessment on their level of intervention (how often they see their parole officer) (CSC Website, CD 715-1).

\section{715-2}

This policy is entitled Post Release Decision Process. The assessment part of this policy is intended for individuals who are supervising offenders in the community who have breached their conditions of parole, had changes to their conditions, have been suspended on conditional release, or have had their parole revoked (CSC Website, $C D$ 715-2). In this case parole officers are to decide what the next steps are for the offender by taking into account their criminal history, community behaviour, and their correctional plan before deciding what to recommend (CSC Website, CD 715-2).

\section{715-3}

This policy concerns Community Assessments and is intended for individuals such as parole officers who complete community assessments (CSC Website, CD 715-3). These assessments are done when something in an offender's life that has changed and could impact them in the community (CSC Website, $C D$ 715-3). These community assessments are also 
done if the offender is going to be granted a temporary absence or work release (CSC Website, $C D$ 717-3). In this policy, staff assess how the offender is doing in the community, what resources are available to them, their support networks, and how their current reintegration plan is going (CSC Website, CD 715-3).

\section{Contextualizing the Policies}

Above, I specifically make note of gender as it relates to Andrews and Bonta's (2010) RNR principles. I also think it is important to position the policies as they relate to gender in order to lay the ground-work for what is being discussed. According to the CCRSO (2018) 3,612 men were granted day parole, and 436 women were granted day parole in 2017-2018, and 1,363 men and 153 women were granted full parole in 2017-2018 (CCRSO 2018). In 2017-2018 CSC had 22,223 federal offenders under their purview, and of these, 6\% were women (CSC Website 2019). Based on these numbers from the most recent CCRSO (2018), it is clear that more men are being supervised in the community, and thus it can be assumed that these policies are being used more often on men. There are also more men in federal custody within CSC, therefore it is not unreasonable to assume that men are the targeted audience for these policies, and that these policies are used on men. To be clear, this thesis is not considering Indigenous status, or women. The focus of this thesis is on non-Indigenous men.

It is also important to note that I chose $C D$ 's that are the main over-arching $C D s$ with regard to community reintegration. These $C D s$ cannot possibly cover every population and all groups and circumstances, which is why CSC has designated women offender $C D s$ to address the specific needs of women both in the institution and in the community (see $C D$ 577: Staff Protocol in Women Offender Institutions; CD 578: Intensive Intervention Strategy in Women Offender Institutions/Units; and CD 715-4: Case Preparation and Supervision of Women 
Offenders with Children Residing at a Community-Based Residential Facility (CSC Website, $2019 ; 2019 ; 2012)$ ). If I wanted to accurately account for female reintegration in the community, I would have to include at least $C D 715-4$, if not the other $C D s$ as well.

\section{Road Map}

This thesis will comprise of the following sections. After this introduction, Chapter One will be a literature review that will explain aspects such as risk, recidivism, and desistance, while relating these concepts to the literature on offending and sexual offending. This chapter will also discuss the theoretical framework for the project. Chapter Two is the research methods chapter which includes discussion on not only what research methods were used in this project, but also on researcher reflexivity, data type, data collection, and data analysis, and ethical considerations. Chapter Three is the analysis section, which will go through critical questions in relation to the analysis, and the primary and focused codes developed for each of the four policies analyzed, while also including a discussion of the risk paradigm. This chapter will also compare the analysis of each policy. Chapter Four is the discussion chapter that will take the focused codes developed in the previous chapter and relate them to the literature on desistance while also making suggestions on how aspects of the desistance paradigm can be further included in these perspective policies. Sex offender desistance will also be discussed. The end of Chapter Four summarizes the themes within the policies in terms of how they relate to desistance, sex offender desistance, and risk. The last section of this thesis is the conclusion, which provides final thoughts on desistance and risk within CSC policy, and the limitations of the research project while also providing ideas for future research in this subject area. 


\section{Chapter 1: Literature Review}

Often times risk and desistance are discussed in relation to an offender and reoffending. Risk factors are factors that can influence or predict if an offender is going to reoffend (or recidivate) (Andrews and Bonta 2010). Desistance on the other hand focuses on factors that contribute to an offender not reoffending (de Vries Robbé et al. 2015). Since this project also touches on sex offenders, this literature review will focus on studies that have been done in relation to recidivism and factors that influence recidivism for sexual offenders. This will include a short section that discusses risk assessment tools for sex offenders.

Given that risk factors are so pertinent within criminological literature, this literature review will give a brief overview of risk factors. Literature on desistance will also be included (and will build on the discussion of risk factors), as these processes are what this thesis project will investigate. It is, however, important to understand the history and background of these concepts. Simply, risk, and risk factors are often referred to within corrections, specifically at CSC. This is similar to what Andrews and Bonta (2003) mention, when they talk about the fact that risk is often stressed and given more attention because focusing on risk factors can protect both the individual from committing more crime, but also the public shall an offender commit more crimes. Nee and Vernham (2016) make the point that because often times within corrections risk is the dominant lens in which reintegration is seen, it means that other factors such as desistance and/or protective factors are not discussed to the same degree.

This can be seen in Stewart et al. 2019's CSC report, wherein it is explained that the criminal justice system often looks at and refers to recidivism rates as "the key indicator of the impact of correctional interventions, providing direction on the efficacy of correctional practices" (1). Stewart et al. (2019) also explain that measuring recidivism is a way to gauge 
how successful a correction agency is in protecting and maintaining public safety. In my conclusion, I mention the notion of public safety, and how risk is often the measurement used in the media when an offender is released in the community. Society seems to be able to understand and conceptualize what risk means for them and their safety in the community. When offenders are being released on parole or denied parole you often hear in the media that the parole board, for example, deems the offender to be low, moderate, or high risk of reoffence. Society is able to understand these labels and relate them to how they feel about the offender being in their community. I think this is the case because the risk paradigm is so heavily used, thus risk of re-offence or risk of harm to society is easily understood by the public. But I also think it is important to consider how desistance can play into the narrative around public safety. I question this more in the conclusion of this thesis.

King (2013) notes that the study of desistance has become popular especially in recent years citing scholars such as Laub and Sampson (2001), and Maruna (2001) as writing and researching these concepts. Weaver (2019) makes note that the desistance paradigm did not become a major area for research until the 1990s. Much of the research done within CSC and the Canadian government as it relates to reintegration focuses on risk and recidivism (see Hanson and Harris 2004, for example, or Stewart et al. 2019). I believe this is because of the aspect of public safety - correctional organizations want to have a measurement to ensure they are meeting their mandate. Given how risk and the risk paradigm dominates a lot of research within corrections, I wanted my research to investigate to what extent the desistance paradigm was reflected within CSC policies. This also seem appropriate given the fact that research at CSC often focuses on the risk paradigm.

Since this project is centered around policies that affect offenders in the community, 
this literature review will also look at reintegration and barriers to reintegration as a basis to understand some obstacles offenders have to overcome in society. This review of literature will conclude with discussing more specifically what research has been done at CSC and Public Safety Canada (PSC) on this topic.

The basis for this project is on Andrews and Bonta's (1998) criminogenic needs. To expand, dynamic factors can include aspects of an offender's life such as antisocial behaviours, or substance abuse issues (Andrews and Bonta 1998). Further, static factors can include age of offender when they committed their first offence and criminal history (Andrews and Bonta 1998). Dynamic factors can change, whereas static factors cannot (Andrews and Bonta 2010). Andrews and Bonta (2010) also developed the central eight risk factors for recidivism which include "history of antisocial behaviour, anti-social personality, anti-social cognition, anti-social associates, family/marital circumstances, school/work, leisure/recreation, and substance abuse" (Grieger and Hosser 2014, 613-614). These factors are often known to have an effect on recidivism while also being predictive of offending (Seewald et al. 2018; Andrews and Bonta 2010; Viglione 2019), and as this literature review will explain, some of these factors are also pertinent when it comes to desistance (Laub and Sampson 2001). These eight factors mentioned above will be discussed in this literature review as they relate to risk.

Furthermore, as discussed in the introduction, Andrews and Bonta (2010) created the RNR principles (Andrews, Bonta, and Hoge 1990). These principles dictate that programming for offenders should be tailored to their risks, needs, and learning style in order to see a decrease in recidivism (Andrews and Bonta 2010). Hanson et al. (2009) completed a metaanalysis of cases of sexual offender treatment outcomes and found that programs that adhered 
to RNR principles saw greater decreases in recidivism. The background for the RNR principles was provided in the introduction, thus this literature review will focus on the different factors.

Risk Assessment Tools for Sexual Offenders, and Recidivism

Although this project's focus is on desistance, having a basic understanding of risk assessment tools for sex offenders, how they work, and how they are closely associated with recidivism is important.

Other than dynamic and static factors, and adhering to the RNR principles, there are additional aspects of risk assessments that are used for sexual offenders. As noted by Smid et al. (2015) the STATIC-99 (Hanson and Thornton 2000) is the most well researched actuarial assessment tool. This is a 10-item scale that looks at individual risk factors of sexual offenders, with scores being added up to reflect risk categories that offenders fall into (Smid et al. 2015; Hanson and Thornton 2000).

Risk assessments for sex offenders can also come in the form of structured professional judgement, wherein the clinician's judgement along with other assessment models are used for assessment (Tully, Chou, and Browne 2013). Several main metaanalyses have been conducted on the accuracy of sex offender risk assessment tools.

Hanson and Morton-Bourgon (2007) found while researching different approaches to sex offender risk assessment (through electronic data bases) that actuarial tools had a better predictive accuracy over structured professional judgement tools. Further, Hanson and Morton- Bourgon's (2009) meta-analysis study also looked at the accuracy of sex offender risk assessment tools and confirmed their results from their 2007 study (Hanson and MortonBourgon 2009). However, Tully, Chou, and Browne (2013) completed a meta-analysis looking 
at six databases where risk assessment decisions were formed using either actuarial tools or structured professional judgement. It was found that all tools had a moderate predictive accuracy (Tully, Chou, and Browne 2013).

Literature on the topic of sex offender assessments is quite expansive (and this section did not touch on every assessment used to measure sex offender risk). Additionally, an important note to make is that risk assessment instruments are not only used for sex offenders but come in other forms to assess a variety of different offenders with different backgrounds. One example includes the Violence Risk Scale (Wong and Gordon 2006) which combines static and dynamic risk factors to assess the likelihood of reoffence while also focusing on factors that contribute to violence (Pozzulo, Bennell, and Forth 2015). Thus, what is important to understand is that there are a multitude of ways in which risk assessments are used.

$$
\text { Risk }
$$

As mentioned above, before discussing desistance it is important to explain risk factors and their definitions.

\section{Definitions, Explanations, Frameworks, Conceptualizations}

Above, I discuss how risk factors are factors that can be used to predict if an offender is going to reoffend (de Vries Robbé et al. 2015). Reoffending is also known as recidivism, and recidivism can have multiple definitions (Stewart et al. 2019). Within the literature recidivism can refer to "new arrests, new convictions, and reincarceration" (Stewart et al. 2019, 1). Given that I am analyzing CSC policy in this thesis, it is important to note that CSC looks at recidivism as returns to federal custody (Stewart et al. 2019). When I discuss risk, and what puts an offender at risk in my analysis and discussion section, I am basing that definition off Stewart et al.'s (2019) definition in relation to new arrests, convictions, and 
reincarcerations.

In their report on recidivism among Canadian federal offenders, Stewart et al. (2019) mention different recidivism definitions. For example, Wartna, Blom, and Tollenaar (2011) define recidivism as a reconviction of a crime after an offence has taken place. Dunrose, Cooper, and Snyder (2014) define recidivism as "an arrest resulting in a conviction with a disposition of a prison sentence" (Stewart et al. 2019, 4). Lastly, Saris et al. (2016) define recidivism as "criminal acts resulting in rearrest, revocation, and/or reincarceration" (Stewart et al. 2019, 4).

When talking about risk factors as they relate to recidivism, the next part of this section will discuss the risk factors that Andrews and Bonta (2010) present as the central eight.

\section{Anti-Social Personality}

Having an anti-social personality or anti-social personality patterns was also identified by Andrews and Bonta (2010) as being a central eight factor. According to Hare $(1993 ; 1996)$ exhibiting certain traits such as impulsivity lend themselves to criminal activity. Furthermore, Moffitt et al. (1996) and Caspi (2000) also theorize that those who commit crimes have impulsivity issues and poor self-control. Through an analysis and follow up of 225 twins from childhood to adulthood (follow up time 10-25 years) Simonoff et al. (2004) found that predictors for antisocial personality and criminality in the twins included childhood disorders such as hyperactivity.

There are many measures (scales) that can be used to assess for anti-social personality traits. These include The Psychopathy Checklist Revised (PCL-R) (Hare 1991) and the 16 Personality Factor Questionnaire (McGurk, McEwan, and Graham 1981). 
Gough, Wenk and Rozynko (1965) discussed how some scales such as The California Psychological Inventory measure self-control and socialization, and obtaining a low score on this checklist meant that individuals are often "adventurous, pleasure seeking, shrewd, mischievous, egotistical, and touchy" (Watt, Howells, and Delfabbro 2004, 143).

\section{History of Anti-Social Behaviours}

Having a history of anti-social behaviours can not only influence recidivism (Andrews and Bonta 2010), but often stems from experiences in childhood (Watt, Howells, and Delfabbro 2004). In other words, young people who have a history of behavioural issues and are exposed to conflict can develop antisocial behaviours (Watt, Howells, and Delfabbro 2004). Criminal propensity theories often look at how likely it is that someone is going to commit a crime (Watt, Howells, and Delfabbro 2004). According to Loeber (1990) when an individual is predisposed to factors that could influence their likelihood of committing a crime, this often occurs early in life.

Furthermore, in looking at juvenile recidivism many studies find that early age of onset of criminal behaviour contributes to a greater risk of recidivism (Wierson and Forehand 1995; Carach and Leverett 1999). Some, however, have not found a significant relationship between age and recidivism (Lueger and Cadman 1982; Katsiyannis and Archwamety 1997).

\section{Anti-Social Cognitions}

Anti-social cognitions are considered a criminogenic need and one of the central eight (Andrews and Bonta 2010) and are known to influence criminal behaviours (Walters 1990). More specifically, deviant thoughts can lead to justification and rationalization of activities that can lead to criminal behaviours (Healy and O'Donnell 2006; Palmer and Hollin 2004). Walters (2003) contends that errors in thinking not only lend themselves to 
criminal lifestyles, but also play a role in lack of willingness to take responsibility for behaviour. As cited in Whited et al. (2015), Mandracchia et al. (2007) found that there are three main aspects to anti-social or criminal cognitions such as "control (i.e., one's need for power over oneself, others and the environment), cognitive immaturity (i.e., overly simplistic and ineffective ways of thinking and understanding the world, and having a selfpitying attitude), and egocentricity (i.e., an overemphasis of one's importance and a sense of entitlement)" (Whited et al. 2015, 3).

In a study that assessed how predictable dynamic risk factors are in two samples of individuals involved in the justice system, it was found through quantitative analysis that in both sample sizes anti-social attitudes predicted recidivism quite well (Caudy, Durso, and Taxman 2013). However, it is important to note that this is combined with other factors such as education, employment and substance abuse which also influenced recidivism rates (Caudy, Durso, and Taxman 2013).

\section{Anti-Social Associates}

Associating with anti-social or criminal associates is also deemed a factor that increases risk of recidivism (Andrews and Bonta 2010). Specifically, in the literature, social norms and environment influence behaviour (Moscovici and Zavalloni 1969). Particularly, social learning theory (Akers $1998 ; 2000$ ) contends that criminal behaviour is learned through social environment through modelled behaviours.

In relation to anti-social peers specifically, Thornberry et al. (1994) in an adolescent sample, found that those who were involved with anti-social peers often committed delinquent acts. Boduszek et al. (2013) found that not only is association with criminal peers important in terms of breaking the law but associating with criminal peers can lead to someone adopting a 
criminal identity which can also contribute to breaking the law. In Whited et al's. (2015) study it was found that spending time with criminal associates relates to criminal thinking.

\section{Family and Marital Circumstances}

Marriage and families have been tied to a decrease in criminal activity (Lo and Zhong 2006; Schwartz 2006). Specifically, those who are married are less likely to commit crime in relation to unmarried individuals (Huebner 2005; Sampson, Laub, and Wimer 2006). But it is important to keep in mind that marriage may have an effect on certain crimes versus others. More specifically, for example, an investigation into married males and criminality found that assault was committed less often if men are married (Wooldredge and Thistlethwaite 2003). Wilcox et al. (2005) found that marriage has an effect on murder and robbery rates. Furthermore, having a family and relationships can be linked to the lower rate of crime because it means that individuals have a responsibility towards other aspects of life like their partners which means that they do not have time for criminal behaviours (Lo and Zhong 2006).

\section{School and Work}

Both of these factors have been identified as having an influence on recidivism (Andrews and Bonta 2010). In terms of the relationship between crime and education, it is recognized that education can contribute to crime prevention (Hansen 2003; Lochner 2004). Research often discusses the importance of encouraging young individuals who are at risk of committing crimes to go to school and obtain a degree (Taheri and Welsh 2016). In some instances, researchers found that education correlated with lower recidivism rates for only certain offences such as shoplifting, whereas other offences such as tax fraud actually increase if the individual has obtained an education (Groot and van den Brink 2010). Individuals can 
also obtain post-secondary education at correctional facilities, and research points to this as a predictor of both employment and recidivism (Batiuk et al. 2005; Chappell 2004). Wilson, Gallagher, and Mackenzie (2000) found that prisoners who participated in correctional programs also had a higher employment rate, and thus, were less likely to recidivate.

Employment and work are also often discussed as factors that influence risk and recidivism. Full time employment is an important factor that distinguishes between those who do not recidivate and those who do recidivate (Benda, Harm, and Toombs 2005). However, Tripodi, Kim, and Bender (2010) found that obtaining employment is not significantly correlated with reincarceration.

\section{Leisure and Recreation}

Leisure and recreation are both factors that influence recidivism (Andrews and Bonta 2010). In the realm of criminological research leisure and recreational activities have been studied in multiple ways. Specifically, scholars have looked at leisure activities while individuals are incarcerated (Frey and Delaney 1996). Leisure activities have been known to have the ability to promote crime-free living (Williams 2006; Williams and Walker 2006). Ambrose and Rosky (2013) found that correctional recreational programs have positive effects on offenders and those pro-social activities could influence behaviour after incarceration.

What is important to understand is that leisure activities can be deviant and nondeviant and both deviant and non-deviant activities could influence and individual to commit a crime (Williams 2006). Deviant leisure and recreational activities can include shoplifting, and vandalism, among others (Atkinson 2014; Stebbins 1996; Williams and Walker 2006). Leisure activities can be directly related to criminal ones. For example, Williams (2005) found that prior to sexual offending, sexual offenders would use leisure time to find their 
victims. However, in some instances, leisure activities are positive. Meek and Lewis (2014) found that physical activities for incarcerated women had positive effects (such as coping skills and self-esteem), which can help those individuals live a pro-social, crime free life.

\section{Substance Abuse}

Substance abuse is the last major risk factor identified by Andrews and Bonta (2010). One meta-analysis found that individuals who use substances are three times more likely to offend (Bennett, Holloway, and Farrington 2008). Other research has suggested that those who are addicted to substances commit crime (Vaughn 2011; White and Gorman 2000). Welte et al. (2005) found that men between the ages of 16 and 19 who regularly drink alcoholic beverages had higher rates of criminal behaviour, but interestingly in this study drug use was not linked with criminal exploits. Håkansson and Berglund (2012) found that of a sample of 4,152 prisoners who relied on substances, and who were followed for approximately 3 years, sixty nine percent recidivated. Recidivism was more likely if the individual used amphetamine and heroin (Håkansson and Berglund 2012). Recidivism was not linked to alcohol and hallucinogenic drugs (Håkansson and Berglund 2012). Caudy, Durso, and Taxman (2013) found that substance abuse along with education and employment were the strong predictors of recidivism.

\section{Desistance}

This section of the literature review will explain and discuss desistance as it relates to offending and more specifically sexual offending.

\section{Definitions, Explanations, Frameworks, Conceptualizations}

Desistance is a phenomenon that, as outlined by Laub and Sampson (2001), is "not well understood" (1). They discuss it as the process by which offenders cease to offend (Laub 
and Sampson 2001). However, as pointed out by Laub and Sampson (2001) there is not one sole definition of desistance, and in this literature review I will go through several definitions before summarizing them at the end. Some define desistance in terms of age ranges (i.e., having no convictions between certain ages) (Farrington and Hawkins 1991), whereas according to Laub and Sampson (2001) others define desistance as a multi-step process including a decrease in frequency of offending, "a reduction in the variety of offending", and "a reduction in the seriousness of offending" (Loeber and LeBlanc 1990, 409).

Above, I briefly touch on risk factors. Risk factors predict risk that an offender will reoffend (Thornton 2013). This approach focuses on areas where the offender needs to improve (i.e., their shortcomings) (Nee and Vernham 2016), and does not pay attention to an offender's strengths or other positive characteristics (Maruna and LeBel 2003; des Vries Robbé et al. 2015). Several other researchers have encouraged those to look at an individual's strengths, instead of focusing on risk factors of recidivism (de Vries Robbé, de Vogel, and de Spa 2011; Thornton 2013; Ttofi et al. 2016; Ward and Maruna 2007). The way I see these two approaches is that they are different ways, models, or paradigms to discuss offending and reoffending.

To reiterate, protective factors can contribute to a reduction in offending (i.e., desistance) and are often more focused on an offender's strengths (de Vries Robbé et al. 2015; Maruna and LeBel 2003), whereas risk factors are not focused on an individual's strengths (Maruna and LeBel 2003; de Vries Robbé et al. 2015). Focusing on strengths, for example, can be beneficial as Attrill and Liell (2007) point out that not focusing on strengths of an offender can lead to offenders feeling stigmatized by the person assessing them. Nee and Vernham (2016) point out that Thornton (2013) discusses how "although risk factors can 
predict crime, protective factors can promote desistance or the prevention of the criminal career beginning at all; thus, can also be predictive of recidivism" (Nee and Vernham 2016, $38)$.

As mentioned previously, some scholars define desistance as a process (not as an event) wherein offending reduces in capacity, seriousness and frequency (Maruna 2001; Bushway et al. 2001). Given that desistance can be seen as a process, some scholars have formed different types of desistance. Most notably Maruna and Farrall (2004) and Maruna, Immarigeon, and LeBel (2004) discuss the difference between primary desistance and secondary desistance. For them, primary desistance is indicative of offenders who temporarily stop their offending behaviour, whereas offenders who do not offend in the longer term are considered to have accomplished secondary desistance (Maruna and Farrall 2004; Maruna, Immarigeon, and LeBel 2004). Furthermore, secondary desistance is also characterized by an offender having a change in their identity (Maruna and Farrall 2004; Maruna, Immarigeon, and LeBel 2004; Maruna 2001). Secondary desistance is also often accompanied by narratives that help offenders compose new identities that help them be a non-offender (Maruna 2001; Vaughan 2007). Maruna and Roy (2007) contend that desistance happens when offenders change their "self-identity and worldview" which can include identity transformations (115).

It is important to understand that desistance is not an easy, straightforward process, in that many people who try to desist are not successful and often go back to criminal offending, or, in some instances, individuals go between committing crimes to not committing crimes (Glaser 1969; Matza 1964; Maruna 1997; Burnett 2004). King (2013) specifically criticizes the idea of primary and secondary desistance saying that "there is limited acknowledgement in this conceptualization that individuals might be able to achieve secondary desistance, but then 
return to offending behaviour again" (149-150). Further to this point, King (2013) states that there is no "acknowledgement that individuals might be able to achieve what is commonly identified as 'secondary desistance' while still retaining certain characteristics or behaviours which may have been prominent during the 'offender' or 'primary desistance' phases of the self” (150). He later makes a point suggesting the possibility that primary and secondary desistance are not as individual as they are made out to be, but that, characteristics of one or the other can be present at each phase (e.g., characteristics of primary desistance could be in an offender's secondary desistance stage etc.) (King 2013).

Above, I mention the importance of narratives and secondary desistance (Maruna 2001; Vaughan 2007). Narratives, or narrative identities have several functions. Firstly, they "condition future social interaction and behaviour" in that "individuals will act in ways which are aligned to the narratives that they have constructed for themselves" (King 2013, 151). Secondly, narrative identities "are conditioned by social structure and social interaction" and thus can be influenced by social or personal events in one's life that can affect behaviour (King 2013, 151). Furthermore, research on this topic indicates that narratives are important because they help offenders come to terms with their offending and can also help them form pro-social identities and relationships (Burnett 2004; Gadd and Farrall 2004; Giordano, Cernkovich and Rudolph 2002; Laub and Sampson 2003; Vaughan 2007).

In talking about narrative identities in relation to desistance it is important to touch on what Paternoster and Bushway (2009) call “cast off” identities (1107-1108). “Cast off” identities encompass the process of leaving behind old identities for new ones (Paternoster and Bushway 2009, 1107-1108). They contend that when this happens, desisters see two versions of themselves: "a "possible self" (the person they are striving to become) and a "perceived 
self" (the offender they once were)" (Paternoster and Bushway 2009, 1107-1108).

In King's (2013) study wherein the researcher interviewed those under probation in England, it was found that participants did construct personal identity narratives especially when they did not want to associate with their past behaviours. After developing these narratives, participants felt as though they better understood their past actions (King 2013). The interviews also showcased that in some instances participants were "developing a sense of moral agency as individuals began to distance themselves from their past self and distinguished between this and their present and future selves" (King 2013, 156).

Moreover, Gottfredson and Hirschi (1990) explain that tendencies to commit crime are present throughout life, thus, desistance "occurs when there is a change in crime or opportunity” (Laub and Sampson 2001, 7). Sampson and Laub (1995), agree with Gottfredson and Hirschi (1990), but add that "opportunities for crime are ubiquitous" (Laub and Sampson 2001, 7). Laub and Sampson (2001) maintain that there are many different theoretical frameworks that can be used to explain desistance (such as social learning theory and rational choice theory). However, they argue that life course perspectives make the most sense to use, as it helps in understanding the "role of social context in shaping the dynamics of desistance" (Laub and Sampson 2001, 3). This has been found to be true of sex offender desistance as well (Harris 2016; Farmer, McAlinden, and Maruna 2015).

Along with life course perspectives, other theoretical frameworks and paradigms are also appropriate when studying desistance. For example, Cullen (1994) advanced the social support paradigm when studying crime, explaining that this paradigm looks at support in multiple ways such as what supports are needed and how they should be given. Lin (1986) discusses how there are different types of support including financial and emotional support. 
Kras (2019) views social supports as encompassing many different people such as family and friends. Social support can increase an offender's informal social control, which can help them reintegrate into society with more ease (Kras 2019; Laub and Sampson 2003; Berg and Huebner 2011). I discuss informal control below, however this discussion on social supports is important in order to understand how support plays into desistance.

As I will explain below, Laub and Sampson's (1993) theory of informal social control looks at how important social bonds are to desistance. A vital aspect of this theory is "turning points" (Laub and Sampson 1993, 304). Originally, Laub and Sampson (1993) looked at turning points as aspects that can change quickly or gradually (Sampson and Laub 1998). Later, they expanded this thought, and said that turning points allow individuals to do five main things: "to 'knife off' the past from the present, invest in new relationships that foster social support and growth, be under direct and/or indirect supervision and control, engage in routine activities centered more around conventional life and/or perform an identity transformation" (Sampson and Laub 2005, 34). Sampson and Laub (2005) also note that narratives are important because they can help desisters recognize turning points in their life that can have meaning to the individual.

Within desistance literature, other terms can be used to talk about this transformation. Most notably, Giordano, Cernkovich, and Rudolph (2002) call these changes "hooks for change" (1000). These researchers "recognize the actor's own role in latching onto opportunities presented by the broader environment", and they recognize the actor's point of view in terms of what they categorize as important influences for change (Giordano, Cernkovich, and Rudolph 2002, 1000).

However, in returning to the discussion on turning points, a turning point is a change 
in someone's life course that changes their offending patterns (Sampson and Laub 2005; Carlsson 2012). Carlsson (2012) notes that turning points are not the actual events in an offender's life (i.e., a turning point is not getting a job), but the way "they can bring about other changes" (Carlsson 2012,3). Maruna (2001) notes that often offenders do not see events in terms of turning points but give "strangely trivial reasons" in answer to questions of why they stop offending (25). As explained above, Maruna (2001) looks at desistance as a process not an event, and in relation to this point, he adds that the process of desistance is slow and is not a fast alteration from someone who offends frequently to someone who does not offend at all.

Above, multiple different aspects and definitions of desistance are presented. Before I move on to discuss informal social control and formal social control as they relate to the factors that have been said to contribute to the process of desistance, I think it is important to outline that for the purposes of this thesis, desistance will be discussed not only as the ceasing of offending (Laub and Sampson 2001), but also as a process (Maruna 2001; Bushway et al. 2001). Later in this literature review I will present a table (Table 1) which will outline the differences between the risk and desistance paradigm.

\section{Informal Social Control and Desistance}

Laub and Sampson (2001) point to elements such as aging, stable work and marriage as important in the general desistance process, as outlined by the literature. This coincides with their (1993) age theory of informal social control, which encompasses the idea that desistance is the result of social bonds in adulthood (Laub and Sampson 1993). Laub and Sampson (2001) explain further that their theory of informal social control revolves around social bonds, and they found that "pathways to both crime and conformity were modified by 
key institutions of social control in the transition to adulthood" and "thus, strong social bonds could explain desistance from criminal behaviour in adulthood despite a background of delinquent behaviour" (Laub and Sampson 2001, 19; Laub and Sampson 1993). This is supported by many researchers such as Homey, Osgood, and Marshall (1995) who looked at the effects of social bonds on desistance and found that life circumstances affect criminal offending.

Age is talked about often in the literature as an element that affects desistance, and it is important to note that desistance can take place at any time in an offender's life, but the factors included in the process may be different at different ages (Weitekamp and Kerner 1994). However, desistance typically occurs within or after adolescent years (Laub and Sampson 2001). In general, the amount of crime committed declines the older the offender is; however, one must take into account the fact that different offence types may be the exception to this rule (Laub and Sampson 2001; Steffensmeier et al. 1989).

For sexual offences, this is also true, however the drop in crime with the increase of age is generally not as dramatic for them (Sampson and Laub 2003). There is often continuity in offending behaviour beginning in childhood through until adulthood (Laub and Sampson 2001). Laub, Nagin, and Sampson (1998) found that characteristics in childhood can predict misbehaviour in adults but cannot always predict desistance in sex offenders. But, Harris (2016) found that a big part of sex offender desistance was age, in that "growing up" was a significant theme mentioned by sex offender desisters in the researcher's study (1724).

There are several studies that look at age and offending. First, Glueck and Glueck's (1943) study consisted of a 15-year follow up of over 500 male inmates. It was found in the follow up period that the amount of people that were arrested in total decreased $(71 \%$ in the 
first five years to 57\% after 15 years) (Glueck and Glueck 1943). Furthermore, McCord (1980) followed participants from the Cambridge Somerville Youth Study past the age of 30, and found that most juvenile offenders committed crimes as adults, and Laub and Sampson (2001) note that McCord's (1980) study reported that those who offended as youth or adolescents were at greater risk to re-offend as adults. In a study of anti-social male children, Robins (1966) looked at how many children were arrested between the ages of 18-30 (more than $60 \%$ of the sample), and also found that of those arrested between age 18-30, more than half were also arrested for an offence after age 30. But, Wolfgang, Thornberry, and Figlio's (1987) followed a sample from the Philadelphia Birth Cohort, and found that most of the individuals offended up to the age of 16 and then rates declined.

Another aspect of informal social control is military service (Laub and Sampson 2003). These scholars argue that the military makes people become responsible, and also gives those who are not used to structure a structured environment to be immersed in (Laub and Sampson 2003). Bouffard and Laub (2004) looked at how the military related to desistance. They found that the military does promote desistance especially in delinquents (Bouffard and Laub 2004). These researchers also point out that the military, by virtue of what it entails, can expose individuals to weapons such as guns (Bouffard and Laub 2004).

Recall above, it is mentioned that life course perspectives are important in the study of desistance (Laub and Sampson 2001). Many studies lend themselves to social bonds and life course perspectives as they relate to desistance. Rand (1987) studied a sample of the Philadelphia Birth Cohort and found that marriage and hands-on job training reduced criminal activity. However, he also noted that personal characteristics played a role in reduced criminal activity (Rand 1987). Conversely, Knight, Osborn, and West (1977) found that marriage did not 
influence a reduction in criminal activities, but reduced behaviours like drinking.

In terms of sexual offender desistance, relationships are often viewed as important. In some cases, sex offender desisters have experience being in long term relationships and identify milestones such as having children as important (McAlinden, Farmer, and Maruna 2017). A lot of research points to family support as a positive force for offender reintegration (Mills and Codd 2008; Visher and Travis 2003; King 2013). Visher and Courtney (2007) found that over half of their sample of participants said that family support was important to them. This is consistent with King (2013) who also found that family played an important role in early desistance. Family is important, however, as will be discussed further below, when it comes to sex offender re-entry and desistance, family bonds can be hard to attain due to sex offender registries and restrictions that prohibit sex offenders from being in certain areas that are close to their families (Mann, Devendran, and Lundrigan 2019; Hipp, Petersilia, and Turner 2010).

Having an intimate partner in some cases can be a form of informal social control (King, Massoglia, and Macmillan 2007; Laub and Sampson 2003). Studies do indicate that being married does contribute to desistance after release from prison (Laub and Sampson 2003; Visher et al. 2009). Research on sex offenders show that feeling lonely and having poor relationships can lead to recidivism (Hanson and Harris 2000; Robbers 2009). Meloy (2005) found that sex offenders who were in serious relationships and who had stable living situations were less likely to be arrested again.

However, some researchers note that relationship histories or bonds that form due to relationships do not always lead to desistance (Farmer, McAlinden and Maruna 2015). Although this relationship is not always linear, in some cases sex offender desisters talk about 
the person who "stuck by them" as someone of great importance, and sometimes an influencer to desist (Farmer, McAlinden and Maruna 2015, 331). Lytle, Bailey, and Bensel (2017) found that those sex offenders who were married did not believe that their marriage lead to desistance but pointed to other aspects of support in the relationship that made a difference for them and their offending.

Kras (2019) contends that friends are also part of the social support system that can be important to offenders. Mallik-Kane and Visher (2008) suggest that friends can help offenders in multiple areas of life including basic support. However, it is important to recognize that in some cases friends are involved in criminal activity which is not ideal (Visher and Courtney 2007). This is supported by Kras (2019) who found that many of their participants found that their friends were "detrimental to their success" because they were "bad influences" on them (44).

Employment is another factor that is important to consider. Many studies have shown that employment reduces offending (Craig and Foster 2013; Verbruggen, Blokland, and Geest 2012) However, some studies show that employment does not reduce offending (Giordano et al. 2011; Simons et al. 2002). Uggen (2000) found that obtaining employment did not play a factor in decreased criminal activity but found that those who had a job and were over the age of 27 were the most likely to desist. Thus, in this case, age, employment, and desistance are related (Uggen 2000).

Consistent with this literature, McAlinden, Farmer, and Maruna (2017) found that employment was important to sex offender desisters, and sex offender desisters thought of going to work as "having a purpose" (272). However, this researcher also makes note of the fact that employment itself was not directly related to non-desisters becoming desisters, as 
many of these participants had careers before they started offending and during, and some participants desisted even if they lost their jobs (McAlinden, Farmer, and Maruna 2017).

This was also a finding in research done by Farmer, McAlinden, and Maruna (2015), who noted that for their participants, employment was related to "happiness and life satisfaction" but not necessarily a direct turning point from non-desister to desister (330). These researchers discuss their findings about employment in terms of desisters getting a job, however, Harris (2016) notes that in her research many of her respondents speak about "remaining free and safe" as a job that encompasses a lot of importance to them (1729). Thus, jobs can take multiple forms- they can be in the form of going to a place of employment, (McAlinden, Farmer, and Maruna 2017), but they can also be in the form of trying not to reoffend while taking care of what you feel is important to desist (Harris 2016). It is important to also recognize that finding employment as a sex offender is not easy given that sometimes they have restrictions which act like a barrier to gaining proper employment (Tewksbury 2005; Mustaine, Tewksbury, and Stengel 2006; Reed 2017).

This section of this literature review has spent a considerable amount of time looking at social context and life circumstances as they relate to desistance. Above, I mention Laub and Sampson's (1993) theory of informal social control. This theory has produced criticism from many scholars such as Maruna (2001), Farrall et al. (2011) and Giordano, Cernkovich and Rudolph (2002) as they criticize Laub and Sampson's (1993) theory for not taking into account personal identity or personal identity changes as they relate to desistance.

Gadd and Farrall (2004) interviewed participants about criminal careers and desistance. These researchers interviewed two participants who recounted their life stories, criminal history, and desistance narratives (Gadd and Farrall 2004). One of the men they 
interviewed was abused by his father as a child, and started committing crimes at a young age, while the other had an absent father who was cold and distant (he also was delinquent from a young age) (Gadd and Farrall 2004). They had their own children and had been in serious relationships with partners whom they were abusive towards, and who eventually left them (Gadd and Farrall 2004). One participant pointed to multiple factors that he said encouraged him to seek help and leave criminal offending behind him including his family, and his own father (who he did not want to be like) (Gadd and Farrall 2004).

Gadd and Farrall's (2004) research to some extent relates to McAlinden, Farmer, and Maruna's (2017) who found that a bond that sex offenders have with someone they care about can "act as a key preventative measure against an escalation of offending" (275). Just as one participant in Gadd and Farrall's (2004) study was influenced by the relationship with his son, those in McAlinden, Farmer, and Maruna's (2017) study discussed the importance of close relationships being a major reason to change. This is consistent with Paternoster and Bushway's (2009) study which found that once someone involved in criminal activity realizes the potential consequences of such activities (including how they can affect relationships), this can lead to early desistance.

Maruna (2001) discusses how participants in his study recognized and saw themselves as non-criminals after desistance. To expand, Maruna (2001) interviewed twenty criminals and thirty desisters of crime. He found that those who were criminals saw themselves in terms of their prior life circumstances, in that they felt that these circumstances contributed to who they were and their criminality (i.e., less than ideal childhoods) (Maruna 2001). Those who had desisted would talk about changes in behaviour as rooted in specific influences that contributed to this change that helped them break away from offending (Maruna 2001). They 
eventually equated the fact that they had not committed crimes to their new identity (Maruna 2001). This aligns not only with a cognitive transformation, but also with the idea that "to desist from crime, ex-offenders need to develop a coherent, prosocial identity for themselves" that leads to "reformed identities" (Maruna 2001, 7-8).

In addition, Kras and Blasko (2016) interviewed 28 male sex offenders in the United States. When interviewing participants whom they describe as persisters of sexual crime (those who have not desisted), these participants attributed their sexual crime to childhood trauma, relating to Maruna's (2001) research on how those living a life of crime see themselves in terms of their past (Kras and Blasko 2016). Consistent with Maruna (2001), Harris (2014) interviewed 21 adult male sex offender desisters and found that cognitive transformation was part of forming new identities. Furthermore, Kras and Blasko's (2016) desister sex offender participants did acknowledge some sort of responsibility for what they did. In line with research presented in this literature review, this acknowledgment of responsibility could be seen as a form of recognition, as described by Harris (2014).

\section{Formal Social Control and Desistance}

Although this project is not specifically focusing on aspects of formal control and desistance (i.e., this project does not involve talking to parole officers, probation officers, or the parole board), it is important to understand that formal social controls can also play a role in desistance processes as this occupies some of the literature on desistance.

Brogden and Harkin (2000) discuss how the controls put in place by the criminal justice system work in such ways that offenders "refrain from certain behaviour even when not legally prohibited" because they understand the consequences of said behaviour (47). Further, 
Paternoster and Bushway (2009) suggest that formal sanctions are effective because often people do not want to continue with their offending behaviour as it is perceived as being not socially acceptable. Thus, the fear of punishment from the criminal justice system can influence a change in behaviour (Paternoster and Bushway 2009).

Parole officers are a large part of an offender's life, especially during the transition into the community. It has been noted by several researchers that although parole officers provide formal control to offenders, they also play a role in providing informal control by being social supports for offenders, and in some cases developing positive social bonds with them (Mills and Codd 2008; Grattet, Lin, and Petersilia 2011). Blasko et al. (2015) found that if an offender had a better relationship with the parole officer, it meant that they adhered to their parole conditions, and recidivated less. It has also been found that if probation officers have a stricter supervision style, their clients are more likely to react negatively to their probation experience, which could lead to reoffending (Morash et al. 2015).

Göbbels, Ward, and Willis (2012) suggest that having close relationships with sex offenders as their parole officer often plays a positive role in changing an offender's identity. Healy (2012) found that those who had a more positive relationship with their probation or parole officer were more likely to desist. King (2013) also found that in early desistance narratives, individuals were more likely to continue down the desisting path because positive reinforcement from their probation officers was important in their desistance journeys. However, Kras (2019), in a mixed-methods study of recidivists, non-recidivists, parole officers and probation officers found that those "who had a helpful parole officer were four times more likely to go back to prison" (44). Cooley, Moore, and Sample (2017) noted that a significant amount of their participants did not feel like their parole officer did a sufficient job 
of discouraging their offending behaviours.

Education is another form of formal control that is important to discuss in relation to desistance. The role of formal education has been linked to crime prevention (Hansen 2003; Machin, Marie, and Vujić 2011). Dropping out of school can impact likelihood of crime (McFarland et al. 2018; Sweeten, Bushway, and Paternoster 2009). It has been found that going back to school after being incarcerated can be essential to establishing positive social bonds in society, along with providing the ex-offender with the skills necessary to move away from offending behaviour (Vilorio 2016). However, it is important to understand that those who are at risk for offending are also at risk for not completing school (Hjalmarsson 2008; Stearns and Glennie 2006).

Abeling-Judge (2019) examined data from the National Longitudinal Survey of Youth 1997 and found that reenrolling in education can "produce partial desistance effects" (527). It has been shown that postsecondary education can not only be a factor of desistance, but also has the ability to increase employability (Blomberg et al. 2011; Lockwood et al. 2012). Runell (2017) collected data from 34 university students who were once incarcerated who either attended university after incarceration or did not.

The participants in Runell's (2017) study were youth who served time at a correctional facility before attending university. Findings indicated that participants did view their educational experience as having a positive impact on their life; however, they did not mention that this experience stopped them from committing crime (Runell 2017). Instead, they talked about how they wanted to desist from crime because they had been incarcerated before and going back to school was a way to do this (Runell 2017). Some participants also talked about adopting new identities (Maruna 2001), commenting on how they now saw 
themselves as college students, not criminals (Runell 2017).

Treatment and therapy are also an important aspect of formal control and desistance as those who undertake treatment are often better able to understand their behaviours (Farmer, McAlinden and Maruna 2015; Harris 2014; Wakeling, Webster, and Mann 2005). The treatment programs discussed here are geared towards behavioural treatment. Mann, Devendran, and Lundrigan (2019) found that participants "were enthusiastic about such programmes, reflecting on processes of cognitive transformation" (6). Participants also commented on how feeling supported by group members in their treatment program was "a good support network" and helped them feel less alone (Mann, Devendran, and Lundrigan $2019,6)$. They also commented on how being in a treatment program helped them become more self-aware, which in turn helped them better understand their past behaviours (Mann, Devendran, and Lundrigan 2019).

However, it is important to note that sometimes offenders participate in these programs because they think it can facilitate a positive risk assessment (Mann, Devendran, and Lundrigan 2019; Brown 2005). Furthermore, it has been suggested that not participating in treatment programs can lend itself to offenders feeling like treatment professionals will judge them or see them as negative because they may be hesitant to participate, so they participate in hopes of the treatment professionals seeing them as having a reduced risk (Brown 2005). Feeling stigmatized has also been noted especially among those convicted of sexual offences who seek treatment (Lacombe 2008; Levins and Crewe 2015). Furthermore Harris (2017) found that, in contrast to the ideas that Maruna (2001), Maruna, Immarigeon, and LeBel (2004) and Maruna and Farrall (2004) presented about how cognitive transformation is needed for secondary desistance, it is not. In their study of 45 men convicted of sex offences who 
attended treatment, they found that desistance occurred even if treatment was mandatory and there was "no initial desire for intervention" (Harris 2017, 3049).

Participants in this study found that mandatory treatment meant that they had no time to try to go back to school or find a job, but some were also relieved to go to treatment because they "experienced regret" for not attending earlier (Harris 2017, 3058). The men in this study said that their arrest was really important and can be seen as a turning point wherein they could reach out for help (Harris 2017). Lastly, some participants did not want to go to treatment, but went anyways (Harris 2017). What was interesting in these cases was those participants who did not want to go to treatment "achieved behavioural change in the absence of any real psychological transformation" (Harris 2017, 3062).

Another aspect of treatment that is important to be explored is substance abuse treatment. Drug use and criminal activity are related, and criminal activity decreases when drug use decreases, however it is important to note that this is not a hard and fast rule, and that there are many variables that can affect drug use and crime such as personal and social factors (Bennett and Holloway 2009; Sevigny and Coontz 2008).

Bahr et al. (2012) investigated seventy inmates who participated in a drug treatment program while in jail, and seventy who did not. They followed them after their release from jail for a follow up time of fourteen months and found that of those who participated in drug treatment, $27 \%$ returned to jail, whereas of those who did not participate in treatment, $46 \%$ returned to jail (Bahr et al. 2012). Davis, Bahr, and Ward (2012) talked to sixteen offenders about reintegration. Among other supports (family and employment) many of the offenders felt as though treatment was necessary for their reintegration (Davis, Bahr, and Ward 2012). Twelve of sixteen offenders expressed that drugs and alcohol contributed to their crimes 
(Davis, Bahr, and Ward 2012).

Another aspect of formal control is sex offender registries, which also come with a plethora of barriers and effects such as difficulty finding employment and housing and money problems (Tewksbury 2005). Participants in Mann, Devendran and Lundrigan’s (2019) study explained how having these restrictions imposed on them because of their offence and their offence conditions made it hard to see certain family members or re-connect with family members, especially children.

Although sex offender registries can affect if sex offenders can see their family or not (Tewksbury 2005; Mann, Devendran, and Lundrigan 2019), they can also affect other areas of life. Since sex offenders cannot always live where they want, or where their family is, housing is a large issue that affects their reintegration (Tewksbury 2005). This means that there is the possibility that offenders may all live in the same area (Gordon 2013). However, this is complicated by the fact that, as found by Evans and Porter (2015), many landlords do not want to rent to tenants with criminal records, and this is especially true if the tenant was convicted of a sexual crime against a child.

Therefore, the importance of understanding desistance in relation to sexual offending is key as it encompasses many informal and formal aspects.

The Relationship Between Risk and Desistance

Above, I go through risk and desistance, and what is involved with their paradigms, mentioning briefly how the risk paradigm is focused on the individual's shortcomings (Nee and Vernham 2016; Maruna and LeBel 2003), and desistance is focused on offender's strengths (Maruna and LeBel 2003; de Vries Robbé et al. 2015). It is also important to note that desistance does not have as much empirical quantitative research done on the factors that are said to 
contribute to the paradigm (Maruna 2017). However, there are some instances wherein desistance and risk have worked together (Horan 2015; Serin and Lloyd 2017). This has been seen in the Next Generation of Community Supervision out of the National Institute of Corrections in the United States curriculum used to educate corrections personnel on reintegration, and Soaring2 which is a program for parole officers out of George Madison University in Virginia (Serin and Lloyd 2017). Both these programs are used to train those in corrections, and they do so by not only focusing on RNR principles, but also by considering an offender's inner motivation and how offenders can strive for a change away from offending (Serin and Lloyd 2017).

Furthermore, in England, there is an assessment tool called Enablers of Change that "frames RNR assessment within the desistance paradigm. The tool assesses the needs and risk of people with convictions and considers their strengths, aspirations and capital" (Horan, Wong, and Szifris 2019, 11). For example, in the second section of this model, which is labelled "healthy lifestyle" there is mention of "drugs and alcohol, thinking skills and attitudes", and "relationships" (Horan, Wong, and Szifris 2019, 10). In this example "thinking skills, attitudes and self-efficacy are areas that support a service user moving from a place where how they think about themselves, their lives and how this translates into offending is moved into how their perception of themselves supports behaviour change in a positive way"; these researchers mention how this not only links to secondary desistance, but includes central eight risk factors such as family and marital relationships (Horan, Wong, and Szifris 2019, 10).

The example above illustrate illustrates how the risk and desistance paradigms have been known to work together despite their differences. Recognizing that my discussion on risk and desistance was long and incorporates many moving parts, Table 1, below, showcases the 
differences between the risk and desistance paradigms, and the similarities, which will become more evident in the context of CSC policies throughout this thesis.

Table 1: Risk and Desistance Paradigm Comparison Table

\begin{tabular}{|c|c|c|}
\hline & Risk & Desistance \\
\hline \multirow[t]{2}{*}{ Definitions } & $\begin{array}{l}\text { "New arrests, new convictions, and } \\
\text { reincarceration" (Stewart et al. 2019, 1) }\end{array}$ & $\begin{array}{l}\text { Stopping offending behaviour (Laub and } \\
\text { Sampson 2001). }\end{array}$ \\
\hline & $\begin{array}{l}\text { Getting reconvicted of a crime after an } \\
\text { offence (Wartna, Blom, and Tollenaar } \\
\text { 2011). }\end{array}$ & $\begin{array}{l}\text { A process wherein offending stops, especially } \\
\text { in frequency (Maruna 2001; Bushway et al. } \\
\text { 2001). }\end{array}$ \\
\hline \multirow[t]{2}{*}{ Factors } & $\begin{array}{l}\text { The central 8: Anti-Social Personality, } \\
\text { History of Anti-Social Behaviours, Anti- } \\
\text { Social Cognitions, Anti-Social } \\
\text { Associates, Family and Marital } \\
\text { Circumstances, School and Work, } \\
\text { Leisure and Recreation and Substance } \\
\text { Abuse (Andrews and Bonta 2010). }\end{array}$ & $\begin{array}{l}\text { Informal Control: Age (Laub and Sampson } \\
\text { 2001; Glueck and Glueck 1943), Military } \\
\text { Service (Laub and Sampson 2003), Social } \\
\text { Bonds such as marriage (Laub and Sampson } \\
\text { 2003; Visher et al. 2009) and friends (Mallik- } \\
\text { Kane and Visher 2008; Kras 2019), } \\
\text { Employment (Craig and Foster 2013; } \\
\text { Verbruggen, Blokland, and Geest 2012). }\end{array}$ \\
\hline & & $\begin{array}{l}\text { Formal Control: The criminal justice system } \\
\text { including parole officers and sex offender } \\
\text { registries (Brogden and Harkin 2000; Blasko et } \\
\text { al. 2015; Tewksbury 2005), Education (Vilorio } \\
\text { 2016; Abeling-Judge 2019), Treatment } \\
\text { (Farmer, McAlinden, and Maruna 2015; Mann, } \\
\text { Devendran, and Lundrigan 2019). }\end{array}$ \\
\hline \multirow[t]{3}{*}{$\begin{array}{l}\text { Other } \\
\text { Aspects }\end{array}$} & & $\begin{array}{l}\text { Primary and secondary desistance (Maruna and } \\
\text { Farrall 2004; Maruna, Immarigeon and LeBel } \\
\text { 2004). }\end{array}$ \\
\hline & & $\begin{array}{l}\text { Secondary desistance happens when offenders } \\
\text { have a shift in identity (Maruna and Roy 2007). } \\
\text { Also, "cast off" identities (Paternoster and } \\
\text { Bushway 2009, 1107-1108) as an aspect of } \\
\text { leaving older identities behind. }\end{array}$ \\
\hline & & $\begin{array}{l}\text { Narratives are important as personal narratives } \\
\text { get constructed when individuals change their } \\
\text { behaviours especially as offender's move closer } \\
\text { to the secondary desistance stage (Maruna } \\
\text { 2001; Vaughan 2007; King 2013). }\end{array}$ \\
\hline
\end{tabular}




\begin{tabular}{|c|c|c|}
\hline & & $\begin{array}{l}\text { The idea of turning points allows offenders to } \\
\text { not only leave the past life behind, but engage } \\
\text { in new activities (Sampson and Laub 2005). } \\
\text { This can also be referred to as "hooks for } \\
\text { change" (Giordano, Cernkovich, and Rudolph } \\
\text { 2002, 1000). }\end{array}$ \\
\hline \multirow[t]{3}{*}{ Focus } & $\begin{array}{l}\text { Focused on weaknesses/offender } \\
\text { shortcomings (see Nee and Vernham } \\
\text { 2016, for example). } \\
\text { "Fixing problems" (Serin and Lloyd } \\
\text { 2017, 8). }\end{array}$ & $\begin{array}{l}\text { Focused on offender's strengths (see Maruna } \\
\text { and LeBel 2003, for example). } \\
\text { "Redemptive script (change possible when } \\
\text { client creates new meaning of self through } \\
\text { prosocial support and stability)" (Serin and } \\
\text { Lloyd 2017, 8). }\end{array}$ \\
\hline & $\begin{array}{l}\text { Addressing the central } 8 \text { factors in an } \\
\text { offender's life (Andrews and Bonta } \\
\text { 2010). } \\
\text { Serin and Lloyd (2017) comment on how } \\
\text { RNR is focused at the "individual level" } \\
\text { (8). }\end{array}$ & $\begin{array}{l}\text { Focus on social support (Cullen 1994). } \\
\text { Serin and Lloyd (2017) mention desistance as } \\
\text { having a more "societal focus"( } 8) \text {. }\end{array}$ \\
\hline & $\begin{array}{l}\text { Managing behaviours that could lead to } \\
\text { more risk (Andrews and Bonta 2010). } \\
\text { This is usually an "internal then } \\
\text { external" change (Serin and Lloyd 2017, } \\
\text { 8). }\end{array}$ & $\begin{array}{l}\text { Focused on aspects that will help with non- } \\
\text { offending behaviours (de Vries Robbé et al. } \\
\text { 2015). This is usually an "external then } \\
\text { internal" change (Serin and Lloyd 2017, 8). }\end{array}$ \\
\hline Similarities & \multicolumn{2}{|c|}{$\begin{array}{l}\text { These aspects can work together, as outlined by Serin and Lloyd (2017), Horan, Wong, and } \\
\text { Szifris (2019) and Horan (2015). In my own policy analysis, I will discuss the similarities } \\
\text { between these two paradigms, as they relate to the CSC policies analyzed. }\end{array}$} \\
\hline
\end{tabular}

Reintegration of Offenders in the Community: Perceptions, Support and Realities

It is also important to understand what affects community reintegration of offenders since parole means offenders are in the community. Generally, research indicates that one of the major obstacles that offenders face in the community in terms of reintegration is employability (Lucken and Ponte 2008). A study done by Varghese et al. (2010) investigated how potential employers see offenders, and it was found that those applicants with severe convictions (such as assaults or sexual assaults) were less likely to be hired in this situation. Another study looked at the perceived employability of ex-offenders by administering surveys to employers, employment service workers, correctional workers, prisoners and offenders (Graffam, Shinkfield, and Hardcastle 2008). It was found that those with a criminal 
record were not as likely to "obtain and maintain employment" (Graffam, Shinkfield, and Hardcastle 2008, 673). However, Griffith and Young (2017) interviewed human resources managers about the hiring process for ex-offenders and found that those who committed less severe offenses were more likely to be hired, but when it came to other charges some managers highlighted "examining the circumstances for each applicant" (509-510). This is important because in "examining the circumstances for each applicant" (Griffith and Young 2017, 509-510), there is the potential for those with criminal records to get jobs, and, as Craig and Foster (2013) and Verbruggen, Blokland, and Geest (2012) point out, jobs can positively contribute to the process of desistance. However, sometimes the process of getting a job can be complicated further, as explained above, by sex offender registries or other geographical restrictions (Mann, Devendran, and Lundrigan 2019).

The research presented above confirms other older but relevant research done in Canadian corrections. Brown (2004), interviewed federal parole officers in Canada regarding what they felt were the biggest challenges for federal offenders on parole were. They indicated that life and financial skills and employment were some of the barriers parolees struggled with once in the community (Brown 2004).

Gunnison and Helfgott (2011) researched what factors influence offender re-entry success. Through self-report surveys, community parole officers in Seattle, Washington "identified unemployment and criminal peers as the primary factors that hinder offender reentry success" (Gunnison and Helfgott 2011, 298). Further, stigma in neighbourhoods, usually fueled by movements that aim to push offenders out of communities (e.g., the Not in My Backyard movement) add to the difficulties offenders face while reintegrating (Griffiths 2015). 
Above, I present a considerable amount of background contextual information on both the assessment of sexual offenders and barriers to reintegration that offenders or exoffenders face while on parole. This is relevant because my research relies on this literature as a basis for potentially pushing for change within $C D$ 705-6, $C D$ 715-1, $C D$ 715-2 and $C D$ $715-3$, and understanding the barriers around reintegration is an important step in understanding how offenders could be supported in their desistance journeys.

\section{Sexual Offender Reintegration: Circles of Support and Accountability}

As evidenced above, those who have a history of offending, and who are on parole, face challenges within the community. An important aspect of reintegration, specifically sex offender reintegration is a program called Circles of Support and Accountability (CoSA). This program started in Canada in the 1990s with the aim of helping those who have been incarcerated for a sexual offence be reintegrated into the community with the help of the community itself (Hannem 2011; Hannem and Petrunik 2007). This program's objectives are "No more victims" and "No one is disposable" (Hannem and Petrunik 2007, 153).

The way this program works is that individuals who have a sexual offence history (who are referred to as the core member of the circle) are paired up with a community volunteer (Hannem and Petrunik 2004). They meet at a weekly meeting wherein "the volunteer members support the core member in his efforts to desist from offending and to integrate into the community, help deal with any crises that may occur, and celebrate him with him milestones and successes" (Hannem and Petrunik 2007, 154). The circle is comprised of several volunteer members and one core member (Hannem and Petrunik 2007).

The program has several rules. Firstly, offenders need to enter the program voluntarily and want to not only be helped by the circle but understand that the volunteer member from 
the community that they will be paired with will hold them to their goals (Hannem and Petrunik 2007). Secondly, the core member needs to agree to share his file with the volunteer so that a truthful relationship builds between them (Hannem and Petrunik 2007). The core member may want help with different aspects of reintegration, and the volunteer member can agree to help them "obtain suitable work, housing, recreation, and access to community resources, and to formulate and follow a relapse prevention plan" (Hannem and Petrunik 2007, 160). The core member receives support for as long as they need with the end goal being that they do not need to meet with the circle as often (Hannem 2011).

Within the Canadian context, there have been two major studies that evaluate CoSA and its recidivism effectiveness. First, Wilson, Picheca, and Prinzo (2005) looked at a group of 60 high risk sex offenders who participated in CoSA after their sentence, and 60 high risk sex offenders who did not, for a follow up time of 4.5 years. They defined recidivism as "having a new sexual offense, or for having breached a condition imposed by the Court" (Wilson, Picheca, and Prinzo 2005, ii). Those who participated in CoSA had a sexual recidivism rate of five percent, and those who did not participate in CoSA who had a sexual recidivism rate of 16.7\% (Wilson, Picheca, and Prinzo 2005).

The study mentioned above was replicated by Wilson, Cortoni, and McWhinnie (2009) with 44 high-risk sexual offenders who were involved with CoSA matched with 44 high-risk sexual offenders who were not involved with CoSA, with a follow up time of 35 months. Recidivism in this study was defined the same was as it was in the study above, and it was found that those who had participated in CoSA "had an $83 \%$ reduction in sexual recidivism" (Wilson, Cortoni, and McWhinnie 2009, 412).

Circles of Support and Accountability is not just a Canadian program and has been 
employed elsewhere in the world. For example, Duwe (2012) looked at CoSA in Minnesota, focusing on 31 sex offenders who had participated in CoSA, and 31 who had not. It was found that of those who participated in CoSA only $39 \%$ were rearrested, in comparison to the offenders who did not participate in the program, in which that number was $65 \%$ (Duwe 2012).

Furthermore, a study done in The Netherlands interviewed those who had been part of a CoSA circle for 6 months, and then again at the 12 month point to discuss how they felt the circle was impacting them (Höing, Vogelvang, and Bogaerts 2017). Specifically, in terms of desistance, they found that after one year in the circle, members discussed how they had "reflective skills, self-confidence, self-esteem” (Höing, Vogelvang and Bogaerts 2017, 765). It was also found that CoSA was instrumental in helping some members develop skills necessary to live in society, but that "social relations outside CoSA probably take more time" (Höing, Vogelvang, and Bogaerts 2017, 765). This study was very similar to an earlier study done by Bates et al. (2012) who found that, by reviewing files of members involved in CoSA, "emotional, cognitive, and behavioural transitions were more prevalent in core members than social transitions" (Höing, Vogelvang, and Bogaerts 2017, 767).

This research is important as it demonstrates some of the supports that are available for sex offenders in the community. It is important to note, however, that CoSA is not a permanent fix to the issues that those with a sex offence history will face in the community, especially given that the goal of CoSA is to ensure that the core member will eventually not need the support of the circle as time goes on (Hannem 2011). Therefore, if reintegration programs are not permanent fixes, understanding the stigma sexual offenders face in society can help in evaluating if policy adequately takes the desistance paradigm into account, as 
they can be an avenue that can help make reintegration easier.

Government Reports: Sexual Offending and Parole

Since this project seeks to examine part of CSC's policy for desistance and risk, it is important to look at how re-offending is discussed in policy. Thus, looking at research studies done by federal Canadian organizations in regard to offending and risk is vital. The studies below outline research done by CSC and PSC and provide a glimpse into supervision, sexual offending, risk, and factors that affect recidivism.

Between PSC and CSC there are many studies that relate to my research on sexual offending. First, Motiuk and Brown (1996) looked at over 500 sex offenders under community supervision and followed them up for approximately 3.5 years after they were released. After this follow up time, it was found that the offenders did not get re-arrested for new sex offences at a high rate (Motiuk and Brown 1996).

The study mentioned above is an older study, however it works to contextualize my project. Harris and Hanson (2004) investigated how often sexual offenders re-offend. In a study of over four thousand participants from Canada, the United States, England, and Wales these researchers followed sexual offenders for several years after release (Harris and Hanson 2004). This sample did not focus on one specific sexual offence (Harris and Hanson 2004). These researchers noted that "after 15 years, $73 \%$ of sexual offenders had not been charged with, or convicted of, another sexual offence" (Harris and Hanson 2004, 11). This is somewhat similar to Motiuk and Brown's (1996) study in that sexual offenders do not reoffend at an alarming rate.

Hanson and Morton-Bourgon (2004) conducted a quantitative review (meta-analysis) of recidivism factors for sexual offenders from several different studies and reports. The 
sample from the various studies included 31,000 sexual offenders and many recidivism predictors (Hanson and Morton-Bourgon 2004). Predictors of recidivism included multiple aspects such as "history of rule violation" having an "unstable lifestyle" and having "deviant sexual interests" (Hanson and Morton-Bourgon 2004, iii, 15). This study found that the "sexual recidivism rate was $13.7 \%$ " (which included a sample of " 20,440 or 84 studies"), whereas the "general (any) recidivism rate was 36.9\%" (which included a sample of "13,196 or 56 studies") (Hanson Morton-Bourgon 2004, 8). These researchers also mention that actuarial risk tools were more accurate in their predictions of sexual offending than a clinician's opinion (Hanson Morton-Bourgon 2004). This result was similar to the findings gleaned from Hanson and Morton-Bourgon's (2007) research on approaches to sex offender risk assessment mentioned in the risk assessment section of this paper.

Further, Hanson et al. (2007) conducted a study on risk assessments where they looked at "identifying the dynamic factors for sexual offenders on community supervision" and also looked at static, stable and acute factors (1). This study involved every province and territory in Canada, along with Alaska and Iowa, and included 156 parole and probation officers and the assessments of 997 sexual offenders (Hanson et al. 2007). In this study the parole and probation officers' notes on offenders were analyzed based on how well they used the STATIC-99 (looks at static risk factors) (Hanson and Thornton 2000), the Stable-2000 (Hanson et al. 2007) (which looks at stable risk factors and labels them from 0-2), and the Acute-2000 (Hanson et al. 2007) which looks at acute factors (Hanson et al. 2007). It was found that "the assessment tools, when properly used, showed levels of predictive accuracy as high as or higher than has been shown for other established methods of risk assessment with sexual offenders" (Hanson et al. 2007, 27). 


\section{Sex Offender Desistance as "Different"}

Throughout this literature review section, I have outlined desistance, and also brought light to sex offender desistance. In this section I am going to reiterate these points to further articulate how sex offender desistance is different from "normal" or "general" desistance, which is why it should be highlighted in policy.

Sex offenders do not re-offend at high rates after release (Motiuk and Brown 1996; Harris and Hanson 2004). I argue that this information within itself is enough to understand why the importance of having sex offender desistance represented in policy is vital if sex offenders do not re-offend often, then that means that they are going to be in the community no matter what, and as soon as they get out of prison they are going to need the support of society in order to have a chance at integrating successfully.

In talking about desistance and sex offender desistance, it is important to discuss social bonds. For non sex offenders there are different views in the literature with respect to how important those bonds are in relation to desistance (see Rand 1987 for why social bonds are important, and see Knight, Osborn, and West 1977 for why they are not). However, for sex offenders, relationships are seen as important; specifically marriage (McAliden, Farmer, and Maruna 2017), and family (Mills and Codd 2008; Visher and Travis 2003). But the issue is that access to family can be hindered by policies that serve to restrict sex offender movements (Mann, Devendran, and Lundrigan 2019; Hipp, Pertersilia, and Turner 2010). Thus, it is important for policy, while sex offenders are on supervision, to allow for them to see their family and build those relationships.

Employment is another big factor for reintegration and for society (i.e., it is often looked highly upon if someone can hold down a job and contribute to society in that way). 
Although not all studies show employment as a factor related to sex offender desistance (see Giordano et al. 2011 and Simons et al. 2002 for unsupportive claims), sex offenders do face employment issues along with other issues such as finances (Tewksbury 2005). Furthermore, Varghese et al. (2010) and Graffam, Shinkfield, and Hardcastle (2008) showcase how offenders who have criminal records, especially for offences that are considered heinous like sexual offending, are less likely to be hired. If sex offenders are not getting hired, then it means that they are not making money, but more importantly it fits into the stigmatizing Not in My Backyard discourse (Griffiths 2015) that is prevalent in society. This discourse, along with sex offender registries and restrictions that were mentioned above, leave sex offenders with little to no options to even try to be "successful" members of society. This, inevitably, could lead to isolation which can contribute to recidivism for sexual offenders (Hanson and Harris 2000; Robbers 2009).

Above, I mention some of the issues that sex offenders face that are different than non sex offenders. This distinction is important because not only is "regular" desistance and sex offender desistance different, but the issues that sex offenders face in the community are basic barriers to get their lives to a place where they can be seen as "normal". Much of the restrictions they face even inhibit them to have social lives with people they value as close (family, friends, significant others) (Mann, Devendran, and Lundrigan 2019; Hipp, Pertersilia, and Turner 2010), which could be a barrier that could diminish their self-esteem to the point that they do not want to go outside and put themselves out there for strangers if they do not have a support network around them.

With this, organizations need to do better at recognizing the importance of sex offender desistance when drafting policies, because they do require special considerations so 
they can further excel in society. I also recognize that one could point out that if sex offenders do not reoffend as often as non sex offenders then policy does not need to cater to their needs (Harris and Hanson 2004). However, I think that this is a gross over simplification in that just because statistics show that this is true, does not mean that there are not fundamental issues at the societal level that need to be addressed to make the transition into the community for sex offenders easier, more enjoyable, and accessible. Thus, this is where policy, at the federal level can help address some of these issues.

\section{Theoretical Framework}

Above, I outline the debates within the literature as they pertain to sexual offending, desistance and reintegration. Although theoretical framework sections present theories, outlooks or frameworks in relation to the ways in which a project will be examined, this will not be the case for this project. For this thesis, the theoretical framework works in tandem with my literature review, as my theoretical framework is the concept of risk and the concept of desistance. When I talk about these concepts in this thesis, I am often referring to them as paradigms. Although I am focusing on the desistance paradigm, the fact of the matter is that I am discussing both.

As explained above, discussing if an offender will re-offend, and why, is what the risk paradigm encapsulates (Thornton 2013). More specifically, the eight factors to consider when discussing risk, as outlined by Andrews and Bonta (2010) include: anti-social personality, history of anti-social behaviours, anti-social cognitions, anti-social associates, family and marital circumstances, school and work, leisure and recreation and substance abuse (Andrews and Bonta 2010).

Furthermore, desistance is "not well understood" (Laub and Sampson 2001, 1). 
Through my literature review it is evident that there is not one universally agreed upon factor or theory that contributes to desistance, and different scholars have contributed and added insights within theoretical frameworks that they feel best explain desistance. Above, I touched on Gottfredson and Hirschi's (1990) theory about crime and opportunity, Cullen's (1994) paradigm of social support, and Laub and Sampson's (1993) theory of informal social control, all of which describe different aspects of desistance.

As stated above, the theoretical frameworks for this project are the risk and desistance paradigms. Below, in my methods section I explain how this thesis will use aspects of policy analysis, thematic analysis, constructivist grounded theory (CGT) and critical discourse analysis, to contribute to the overall analysis of CSC policy around releasing offenders into the community.

Therefore, for this research project, data will be analyzed inductively. The goal of this analysis is to see how, and in which ways these polices include aspects of the desistance and risk paradigms. These paradigms will be discussed in terms of sex offenders as well. The analysis will also point to ways in which the polices can better include aspects of desistance, while also taking into account the realities of the way sex offenders are viewed and socially constructed in society.

The next section of this thesis will discuss the methods used for this paper. 


\section{Chapter 2: Research Methods}

This section will explain the evolution of my research questions, sampling techniques, and data analysis methods. It will also touch on the notion of reflexivity and researcher positionality along with ethical considerations.

\section{Choosing Qualitative Research}

For this project I decided early on that I would undertake a qualitative project because of the type of thematic analysis I wanted to do. Once I narrowed down my research idea, I knew that I wanted to examine sex offender policy because I wanted to understand the social phenomenon of sex offenders. Furthermore, I connected with van den Hoonaard's (2015) explanation of qualitative research which states that "qualitative research encompasses a variety of approaches through which researchers attempt to understand the everyday lives and social settings of those they study" (2). Although not speaking to sex offenders directly (I will later explain why this was not an avenue I took), examining policy does help contextualize the ways in which society looks at phenomena. Furthermore, societal actors (in this case sex offenders) are living in society based on policy, thus policy can help to understand the social settings in which sex offenders live. These are the reasons I wanted to analyze policy. Schulenberg (2016) mentions that qualitative research is something that explores a relationship, and why it needs to be looked into further. I wanted to explore the relationship between policy, the desistance paradigm, and community reintegration for sex offenders. To be clear, not every policy I analyzed related to sex offenders only, thus, this research also contextualizes the ways in which policies discuss reintegration for non sex offenders.

Tracy (2013) also offers insight into the importance of action and structure in qualitative research. She discusses how qualitative researchers look at people's actions and 
the structures around those actions (structures being aspects or things that shape or change the course of the action) (Tracy 2013). She argues that this is important, because qualitative researchers often study everyday life practices, but also try to understand the structures around those practices "that are driven by our formal expectations for things to unfold in a particular way" (Tracy 2013, 23). I wanted to understand how the bigger structures (in this case the government) contribute to the expectations of how both sex offenders and non sex offenders should be reintegrated into society.

Lastly, Tracy (2010) points to eight criteria that make up qualitative research. When I decided what approach I would take for this research I referenced this list. Specifically, she talks about the importance of having a worthy topic and says that "worthy studies are interesting and point out surprises- issues that shake readers from their common-sense assumptions and practices" (Tracy 2010,841). This is important because in society discussing sex offenders and the life of sex offenders is not mainstream, and often comes with associated stigma (Griffiths 2015). I thought that this topic was worthy of further investigation in order for readers to understand the barriers that exist after coming out of the criminal justice system, but to also understand how policy can be one of those barriers.

\section{Evolution of the Research Project}

As with many research projects, the ideas for this project changed several times. In general, I knew that I wanted this project to focus on sex offenders, as my undergraduate work interrogated the concept of restorative justice as it pertains to sexual offender programs such as The Circles of Support and Accountability (CoSA) Program in Canada. Originally, I thought that this project would involve CoSA again to some extent, potentially by interviewing participants in the program in order to better understand how they thought the 
program was helping them, and to see if they thought it was "restorative" and what that meant to them. In this original project idea, I also thought of including other organizations that run sex offender programming, or that provide support to sex offenders in the community such as House of Hope, The St. Leonard's Society of Canada, and The John Howard Society. This idea eventually evolved again into just using The John Howard Society of Ottawa to recruit individuals who have sexual offense histories to talk to me about the barriers that they face in society.

Although this seemed like a viable option at the time, my thought process shifted slightly, mostly due to the fact I had started a placement at CSC, working on a team that looks at parole officer resources. Although this has very little to do with sex offenders, it prompted me to think of how parole officers and parole play into reintegration.

At the start of this project these were my research questions: What elements do high risk sex offender ex-parolees, post warrant expiry, believe are factors that contributed to their success while on parole? How do they define successful parole? And lastly, are the factors mentioned by the ex-parolees or parole officers similar to those outlined in the assessment portion of CSC's CD-715-1? How can CSC policy change to include relevant factors? Within these questions I wanted to include parole officers, but that brought forth ethical concerns such as privacy, since I am also an employee of CSC.

I arrived at my current questions around policy specifically as a way of addressing how reintegration is assessed at the governmental level. Furthermore, I found that, although my original question around talking to ex-sex offender parolees brought an interesting angle to this project, the population was harder to reach than I initially thought. While this took away the human participant aspect of qualitative research, it also allowed me to research how 
many policies actually deal with sex offender reintegration. Before, I was looking at one policy in particular, and upon further investigation, I found that there are at least four policies that deal with reintegration at CSC. Therefore, I concluded that looking at sex offender reintegration from the policy angle would be beneficial because the topic stretches over multiple institutional reports that can affect sex offender's lives in the community.

\section{Research Questions}

As noted in the introduction, the questions for this project are in multiple parts. I chose to ask: Do Correctional Service Canada (CSC) policies encompass aspects pertinent to reducing recidivism, and what does this look like? How is desistance incorporated into CSC policy around community supervision and parole? Are specific desistance factors related to sex offenders considered in these policies? How could they be included in these policies? Or, more specifically, how do the assessment portions of CSC Commissioner's Directive (CD) 705-6 (Correctional Planning and Criminal Profile), CD 715-1 (Community Supervision), $C D$ 715-2 (Post-Release Decision Process), and CD 715-3 (Community Assessments) discuss desistance? Are aspects of sex offender desistance present within these policies? How could they be incorporated into these policies? These questions fit within CSC's priorities because one of their priorities is to have "safe management of eligible offenders during their transition from the institution to the community, and while on supervision" (CSC Website, 2016). Although this project does not concern safety specifically, if there are additional factors that should be included in policy about desistance then not having those be included could ultimately affect the safety of those in the community. This project was not done in conjunction with CSC, however since I intended on examining CSC policy for this project, I deemed it important to understand how it could fit into CSC's larger mandate. 
I wanted to determine if aspects of the desistance paradigm were present in CSC policies at all, especially given how many ex-sex offender parolees are in the community (CCRSO 2017, 2018). It would also be interesting to see how narratives of desistance either currently play into policy or could be incorporated into policy. Furthermore, the inclusion of the first question in relation to risk factors is also interesting here because there is the possibility that if narratives in relation to desistance are not present within the policies then the policies take a more risk-based paradigm approach.

I am also focused on how these federal policies address the desistance paradigm in relation to sex offenders, given their unique needs. Understanding and examining how policy can be improved could shed light on what other resources are needed in the community to break down the obstacles that this population faces, such as unemployment (Lucken and Ponte 2008; Varghese et al. 2010; Graffam, Shinkfield, and Hardcastle 2008). More importantly, however, I ponder if policy needs focus less on the risk paradigm, and more on the desistance paradigm.

\section{Researcher Positionality and Reflexivity}

When thinking about reflexivity I used a combination of Mason's (1996) and Hertz's (1997) definition. Mason (1996) says that for reflexive research to take place, "the researcher should constantly take stock of their actions and their role in the research process and subject these to the same critical scrutiny as the rest of their data" (6). Hertz (1997) adds that those doing reflexive research should ask several questions such as "what do I know?" and "how do I know what I know?" (viii).

In doing this research project these simple, yet important questions ran through my mind consistently. I took the literal approach to these questions in that when asking myself 
what I knew and how I knew it, I took the time to reflect on how my perceptions of parole and reintegration are largely shaped by CSC and the government since that is where I work. Although I was aware of the issues pertinent to those on parole, I had to constantly remind myself that the information I get about these topics is not only related to my job but is also from parole officers meaning that I needed to take a step back in order to understand how these policies affect the lives of people in the community. I also have to remind myself that much of what I know comes from having an undergraduate degree in Criminology from an institution, which in itself is a privileged environment to be in and learn from.

With the acknowledgement that I work at CSC, and that I work closely with the parole process, and often speak to parole officers for work, it is important to understand the angle from which I am approaching this thesis. Although I am not a parole officer myself, my job has led me to understand the real-life realities of parole officers on the job, thus, when I am discussing policies for my analysis, I am doing so in a way that definitely is informed from a parole officer's perspective, despite not interviewing them for this project.

Guillemin and Gillam (2004) suggest that reflexivity is a "continuous process of critical scrutiny and interpretation" and that this does not just involve those who are actively participating in the research, but also encapsulates the context in which the research is undertaken (275). I thought that this was vital because not only did I want to be reflexive in the research, but I also wanted to use CGT, which is a method that allowed me to critically analyze the data consistently (Charmaz 2008).

Furthermore, Finlay (2003) breaks reflexivity down even further into categories that can be helpful in differentiating different types of reflexive research. In this project, I tried to employ reflexivity as "social critique" (Finlay 2003, 12). This was pertinent to this research 
because, as Finlay (2003) explains, "using reflexivity as a social critique is how to manage the power imbalance. . .arising from different social positions. . . for instance, in relation to class, gender, and race" (12). This was important for my reflexive journey because from a societal point of view, I am of a higher social position than those who are affected by the policies I am analyzing, and by those whom the policy was written for. I am a university educated public servant, working for the organization that drafted these policies, and that was something I always had to keep in mind. Although I was not talking to individuals with sexual offence histories, understanding your own positionality and biases as you analyze data is important. Thus, in being reflective and engaging in reflexivity I came to remind myself of the fact that I am a white, female university student, who works for the public service, and who has never been in contact with the criminal justice system. All of the characteristics that I just listed are important parts of myself and important characteristics to interrogate especially when I was analyzing and organizing my data.

\section{Data Type and Data Collection}

For this project I chose to look at policy documents, and therefore chose an unobtrusive method for this research. This was mostly because I am looking at a specific population that is not easy to reach. Lee (2000) discusses how this is one of the strengths of unobtrusive research; it becomes easier to investigate what you are interested in if the specific population is too hard to access. Furthermore, this method has other advantages, such as fewer ethical concerns and cost efficiency (Schulenberg 2016).

The unobtrusive method that I chose for this research is document analysis.

Document analysis can be combined with other types of methods such as interviews to provide additional angles to research (Bowen 2009; Danto 2008). However, document 
analysis can also be applied by itself, and is defined as "finding, selecting, appraising (making sense of), and synthesizing data contained in documents" (Bowen 2009, 28). Documents can come from different sources and can include text and images (Bryman 2016; Creswell and Plano-Clark 2011). Merriam (1988) explains that "documents of all types can help the researcher uncover meaning, develop understanding, and discover insights relevant to the research problem" (118).

Specifically, for this research I decided to look at policy and government documents because as a researcher, analyzing bureaucratic documents can be used to understand how they "represent people, establish priorities, and dismiss specific events or individuals" (McCloskey 2008, 44). In this case these documents could represent the interests of CSC and policy makers, along with stakeholders, but they also represent the priorities organizations have for the people that these policies were intended for (in this case, offenders and sex offenders).

Furthermore, the point of this analysis is to see if policy recognizes aspects of the desistance and risk paradigms (including sex offender desistance). Thus, the idea that McCloskey (2008) brings forth about how document analysis can shed light on if people are being dismissed in documents could be relevant to this research in that there is the chance policy does not include the important factors of desistance or sex offender desistance throughout. Danto (2008) explains how government documents are useful for qualitative researchers because they are official and are seen as being reliable due to their official status. There are many examples of government documents being analyzed. For example, Mackieson, Shlonsky, and Connolly (2019) examined parliamentary documents in Australia around child adoption, and Kronick and Rousseau (2015) analyzed legislation from Canadian parliament as it pertained to detaining refugee children. 
For this project, picking which documents I wanted to analyze was simply a process of going onto CSCs website and scrolling through the Commissioners Directives that related to aspects of community reintegration, and that had an assessment portion at the end of them for parole officers or other staff. These were ideal because the assessment portions of policies give a glimpse of how certain factors are evaluated, and how they, in turn, affect offenders in the community.

\section{Data Analysis}

Data for this project was analyzed using aspects of several methods. This section will discuss thematic analysis, constructivist grounded theory and critical discourse analysis as the three types of analytical lenses that contributed to analyzing CSC policy for this project.

To be clear, for this project, thematic analysis is the overarching method used to analyze the policies. Thematic analysis is used in order to examine the extent in which desistance and risk paradigms are included within the four CSC policies. In terms of coding for themes and asking critical questions necessary for this type of analysis this project engaged in a constructivist grounded theory (Charmaz 2008; 2006). Also, critical discourse analysis was used as a way to analyze both large and small interpretations of the policies in terms of wording and word choice (Fairclough 2013). The reason why I chose to use these a variety of methods instead of just using thematic analysis is because in order to derive themes, constructivist grounded theory provided me with a ground-up approach, while also allowing me to engage with important questions around the policies (see Charmaz 2006 for questions). Moreover, critical discourse analysis allowed me to really engage with specific word choices in the text and how they relate to the offender and society (Fairclough 2013). If I just focused 
on thematic analysis there would not have been this multi-layered approach to the analysis of what was in the policies.

Before I discuss these methods, I will discuss policy analysis and my justification as to why this project encompasses some aspects of policy analysis.

\section{Policy Analysis}

Policy analysis as described by Fairclough and Fairclough (2012) identifies policy arguments and discusses how they address a recognized problem, which includes looking at the policy response to the problem (i.e., if the policy has identified a way in which the problem can be solved). Furthermore, critical policy analysis recognizes policy as the avenue through which social issues are represented and reconstructed in specific ways that represent the interests of the government (Bacchi 2000; Diem et al. 2014).

For example, Thomas and Bull (2018) investigated how policies in Australia discuss substance abuse in relation to women. They found that policies focused on how drug use affects women's reproduction, and how drug use can make women more vulnerable to harm such as assault (Thomas and Bull 2018). In doing this analysis they also found that harm reduction was not discussed for all types of women ranging across different demographics (Thomas and Bull 2018). Another study used policy analysis to examine dental contracts in the United Kingdom which included a clause that says that says that patients cannot obtain treatment unless they attend additional appointments and additional care practices (Laverty and Harris 2018). These researchers argue that this clause can contribute to further dividing health inequalities in the community (Laverty and Harris 2018).

May et al. (2013) conducted a study on palliative care policy in Ireland, as Ireland was one of the first countries that adopted a national palliative care policy. They analyzed this 
policy looking at its context, the actors involved in policy making and at how the policy affects healthcare services and other stakeholders in the healthcare industry (May et al. 2013). The researchers found that the policy was not only quite ambitious but did not take into account resourcing issues in the job market such as expanding the palliative care market so there would be enough workers to attend to patients (May et al. 2013).

These studies relate mostly to the sociology of health, and they also address an aspect of social life that is represented in policy (i.e., female drug use) (Thomas and Bell 2018), or they examine aspects of policy that could have an effect on those who the policy is geared towards (Laverty and Harris 2013), or they research the context of the policy and find gaps within that should be addressed (May et al. 2013).

Fairclough and Fairclough (2012) discuss how, in critical policy analysis, often times the policies discuss the ways in which the government plans to address an issue. Policy analysis can also be used to highlight the interests of the government (Bacchi 2000; Diem et al. 2014) Although parole officers work for CSC, and are the ones administrating the assessment portions of the policies that I am investigating, the assessment portions do not contain specific statements as to how the federal government wants to "deal with" reintegration and they do not talk about reintegration as a "problem" (since the assessments are focused on the offender's life). However, I recognize that this is not as black and white as it may seem, since the assessment portion of each policy is representative of how CSC wants reintegration to be implemented, which could relate to the interests of the government (Bacchi 2000; Diem et al. 2014).

To conclude, my research questions address suggesting where aspects of the desistence paradigm could be more present in the policies that I am analyzing. In this way my research is 
similar to that of Thomas and Bull (2019) and May et al. (2013) because I am analyzing the policy for gaps, specifically to see if there are areas in which desistance is not present, but does not necessarily reflect Fairclough and Fairclough's (2012) definition (i.e., policy as a way to address an issue).

\section{Thematic Analysis}

This project will employ thematic analysis. Thematic analysis is a process wherein themes are looked for in data (Fereday and Muir-Cochrane 2006). In this process the researcher looks at data and "performs coding and category construction based on the data's characteristics to uncover themes pertinent to a phenomenon" (Bowen 2009, 32). Codes may be predefined (usually when the method is used in conjunction with another method), or codes may develop as the documents are analyzed (Bowen 2009). Similar to Bowen (2009), Staller (2015) describe thematic analysis as a way of interpreting data through patterns. However, thematic analysis has been criticized for not having an agreed upon approach of analyzing data (Bryman 2016).

Despite this, I argue that this method is appropriate for this research project as, although policy is written out in a way that should be easy for everyone to understand, the assessment portions of policy can still be subjective depending on who is filling it out. Therefore, policy is not always interpreted in one way, and should not be analyzed according to one approach. It is also for this reason that I decided not to analyze policy through a content analysis approach. Using Mackieson, Shlonsky, and Connolly's (2019) definition of content analysis as "the process of organising and quantifying the contents of the data into predetermined categories relevant to the central research questions(s) in a systematic, replicable and objective manner" (969), I feel as though the analysis for this current research project 
should be more theme related. This is because I intend to use grounded theory as the approach to come up with themes present within data, instead of using pre-determined categories, in order to gather a picture of what the policies convey.

I realize one could argue that risk, desistance, and sex offender desistance literature does outline pre-determined categories for what contributes to them, and I could code from those pre-determined categories. However, I feel as though that approach is too "black and white" and I recognize that I could notice other themes within my data that do not fit within those pre-determined categories. Thus, I chose to code my data in a way that breaks down the themes found in the literature review differently.

\section{Constructivist Grounded Theory (CGT)}

I also analyzed data using constructivist grounded theory (CGT) (Charmaz 2006). Kathy Charmaz is the champion of this theory; however, grounded theory was founded by sociologists Barney Glaser and Anslem Strauss (Charmaz 2006). Glaser and Strauss believed that one could develop a theory from data that they analyzed (Glaser and Strauss 1967; Charmaz 2006). They also noted that grounded theory does not just have to be employed by using interviews, rather, it can be conducted using documents (Glaser and Strauss 1967). Grounded theory has been used in conjunction with document analysis before. Bowen (2003) used this approach when studying social investments funds in Jamaica (that would give grants to communities for projects) by analyzing documents in the form of newspapers, reports, meetings and letters as they pertained to this initiative.

For Kathy Charmaz CGT differs from grounded theory because data and theory are not discovered, rather, we are part of the environment that data comes from (Charmaz 2006). Specifically, she stresses the importance of constantly analyzing your research decisions and 
collecting enough data that you can document how participants construct their social world (Charmaz 2008).

However, Charmaz also discusses the role of textual analysis in CGT. Specifically, she discusses extant texts such as government documents or personal correspondence, and how they can be analyzed using CGT (Charmaz 2006). She emphasizes the importance of asking questions when you analyze the texts such as: "what are the parameters of the information?", "what does the information mean to various participants or actors in the scene?", "what does the information leave out?", "who is the intended audience for the information?", and "who benefits from shaping or interpreting this information in a particular way?" (Charmaz 2006, 37-38). These are questions that were considered in my research especially since I wanted to understand the ways in which policy was drafted in terms of desistance. For example, I wanted to answer the question of "what does the information leave out"? because I wanted to see how the desistance paradigm fit into the process of policy construction (Charmaz 2006, 37-38).

Therefore, as mentioned above, although CGT can be about how participants view the world, it also encompasses how texts are important in the social world, what role they play in that world, and how they are interpreted and acted in society (Charmaz 2006). It is for this reason that CGT is appropriate for this research project.

Charmaz also makes the case that analyzing texts can be used for "analytic scrutiny themselves" instead of being used as a supplementary method (Charmaz 2006, 39). She presents additional questions that can be asked when you are looking at texts. These include:

How does the text represent what its author(s) assumed to exist? Which meanings are embedded within it? How do those meanings reflect a particular social, historical, and perhaps organization context? How does its structure shape what is said? Which categories can you discern in its structure? What can you glean from these categories? What kinds of comparisons can you make between texts? Between different texts on the same topic? How is language used? (Charmaz 2006, 39-40). 
These questions are important when looking at policy because, for example, the categories of the assessments in the policies and the ways in which they are grouped together makes for an important discussion around what CSC finds to be pertinent to ask parolees. These categories also mean I can see, as a researcher, if risk and/or desistance paradigm aspects are incorporated into the policy, in which category they are incorporated, and more importantly, how they could be incorporated if they are not already. Therefore, although CGT is often used for analyzing interviews (Charmaz 2006), the questions presented above also have value to textual analysis. Therefore, I argue it is a valuable tool to use in order to understand how policy has larger implications in the social world.

Charmaz (2006) is not the only scholar to mention how extant texts can be used in a grounded theory analysis. Ralph, Birks, and Chapman (2014) discuss "contextual positioning" (4). For them, contextual positioning is a way in which researchers can interact with documents using grounded theory, while engaging in critical questions about the texts they are interpreting, which "makes it possible to establish a three-dimensional context centered around the positionality and reflexivity of the researcher toward the data and its source, grounded theory methods, and the research process collectively" (Ralph, Birks, and Chapman 2014, 4). This is important because unlike when grounded theorists use participant interactions (i.e., interviews) to generate data, collecting data from documents does not offer the researcher the same context they could obtain from being in the same room as a participant (through body language for example) (Ralph, Birks, and Chapman 2014).

Questions that Ralph, Birks and Chapman pose for researchers using grounded theory on extant texts are similar to those of Charmaz (2006) and include: "Who participated in conceiving, supporting, shaping, writing, editing, and publishing the text? What are the 
parameters of the information? When was the document conceived, produced, updated? Where is the document positioned in respect of sociological context? How is the text written?" (Ralph, Birks, and Chapman 2014, 4). These are questions that are important to consider when analyzing policy, especially since policy is constructed by organizations, and that dynamic can influence how policy is written, and more importantly, how it affects people in society.

Using CGT also helped when it came to the coding process. Before discussing the elements that Kathy Charmaz recommends using when coding I will explain my own coding process. Specifically, I used what Tracy (2013) calls a "manual approach" to coding (186). She explains how a manual approach to coding can come in different forms, from copying and pasting transcripts on bristol boards to using coloured pens or highlighters to code data (Tracy 2013). The approach that I took consisted of using coloured pens and highlighters and making a small legend in corner of the policy, so I knew which colours represented what theme or buzz word that was important.

As Charmaz (2006) explains, when coding one should consider "which theoretical categories might these statements indicate?" (45). This was the starting question for me when I was coding. I used CGT because I wanted to understand how the desistance paradigm played into policy. When coding I looked at the data and grouped it together in ways that I saw made sense, and then, during focused coding, looked at the different categories or sections of desistance and sex offender desistance that might be present in the policies. To expand, Charmaz (2006) explains that grounded theory coding has multiple phases "(1) an initial phase involving naming each word, line, or segment of data followed by (2) a focused, selective phase that uses the most significant or frequent initial codes to sort, synthesize, integrate, and 
organize large amounts of data" (46). This is similar to what Tracy (2013) identifies as “primary cycle coding” and "secondary cycle coding" $(189,194)$. Van den Hoonaard (2015) suggests that during primary coding while using grounded theory, it is important not to look at data with the codes that are relevant to your research question, as this can limit what the data represents. This is why I focused on the patterns of the data first, and then made the link to desistance.

Charmaz (2006) points to initial coding as being particularly important for grounded theorists because it is at this stage that it is pivotal that grounded theorists "remain open" to what the data represents (47). This involves coding in a way that mirrors the data closely, paying attention to actions within text (Charmaz 2006). Charmaz (2006) also suggests that coding "line by line" is a good practice when data is detailed (50). At first, I was not sure if this was an aspect of coding that would work for my data because I was looking at assessment portions of policy (which are not as detailed, as say, interview transcripts), but it became clearer to me that this process was pivotal in analyzing how words fit into the larger paradigm of desistance, and was also pivotal in trying to understand the larger implications to the actors (sex offenders) which these assessment questions affected.

Furthermore, I used elements of Charmaz's (2006) comparative method coding. She explains it as comparing data to one another within an interview and within different interviews together (Charmaz 2006). However, this same idea was useful in analyzing policy because I could understand and absorb how different policies incorporate aspects of the desistance paradigm.

Lastly, Charmaz (2006) explains focused coding as summarizing earlier codes made from line by line or comparative coding. What is important at this stage is understanding which 
initial codes can transform into bigger codes, or which ones can be summarized in other codes that capture the data accurately (Charmaz 2006). I found that in doing data analysis for this project most of my primary codes were able to become focused codes, and in situations where that was not possible, I simply made reference to the primary codes and used those as the basis of the data.

\section{Critical Discourse Analysis (CDA)}

Lastly, data analysis for this project also took the form of critical discourse analysis (CDA), from the view of Norman Fairclough (Fairclough 2013). CDA "aims to produce interpretations and explanations of areas of social life" in order to produce knowledge, and can come in the form of text analysis (Fairclough 2013,8). CDA was useful in analyzing the policies for themes, differences, or commonalities, and how they related to the literature on desistance and sex offender desistance. Fairclough (1989) also suggests that there are different ways to approach CDA. Specifically, he says that texts can be analyzed at a micro level (looking at word choice, for example), a mezzo level (how texts are interpreted or produced), and a macro level which analyzes the importance of texts in context to the larger social world, and society (sometimes this includes the analysis of power) (Fairclough 1989).

This is an appropriate analysis method for this project because the reality is that more offenders are being released into the community to carry out their sentences (CCRSO 2017, 2018). With the Not In My Backyard attitude, many offenders are not welcome into communities (Griffiths 2015). This has become a social issue; thus, this project does relate to areas of social life that are prevalent in many communities.

More specifically, however, I found the breakdown of CDA into parts interesting as it relates to this project. In terms of what I am investigating, the coding I did on policy can be a 
micro level of analysis because I looked at themes and word choices that were present to assess parolees (Fairclough 1989). Moreover, in addition to using the micro analysis of CDA there was also a macro perspective to my analysis because policy affects the larger world and has implications for society (Fairclough 1989). Policy is not only interpreted by society; but what is going on in the world and attitudes around parole can also shape policy about parole (this can also be macro) (i.e., tough on crime politicians have the ability to influence policy, and also how society thinks about parole) (Fairclough 1989). Thus, what is happening in society can influence how policy is interpreted (Fairclough 1989). I think this was vital to my analysis because as much as word choice is important in these instances, it is the way that those words are interpreted by whoever is doing the assessments attached to the policy that have effects for the social world. To expand, the ways in which a parole officer interprets the assessment portion of policy not only affects the offender who is being integrated into the community but can affect the community itself especially if the person on parole commits a crime. In this instance, people in the community may have a coloured perception of parolees based on the fact someone on parole committed a crime. This could contribute to the Not in My Backyard attitude (Griffiths 2015), and thus one can see how micro and macro CDA are related.

\section{Summary of Methods}

Therefore, for this research project I am using thematic analysis as the over-arching principle (i.e., the policy data will be analyzed for themes), while also combining some aspects of policy analysis. The questions that CGT offers when discussing how to analyze and look at texts for analysis purposes will also be influential to this project (Charmaz 2006).

Furthermore, the way in which Charmaz (2006) discusses coding in a CGT manner was 
important because it allowed for the contextualization of how policy fits into the risk or desistance paradigms and has larger implications in the social world. Charmaz's (2006) discussion of comparative coding was also important as multiple documents around the same topic were analyzed. Lastly, the micro and macro approaches to CDA will also guide my analysis process (Fairclough 1989).

I recognize that above I explain CGT and CDA as two separate methods I am using in the project. Although they are separate, there are aspects of both of these methods that are closely related and for the purpose of this project, woven together. To elaborate, I am using CGT as a ground-up approach to not only asking critical questions about the policies, but to interpret what the policies are telling me, which can be done through word choices (Charmaz 2006). However, I am also using CDA to contextualize policies by focusing on word choice (or micro analysis) (Fairclough 1989).

This is evident throughout certain areas of my analysis section wherein I use CGT to talk about what the policies say and to code aspects of what they indicate, while also using CDA and micro analysis in terms of both word choice and micro-scale associations between how the policies talk about offenders and their relationships to society (i.e., discussing how interpersonal relationships can be seen as micro) (Charmaz 2006; Fairclough 1989) (in relation to analyzing $C D$ 705-6). Another example of this from my analysis would be the way I use CGT to analyze and code certain words or phrases in the policies, but the individualized nature of the language in the policy makes the offender micro in relation to society (Charmaz 2006; Fairclough 1989) (in relation to analyzing $C D$ 715-1). Lastly, I use the idea of a macro perspective in relation to society when discussing how certain questions in $C D$ 705-6 are phrased in a way that highlights how offender's decisions affect those in society (such as 
victims), while also using a grounded theory approach to interrogate and ask questions about the text (Fairclough 1989; Charmaz 2006).

Thus, CGT and CDA are similar in several ways. Analyzing texts using CGT concerns the world and society at large and part of analyzing texts using this method includes word choice (Charmaz 2006). Critical discourse analysis is also similar since the three levels of CDA (micro, mezzo and macro) not only have elements of word choice that can be used when analyzing, but this method can also relate to society at large (Fairclough 1989). Together, these methods can play off one another and work together in a way that is complementary to the texts that are being analyzed. This will become further evident in my analysis section.

\section{Ethical Considerations}

Unobtrusive methods are known for not having as many ethical concerns as other qualitative methods such as interviews (Schulenberg 2016). In some situations, wherein the researcher is analyzing personal documents, for example, there may be questions about privacy and consent (Schulenberg 2016).

For this project there were no major ethical concerns as the policies being analyzed are available on CSC's website. However, ethical concerns are often thought of as the ramifications of a project to participants and organizations and sometimes to the larger world. An important aspect of ethics is how sometimes it can include the researcher and their position to the research. Above, I wrote about my positionality and some reflexive thoughts that I had going into this research project which included the power I hold as a universityeducated person who is analyzing policy that affects people with less status than I have in society. I also mentioned how the information I get about parole is often from my job, and that is something I had to keep in perspective while doing this research project. 
To add to this, however, I think it is important to discuss the fact that I am analyzing the policies for an organization I work for. Ethically there is nothing wrong with this as I have been forthcoming about my relationship with CSC. But it is also important to unpack the fact that I agree with the mission statement of the organization I work for, therefore in analyzing policy I could have certain positive biases that may not be present if someone who did not work for the organization analyzed the same policies. This could be related to my positionality and reflexivity; however, I think it is an ethical consideration wherein it is appropriate to ask, what makes someone qualified to analyze certain documents or phenomenon? What kind of knowledge should the person have, and does it matter where they get that knowledge? How does that affect the analysis being done? I do not have the answers to those questions as I do not think they are clear cut, but, nonetheless, it is important to mention these ethical considerations when taking on research of any kind.

Now that the evolution of this research project, my research questions, my proximity to this research, and my data collection and analysis methods have been explained, the next chapter of this thesis will include the analysis of CD 705-6, 715-1, 715-2, and 715-3. This chapter will focus on the primary and secondary codes developed for each policy. 


\section{Chapter 3: Analysis}

This section will engage in the analysis of the policies. I used thematic analysis as the broad investigative tool to analyze the documents, taking into account certain aspects of policy analysis. More specifically however, I also analyzed the texts using CDA in order to interrogate the language used in the policies in relation to how they explain reintegration (Fairclough 2013), while also keeping in mind the policies macro perspective and its relationship to society (Fairclough 1989). Further, I used Cathy Charmaz's CGT as a way to derive meaning and themes from the text as they relate to desistance (Charmaz 2006). This analysis was done through several stages of coding, starting from specific detailed coding, to more general thematic coding (Charmaz 2006). I analyzed data while keeping in mind questions that Charmaz (2006) presented as pertinent when analyzing extant texts, as well as keeping "contextual positioning" (Ralph, Birks, and Chapman 2014, 4) at the forefront of my analysis.

For this analysis I looked $C D$ 705-6 which is an extensive policy which incorporates what parole officers are expected to ask offenders once they have been released on parole. This policy covers many areas of the offender's life including static and dynamic factors, criminal profile, and reintegration potential (CSC Website, $C D$ 705-6). This policy is over fifty pages, and is the main policy referenced by other policies as they pertain to reintegration (specifically as they relate to criminal profiles and correctional plans). Correctional plans are plans developed by the parole officer, case management team, and offender and outline the offender's needs, how those needs are to be met, and any programming suggestions for the offender to help with prosocial behaviour (CSC Website, $C D$ 705-6). I also analyzed $C D$ 715-1 which is used for community supervision, specifically when offenders are applying to be 
released on work releases (CSC Website, $C D$ 715-1). This policy includes a staff safety assessment, a rating reassessment framework, and a section for a correctional plan update (CSC Website, CD 715-1).

Furthermore, $C D 715-2$ is the policy that not only outlines what happens when an offender gets suspended or fails to meet their conditions, but also includes an assessment for how to determine if their conditions should be changed, if a correctional plan update should be done, and includes a risk assessment framework (CSC Website, $C D$ 715-2). Lastly, CD 715-3 is a policy that is concerned with community assessments; in other words, this policy is referenced when something in the community changes for the offender (support, work release, day parole to another location is being considered etc.) (CSC Website, CD 715-3). The policy includes questions that parole officers are to ask of offenders and their contacts in the community about a prospective change to the offender's parole program that could affect reintegration (CSC Website, CD 715-3).

To be clear, the assessment portions of these policies are written with their own headers and divided in a way that makes sense to CSC and the way they structure policy. For this analysis, however, I have looked beyond these pre-determined headings of the assessment portions of these policies and grouped themes across headers. Thus, the themes I have uncovered in this data are not the same as the way the Annexes of each are grouped and labelled in policy. For example, in $C D$ 705-6 the Annex B assessment is the Revised Statistical Information on Recidivism Scale (SIR-R1), while the Annex C assessment is the Criminal Risk Index (CSC Website, CD 705-6). These were the prescribed labels, but I looked at common themes among the two assessments regardless of their pre-categorization by CSC. This is an example, and I looked at each Annex in each policy holistically and derived themes 
from the policies as a whole. In this analysis, in order to reiterate how common a theme was across assessments in a given policy I may discuss which assessments discuss a specific primary code (for example) in order to showcase why it was worthy of said code.

It is also important that I note that throughout this analysis section where in I go through my primary and secondary codes for each policy, I use the word deviant, and have codes that pertain to deviant behaviour. For the purposes of this thesis, when I discuss deviant behaviour in relation to codes and my analysis, I define it as behaviour that is contrary to the correctional plan, and terms of release.

First, this section will discuss Charmaz's (2006) questions, along with Ralph, Birks, and Chapman's (2014) questions about positioning the text as they were pivotal questions to keep in mind while doing this analysis. Then, this section will look at the themes derived from each of the four policies individually, while discussing the process of how certain open codes became other focused codes, and their importance. This section will also incorporate a small discussion on how aspects of the risk paradigm are or are not incorporated in these each of these codes. After this, there will be a comparative section wherein I discuss the common themes found across all four policies. The comparative section will discuss the focused codes that were similar across the documents. This analysis section will focus on themes and the critical questions asked around these documents, while the discussion section will relate the analysis more closely to literature on desistance.

\section{Critical Questions}

There are several critical questions to consider while analyzing texts. For this project I will engage with both Charmaz (2006) and Ralph, Birks, and Chapman's (2014) questions. As indicated by these authors, these questions are supposed to be answered while analyzing the 
texts (Charmaz 2006; Ralph, Birks, and Chapman 2014). I did answer these questions while analyzing the text but chose to discuss them before I analyzed policy as they can help set the tone for the analysis.

Ralph, Birks, and Chapman (2014) discuss the importance of asking "who participated in conceiving, supporting, shaping, writing, editing, and publishing the text?" (4). In this case, these texts were shaped, written, edited, and published by CSC which is an extension of the Canadian Federal Government. It is important to realize that this policy is drafted from an organizational perspective and thus represents what the organization sees as important when it comes to reintegration and community corrections. Furthermore, in terms of the "sociological context" (Ralph, Birks, and Chapman 2014, 4) these policies fall within the discipline of Sociology and the related field of Criminology in relation to reintegration, and barriers to reintegration. My discussion section will shed further light on how the concept of desistance is or is not incorporated in the context of these texts.

Charmaz (2006) points to asking what the "parameters of the information are", and what it means to "various participants or actors in the scene?" (Charmaz 2006, 37-38). For these particular policies the parameters of the information rely both on the parole office and justice system to accurately and thoroughly record aspects of the offender's criminal profile and correctional plan. The parole officer also needs to do their due diligence and be thorough in their assessments of the offender. Furthermore, the parameters of the information also rest on the offender themselves. In the instances in which the offender needs to answer questions about their offences, the information lies within them, and they could, for example, lie to parole officers. More importantly, however, if we look at these policies at face value (i.e., through the fact that they are stand-alone texts) the parameters of the information lie with CSC 
and what they choose to put into policy. The information gleaned from these policies not only affects the parole officer's job, but also affects the offender, their reintegration, and their connection to the community.

Interrogating who benefits from the text and how it is shaped is tricky (Charmaz 2006). These policies tend to be written in a straightforward manner, however that is not to say that a parole officer could interpret a question or a statement in a way that another parole officer would not. Further, an offender could benefit from the way a parole officer shapes the information. For example, it is possible that one parole officer is stricter than another parole officer and thinks that one element of reintegration is more important than another. If they put more weight on this aspect of reintegration it could, in theory, mean that an offender has stricter conditions, more conditions, or is being supervised at a higher level.

Later in this analysis section I will discuss comparisons between the texts, and how language is used between the texts, as these are also questions that Charmaz (2006) poses. I will also make a further note on structure of the policies when I compare them further in this section (Charmaz 2006).

\section{705-6: Correctional Planning and Criminal Profile}

When coding this policy, I came up with twelve primary cycle codes which represented line by line data that I could easily group into themes. These codes were quite specific as they pertained to what was seen in the policy. This section will describe the importance of these primary codes and provide examples as to what fell under the primary codes. This section will also discuss the focused codes I developed for this policy. It is important to note that in this policy there is a section for Indigenous Offenders (Annex H) relating to their unique needs and social history (CSC Website, CD 705-6). This was not coded as part of my analysis as it is 
recognized that Indigenous needs in the correctional system differ from those of other offenders. To expand, CSC has its own CD specifically for Indigenous Offenders titled: $C D$ 702- Aboriginal Offenders (CSC Website, CD 702). In this policy there is discussion on cultural interventions, including that of the Aboriginal Corrections Continuum of Care Model which recognizes Aboriginal culture and practices while attending to Aboriginal offender's needs through appropriate cultural practices (CSC Website, $C D$ 702). For this reason, I felt as though it was appropriate not to include Indigenous offenders in my discussion, as there is another policy that specifically addresses their needs.

\section{Primary Codes}

To start, a large component of the assessment portion of this policy was centered around the offender's history. More specifically, I coded this as "current offences/history of offences/convictions (current and past)". This was a large primary code, but it covered a significant part of many of the beginnings of the assessment portions in this policy. This policy had sections in Annex B (Revised Statistical Information on Recidivism Scale) on the type of current offence committed, which was a list that ranged from "break and enter, to theft, kidnapping, arson, dangerous driving, homicide, incest and sexual intercourse with the underage" (CSC Website, CD 705-6, 11). Included in this code is if the offender had escaped custody before, and if they had been charged as such (CSC Website, CD 705-6).

Furthermore, the Criminal Risk Index asks parole officers to score offenders on how many past convictions they have had, on a scale of five to fifteen or more; it also asked if the offender has been to youth court (CSC Website, CD 705-6). Annex C also has questions relating to if the offender had received disciplinary reports or transfers while they were in custody (CSC Website, CD 705-6). Annex D (Static Factors Assessment) also discussed 
previous sentences, while also asking about the types of convictions (scheduled or otherwise) that the offender has received (CSC Website, CD 705-6). In a similar fashion of Annex B, Annex D goes through the types of convictions the offender currently has (CSC Website, $C D$ 705-6). Lastly, Annex E (Dynamic Factor Identification and Analysis Revised (DFIA-R)) is an extensive list of dynamic factors that should be asked to offenders, which include aspects of current offences and/or history of offences (including inquiring about "deviant sexual attitudes") (CSC Website, CD-705-6, 46). This code lends itself to a more risk-based paradigm angle in that the discussion of past offences can set a parole officer up for not only understanding the offence cycle, but how long the offender has been offending for, and the escalation of said offences (Andrews and Bonta 2010). Also, those who commit offense could very well possess risk factors such as history of anti-social behaviours, anti-social personality, and anti-social cognitions (Andrews and Bonta 2010).

Another primary code that I developed was "previous supervision in the community". This was not only a reoccurring theme, but I felt as though it was different than the code I described above because the language used in the policy is harsh. Engaging in Fairclough's (1989) discussion of micro level of analysis made the word choice that is encapsulated in this code of interest. For example, in Annex B part of the assessment reads "has previously had a term of day parole, full parole or statutory release revoked or forfeited (does not include termination)" (CSC Website, CD 705-6, 12). This does not seem like much, however, the use of words such as "revoked" or "forfeited" seem serious given the context (CSC Website, CD $705-6,12)$. It is clear that to the organization this is important, as evidenced by the fact that if an offender had been previously revoked or forfeited, they would get a negative score in this section (CSC Website, CD 705-6). It is also not unreasonable to assume that this negative 
score would and/or could reflect what the organization deems as at risk. In other words, having not completed community supervision in the past is not only thought of as negative but could lend itself to the organization thinking the individual would be higher risk in the community because they have never finished community supervision successfully before (CSC Website, $C D$ 705-6). If the offender turned back to a life of crime, this could be due to several risk factors such as anti-social cognitions, or anti-social peers, both of which have been shown to influence recidivism (Andrews and Bonta 2010; Healy and O’Donnell 2006; Palmer and Hollin 2004; Boduszek et al. 2013; Whited et al. 2015).

Furthermore, in Annex C (Criminal Risk Index) there are two areas that deal with community supervision. First, there are questions about the offender's youth history, including if they have ever been "sentenced by the court to a period of supervision in the community (i.e., probation, community service order, house arrest)" or if they had been in open custody or secure custody before (CSC Website, $C D$ 705-6, 17). They also ask if the offender "failed" during community supervision (CSC Website, CD 705-6, 17). Similar questions are asked in the Annex about an offender's adult court sanctions, but they also include questions around if sentences were provincial or federal (CSC Website, CD 705-6). Of interest, however, is that in the section around failure during community supervision it mentions that failure "may have been caused by further criminal behaviour or for a breach of a condition attached to community supervision order" (CSC Website, CD 705-6, 18). These questions around community supervision are also relevant in other Annex's, such as Annex D (Static Factors Assessment), therefore this primary code seems to be consistent throughout this policy (CSC Website, $C D$ 705-6).

The next primary code that was relevant throughout this policy at various times was 
what I called "time between incarceration". Quite simply within the assessment of these policies there were often questions around how long the offender had been crime free (CSC Website, $C D$ 705- 6). It is similar to the last code in that it shows up in several assessments across this policy. For example, in Annex C (Criminal Risk Index) it is asked if it has been "less than six months since the offender's last incarceration?" and if they have had "no crimefree period of one year or more?" (CSC Website, CD 705-6, 19). This was also mentioned in Annex D (Static Factors Assessment) (CSC Website, CD 705-6). In this particular case, it seems that the time value matters as the assessment emphasizes six months and one year as the time lapses they are concerned about (CSC Website, CD 705-6). This seemed like interesting word choices in that they are defined amounts of time, and offenders either meet or do not meet the thresholds. This is one area wherein having a crime free period lends itself to the policy incorporating elements of desistance especially since desistance can be seen as the reduction of offending (Loeber and LeBlanc 1990; Laub and Sampson 2001).

My next primary code was "victims/injury to victims". The mention of victims is quite extensive, and the language used to describe questions that fit into this code was specific. For example, in Annex D (Static Factors Assessment) there are several headings that discuss victims (CSC Website, CD 705-6). Within these headings, questions to be asked include: "Victims were children? Three or more victims? Two victims? One victim?" (CSC Website, CD 705-6, 22). Further, there is a section about victim harm (physical and psychological) which includes questions such as "Threat of violence to victim? Violence used against victim? Caused death of victim? Serious psychological harm to victim? Mild psychological harm to victim?" (CSC Website, $C D$ 705-6, 22). These questions have the potential for the offender to either come to terms with or realize the severity of their crimes, 
and talk about it with their parole officer (CSC Website, $C D$ 705-6). But these questions, because of the severity of the subject matter, could also potentially point to the parole officer contemplating risk (i.e., if injury to victims was severe, what is the risk that the offender will commit the crime again?) (CSC Website, CD 705-6).

Furthermore, in this Annex there is a Sex Offence History Checklist where there are again questions about victims (CSC Website, $C D$ 705-6). In this checklist the questions ask how many victims there are, how old the victims were, if they were male or female, and what kind of harm was perpetuated onto the victim (CSC Website, CD 705-6). The mention of victims is also prominent in Annex E (DFIA-R) in that there is a question about empathy skills, and how that translates into what the individual feels towards victims (CSC Website, CD 705-6). Guiding questions about empathy include the parole officer asking the offender "What effect has your crime(s) had on the victim(s)? Has your conviction(s) hurt anyone else?" (CSC Website, CD 705-6, 45). From this coding process, it seems as though CSC is not just concerned with the criminal act itself and its effect on victims, but rather wants to understand the type of victim that was victimized, and wants to understand the severity of said victimization, but not just in terms of physical harm.

The fifth and sixth primary codes for this policy are related. These codes are "relationships/support in general", and "relationship history". These two codes do not just include romantic relationships, but rather any sort of relationship in society that an offender has. For the "relationships/support in general" code there were many aspects of the assessments in this policy that were relevant. To start, in Annex B, the parole officer is to ask the offender for their current marital status- these include questions around the offender's sexuality and how they identify, along with if they were single or married (CSC Website, $C D$ 
705-6). This is important and will be discussed later in the discussion section in regard to how marriage and family relates to desistance and the desistance process (see Laub and Sampson 2003 , for example). However, of note here is that marriage is also mentioned within the risk paradigm, as marriage has been documented as a factor that decreases criminal activity (Lo and Zhong 2006; Schwartz 2006).

Further, Annex E (DFIA-R) poses many questions about relationships and relationship history that could be asked of offenders (CSC Website, CD 705-6). Relationship history does not just concern romantic relationship history- but rather all types of past relationships and how they could have impacted the offender (CSC Website, CD 705-6). They include asking offenders about their relationships with/to their own parents, if they would describe that relationship as caring, and if Children's Aid was involved (CSC Website, CD 705-6). These questions also include asking the offender if they have "witnessed family violence during childhood?" (CSC Website, CD 705-6, 29). Annex E also has its own section on parenting- in which the prompt questions concern whether or not the offender has children, how they deal with the responsibilities of children, and how they discipline them (CSC Website, CD 705-6). These questions also concern how often they see their kids, what they do daily with their kids, and how they treat their children (CSC Website, $C D$ 705-6). This fits into the relationship code because it concerns the relationships the offenders have in their life.

Moreover, questions about intimate relationships are encapsulated in these codes, as they fall under both relationship history and support. Intimate relationships are a considerable part of Annex E and there are many prompts that are written in the assessment that could be used by parole officers (CSC Website, CD 705-6). These include:

Have you ever been divorced or separated? If yes, how many times? How many girlfriends/boyfriends would you say you have had? On average, how often do you 
and your partner argue? About what (e.g., money, suspected infidelity, children, sex)? How does the argument(s) get resolved? Are/were you happy in your relationship(s)? How do you normally solve disagreements with your partner(s)? Have you ever gotten the sense that your partner(s) was/is afraid of you? Do you believe that both partners should have equal say in a relationship? (CSC Website, CD 705-6, 29-30).

These questions encapsulate many aspects of relationships which I believe is thoughtprovoking because these questions do not just concern what types of relationships offenders are having, but instead also focus on how the offenders (in their social relationships) deal with aspects of life (i.e. money or children) (CSC Website, CD 705-6).

Additionally, questions around relationships also include inquiring about if the offender's partner is involved with crime, if family members are involved with crime, and how supportive your intimate partner is to you, and how close you are with your family and friends (CSC Website, CD 705-6). Questions also inquire about if you have acquaintances or friends who are involved in crime (CSC Website, $C D$ 705-6). In the discussion section I will discuss further how this is important for desistance, commenting on how support, friends, and family can help with the desistance process (especially when they are not involved in crime themselves) (Mills and Codd 2008; Visher and Travis 2003; King 2013; Kras 2019; MallikKane and Visher 2008). At the same time, however, in terms of risk, marriage is also important as a factor that helps reduce crime (Huebner 2005; Sampson, Laub, and Wimer 2006).

The relationship an offender has to the community is also vital to consider. It is expressed within the assessment portion in Annex E that parole officers could ask offenders what they do in their spare time, if they belong to any organizations or community groups and how they rely on the community for support (CSC Website, CD 705-6). To be clear, in Annex E there are many subheadings that describe certain dynamic factors, and the various types of 
questions around relationships that I have described above do not just come from one subheading, they come from several (CSC Website, $C D$ 705-6). Thus, although most of the content for the two codes "relationships/support in general", and "relationship history" come from Annex E, they are not all laid out in one section in particular (CSC Website, CD 705-6). In the literature there is discussion regarding leisure time and how individuals spend their spare time including recreational activities. I discuss how leisure activities can help promote a crime free lifestyle, but also how certain activities that are deviant put individuals at risk for reoffending (Williams 2006; Williams and Walker 2006; Atkinson 2014; Stebbins 1996; Williams 2005). In relation to this part of the question in Annex E, I think CSC is trying to gauge risk (i.e., does the individual have ties to groups in the community that would impact their correctional plan progress negatively), while also engaging with the idea that social support relates to desistance (CSC Website, CD 705-6; Lin 1986).

The next code I developed was "relationship with drugs and alcohol". This code encompasses both past and current relationships. This code differs from previous codes in that it does represent itself in Annex E over the span of four pages (35-38) in different subheadings under one section (CSC Website, $C D$ 705-6). Although the mention of drugs and alcohol are not present elsewhere in the policy (i.e., across different Annexes), I considered this its own code because of how often it is mentioned, and how detailed the both the substance abuse domain indicators and the interview prompts that parole officers can use to guide their questioning were (CSC Website, CD 705-6). Questions in the assessment portion for this code include:

Early age alcohol use? How old were you when you first consumed alcohol? How often did you drink (daily, weekly, monthly)? During the last year how often did you drink in bouts or binges? Did you ever do it for more than two days in a row? Have you ever used alcohol and drugs at the same time? Alcohol use interferes with physical or 
emotional well-being? During the last year, did you ever use drugs for more than two days in a row? In the past year, how often have you used illegal drugs or abused prescription drugs (never, yearly, monthly, weekly, daily)? Have you ever been arrested, charged or convicted for any offence that involved alcohol or drugs? Have you ever been under the influence of alcohol/drugs when you committed a crime? (CSC Website, CD 705-6, 35-38).

The ways in which the prompt questions are phrased for this code exemplify how important this is for parole officers to assess. These questions are not only about substance abuse and frequency of said abuse, but also combine physical and emotional aspects and crime to the line of questioning (CSC Website, CD 705-6). Just as Fairclough (1989) mentions, wording within critical discourse analysis is important. Furthermore, although, for example, the questions around relationships were also invasive, I also argue that these questions take it a step further in terms of their personal details (CSC Website, CD 705-6). I will also explain below how these questions intertwine aspects of other codes I have developed, which is why it has led me to think that drugs and alcohol are perhaps a priority for CSC to understand when it comes to offenders being released in the community. The thoroughness of this discussion lends itself to the idea that CSC believes that substance abuse could be a risk factor for individuals in the community (CSC Website, $C D$ 705-6). Given the literature on risk, substance abuse does contribute to offending (Vaughn 2011; White and Gorman 2000). The fact that CSC is asking detailed questions regarding this fits into the risk paradigm because not all drugs contribute to offending, thus the intense questioning around this makes sense when trying to assess specifically for risk (i.e., trying to address which substances play a role in an offender's life) (Håkansson and Berglund 2012; Caudy et al. 2015; Caudy, Durso, and Taxman 2013; CSC Website, $C D$ 705-6). However, there is also an element of desistance present here, which will be discussed in the discussion section.

Another theme that I found throughout this policy that was developed into a primary 
code was "personal interpretations of situations/feelings/reactions to an event". This ended up being a code because through looking at the policy I found that there were several questions in which parole officers are to ask offenders how they act and react to what they did, or to other situations (CSC Website, CD 705-6). Some of these domain indicators and interview prompt questions included:

Were your crimes planned or spur of the moment? Do you make decisions on the spot, or do you like to have time to think things over before making a final decision? How do you feel when you are doing crime (excited, nervous)? Do you like to do risky things? What effect has your crime(s) had on the victim(s)? Do your friends ever accuse you of over-reacting or reading too much into a given situation? Takes pride in criminal exploits? How do you feel about the crime(s) you have committed? Under what circumstances is violence acceptable? (CSC Website, CD 705-6, 43-48).

As I explained above, a majority of these questions relate to how the offender categorizes their habits and thoughts about situations (CSC Website, $C D$ 705-6). Most of these questions, again, are quite pointed, but leave room for open ended answers, and it is interesting to note, however, that these questions do not just involve crime but also involve trying to discern how the offenders make decisions (CSC Website, CD 705-6). The decisions that the offenders make have a macro perspective tied to them in that those decisions could affect people in society (i.e. people as victims) (Fairclough 2013). Also, an offender's actions could influence how society sees offenders as a whole (and on the bigger scale, how society could feel about parole policy) (Fairclough 1989). Also, although this code was not labelled "personal responsibility", the questions encapsulated in this code do, to some extent, leave the door open for the offender to come to terms with the ways other see them, and potentially to terms with the way they act (i.e., their friends do tell them they overreact, and upon reflection they can pinpoint events or ways in which they do overreact) (CSC Website, CD 705-6). Thus, with this being said, (and as I will elaborate on in my discussion), this code heavily relates to 
desistance as a process and the prospect of identity change as important for secondary desistance (Maruna and Farrall 2004; Maruna, Immarigeon, and LeBel 2004; Maruna 2001). Additionally, the ninth primary code that I developed from the data was "personal personality characteristics" (at the time of the assessment). For this code the questions were slightly broader than the other codes and were mostly situated in Annex E (CSC Website, $C D$ 705-6). For example, the parole officer should ask offenders about their thinking about situations in order to gauge if they have a narrow way of viewing tasks (CSC Website, $C D$ 705-6). Some of the prompts also involved giving the offender a situation (such as getting in an argument with their partner or parole officer) and asking them how they would deal with the situation (CSC Website, CD 705-6). Other aspects of this code include the expectation that parole officers ask offenders how they cope with stress, what happens when they feel as though they cannot attain a goal, how they plan long term goals, and how they plan their daily activities (CSC Website, CD 705-6). Furthermore, some of the prompts that were included in this code also centered around emotions and how offenders deal with anger (CSC Website, CD 705-6). Like what I mentioned about the code above, this code could also lend itself to the offender understanding how they react in certain situations, and this could lead to a good self-reflection piece for the offender (CSC Website, CD 705-6). In terms of the way language is utilized for this code, it is less harsh and more inquisitive instead of pointed, in that the questions deal with more day-to-day- questions, and are about specific situations (CSC Website, $C D$ 705-6). In this way it relates to every day social situations in relation to the offender's social world (Fairclough 2013; CSC Website, CD 705-6). These personal personality characteristics are not specifically related to the risk paradigm in their wording, but at the same time, understanding how people deal with day to day situations could bring to 
light anti-social personality or anti-social cognitions that are risk factors for recidivism (see Andrews and Bonta 2010; Caspi 2000; Mandracchia et al. 2007 as examples).

The tenth code in relation to $C D$ 705-6 is "situational factors". This code has the potential to overlap with other codes such as "relationships/support" and "relationship history" as these codes also pertain to situations in an offender's life. But, for this particular code, situational factors pertain to physical environment and life circumstances that could affect reintegration. This includes assessment questions such as "Did you live in a high crime area? Did you feel safe at night?" (CSC Website, CD 705-6, 33). It also includes questions regarding where the offender sleeps and how stable their residences are (CSC Website, CD 705- 6). In terms of circumstances that could affect reintegration, I found that questions around social assistance and financial instability which were present in this policy fit within this code because these questions deal with current circumstances that offenders are dealing with (CSC Website, $C D$ 705-6). There were not many of these questions present in this policy, and thus, I do not think this topic is of great importance to CSC (CSC Website, CD 705-6). The way questions in this code are phrased are not particularly strong, but rather invite yes or no answers, which is another indicator that maybe these questions are more of a formality rather than am important part of the policy (CSC Website, CD 705-6). Although not having a stable residence or financial stability could be risk averse factors that could contribute to recidivism, they are not one of the big eight factors (Andrews and Bonta 2010). Since these questions are not of abundance in this policy, I do not think CSC was trying to take a risk approach, but rather these are "need to know" questions that add additional background information to what is already discussed in the policy as a whole (CSC Website, CD 705-6).

The eleventh code was "education and learning". This code is self-explanatory and 
explored the questions in relation to learning. These included "Does the offender have less than grade 10 or equivalent? How far did you go in school? What is the last grade you completed? Have you ever received any kind of formal training, certificate or diploma?" (CSC Website, $C D$ 705-6, 25-26). Furthermore, the topics around learning include how well the offender can read and write, how the offender concentrates, and if they have any language barriers (CSC Website, CD 705-6). This falls directly into the responsivity part of Andrews and Bonta's (2010) RNR principles, and these questions are specific (i.e., pinpoint grade 10 as important, ask about formal training, certificates and diplomas) — and thus, the ways in which the questions incorporate several different elements suggest that learning is not only important to CSC, but also to their correctional planning (CSC Website, CD 705-6). In terms of correctional planning, another aspect of this code is the questions that parole officers should ask offenders regarding if they have any learning issues that may interfere with correctional programming (CSC Website, $C D$ 705-6). In the discussion section I expand on what other questions I believe should be asked in terms of education to foster desistance, and I also discuss how the mention of education fits into the desistance paradigm. However, the questions asked in this policy also fit into the risk paradigm because asking questions about past education fist into the research that says that education is linked to crime prevention, and at risk individuals should be encouraged to go to school (Hansen 2003; Lochner 2004; Taheri and Welsh 2016; CSC Website, CD 705-6).

The twelfth and final primary code for this policy was "employment/aspects of employment". This concerns everything related to employment at the time of arrest and overall (i.e., employment history). Annex B (SIR-R1) has a section in which the parole officer is to ask offenders (and score them) based on if they have full or part time employment (this 
employment must be legal) (CSC Website, $C D$ 705-6). Further, Annex E poses questions about employment history, including if the offender has had jobs that were unstable and how they describe their work ethic (CSC Website, $C D$ 705-6). This code is interesting because it also combined aspects of the "relationship with drugs and alcohol" code. For example, parole officers are to ask if "Alcohol use interferes with employment?" and if "Drug use interferes with employment?" (CSC Website, $C D$ 705-6, 36-37). Through this analysis I found that the questions that correlate with this code to be much more nuanced than others in that they incorporate other aspects of social life (Fairclough 2013; CSC Website, CD 705-6). This code fits into desistance, and in my discussion section I further expand on how and what should be added to this code in relation to the desistance paradigm.

However, again, this code also fits into the risk paradigm simply because employment can affect recidivism rates especially since employment gives individuals something to do and something to be a part of (Benda, Harm, and Toombs 2005). This code also relates to "situational factors" (code ten) that could affect reintegration, however it was my choice to separate this code and make it its own because of how nuanced the questions were (not just employment history, but also current employment, and how employment interacts with other aspects of life, such as drugs) (CSC Website, CD 705-6).

The purpose of this section was to go through the codes I developed and what I included in said codes in order to understand the themes that I found to be important in $C D$ 705-6, while also including a small discussion on risk and the risk paradigm. Below is a table that summarizes the primary codes for $C D$ 705-6.

Table 2: $C D$ 705-6 Primary Codes

Policy CD 705-6 Primary Codes

Current Offences/History of Offences/Convictions (current/past)

Previous Supervision in the Community 


\begin{tabular}{|c|}
\hline Time Between Incarceration \\
\hline Victims/Injury to Victims \\
\hline Relationships/Support in General \\
\hline Relationship History \\
\hline Relationship with Drugs/Alcohol \\
\hline Personal Interpretations of Situations/Feelings/Reactions to an Event \\
\hline Personal Personality Characteristics \\
\hline Situational Factors \\
\hline Education and Learning \\
\hline Employment/Aspects of Employment \\
\hline
\end{tabular}

From these open and primary codes, I formed focused codes that succinctly described and grouped the primary codes together. In the next section I am going to describe the secondary (or focused) codes. Note that since I went through the primary codes and information in the policy that corresponded to these codes, when discussing focused codes, I am not going to reiterate the types of questions in the assessments that go along with the codes, instead going to discuss what I grouped together and why.

\section{Focused Codes}

The first focused code that was developed was "reactions and thoughts". This code encompassed three primary codes: "personal interpretations of situations/feelings/reactions to an event", "personal personality characteristics", and "victims/injury to victims". To start, the personal interpretations primary code is included in this focus code because it includes questions around how the offender deals with what happens to them in their daily life, as well as how they react to situations (CSC Website, CD 705-6). Secondly, the primary code on personality is relevant here because that code also encapsulates how offenders deal with every-day challenges that may arise in life and how they think about the world around them (CSC Website, $C D$ 705-6). And, lastly, "victims/injury to victims" belongs in this focused 
code group because, as I mentioned above, it allows for critical reflection. To note, "Victims/injury to victims" could have been included in another focused code (that I will explain below) that I titled "criminal experiences", however I did not include the victims primary code in that focused code because I believe that victims are more than a product of criminal experiences. Rather, the discussion and questions about victims in this policy (although quantified in some ways by a number) allow for explanations from the offender.

The second focused code that I developed is "legitimate pathways". This focused code included two primary codes: "education and learning", and "employment/aspects of employment". Quite simply, these were included because they reflect how much training an offender has had, and how much education and experience they have had (CSC Website, $C D$ 705-6).

"Employment/aspects of employment" looks at the history the offender has with legal jobs and can help a parole officer understand where their potential skills are (CSC Website, $C D$ 705-6). With this information a parole officer can not only infer what qualifications and offender has but can better point them and place them in programming that could be beneficial to them based on said skills.

The primary code "education and learning" encapsulates difficulties that an offender thinks they could have in learning (i.e., learning styles) (CSC Website, CD 705-6). This is important because with this information a parole officer can make suggestions around helping the offender reach their full potential (CSC Website, CD 705-6). If, for example, an offender has never completed school because they found it difficult, this could have led them to find work in illegitimate or illegal ways because they did not have the support they needed to learn. With help from a parole officer and programming that takes into account an offender's needs, 
they could work towards "legitimate pathways" in education, learning, and employment. Furthermore, on a macro level, I felt this focused code was appropriate because education and employment are seen as "legitimate" pathways in society and often those who are seen as productive members of society have a decent level of education and employment (Fairclough 1989).

Next I developed the focused code of "criminal experiences". This included the primary codes of "current offences/history of offences/convictions (current and past)", "previous supervision in the community", "time between incarceration", and "relationship with drugs and alcohol". The reason why these primary codes were included in this focused code are somewhat self-explanatory. I felt as though the current offences/history of offences, previous supervision, and time between incarceration codes fit well within this focused code because all include elements of having a criminal past. For example, "previous supervision in the community" and "time between incarceration" both imply that the individual has been arrested before, and "current offences/history of offences/convictions (current and past)" also lays out an offender's past convictions. The decision to group "relationship with drugs and alcohol" in this focused code was difficult. This is because this primary code in $C D$ 705-6 did not always refer to the use of drugs and alcohol as something illegal (some questions asked how often the offender used such substances), however, there were instances in the policy where questions did relate to arrests for illegal drugs and if the offender was under the influence of drugs or alcohol at the time that they got arrested (CSC Website, CD 705-6). I felt as though questions of that nature were abundant enough that "relationship with drugs and alcohol" should be included in this code (CSC Website, CD 705-6).

The fourth and final focused code that I developed was "connections to society". 
This included the primary codes of "relationships/support in general", "relationship history", and "situational factors". Relationships, relationship history, and support all encapsulate how the offender has or is connected to others in the community, which is why I opted to include that primary code in the focused code. Above, I defined the "situational factors" primary code as pertaining to the environment around the offender and to circumstances that could affect reintegration. Not only could environmental situations pertain to societal connections (i.e., if the offender lived in a safe neighbourhood, they could in theory have pro-social relationships with neighbours), but situational factors such as using social assistance can be seen as an indicator of how dependent an offender is on society. This dependency can be seen as a connection to society in a macro sense, whereas interpersonal relationships are on the micro scale in relation to the offender and their relationship to society (Fairclough 1989). This differs from what Fairclough (1989) describes as micro CDA (i.e. analyzing word choice) but is still relevant because the word choice within this policy indicates a division between interpersonal relationships, and societal ones. This division within itself is both macro and micro.

Of note is that within this policy, specifically under Annex D (Static Factors Assessment), there is a section called Sex Offence History Checklist (CSC Website, $C D$ 705-6). This within itself did not become a primary code because the information in this checklist fit under codes such as "victims/injury to victims" and "current offences/history of offences/convictions (current and past)". Nonetheless, it is important to mention as it is interesting that other crimes (homicide for example) do not show up within this policy with their own assessment criteria embedded within. I will come back to this topic later in this 
paper in my discussion section, as it relates to the desistance and risk paradigms. Below is a list of the focused codes for $C D$ 705-6.

Table 3: $C D$ 705-6 Focused Codes

\begin{tabular}{|c|}
\hline Policy $\boldsymbol{C D}$ 705-6 Focused Codes \\
\hline Reactions and Thoughts \\
\hline Legitimate Pathways \\
\hline Criminal Experiences \\
\hline Connections to Society \\
\hline
\end{tabular}

\section{715-1: Community Supervision}

The next policy that I coded and examined was $C D$ 715-1. This policy is shorter than $C D$ 705-6, thus there were not as many primary codes that were developed. To reiterate from what was said above, the policies in the $C D 715$ series $(1,2$ and 3$)$ often make reference to $C D$ 705-6 (i.e., make reference to the criminal profile of the offender). Also, if there are elements of $C D$ 705-6 intertwined with $C D 715-1,2$, and 3, I will mention them in my analysis of $C D$ $715-1,2$, and 3, but I will not go back to $C D$ 705-6 to recode them. Also, of note, is that for this policy Annex D is meant for CSC employees to understand how to get passports for offenders, and as such is not an assessment portion of the policy, therefore is not included in this analysis (CSC Website, $C D$ 715-1). Also, Annex E guides the parole officer in writing a community progress report after they have gathered all the information from the assessment portions of this policy, thus it is also not included in this analysis (CSC Website, CD 715-1).

\section{Primary Codes}

The first primary code for $C D$ 715-1 that I developed was "history of illegal behaviours". This code is self-explanatory and includes certain questions a parole officer is to assess such as if the offender has a history of violence, weapons use, or predatory behaviour (CSC Website, $C D$ 715-1). This code also includes questions where the parole officer needs to 
gather information about if the offender has been previously hostile towards correctional staff, and if they have a criminal history where they reside (CSC Website, CD 715-1).

Annex $\mathrm{C}$ in this policy is the Rating Reassessment Framework. This Annex is designed to look at static factors in order to re-assess the offender's level of intervention (LOWMEDIUM- HIGH) (CSC Website, CD 715-1). In this Annex the policy lists that the information for this re-assessment can come from the SIR-RI among other information that the parole officer can gather from when the offender admitted to federal custody (CSC Website, CD 715-1). More specifically, however, this Annex lists several criteria which the parole officer should review when examining level of intervention based on static factors (CSC Website, $C D$ 715-1). This includes looking at how often the offender has been in and out of the institution (CSC Website, CD 715-1). "Time since the offender's release" was included in the focused code "history of illegal behaviours" as I thought that it encompassed how often the offender has committed illegal acts and has been held accountable for them in some way (CSC Website, $C D$ 715-1, 12). In terms of risk and what is encapsulated in the risk paradigm, this code encapsulates the same information of the same code in the policy above (CSC Website, CD 715-1; CSC Website, CD 705-6). Quite simply, understanding the history of illegal behaviours could shed light on identified risk factors such as history of anti-social behaviours, anti-social personality, and anti-social cognitions (Andrews and Bonta 2010).

The second primary code that I developed was "current situational factors". This was a small code, but similar to that of the situational factors code in $C D$ 705-6 in that it pertains to physical environment (CSC Website, CD 705-6). However, in CD 715-1's case this code did not necessarily relate to reintegration, but rather just encapsulates the physical environment, which is how it differs from $C D$ 705-6's primary code (CSC Website, $C D$ 715-1). For $C D$ 
715-1, this code included what the parole officer should examine, including if the offender lives in a "remote location", if they have "restricted cell phone coverage", if they have "restricted access to outside intervention", the "availability of police", and their "proximity to criminal/gang activity" (CSC Website, $C D$ 715-1, 11). These codes are important because they work to situate the offender's every-day physical environment in assessment questions in order to determine important aspects of supervision. In this case, these situational factors could relate to risk in that if individuals lived near gang activity that could have interactions with anti-social associates which could lead to situations wherein the individual is at risk for law breaking (Boduszek et al. 2013).

The third primary code I developed was "support". This was relevant specifically in Annex C (Rating Reassessment Framework) of this policy (CSC Website, CD 715-1). Specifically, when looking at Level of Intervention Based on Dynamic Factors, it is mentioned that the parole officer should look at the Correctional Plan and see how much progress the offender has made, along with looking at other dynamic factors including personal situations (CSC Website, $C D$ 715-1). As mentioned in the above analysis of $C D$ 705-6, the DFIA-R in Annex E incorporates many aspects including support, jobs, and relationships (CSC Website, CD 705-6). Therefore, this code includes the Level of Intervention Based on Dynamic Factors section of $C D$ 715-1 because it can relate to supportive dynamic factors mentioned in $C D$ 7056 Annex E (CSC Website, $C D$ 705-6). In Annex C of $C D$ 715-1, under the Level of Intervention Based of Static Factors, once criteria to review is whether or not there is "existence of collateral contacts that could assist in the supervision" (CSC Website, CD 715-1, 12). This could be considered a level of support for the offender in the community. Furthermore, in Annex $\mathrm{C}$ there is a section that assesses the Level of Motivation for the 
offender, and within the seven criteria for this it states "level of external support from family, friends or other community members" as something to assess in relation to motivation levels (CSC Website, CD 715-1, 14).

This code in relation to the risk paradigm is very similar to that of the support code in $C D$ 705-6, however there is no focus on marriage and partners. Nonetheless, support from family members, friends and the community have a risk element because since having family and relationships with family contributes to lower crime rates and recidivism rates (Lo and Zhong 2006), that it means that not having that sort of support could contribute to offending behaviours. Moreover, although having support from family and the community is a good thing, it is also worth being conscious of the fact that some support networks could include people who are anti-social associates, and this could be a risk factor for criminal thinking (Whited et al. 2015).

The fourth primary code is "personal understanding about event/personal behaviours". In this case "event" refers to the criminal act that took place. This code is in reference to the parts of $C D$ 715-1 wherein the parole officer assesses how and if the offender recognizes what they have done (CSC Website, CD 715-1). This code includes looking at Annex C (Rating Reassessment Framework), specifically at the Level of Intervention wherein one of the criteria of importance for level of intervention assessment is the "offender's progress and motivation to participate in their Correctional Plan" (CSC Website, CD 715-1, 12). This criterion is part of this code because the offender's discipline and drive to participate in their plan counts as both their personal behaviour, and can also translate into how they can understand their criminal event and how to move past it to become pro social in society (CSC Website, CD 715-1).

This code also includes certain criteria from Annex C, under the Accountability section 
(CSC Website, $C D$ 715-1). Of the nine criteria used to assess an offender's accountability, four of them fit under the "personal understanding about event/personal behaviours" code (CSC Website, CD 715-1). These include "level of acceptance of responsibility for their criminal behaviour", "level of remorse and victim empathy", "understanding of their offence cycle", "understanding and commitment to their relapse prevention", and "meeting of courtordered obligations" (CSC Website, CD 715-1, 13-14). The criteria included for these codes are self-explanatory in that they all have to do with the offender's cognitive abilities to process their criminal exploits, but also what they need to do in the future to break the criminal offence pattern.

In the same Annex, under the Motivation section, there are seven criteria that are used for reassessing Motivation (CSC Website, CD 715-1). Of those, four fit into the code "personal understanding about event/personal behaviours". These four criteria are: "recognition that a problem exists with lifestyle, behaviour and resulting consequences", "level of comfort with problem and its impact on the offender's life", "level of feeling of personal responsibility for the problem(s)", and "willingness to change, i.e. expression of a wish to change, or of intention to fully participate in Correctional Plan" (CSC Website, $C D$ 715-1, 14). These four criteria fit within this code because they encompass what a parole officer looks for in terms of how the offender's thoughts and behaviours should evolve so that they can understand the impact of their crime (CSC Website, CD 715-1). Lastly, when a parole officer is to assess for Engagement, one of the four criteria for this is "actively participate in their assigned Correctional Plan", and this relates to this current code because it encapsulates the willingness of an offender to partake in a plan to move forward from past behaviours (CSC Website, CD 715-1, 15). 
In terms of the risk paradigm, this code and the information presented in $C D$ 715-1 that is included in this code relate to the offender's anti-social personality, and anti-social cognitions. In the discussion section I discuss how this code relates to desistance (particularly secondary desistance) (Maruna 2001), but it can also relate to risk. This is because if an offender cannot understand what they did wrong, why it was wrong, and how it hurt others it is not unreasonable to assume that they have aspects of anti-social personality and cognitions that they are still relying on or that they have not worked to change. Possessing these attributes can be seen as factors that increase risk of offending (Andrews and Bonta 2010; Walters 2003).

The fifth primary code is "current behaviours perceived as negative". This code encompasses the ways in which offenders act that could be perceived as negative. In the policy it is not written that these are negative behaviours but given the harsh language of some of the assessment criteria, I categorized them as negative. For example, in this code in Annex B (Staff Safety Assessment), offender factors to be looked at include "relationship between intoxicants and violent behaviour", "instability of intimate relationships", "mental health issues", "uncooperative hostile collateral" (CSC Website, CD 715-1, 10-11). These factors (behaviours) could be interpreted as negative, which is why they were included in this code. Furthermore, in Annex C (Rating Reassessment Framework), under the Level of Intervention Based on Static Factors section, one of the four criteria that should be reviewed for level of intervention is "significant disciplinary problems, suspensions or police intervention in the last year" (CSC Website, CD 715-1, 12). This criterion could have also been included in the "history of illegal behaviours" code, but because of its wording, I thought it was more indicative of current problems offenders have that could have included past police 
intervention. It is also important to note that what is mentioned in this policy that pertains to this code (e.g., drugs and alcohol, and intimate relationships) are mentioned at length in $C D$ 705-6 especially in Annex E (DFIA-R) which is why I believe that these categories are not mentioned in detail in this policy—because the correctional planning policy already assesses these factors in an in-depth way (CSC Website, CD 715-1).

This code incorporates elements of the risk paradigm in multiple ways. First, looking at the relationships between drugs and alcohol is important especially if offenders are using multiple substances. More to the point, however, is the fact this code touches on substance abuse, which is a risk factor for offending (Vaughn 2011; White and Gorman 2000). Furthermore, similar to the code about relationships in $C D$ 715-1, relationships themselves can help in lowering risk of committing crime (Huebner 2005; Sampson, Laub, and Wimer, 2006). Therefore, having unstable relationships is a risk that could contribute to higher offence rates. Investigating past suspensions and disciplinary problems can relate to risk simply because the activities are indicative of anti-social cognitions along with anti-social personality, especially since anti-social personalities include having self-control issues (Moffitt et al. 1996; Caspi 2000) both of which can contribute to a break in conditions and behaviours that condone discipline.

The next open code is "learning/behaviour adaptations". This code encompasses aspects of $C D$ 715-1 that have to do with assessing how offenders learn to be in the community in terms of how their behaviour has modified and what they have done to change it. Under the Accountability section in Annex C, of the nine criteria listed, four of them fit into this code (CSC Website, CD 715-1). These include "institutional adjustment and/or behaviour under community supervision", "conduct that demonstrates respect for other 
persons and property", "communication to their Parole Officer of their willingness to engage in their Correctional Plan", and "active participation in setting and achieving aspects of their Correctional Plan" (CSC Website, CD 715-1, 14).

The above factors fit into the "learning/behaviour adaptations" code because they have to do with changing behaviours to suit an offender's supervision plan, but also have to do with learning (i.e., learning to respect others, learning to communicate effectively with their parole officer, learning to be active in terms of their Correctional Plan) (CSC Website, CD 715-1). Although the policy does not mention that these behaviours need to be learned, it is important to note that what is being assessed are expectations that the offender needs to potentially learn/modify their institutionalized behaviour for (CSC Website, CD 715-1). Lastly, under Level of Motivation, two criteria that are relevant to this code include "possession of skills and knowledge required to effect change in behaviour", and "past history of demonstrated change" (CSC Website, $C D$ 715-1, 14). These last two criteria fit into this code simply because they have to do with past and present behaviour changes. The language used for the criteria is very personalized, and addresses the offender's willingness, capacity, and drive to change (Fairclough 2013). It is in this way that this section (or code) of CD 715-1 is micro (CSC Website, $C D$ 715-1). But, not in the sense that Fairclough (1989) mentions, (i.e., not because I am looking at the work choice specifically in this analysis) - but because this specific section of the policy is individualized for the offender, and does not mention aspects of criminal behaviour that have larger implications in society (i.e., harm towards victims or the community or society) (Fairclough 1989).

This code (as I will discuss in my discussion section) is very desistance based especially because it involves an offender's personalized change in identity (i.e., secondary 
desistance) (Maruna and Farrall 2004; Maruna, Immarigeon, and LeBel 2004; Maruna 2001). However, I think this can be seen in the realm of the risk paradigm as well because if the offender is not adjusting properly it could simply be due to issues such as history of anti-social behaviours or anti-social personality, or it could be due to factors such as family and marital circumstances or substance abuse (Andrews and Bonta 2010). In this particular instance, I recognize that although I am making the point that in this code there is recognition of the offender's ability to change, and this could be a good avenue for an identity change which is part of the desistance process, I also mention that that language is individualized (Maruna and Farrall 2004; Maruna, Immarigeon, and LeBel 2004; Maruna 2001; Fairclough 2013; Fairclough 1989). This individualized language fits into what Serin and Lloyd (2017) mention: that risk is "considered at the individual level" (8).

The seventh and final primary code for $C D$ 715-1 is "responsivity and learning styles". This is self-explanatory and relates very closely to $C D$ 705-6's open code "education and learning". In $C D$ 715-1's case, however, the criteria mentioned for "responsivity and learning styles" was all from the Responsivity section of Annex C. Included in this code are criteria such as: "language barriers interfere with learning, work or intervention", "concentration problems are evident" and "intellectually disabled" (CSC Website, CD 715-1, 15). These include aspects of an offender's life that could hinder learning. Within the Responsivity section in the policy there are fourteen criteria related to what is mentioned above (CSC Website, $C D$ 715-1). This is the longest list of criteria within this policy, which is my justification for making it its own code. Again, I argue, given the individualized nature of these criteria, and after analyzing the wording in this section (i.e., a micro analysis according to Fairclough (1989)), the impact for society in relation to this section of the policy is not as 
great because of the personalized language used to assess the offenders learning, therefore the macro element is not as prominent. This code fits in with the risk factor of school (Andrews and Bonta 2010). If offenders have issues with concentration or learning this could point to the reality that they did not finish school or have not attended school in a long while. Since school can be a factor that helps with crime prevention (Hansen 2003; Lochner 2004) if the offender is having difficulties in terms of learning, it could indicate to the parole officer that school was not attended, and can contribute to the parole officer understanding factors that could have influenced that offender's offending behaviour. Below is a table that outlines the primary codes for $C D$ 715-1.

Table 4: $C D$ 715-1 Primary Codes

\begin{tabular}{|c|}
\hline Policy $\boldsymbol{C D}$ 715-1 Primary Codes \\
\hline History of Illegal Behaviours \\
\hline Current Situational Factors \\
\hline Support \\
\hline Personal Understanding about Event/Personal Behaviours \\
\hline Current Behaviours Perceived as Negative \\
\hline Learning/Behaviour Adaptations \\
\hline Responsivity and Learning Styles \\
\hline
\end{tabular}

\section{Focused Codes}

The first focused code for this policy is "connections to society". This is one of the same focused codes that was presented for $C D$ 705-6 (which included relationships and support, and situational factors). For $C D 715-1$ this focused code includes the primary codes "support" and "current situational factors". This is extremely similar to the policy presented above, and the reasoning behind why I decided to group these primary codes together is also similar (CSC Website, CD 705-6; CSC Website, CD 715-1). The support an offender receives in society can offer glimpses in how they are connected to society and connected to people in said society. The situations that offenders are in, in this case are focusing more on physical 
environment, which can relate to connections an offender has in their community.

The second focused code for this policy is "deviant behaviours". This focused code incorporated the primary codes "history of illegal behaviours" and "current behaviours perceived as negative". Since not all behaviours that are perceived as negative are illegal or criminal, I decided that grouping these two primary codes together and calling them deviant the essence of both codes. Something worth interrogating, however, is the question of "who considers these acts "deviant"'? For the purpose of this code, these acts are considered to be deviant to the federal government (or more so deviant in terms of the offender's correctional plan), specifically CSC, and this is important context to consider in the realm of this project because deviance does not necessarily have only one definition.

The last focused code developed for $C D$ 715-1 is "comprehension of realities". This focused code groups together the primary codes of "personal understanding about event/personal behaviours", "learning/behaviour adaptations" and "responsivity and learning styles”. Simply, these three primary codes are included in this focused code because they involve the parole officer assessing and understanding the reality of the offender (whether that would be how the offender learns new behaviours, how the offender views the impacts of their crime, and how the offender learns in an academic setting). This focused code also incorporates aspects of $C D$ 715-1 that could make the offender understand their own realities (i.e., after the assessment, the offender could realize that currently, they are not willing to change, but they want to work towards having a higher level of motivation) (CSC Website, $C D$ 715-1). The focused codes for this policy are presented below in a table.

Table 5: CD 715-1 Focused Codes

\section{Policy CD 715-1 Focused Codes}

Connections to Society

Deviant Behaviours 
Comprehension of Realities

\section{715-2: Post Release Decision Process}

The purpose of this policy is to be able to guide a parole officer's decision regarding both a change of condition while an offender is in the community, and the decision as to what happens when an offender is suspended (CSC Website, CD 715-2). The assessment portion of this policy is not long, therefore there are only three primary codes. As such, a decision was made to forgo the focused coding process for this policy, as the primary codes are not related to one another, and there is not an abundance of them to recategorize into higher level codes.

\section{Primary Codes}

The first primary code for this policy is "history/offence history". In Annex B (Assessment for Decision- Post- Suspension/Change Conditions- Report Guide), there is a list of suggested questions/areas that the parole officer should inquire about before making a decision in regard to conditions (CSC Website, $C D$ 715-2). Of importance are the questions presented around past criminal history, along with other conditional release history (CSC Website, $C D$ 715-2). Along with this, there is also a section wherein the parole officer is to inquire about the individual's behaviour while incarcerated (CSC Website, CD 715-2).

Moreover, in Annex C (Correctional Plan Update- Community Progress- Release Maintained- Report Guide) there are several sections in which the parole officer is to inquire about past history of the offender (CSC Website, CD 715-2). This Annex stresses the importance of the Correctional Plan to assess decisions for release (CSC Website, CD 715-2). With this, the parole officer is to include the offender's offence and offence history, and "the circumstances of the suspension/increase in risk" (CSC Website, CD 715-2, 17). Furthermore, the offence cycle should also be updated with any changes including those of the offender 
(CSC Website, CD 715-2).

Lastly, (and more specifically), in accordance with Annex D (Risk Assessment Framework), when there has been a breach or increase in risk, parole officers are to inquire about: "current risk to re-offend, including existence of high risk situations/triggers", information from assessments from mental health professionals regarding risk, "nature of the breach/increase in risk and its relationship to the offence cycle", "existence of a pattern of similar breaches during the supervision period", "police and preventative security information regarding the breach/increase in risk", "intoxicant type, severity of the addiction and its relationship to the offence cycle" (CSC Website, CD 715-2, 19-20). Similarly, when assessing how the offender has done under supervision, criteria eight of nine suggests that the parole officer look at substance abuse and how it influences criminal behaviour (CSC Website, $C D$ 715-2). The wording in Annex D suggests that not only is risk to re-offend important to CSC, but it seems as though substance abuse and addiction also have meaning in assessing factors for post-release (CSC Website, CD 715-2). Of importance here is the fact that Annex D is centered upon risk specifically. Despite this, I will discuss how these policies incorporate or do not incorporate desistance factors in my discussion section, because just because the work "risk" is used in these policies, does not mean there is an absence of desistance factors or aspects of the desistance paradigm.

To continue, the word "risk" is used in this code in terms of risk to parole officers and suspension and risk. In these instances, I believe that risk is being assessed here because it is important to assess risk as it pertains to CSC staff and the community. Moreover, based on Andrews and Bonta's (2010) factors, this code not only encompasses offence history, but also substance abuse which is a risk factor. Interestingly, when this policy mentions looking at 
"risk and its relationship to the offence cycle" (CSC Website, $C D$ 715-2, 20), that also relates to risk factors because the offence cycle could be influenced by factors such anti-social cognitions, or anti-social peers, family or marital issues, substance abuse and work or school, to name a few (Andrews and Bonta 2010). This is not necessarily a complicated connection to make, but I think that this code lends itself to risk simply because it includes aspects such as substance abuse when talking about offences and offence history (CSC Website, CD 715-2). When examining this policy (especially in creating these primary codes) I found that it was less thorough in length, and besides Annex B which suggests several in-depth questions that the parole officer should inquire about, this policy makes many references to the Correctional Plan, and other factors (specifically dynamic factors) that can be found in CD 705-6.

The second primary code that I developed for this policy was "relationships/support/community". Simply, this code relates to the relationships the offender has, the support they receive, and their ties to the community. This code is specific to Annex D, under the Progress Under Supervision section (CSC Website, CD 715-2). There are eight criteria in this section, and of the eight, three are relevant to this code (CSC Website, CD 715 2). Those that are relevant are "length of time and level of stability in the community", “information from collateral sources with special attention to recent breakdown of relationships, domestic problems and family violence", and "recommendations from supervision team members e.g., community-based residential facility, program facilitators, police, etc.." (CSC Website, $C D$ 715-2, 20). In terms of the last criterion that makes up this primary code, the input from community partners that have stakes in the criminal justice system is important because the input is demonstrative of the interactions the offender has while in the community on 
supervision. Thus, although, the criterion does not incorporate personal relationships (romantic, social, familial, or otherwise), it is still important to include in this code.

In relation to the risk paradigm, this code inquiring about breakdowns of relationships is important because relationships have been linked to a lower crime rate (Lo and Zhong 2006). Thus, the fact that this policy wants to pay special attention to those relationship breakdowns is important, and incorporates aspects of the risk paradigm (CSC Website, $C D$ 715-2). Lastly, the community aspect is important here. In terms of risk, this could fall under leisure and recreation. Usually leisure and recreation are talked about as activities that individuals do, however in this case I think it could also relate to ties to the community since the community can be a source of relationships for offenders. This policy is asking about aspects such as stability in the community, and that stability could come from leisure and recreation activities which are known to help facilitate a crime-free life (Williams 2006; Williams and Walker 2006).

The last primary code for $C D 715-2$ is "responses to interventions including situations". "Situations" in this context include how the individual on parole behaves in everyday situations. Annex B provides several questions with prompts that a parole officer should be engaging with, including questions regarding the Correctional Plan (CSC Website, $C D$ 715-2). These include "what changes in the offender's attitudes and/or behaviour have occurred since the beginning of the sentence and what effect have these changes had on the offender's risk level?" and "how does the offender demonstrate their understanding of their crime cycle?" (CSC Website, CD 715- 2, 14). These questions in particular point to the ways in which the offender has responded to being in the community and to their plan. For this reason, these questions belong to this code, as they highlight reactive responses that the 
individual has to their situation.

Furthermore, in Annex B one of the questions for parole officers has to do with whether the current release plan supports the offender's reintegration safely in the community. Some of the follow up prompt questions for this question include: "how will the available programs and/or interventions mitigate risk?", "are there negative aspects to consider in the release environment?" and, "can the specific areas of risk be effectively managed by the Parole Officer and others in the Case Management Team?" (CSC Website, CD 715-2, 14). Other than the fact that these questions deal with interventions and situations that the offender needs to be aware of, this policy clearly focuses on "risk" when discussing interventions, and it is quite clear through word choice that the mitigation of risk in the community is important (Fairclough 2013; Fairclough 1989; CSC Website, CD 715-2). This is further exemplified in the same Annex wherein the parole officer is to look at the individual's Correctional Plan Progress and Engagement, and it is stated that they should examine how influential the programs are for offenders and that "the key consideration is whether there has been a reduction in risk" (CSC Website, $C D$ 715-2, 15). However, as mentioned above, just because "risk" is discussed does not mean that desistance is not present. In other words, both aspects of the risk and desistance paradigms can be present despite the specific word use of "risk".

Lastly, Annex D provides is the section entitled Progress Under Supervision (CSC Website, CD 715-2). This section has three areas that are incorporated into the primary code "responses to interventions including situations". These are "progress against case specific dynamic factors", "previous response to interventions", and "demonstrated ability to manage offence cycle" (CSC Website, CD 715-2, 20). Straightforwardly, these criteria have to do with how the offender situates themself through ever-changing life events while managing and 
keeping up with their targeted interventions. Again, in this code the word risk has been used multiple times especially in assessing how attitudes/attitude changes have affected risk, and how exactly interventions affect risk (CSC Website, $C D$ 715-2). In terms of attitudes and how they include risk, this is similar to what I have mentioned in relation to other primary codes for other policies. The changes in attitude could either heighten or lessen risk depending on how the offender's attitudes change. With this comes the idea that some of these attitudes or cognitions may be anti-social. If an individual has anti-social cognitions that have not changed, this could increase their risk for offending (Healy and O'Donnell 2006; Palmer and Hollin 2004). Thus, if the offender has demonstrated change in attitudes, their risk could be lower. Information in this code also includes assessing if there are negative aspects in the environment that the offender is living in (CSC Website, $C D$ 715-2). This is important for risk mostly for the presence of anti-social associates, but also because there could be a chance that the leisure and recreational activities the community does could be "negative" and could lead to the offender engaging in criminal activities (see Atkinson 2014, for example). A summary of the primary codes for $C D 715-2$ can be found below.

Table 6: $C D$ 715-2 Primary Codes

\begin{tabular}{|c|}
\hline Policy $\boldsymbol{C D}$ 715-2 Primary Codes \\
\hline History/Offence History \\
\hline Relationships/Support/Community \\
\hline Responses to Interventions Including Situations \\
\hline
\end{tabular}

CD 715-3: Community Assessments

This policy is used for correctional planning, and more specifically, this policy can be used to aid parole officers if there is a change in the community (i.e. source of community information), or if the file of information for an offender needs updating (CSC Website, $C D$ 715-3). This policy is similar to $C D 715-2$, however is not specifically aimed at an offender 
who has been suspended (CSC Website, CD 715-3). Although the assessment portion for this policy is quite short, there were still several focused codes derived from this policy. Moreover, this policy has an Annex specific to Indigenous offender's and social history. Although this is important for community corrections, I did not include this in the primary codes, as the needs for Indigenous offenders are not the same as non-Indigenous offenders, thus the focus of Indigenous specific assessments in the policy would take into account different considerations (refer to my point regarding this under $C D$ 705-6 above).

\section{Primary Codes}

The first primary code for this policy is "criminal past/history/escape/current status". Although these are many specific aspects to be grouped together, they all have to do with an offender's life in relation to crime. Annex B (Community Assessment Report Guide) guides parole officers in writing the community assessment report (CSC Website, CD 715-3). Within this section, under contributing factors, parole officers should ask contacts in the community if they know "what contributed to an offender's criminal activity", and the parole officer should then assess "all dynamic factors associated with the offender's criminality" (CSC Website, $C D$ 715-3, 7). Specifically, the dynamic factors can be found in $C D$ 705-6 in Annex E (DFIA-R), which was already analyzed above for that policy (CSC Website, CD 705-6).

Furthermore, in Annex B a parole officer is to engage in an examination of if the offender has "in the past escaped lawful custody or breached a court order or probation/parole order", and if the parole officer "has knowledge whether the offender has links to criminal organizations, gangs or security threat groups, and, if so, what was the offender's involvement?" (CSC Website, CD 715-3, 11). In this particular policy, other than asking about what contributed to an offender's criminal activity (including dynamic factors), of note is the 
fact the rest of the questions have to do with the offender in relation to the criminal justice system (breaching custody) and their criminality in relation to threat groups (CSC Website, $C D$ 715-3). Given that this policy has to do with community assessments and is more focused on this connection between the offender and the community, it makes a degree of sense that the choices of wording relate to the larger social world (Fairclough 2013; Fairclough 1989).

The criminal history code has appeared in all the policies, and the ways in which they all incorporate risk are not that different. For $C D$ 715-3 aspects of the risk paradigm are incorporated because dynamic factors should be assessed, and these changing factors could include aspects that heighten risk, such as increased substance abuse or lack of employment (Bennett, Holloway, and Farrington 2008; Benda, Harm, and Toombs 2005). Escaping custody and "links to criminal organizations" are also risk related because escaping custody could be a result of anti-social cognitions for example; whereas associations with criminal organizations could increase the level of anti-social associates an individual has, and this can increase risk for offending (Boduszek et al.2013; CSC Website, CD 715-3, 11).

The second primary code is "support/community". This code is self-explanatory in that it has to do with the support the offender receives in the community. Within this policy, the notion of support is a large reason why a community assessment is done; "Reasons for Community Assessment: source of support, private family visits (if required), community support for leave privileges" (CSC Website, CD 715-3, 6). Parole officers should ask contacts in the community if they know if the offender is using community services (CSC Website, $C D$ 715-3). Furthermore, the parole officer should assess if there are community resources in the area that the offender might be released to that will help them with their reintegration (CSC Website, $C D$ 715-3). 
Depending on the request for the Community Assessment (work release, private family visits, institutional mother-child program etc.) the parole officer will ask certain questions in regard to supports (CSC Website, CD 715-3). To start, for the institutional mother-child program, the parole officer should assess with the community contact what the relationship is like between the child and the mother, and if the mother is able to parent (CSC Website, $C D$ 715-3). Moreover, for a request for day parole to a different location, the parole officer should inquire about if there are readily available social services in the new location, including services to help with addiction (CSC Website, CD 715-3). Furthermore, for day parole to a different location, the parole office should be aware of the details of what support is needed by the offender (i.e. financial or social) (CSC Website, CD 715-3). Lastly, it is also important for the parole officer to have information regarding the social ties the offender has in Canada:

Nature of the relationship with family or friends. How often was there communication or visits prior to and/or after the present offence? What services or support can be offered? Is this person a positive support? Does the family/contact or Global Affairs Canada have to subsidize the offender's incarceration and provide for their well-being and welfare? (CSC Website, CD 715-3, 10).

In relation to this, the parole officer should ask the community contact if they "know the offender is receiving programming and/or treatment in the foreign prison? In the contact's opinion, does this institution or country pose a threat to the offender's health or safety?" (CSC Website, $C D 715-3,10)$. Although support is community oriented, there is also an aspect of this code that concerns the country, and potentially other countries as well. To expand, the quote above is interesting because there is a personal element to it (i.e. is the offender's support system positive, and how often do they communicate with them), but there is also a larger implication here (i.e., what are the chances and how likely is it that the offender will leave the country?). 
This code relates to the risk paradigm because it centers around community services, and social support including addiction help. Community services, although mandated, could help the offender developed social bonds and in turn could contribute to a sort of leisure and recreation situation (i.e., socializing in the community) which could be positive for the offender as it could lower risk of offence (Williams 2006; Williams and Walker 2006). The fact the policy mentions support for addiction relates to risk because it seems that the policy recognizes that substance issues can play a role in recidivism and offending (Håkansson and Berglund 2012).

The third primary code is "willingness and responsibility". These codes mostly have to do with how the offender has acted throughout the process of their sentence. For example, the parole officer should assess how willing the offender has been to participate in programming for reintegration and rehabilitation, and if they have had adequate motivation to engage in their correctional plan (CSC Website, CD 715-3). To this end, the parole officer can also discuss with the community contact if the community contact can help the offender complete programs and be active in that part of reintegration (CSC Website, CD 715-3). Furthermore, according to this policy, it is also important to assess "whether the offender has accepted responsibility for the offence for which they have been convicted, including by acknowledging the harm done to victims and to the community" (CSC Website, CD 715-3, 10). The language here is direct, and pairs personal harms (i.e., to the victim), to that of the community (i.e., society) and for this reason, there is a larger macro approach to this question (Fairclough 1989). Through the analysis of word choice (micro analysis according to Fairclough (1989)) there is also more of a personal element to this question as there is a direct link between the offender and the victim. Lastly, a parole officer is to investigate if the offender has cooperated 
with the law and with the police (CSC Website, $C D$ 715-3).

The aspects of the risk paradigm here that are present are the same as what was mentioned for $C D$ 715- 1 in relation to the code "personal understanding of event/personal behaviours". Willingness to take responsibility can be hampered by anti-social cognitions which contribute to individuals not willing to take responsibility for their actions (Walters 2003), and since anti-social cognitions are a risk factor identified by Andrews and Bonta (2010), this code incorporates an element of risk.

The final primary code for this policy is "employment/aspects of employment". This code is relevant if the offender wants to go on a work release. In this case the parole officer should talk to the potential employer to see if they understand the needs of the offender, and if they still want the offender to work for them, and the parole officer should also work out a release plan for the offender including their conditions for a work release (CSC Website, $C D$ 715-3). According to the policy, it is also imperative that the parole officer assesses if there are employment opportunities, or opportunities for meaningful training (if there is a request for day parole to another location) (CSC Website, $C D$ 715-3). Similar to the code "employment/aspects of employment" in $C D$ 705-6, the mention of employment and training in the policy simply recognizes that employment is important, probably because it can be shown to decrease risk (Benda, Harm, and Toombs 2005). This is important because in $C D$ 715-3 the policy works to recognize that working could be valuable for the offender in relation to risk. A table outlining the primary codes for $C D 715-3$ can be found below.

\begin{tabular}{|c|}
\hline Policy $\boldsymbol{C D}$ 715-3 Primary Codes \\
\hline Criminal Past/History/Escape/Current Status \\
\hline Support/Community \\
\hline Willingness and Responsibility \\
\hline Employment/Aspects of Employment \\
\hline
\end{tabular}




\section{Focused Codes}

The first focused code for $C D$ 715-3 is "acceptance and understanding". This code incorporates the primary codes of "willingness and responsibility" and "criminal past/history/escape/current status". Simply these primary codes exemplify whether or not the offender is willing to accept responsibility for what they did and move forward while also coming to terms with their past. These codes are similar as they center around the parole officer evaluating the offender's criminal activity, and their motivation for changing.

The second focused code is "connections to society". Similar to policies above, this code encapsulates the primary codes of "support/community" and "employment/aspects of employment". As reiterated above, these primary codes are adequate for this focused code because they center around the offender's connections to society. Support and community is a personal connection that the offender has with a few people in their social circle. A small table outlining the focused codes for these policies is below.

Table 8: $C D$ 715-3 Focused Codes

\begin{tabular}{|c|}
\hline Policy $C D$ 715-3 Focused Codes \\
\hline Acceptance and Understanding \\
\hline Connections to Society \\
\hline
\end{tabular}

\section{Policy Comparisons}

In this section I will compare the analysis completed above across $C D$ 705-6, $C D$ 7151, $C D 715-2$, and $C D$ 715-3. These comparisons are going to serve as a pre courser to my discussion section in which I will dissect the ways in which desistance is or is not present within the policies. Given that I went through primary codes in detail above, this section is going to compare focus code themes in order to examine where there are similarities and differences across policies. In the case of $C D$ 715-2 wherein there were no focused codes, I will incorporate the three primary codes for this comparison. Given that the focused codes 
developed grouped together primary codes and brought them to a higher level, for this comparison I grouped the focused codes into three groups that deal with similar themes. To reiterate from above, this section will not discuss each focused code as they relate to the four individual policies (as that was done above), but rather, this section will look at the codes holistically to compare them. A discussion around the comparison of how these codes incorporate the desistance and risk paradigms will be present at the end of my discussion section. The purpose of this section, however, is to discuss purely how the codes are similar across the policies, with less attention on the risk and desistance aspects.

\section{Group One}

Group one encompasses the focused codes of "criminal experiences" and "deviant behaviours". Simply, across the policies analyzed these two focused codes are similar because they incorporate many aspects of the offender's criminal exploits, along with aspects of their sentence. For example, as explained above, these two codes look at an offender's current offences, their history of offences, and their current status (including behaviours that are seen as negative). The history of the offender's criminality was present in all policies including $C D$ 715- 2, as a primary code (CSC Website, CD 705-6; CSC Website, CD 715-1; CSC Website, $C D$ 715-2; CSC Website, $C D$ 715-3). The conclusion that can be reached from this is that it is important for parole officers to be aware of this history, and that that is a consistent part of the assessment of policies.

\section{Group Two}

The second group of focused codes grouped together all relate to society. Across three of the four policies the focused code of "connections to society" was used, and in one policy, "legitimate pathways" was used. These are the codes included in group two. This code 
encompasses different aspects of connections to society (i.e., encompasses different primary codes), but they all relate to how the offender interacts with the societal world. For example, primary codes that were included in this focused code across policies comprise the offender's relationships and support networks, their situational factors, along with employment and employment opportunities. As a whole, these themes were pretty consistent across policies in that all policies included some aspect of the offender's societal relationship, including $C D$ 715-2 which had a primary code that was related to relationships and support in the community (CSC Website, CD 705-6; CSC Website, CD 715-1; CSC Website, CD 715-2; CSC Website, CD 715-3).

\section{Group Three}

Group three includes the focused codes of "reactions and thoughts", "comprehension of realities", and "acceptance and understanding". These codes are all related because they have to do with how the offender has come to terms with what they have done, how the offender feels about what they have done, and how the offender is going to learn from their behaviours (and more importantly, their willingness to learn from their behaviours) (CSC Website, $C D$ 705-6; CSC Website, $C D$ 715-1; CSC Website, $C D$ 715-3). In $C D$ 715-2 the focused code that aligns with group 3 is "responses to interventions including situations" as it encapsulates how the offender is going to respond to interventions provided for them that will aid in reintegration, along with how they react to certain situations (CSC Website, $C D$ 715-2)

Therefore, in touching on Charmaz's (2006) question about what can be compared between texts, it is clear that these policies cover a lot of the same topics. Therefore, grouping topics together across policies was doable, regardless of the fact that they were not 
all the same size, and covered slightly different aspects of community reintegration.

\section{Returning to Critical Questions}

Now that an analysis has been done of the policies, and they have been compared, it is important to return to some of the critical questions posed by Charmaz (2006), and Ralph, Birks, and Chapman (2014).

Charmaz (2006) asks questions about structure and how it impacts the texts. In relation to these policies, structure plays an important part in how these documents are put together. For example, all the Annexes are at the back of the policies and are intended for the parole officer or other correctional staff to use as guidelines when assessing the offender (CSC Website, $C D$ 705-6; CSC Website, $C D$ 715-1; CSC Website, $C D$ 715-3). The analysis I completed, however, made a conscious effort to not pay attention to structure in most cases.

For example, in $C D$ 705-6 Annex E was the DFIA-R, and I made reference to Annex E and the DFIA-R when discussing aspects of Annex E, but of importance here is the fact that I did not group together what was under every sub-heading in Annex E (CSC Website, CD 7056). To further expand; as an example, Annex E has a sub-heading called Associates Domain Indicators (page 32), and under this sub- heading there are seven prompts (CSC Website, $C D$ 705-6). When I was coding, I did not code these seven prompts under a code called Associate

Domain Indicators, rather, I coded the prompts under primary codes such as "relationship with drugs and alcohol", "situational factors", "relationships/support in general", and "current offences/history of offences/convictions (current and past)" (CSC Website, CD 705-6). Another example includes how Annex E in $C D$ 705-6 has a sub-heading called Parenting, however, as explained in my analysis, this was not included as a code within itself, but rather was grouped into the codes of "relationships/support in general", and "relationship history" 
(CSC Website, CD 705-6).

Charmaz (2006) also asks "what categories can you discern from its structure?", and "what can you glean from these categories?" (39-40). Using CGT allowed me to make connections throughout each individual policy to aspects of the policy that were not always grouped under the same sub-heading, or that were not always part of the same Annex (Charmaz 2006). This allowed me to look at the policies more holistically. On one hand, it is understandable from the view of bureaucracy that the assessment portions of the policy should be very structured so that it is easy for parole officers to understand what is being asked of them and how they should fulfill their job requirements. On the other hand, however, it also shed light on how CSC compartmentalizes what they expect from corrections personnel.

An important question that Ralph, Birks, and Chapman (2014) ask is "When was the document conceived, produced, updated?" (4). These four policies came into effect on April $15^{\text {th }}, 2019$ (CSC Website, $C D 705-6$; $C D$ 715-1; CD 715-2; CD 715-3). They were all modified in April of 2019 as well with $C D$ 705-6 being modified on the $3^{\text {rd }}, C D$ 715-1 on the $4^{\text {th }}, C D 715-2$ on the $11^{\text {th }}$, and $C D 715-3$ on the $25^{\text {th }}$ (CSC Website, $C D 705-6$; $C D$ 715-1; $C D$ 715-2; $C D$ 715-3). Given the fact that these policies all relate to the same topic, the fact they all came into effect on the same day and were modified within the same month is not surprising. In terms of validity and continuity, it is ideal that these policies were written around the same time, as this contributes to a sounder analysis, especially since the policies are all compared to one another. If the policies were written years apart from one another there is the potential that it could warrant an investigation into changes that could have occurred between when the older policy was written, and current day. Finally, in discussing this question posed by Ralph, Birks, and Chapman (2014), I noticed that these policies came 
into effect and were modified under the Liberal federal government. Since I am analyzing policy of the federal government, the fact they all came into effect at the same time adds another layer of validity to the analysis, as I would assume that the policies were fulfilling an aspect of the corrections portfolio for that government. 


\section{Chapter 4: Discussion}

In this discussion section, I will discuss the ways in which $C D$ 705-6, $C D$ 715-1, CD715-2, and $C D$ 715-3 either do, or do not incorporate aspects of the desistance paradigm. Each of the policies will be discussed individually, as that is how they are addressed in my research questions. In this discussion of the desistance paradigm, I will return to referencing the higher-level focused codes for these policies. When I discuss desistance, I will break down the examination further in order to present ways in which these policies incorporate (or do not incorporate) aspects of informal and formal social control in relation to the desistance paradigm.

Furthermore, I will also turn my discussion into a discussion of if there are aspects of sex offender desistance in these policies. Throughout this section I will be providing commentary on the ways in which CSC does or does not incorporate aspects of the desistance paradigm into their policies and provide examples of how I believe they should include desistance in their policies (including sex offender desistance). This will be brought together at the end of the section wherein I will summarize my discussion on this topic. I recognize that in my analysis section I brought the risk paradigm into the conversation in regard to some of the codes. The risk paradigm will also be discussed in this section (to a lesser extent than desistance) especially when there are aspects within the codes discussed that overlap with the desistance paradigm. The main purpose of this will be to mention where this overlapping occurs in order to highlight the co-occurring nature of these two paradigms, in preparation to discuss the conclusions around desistance versus risk. Throughout this discussion section, there will be mention of the focused and primary codes, when discussing the desistance and risk paradigms. Below is a summary table of these codes. 
Table 9: All Primary and Focused Codes Per Policy

\begin{tabular}{|c|c|c|c|}
\hline $\begin{array}{l}C D 705-6 \text { Focused and } \\
\text { Primary Codes }\end{array}$ & $\begin{array}{l}C D 715-1 \text { Focused } \\
\text { and Primary Codes }\end{array}$ & $\begin{array}{l}C D \text { 715-2 Primary } \\
\text { Codes }\end{array}$ & $\begin{array}{l}C D 715-3 \text { Focused } \\
\text { and Primary Codes }\end{array}$ \\
\hline Reactions and Thoughts & Connections to Society & History/Offence History & $\begin{array}{l}\text { Acceptance and } \\
\text { Understanding }\end{array}$ \\
\hline $\begin{array}{l}\text { - Personal } \\
\text { Interpretations of } \\
\text { Situations/ } \\
\text { Feelings/Reactions } \\
\text { to an Event } \\
\end{array}$ & - Support & $\begin{array}{l}\text { Relationships/Support/ } \\
\text { Community }\end{array}$ & $\begin{array}{l}\text { - Willingness and } \\
\text { Responsibility }\end{array}$ \\
\hline $\begin{array}{ll}\text { - } & \text { Personal } \\
\text { Personality } \\
\text { Characteristics }\end{array}$ & $\begin{array}{l}\text { - Current } \\
\text { Situational } \\
\text { Factors }\end{array}$ & $\begin{array}{l}\text { Responses to } \\
\text { Interventions Including } \\
\text { Situations }\end{array}$ & $\begin{array}{l}\text { - Criminal } \\
\text { Past/History/ } \\
\text { Escape/Current } \\
\text { Status }\end{array}$ \\
\hline $\begin{array}{l}\text { - Victims/Injury to } \\
\text { Victims }\end{array}$ & Deviant Behaviours & & Connections to Society \\
\hline Legitimate Pathways & $\begin{array}{ll} & \text { History of Illegal } \\
& \text { Behaviours } \\
\end{array}$ & & $\begin{array}{ll}\text { - } & \text { Support/ } \\
\text { Community }\end{array}$ \\
\hline $\begin{array}{l}\text { - Education and } \\
\text { Learning }\end{array}$ & $\begin{array}{ll}\text { Current } \\
\text { Behaviours } \\
\text { Perceived as } \\
\text { Negative } \\
\end{array}$ & & $\begin{array}{l}\text { Employment/ } \\
\text { Aspects of } \\
\text { Employment }\end{array}$ \\
\hline $\begin{array}{l}\text { - Employment/ } \\
\text { Aspects of } \\
\text { Employment } \\
\end{array}$ & $\begin{array}{l}\text { Comprehension of } \\
\text { Realities }\end{array}$ & & \\
\hline Criminal Experiences & $\begin{array}{l}\text { - Personal } \\
\text { Understanding } \\
\text { about } \\
\text { Event/Personal } \\
\text { Behaviours } \\
\end{array}$ & & \\
\hline $\begin{array}{l}\text { Current Offences/ } \\
\text { History of } \\
\text { Offences/ } \\
\text { Convictions } \\
\text { (current/past) } \\
\end{array}$ & $\begin{array}{l}\text { Learning/ } \\
\text { Behaviour } \\
\text { Adaptations }\end{array}$ & & \\
\hline $\begin{array}{l}\text { - Previous } \\
\text { Supervision in the } \\
\text { Community }\end{array}$ & $\begin{array}{l}\text { - Responsivity and } \\
\text { Learning Styles }\end{array}$ & & \\
\hline $\begin{array}{ll}\text { - } & \text { Time Between } \\
\text { Incarceration }\end{array}$ & & & \\
\hline $\begin{array}{ll}\text { - } & \text { Relationship with } \\
& \text { Drugs/Alcohol } \\
\end{array}$ & & & \\
\hline \multicolumn{4}{|l|}{ Connections to Society } \\
\hline $\begin{array}{ll}\text { - } & \text { Relationships/ } \\
& \text { Support in General } \\
\end{array}$ & & & \\
\hline $\begin{array}{ll}\text { - } & \text { Relationship } \\
& \text { History } \\
\end{array}$ & & & \\
\hline - Situational Factors & & & \\
\hline
\end{tabular}




\section{705-6: Correctional Planning and Criminal Profile}

For this policy, there were twelve primary codes, and four focused codes. Focused codes included: "reactions and thoughts", "legitimate pathways", "criminal experiences", and "connections to society". For this policy I will look at ways in which the information in these focused codes either encapsulate or do not encapsulate aspects of informal and formal social control, and desistance.

\section{"Reactions and Thoughts"}

This focused code includes primary codes that have to do with how the offender personally feels and reacts to what they did, including how they process their actions. This includes the primary codes of "personal interpretations of situations/feelings/reactions to an event", "personal personality characteristics", and "victims/injury to victims".

\section{Informal Social Control}

Since this focused code looks at personal thoughts that the offender has about their crime and how they view it, many of the informal social control aspects such as age, marriage and work (Laub and Sampson 2001) are not the most applicable here. Of interest, however, is how the offender sees themselves, and the ways in which the questions in the prompts of the assessment section for CD705-6 lend themselves not only to the idea that desistance is a process (Maruna 2001; Bushway et al. 2001), but also to secondary desistance (Maruna 2001). This will be explained further below.

Above, in my analysis section, I explain how within "reactions and thoughts", the primary codes of "personal interpretations of situations/feelings/reactions to an event", "personal personality characteristics", and "victims/injury to victims" were relevant because they all gave the offender an opportunity to discuss what they felt they needed to discuss in 
relation to the topic.

There are several examples of this, including questions wherein the parole officer is trying to assess if the offender "gives up easily when challenged?" by asking several questions such as what goals they have set for themselves in the past, if they felt they achieved them, and why or why not (CSC Website, $C D$ 705-6, 43). Another question includes asking the offenders if they have "difficulty setting long-term goals?", and inquires further by asking them if they have any long-term goals, and what they are (CSC Website, CD 705-6, 44). One last example from this policy includes questions about empathy, in which the parole officer asks about empathy skills and if the offender if they understand the effect their crimes have had on the victim or victims (CSC Website, CD 705-6).

As explained in the literature review, secondary desistance is thought of as what happens when an offender has a change in their identity (Maruna and Farrall 2004; Maruna, Immarigeon, and LeBel 2004; Maruna 2001). These new identities change the offender from someone who offends to someone who does not (Maruna 2001; Vaughan 2007). Researchers such as Maruna (2001) criticize Laub and Sampson's (1993) informal theory of social control for not taking into account personal characteristics into informal desistance. In no way do the questions in $C D$ 705-6 above exactly address this shift, but the questions could foster an identity shift, or, at least a recognition that a shift is possible.

For example, when the parole officer asks the offender to identify long term goals and if they give up when challenged (CSC Website, CD 705-6), it could be a moment of reflection for the offender in which they realize that they (a) have long term goals, (b) have long term goals that they have met, or (c) do not have long term goals but want to set them. The idea of having long term goals in general could fit into the idea of identity change (Maruna and 
Farrall 2004; Maruna, Immarigeon, and LeBel 2004; Maruna 2001). This also could fit into the idea of focusing on an offender's strengths, and getting them to plan, and realize what they are good at (Maruna and LeBel 2003). Identifying goals could be an example of an aspect of a protective factor (Nee and Vernham 2016). I realize, however, that the fault in this argument is the assumption that the long-term goals would be prosocial and positive.

Furthermore, social support is an important aspect of informal social control that can help offenders not only reintegrate, but come to terms with their actions (Kras 2019; Laub and Sampson 2003; Berg and Huebner 2011). In relation to the questions presented above, there could be a support element that the parole officer is not aware of (i.e., someone in the offender's life is helping them achieve long term goals or helping them realize their harm to victims). If this is the case, then it fits with what King (2013) describes as positive aspects of narrative identities, wherein the offender is able to come to terms with what they have done, and the harm they have caused victims; through social interactions.

Thus, although there are no explicit informal desistance aspects included in this code, I believe there are aspects of informal desistance present here even though they have to do with the idea of identity shifts (Maruna and Farrall 2004; Maruna, Immarigeon, and LeBel 2004; Maruna 2001).

\section{Formal Social Control}

For this particular focused code, formal social control aspects as they relate to desistance aspects quite simply come in the form of parole officers. To note, however, since I am analyzing the assessment portions of policies intended for parole officers to ask offenders, that means that for every policy, the criminal justice system in the form of parole officers is an aspect of formal control. Thus, I will not be mentioning the role of parole officer's 
subsequently below, as that would be repetitive. Instead, I will discuss this aspect for the code of "reactions and thoughts" in $C D$ 705-6.

To recap, it was found by Blasko et al. (2015) that if an offender had a positive relationship with their parole officer, they were more likely to adhere to parole conditions. This is an overarching statement, that I do not believe can be directly related to the focused code of "reactions and thoughts", but rather relates to the parole officer assessment process in general. In other words, I take this to mean that if an offender feels as though their parole officer is assessing them fairly, and understands them, then they will be more inclined to follow their conditions.

\section{"Legitimate Pathways"}

This focused code encapsulates the primary codes of "education and learning", and "employment/aspects of employment" and aims at including aspects of the assessment that have to do with the offender trying to gain skills in order to integrate appropriately into society.

Informal Social Control

Since employment is a form of informal control as it relates to desistance, I will discuss that element of "legitimate pathways" first.

In terms of informal social control, Laub and Sampson (2001) discuss how having a job contributes positively to desistance. As stated in the literature review, most studies done on desistance and employment maintain that employment contributes positively to the desistance process (Craig and Foster 2013; Verbruggen, Blokland, and Geest 2012).

Within $C D$ 705-6 there is a significant mention of employment and the role it plays in the offender's life. For example, many of the questions relate to how long an offender has held 
a job, how long they have been unemployed, if they have enough skills to be employed, and how they think of their work ethic (CSC Website, CD 705-6). An interesting point to make is that talking about skills in relation to employment I believe also brings in an aspect of strength, as it can be used to highlight what an offender is good at (CSC Website, CD 705-6). As I mention in my analysis section, these questions in this policy go further as they ask offender's if substance abuse has contributed to issues around employment (CSC Website, $C D$ 705-6). The thoroughness of this section obviously indicates that CSC is aware that employment is an important aspect of reintegration in the community (CSC Website, CD 7056).

What is interesting, however, is the fact that in this policy employment is treated "formally", in that it is referred to as a job (CSC Website, CD 705-6). But what is missing in these questions, is a more personalized level of discussion about how the offender (a) plans to adhere to their correctional plan and conditions while working, but more importantly (b) asking the offender what else they consider to be work. A parole officer or CSC could even be blunter in this case, and ask the offender how much "work" they think it would take for them to focus on not offending. This form of work is exactly what Harris (2016) discusses, as participants in her study expressed that they felt like desisting within itself was an important job.

Although I understand that these policy documents serve a bureaucratic purpose and it could be hard to write them in a way wherein a "job" can have more than one meaning, perhaps it is necessary to do so, as some research also indicates that employment is not necessarily something that turns someone from a desister to a non-desister (Farmer, McAlinden, and Maruna 2015). I also understand that from a policy perspective, the 
questions around work are only one part of what is written to be assessed in $C D$ 705-6 but I maintain that in this section a broader definition of "a job" or "work" could be beneficial for the parole officer to inquire about (CSC Website, $C D$ 705-6). This is important so they can gauge how much the offender can participate and engage in other aspects of reintegration (i.e., the correctional plan/programming) while maintaining a level of balance that allows them to focus on their goal in the community (to be prosocial).

\section{Formal Social Control}

When discussing "legitimate pathways" that offenders can partake in, education is one aspect given that it is a formal social element that children need to attend to a certain point. As explained in the literature review, dropping out of school makes someone more likely to live a life of crime (McFarland et al. 2018; Sweeten, Bushway, and Paternoster 2009). Education can also be seen as a positive aspect for ex-offenders as a way to learn and as a way to help them become employable (Vilorio 2016).

The discussion around education is prominent in that parole officers are expected to ask their offenders how far they had made it in school, and what sorts of training they have (CSC Website, CD 705-6). This is important because it gives the correctional professional an angle in which they can understand the offender's background. The rest of the information this policy tries to uncover about the offender is also vital, including asking how much difficulty they had with school related tasks such as reading or writing, if they have concentration issues, and if they had ever repeated a grade or if they were tested for a potential learning disability while in school (CSC Website, CD 705-6).

In terms of use of language around some of the main assessment prompts in regard to education, it is interesting to note that they are all in the past tense. This makes sense in 
that the parole officer is trying to understand past history of education, but it also does not try and understand the current state of the offender's learning. The policy does ask one question about if the offender "may have personal/emotional/psychological/physical issues that would interfere directly with correctional programming?", but that does not try to address the offender's educational needs directly in the moment (CSC Website, $C D$ 705-6, 51). It could be argued that it is not the parole officer's job to assess for these skills at the time of the assessment. But I argue that it could be beneficial to understand the offender's current status in relation to education (i.e., before entering the community did they write or read in prison? What kind of books did they read?). It is also possible that the offender does not know what their current status in relation to academic skills is but asking questions about it could at least shed light on the potential level the offender is at when it comes to education. Although the questions in this section seem very much so focused on the shortcomings of the offender and their weaknesses, I think they not only incorporate desistance, but as a virtue of that, can also pave the way for an offender to know what they are good at (strengths), and could also incorporate protective factors (i.e., education), despite focusing on negative aspects of learning (Nee and Vernham 2016; de Vries Robbé et al. 2015; Maruna and LeBel 2003; CSC Website, CD 705-6).

\section{"Criminal Experiences"}

This focused code is in relation to any activity the offender had or has done that can be seen as criminal or incorporates criminal aspects. As I described above, this focused code included these primary codes: "current offences/history of offences/convictions (current and past)", "previous supervision in the community", "time between incarceration", "relationship with drugs and alcohol". I will discuss them in relation to the desistance paradigm below. 
Informal Social Control

This policy incorporates some aspects of factors of informal social control in relation to desistance. This policy in numerous instances asks the parole officer to assign a score to the offender for how serious their offences were (including their current offense) — on this scale offenses like break and enter are at the lower end, whereas offences such as incest, seduction, and gross indecency are ranked the highest (CSC Website, CD 705-6). I will come back to the discussion on sexual deviances when I discuss the ways in which this policy incorporates sex offender desistance. Of interest, however, is that in this policy there is a ranking scale in which the parole officer needs to record what age they were at their first conviction as an adult (CSC Website, $C D$ 705-6). The categories are as follows: "was under 19, was 19-22 inclusive, was 23-30 inclusive, was 31-40 inclusive, was 41-49 inclusive, was over 49" (CSC Website, $C D$ 705-6, 13). These ages could be an arbitrary way to break up an age range, but it is notable how CSC includes the over 49 age range because according to the literature, the older someone is the more likely they are to desist (Laub and Sampson 2001). It is also notable that this policy does inquire about youth court and if the offender had convictions as a youth, and what their sentence was (CSC Website, $C D$ 705-6). But, the policy does not ask how old they were when the offences occurred.

For the purpose of analyzing if informal desistance is present in this policy, I would argue that in relation to age, it is. At the same time, I argue that it would not be detrimental to CSC to add a sub-section in this policy that addresses the age of which and offender was either charged or sentenced in youth court. From this information, a longitudinal study could be done, like Gluek and Gluek's (1943) study. This type of longitudinal study may not be of priority for CSC as an organization, but collecting data on youth offending (i.e., age) could be 
beneficial for a potential research avenue. I understand this information could be collected by the parole officer by simply asking the offender how many previous convictions they have had (which is a question within itself in the policy). But adding specificity to these age questions would not de-value their purpose in any way. Lastly, this policy also inquires about how long the offender has been crime free (or time between incarceration) this can also add another layer to the discussion of age, as age of offences could be hypothetically derived from how long the offender has been in and out of the prison system (CSC Website, CD 705-6).

\section{Formal Social Control}

Previous supervision in the community is addressed in Annex B (SIR-R1), Annex C (Criminal Risk Index), and Annex D (Static Factors Assessment) (CSC Website, CD 705-6). Given that parole officers can play a role in formal desistance processes it is important to discuss this in relation to formal desistance (Mills and Codd 2008). Within CD 705-6, most of the questions surrounding previous supervision ask if the supervision was federal or provincial, and if the offender successfully completed it (CSC Website, CD 705-6). This makes sense as the parole officer simply wants to assess whether or not an offender has been successful at parole before, but I maintain that it does not go far enough.

The literature clearly indicates that the relationship an offender has with a parole officer can affect desistance and recidivism (a positive relationship meant less recidivism whereas a negative relationship lends itself to the possibility of recidivism) (Blasko et al. 2015; Morash et al. 2015). I argue that in these assessments there needs to be a follow up to questions such as if the offender has had previous supervision in the community, because it can give additional insight and context to previous experiences. While I understand that these sessions are not meant to be a therapy session for the offender, the element of personable 
human interaction could be beneficial to the parole officer, and in turn the desistance process. Asking the offender what their previous relationship was with their parole officer or case management team could at least provide the current supervisor with a bit of context going into this new supervision period that could lead to a smoother transition from the institution to the community and eventually to desistance. There is also the reality that the offender may not know what worked or did not work with their previous supervision team, but that does not mean that one should not ask.

The discussion around drugs and alcohol in this policy is abundant, with a lot of the questions intending to acquire background information on the habits of the offender (how often they drink, when they started drinking, if they do drugs and alcohol together) (CSC Website, $C D$ 705-6). But this discussion is going to focus on treatment. Literature on treatment as a form of formal control is mixed: some scholars say that treatment is positive and can nurture positive social bonds between people within the group that can contribute to them understanding their past crimes (Mann, Devendran, and Lundrigan 2019), whereas in some cases mandatory treatment can lead to participants participating in hopes of a positive risk assessment (Mann, Devendran, and Lundrigan 2019; Brown 2005), or because they recognize that not participating may not be approved of (Brown 2005). Lastly, stigmatization from those running the treatment program is a reality, especially for sex offenders, which is something to consider especially in the realm of treatment (Lacombe 2008; Levins and Crewe 2015).

The literature mentioned above talks mostly about behavioural treatments that address past behaviours. In context of $C D$ 705-6 the policy mentions correctional planning programs throughout which work on behaviour modification (CSC Website, CD 705-6). Therefore, 
when discussing treatment in the context of this policy, they are targeting drug and alcohol treatment. This is done through only one question in the policy and it asks "have you ever participated in a drug or alcohol program"? (CSC Website, CD 705-6, 38).

This question could have more natural follow-ups in conversation, however despite this it would also be a good idea to have questions written down about how the offender thought those programs went, what worked for them or what did not work for them and how they felt after the program. Even if the parole officer deems that the offender should go to mandatory programming, it would still be wise to investigate in detail what interventions have been done.

To expand, research shows that substance abuse and desistance are related, and that treatment programming works for offenders in most cases (Maruna 2001; Bahr et al. 2012; Davis, Bahr, and Ward 2012), therefore some more questions are warranted. The questions could be: Did anyone support you during the treatment process? How did you find the treatment process affected you personally (i.e., how do you feel about treatment)? How would you feel about going back to treatment? What specific aspects of treatment worked for you? What aspects did not work? To conclude, research also indicates that those who go to behavioural treatment can feel like they had to in order to appear lower risk, while also feeling stigmatized from this process (Mann, Devendran, and Lundrigan 2019; Brown 2005; Lacombe 2008; Levins and Crewe 2015). This could also be the case for substance abuse treatment, which is why the questions I posed above would lend themselves to an assessment process that not only takes into account desistance but have a more personal and caring element to them. However, I also realize that because the parole officer is asking these questions, the offender may already feel like they are going to be stigmatized, therefore answers may not be reflective 
of the offender's thoughts on the matter.

\section{"Connections to Society"}

This focused code brings together the primary codes of "relationships/support in general", "relationship history", and "situational factors". Due to this, this discussion will focus on informal aspects of social control in relation to desistance.

\section{Informal Social Control}

This policy focuses greatly on relationships. For example, marital status is inquired about multiple times; questions about having and maintaining intimate relationships are present along with questions relating to spousal abuse (CSC Website, CD 705-6). Most research indicates that marriage and relationships can contribute to desistance (King, Massoglia, and Macmillan 2007; Laub and Sampson 2003). In reference to my analysis section above, specifically Annex E (pages 29-30) it is evident that questions in this policy around relationships are in-depth and clear and cover a range of issues that could arise in intimate relationships (CSC Website, CD 705-6).

Social bonds and social support networks are also important for offenders as indicated by Cullen (1994) and Lin (1986), as they can help the offender reintegrate in the community. In this discussion, relationships and support are not just in reference to romantic relationships, but to other relationships as well. $C D$ 705-6 does a good job of asking about prosocial family and friend support with questions such as "Are you close to your family? Have they ever helped you out when you needed it?, Have your friends ever helped you out when you needed it (money, talk to them about a problem)?" (CSC Website, CD 705-6, 34). Within this policy there are also questions about community, if the offender seeks support from the community, and in which ways (CSC Website, CD 705-6). These questions also ask about spare time, and 
if the offender volunteers in the community (CSC Website, CD 705-6).

Furthermore, $C D$ 705-6 has a section that discusses parenting, including asking if the offender is a parent, if they have difficulties handling being a parent, and if they have neglected or abused their child (CSC Website, CD 705-6). This is important and encompasses informal social control because as Gadd and Farrall's (2004) research demonstrated, some of the men interviewed who had a criminal history (and eventually worked towards desistance), were abused as children. Although for these men this abuse was something they did not want to pass on to their children, it was still a factor in their life that affected social bonds they had with their own parents (Gadd and Farrall 2004). Therefore, inquiring about parenting is another way $C D$ 705-6 incorporates aspects of informal social control (CSC Website, CD 705$6)$.

Moreover, "situational factors" also encompass aspects of informal social control in the form of support. The questions in the policy are if the offender has criminal friends or acquaintances and if they live in a high crime area (CSC Website, CD 705-6). These topics have to do with support and community (both in the supportive sense, and in the physical environment sense) (CSC Website, CD 705-6) There are also questions that relate to finances, specifically if the offender is using social assistance (CSC Website, CD 705-6). Social assistance is an aspect of community "help" and support from the government which is why it is applicable to discuss in this code.

It is clear that $C D$ 705-6 covers its bases well when it comes to informal social control and factors that relate to desistance. The questions outlined that deal with support do so on multiple levels that show that support is not just from interpersonal relationships.

\section{Sex Offender Desistance}

Above, I specifically discussed general desistance in relation to the assessment portion 
of $C D$ 705-6. In this sub-section I am going to look more closely at sex offender desistance. This policy has the Sex Offence History Checklist included within it which is where this discussion is going to start (CSC Website, CD 705-6). From there I will discuss other aspects of sex offender desistance that were noticeable throughout the policy. Something important to note, however, is that this policy is the only policy of the four analyzed for this project that has its own sex offender section. Because of this, the discussion around sex offender desistance in relation to the other policies below will not be structured in this way and will not necessarily contain as much detail.

Sex Offence History Checklist $C D$ 705-6

The Sex Offender History Checklist in $C D$ 705-6 is short and not extremely thorough. It starts by inquiring if the offender has a sexual offense history or if they are currently serving time for a sexual offence (CSC Website, CD 705-6). Then, the policy asks for what kind of sexual offence the offender committed: "incest?, paedophilia?, sexual assault?, other previous sex offence(s) (voyeurism, exhibitionism)?" (CSC Website, CD 705-6, 24). Next, the parole officer is to ask the offender how many victims they have had, before asking the age of the victims, and if they were male or female (CSC Website, CD 705-6). And lastly, the checklist asks if the offender has been to treatment: "prior psychological/psychiatric assessments in relation to sex offences?", "prior treatment/intervention in relation to sex offending?", "current treatment/intervention in relation to sex offending?" (CSC Website, CD $705-6,24)$

From reading this checklist it is quite obviously a surface level information tool to gather a better understanding of sex offences in particular. Since it is part of the bigger assessment it is more than safe to assume that the parole officer knows, for example, the age 
of the offender because that was asked previously in Annex B (SIR-R1) (CSC Website, $C D$ 705-6). Thus, in situations such as this, the parole officer is capturing informal aspects of social control, and if the offender happens to be a sex offender the information already collected can be complied with that of this checklist.

Thus, the biggest issue noticeable within the checklist is the fact that it asks many yes or no questions. For this discussion I believe that it is important to focus on the treatment aspect of the list. These questions within themselves are beneficial to ask, but just as I critiqued the other part of $C D$ 705-6 for not adding a personal element when talking about treatment, I think that is still applicable here. In reality it is more relevant here because sex offenders are extremely ostracized from society, and when it comes to getting treatment for their sexual tendencies, they feel stigmatized (Lacombe 2008; Levins and Crewe 2015). Therefore, I believe that the parole officer should discuss how the offender feels about treatment, how treatment has gone for them in the past, and how the offender feels about the prospect of being in the community. I understand that these questions within themselves could contribute to the stigma sex offenders face in society, but they are still worth asking because in the long run the information the parole officer gathers could further help the offenders in the community. Community questions are vital because there are programs in the community geared towards helping sex offenders such as CoSA, but the offender needs to feel comfortable in that treatment and community situation.

Other Aspects of Sex Offender Desistance

There are other aspects of sex offender desistance that should be added to the Sex Offender Checklist. I am making the argument that these additions should be added to the checklist instead of just being added to the other Annexes in the policy because although sex 
offender desistance has certain aspects that overlap with general desistance, there are also more factors to consider (e.g., stigma) which means sex offender desistance is not the same and needs to be paid extra attention to (see Griffiths 2015 for a discussion around Not in my Backyard). Therefore, if an offender is being assessed to be released into the community, assessments on sex offending that should include desistance.

Above, I praise $C D$ 705-6 for doing a respectable job of assessing informal social control as it relates to desistance, specifically in relation to social bonds (CSC Website, $C D$ 705-6). Social bonds such as marriage and family are seen as important to sex offenders (McAliden, Farmer, and Maruna 2017; Mills and Codd 2008; Visher and Travis 2003). Many of the questions presented around family and marriage touch on violence, relationship commitment and length, which is ideal (CSC Website, CD 705-6). However, I argue that in the Sex Offender History Checklist, questions around social bonds should include if the offender has ever offended towards family or friends, if their family or friends also have sexual offending habits, and if their family and friends are aware of the offender's own sexual offence history. These questions are extremely personal, but it would be in the parole officer's best interest to know what the offender's relationship with their family is, because that could lead into a discussion on who their support network is. This is also vital because sex offender movement can be restricted both physically (sex offender registries) and emotionally (if they have offended against family) (Mann, Devendran, and Lundrigan 2019; Hipp, Petersilia, and Turner 2010).

I mention above that $C D$ 705-6 includes questions on support in terms of situational factors such as living accommodations and finances (CSC Website, CD 705-6). Although a parole officer will eventually get to that section of the assessment since it is not included in 
the Sex Offender History Checklist, I believe that living accommodations is an aspect of support that needs to be added to the checklist. In the context of the Sex Offender History Checklist it would be beneficial to ask if they ever ran into issues with housing before, if they have anywhere safe to go wherein they will not victimize past victims, and if they do not have any options questions should be geared towards where they would like to live. None of these questions address the fact that landlords are not always supportive of sex offenders moving into their properties (Evans and Porter 2015), or that finding somewhere to live can be difficult because of sex offender registries (Tewksbury 2005; Mann, Devendran, and Lundrigan 2019), but they do contextualize the past experiences that sex offenders have had. This in turn can shed light to the parole officer on how they may act in certain situations (if they have had a hard time finding housing before, or if they have been turned away from housing this could be a "trigger" for them and could potentially further derail the desistance process).

When examining the ways in which $C D$ 705-6 evaluates employment, I maintain that it is thorough, but I also comment on how it should include more than just discussion about jobs in the "formal" sense. This makes sense for general desistance, but it does not necessarily make sense for sex offender desistance. What the Sex Offender History Checklist needs is a section on jobs wherein the parole officer can ask similar questions that were posed in the other assessments (i.e., about job skills and work ethic), but also a section on where the offender would feel comfortable working, and how they would navigate a conversation on their offense history should it come up. Not only do sex offenders have the initial barrier of getting hired due to the stigma of their offense (Graffam, Shinkfield, and Hardcastle 2008; Varghese et al. 2010), they are so stigmatized in the community (Griffiths 
2015) that it is not unreasonable to assume that even if they get a job, if their history becomes public that will cause a public scene. The questions about employment could also be a precursor to introducing programs such as CoSA to the offender as a potential avenue to help them, if they agree. Lastly, through employment, a sex offender can also form positive and pro social bonds, and this could also be beneficial for their reintegration.

\section{Summary CD 705-6}

The purpose of this section is to summarize what has been discussed in relation to $C D$ 705-6 and my suggestions in relation to the desistance paradigm. This section will also break up the summary in terms of informal social control and formal social control. There will be a discussion of the risk paradigm at the end.

Informal Social Control

Starting with general desistance, $C D$ 705-6 does an effective job at incorporating an avenue for secondary desistance (Maruna 2001) to eventually be present by asking offenders about their thoughts and perceptions about their offence and other situations (CSC Website, $C D$ 705-6). Further, when discussing employment, $C D$ 705-6 does ask questions that incorporate many important aspects of the employment process (skills, teamwork, work ethic), but I suggest that it also take Harris's (2016) research into account and inquire about nonformal aspects of work (CSC Website, $C D$ 705-6). The questions on employment also incorporate an avenue to look at an offender's strengths, which as mentioned above is deemed important by many scholars such as de Vries Robbé et al. (2015), and Maruna and LeBel (2003). Thirdly, while age and offence type are addressed within the assessment portion of this policy, paying more attention to youth age at first offence would be beneficial from a research perspective to understand continuity of offending (CSC Website, CD 705-6). Lastly, the 
assessment portion of $C D$ 705-6 understands the multi-layered complexity of social bonds and makes this abundantly clear through asking questions that include topics such as relationships, family (including parenting), friends, and community connections (CSC Website, CD 705-6).

\section{Formal Social Control}

In terms of formal social control, this policy deals with parole officer involvement which within itself is an element of formal social control (CSC Website, CD 705-6). In terms of education, this policy asks adequate questions about how the offender thinks they learn, and about their previous learning experiences, but fails to try and gauge their current abilities when it comes to academics (CSC Website, CD 705-6). These discussions could foster a more strength-based approach in the policy (CSC Website, CD 705-6). Thirdly, within the policy there is a section on previous supervision in the community that touches on the outcome of that supervision in a legal sense (i.e., was it completed?), but no attention is paid to the parolee/parole officer relationship, which is important because the dynamics of that relationship can affect offending (Blasko et al. 2015; CSC Website, CD 705-6). Lastly, treatment was discussed in this policy, but it did not go any further than asking if the offender had received treatment (CSC Website, $C D$ 705-6). I make the point that questions should be more personalized in order for the parole officer to understand how that process went, given that offenders could feel like they have to attend treatment especially if they feel that is the only way to have a positive risk assessment (Mann, Devendran, and Lundrigan 2019; Brown 2005).

Sex Offender Desistance

Within $C D$ 705-6 aspects of sex offender desistance should be added to the Sex Offender History Checklist. Below, I will discuss those different aspects in relation to 
informal and formal social control.

Informal social control. As mentioned above, $C D$ 705-6 includes questions about social bonds quite thoroughly in other Annexes, and this should be added to the Sex Offender History Checklist (CSC Website, CD 705-6). But, more importantly, the checklist should include questions about if the offender has family or friends that know about their sex offence history and if those people are supportive (CSC Website, CD 705-6). This is a vital question simply based on the fact that sex offenders can be restricted in many ways that other offenders are not, therefore understanding how close they are to the community is imperative (Mann, Devendran, and Lundrigan 2019; Hipp, Pertersilia, and Turner 2010). Lastly, the Sex Offender History Checklist should include questions about employment geared to the reality of social outcry and ingrained negative attitudes towards sex offenders, and the barriers sex offenders face in the community, and professionally (Griffiths 2015; Graffam, Shinkfield, and Hardcastle 2008; Varghese et al. 2010).

Formal social control. In terms of informal social control and sex offender desistance, the Sex Offender History Checklist should include more questions about treatment, as it only currently includes a few that are not detailed (CSC Website, CD 705-6). This is the same critique I gave the non sex offender aspects of the assessment portion of this policy, but it is even more important here, because as reiterated many times throughout this paper, sex offenders can be stigmatized especially in a treatment setting (CSC Website, CD 705-6; Lacombe 2008; Levins and Crewe 2015). Thus, knowing how they feel about treatment including their past experiences could help ease anxiety levels for them and help the parole officer acquire the appropriate context needed to know how to help them. Lastly, the Sex Offender History Checklist needs to further inquire about housing and accommodations in the 
way in which the other portions of the policy do (CSC Website, CD 705-6). This is because asking questions about accommodations ties in aspects of social bonds to the community, which can be very difficult for sex offenders to maintain because many people do not want them living in their neighbourhoods or on their property, and sex offender registries also restrict movement for sex offenders, making finding living arrangements harder (Evans and Porter 2015; Tewksbury 2005; Mann, Devendran, and Lundrigan 2019).

Risk

The purpose of this discussion section was to discuss the concept of desistance specifically as it relates to $C D$ 705-6 (CSC Website, $C D$ 705-6). However, in my analysis section I engage with a simple narrative of how risk, or rather aspects of the risk paradigm either do or do not play into the primary codes for this policy (CSC Website, $C D$ 705-6). In this section I am going to go into some detail around the risk narrative. To be clear, I will be discussing the primary codes in the order they are presented in the analysis section as that is how risk was introduced. Sex offending was not its own primary code which is why risk was not discussed in relation to sex offending and $C D$ 705-6 in the analysis section (CSC Website, $C D$ 705-6). Thus, in this summary section on risk, there will be a small discussion on how sex offender desistance also plays into the risk narrative. This is important because it highlights the parallel nature of risk and desistance in particular instances within the $C D$ 705-6.

In terms of discussing "current offences/history of offences" and "previous supervision in the community" both of these codes have the ability to predict risk as escalation of offences and failure to successfully complete previous supervision can be a risk factor (CSC Website, $C D$ 705-6). This is especially true given that an individual who commits crime, and who fails at community supervision could be exhibiting signs of history of anti-social personality, anti- 
social behaviour, and anti-social cognitions (Andrews and Bonta 2010; Healy and O'Donnell 2006; Palmer and Hollin 2004; Boduszek et al. 2013; Whited et al. 2015).

In terms of "time between incarceration", I believe that it is a purely desistance question that is being asked in this policy especially considering the idea that desistance is a process (Maruna and Farrall 2004; Maruna, Immarigeon, and LeBel 2004). The discussion around "victims/injury to victims" has a desistance aspect in my opinion (especially given the questions asked around empathy and understanding), and a risk aspect as severity of harm to victims could potentially indicate risk the individual has in the community to harm again.

"Relationships/support in general" and "relationship history" both have desistance aspects (i.e., reduce offending as per the desistance literature (see King (2013)) for more information). Relationships and marital circumstances are also shown to relate to reducing risk of offending (see Lo and Zhong 2006 or Sampson, Laub and Wimer 2006). In both instances it is important however that relationships (whether they would be with romantic partners or friends) be prosocial (see Kras 2019 and Visher and Courtney 2007 for desistance literature indicating why this is important) and refer to Boduszek et al. 2013 and Whited et al. 2015 as to how anti-social associates lead to criminal activity (i.e., is also a risk).

"Relationship with drugs and alcohol", while being a desistance factor, is also a factor associated with risk to offend or re-offend (Andrews and Bonta 2010; Vaughn 2011; White and Gorman 2000). Furthermore, "personal interpretations of situations/feelings/reactions to an event" is more desistance based which is what I explained above. "Personal personality characteristics" are both risk and desistance focused (i.e., contain aspects from both paradigms). When looking at risk specifically, this code, and 
everything encapsulated within this code, can lend itself to the parole officer looking at aspects of characteristics such as anti-social personality or anti-social cognitions that are risk factors for recidivism (CSC Website, CD 705-6; Andrews and Bonta 2010; Caspi 2000; Mandracchia et al. 2007). Furthermore, the information included in the primary code "situational factors" is not necessarily risk based in the ways in which Andrews and Bonta (2010) outline risk factors, but rather these questions act like background informational questions (i.e., is the offender associating with anti-social associates).

Lastly, "education and learning" and "employment/aspects of employment" include elements of both the risk and desistance paradigm. It encapsulates aspects of risk because education can act as a diversion away from crime (Hansen 2003; Lochner 2004; Taheri and Welsh 2016). Employment can be seen as being included in the risk paradigm because obtaining employment negates the risk of an offender recidivating because they have something to do (Benda, Harm, and Toombs 2005).

For this policy I had a lot of suggestions on how to make the sex offender desistance aspect clearer and more detailed, thus, I will not repeat these suggestions. However, the one aspect this policy's Sex Offender History Checklist did have was a question on treatment (CSC Website, $C D$ 705-6). Although I suggest there should be more questions on this subject, the fact it is presented means CSC understands substance abuse is a risk factor of which to be cognizant (CSC Website, $C D$ 705-6; Andrews and Bonta 2010).

Code Summary

Above, I present information in relation to how the codes for $C D$ 705-6 encompass desistance paradigm aspects, risk paradigm aspects, and sex offender desistance. In the table 
below, I summarize these findings in relation to the focused codes, and then make a

determination as to whether the focused codes are more desistance or risk based.

Table 10: $C D$ 705-6 Code Summary

\begin{tabular}{|c|c|c|c|c|}
\hline $\begin{array}{l}C D \text { 705-6 } \\
\text { Focused Codes }\end{array}$ & $\begin{array}{l}\text { Main } \\
\text { Desistance } \\
\text { Paradigm } \\
\text { Factors } \\
\text { Included }\end{array}$ & $\begin{array}{l}\text { Sex Offender } \\
\text { Desistance }\end{array}$ & $\begin{array}{l}\text { Main Risk } \\
\text { Paradigm } \\
\text { Factors } \\
\text { Included }\end{array}$ & $\begin{array}{l}\text { Desistance or } \\
\text { Risk Paradigm } \\
\text { Dominated? } \\
\text { Or Both? }\end{array}$ \\
\hline $\begin{array}{l}\text { Reactions and } \\
\text { Thoughts }\end{array}$ & $\begin{array}{l}\text { Reflective nature } \\
\text { of the questions } \\
\text { and aspects in } \\
\text { this code could } \\
\text { lead to } \\
\text { secondary } \\
\text { desistance (see } \\
\text { Maruna 2001). }\end{array}$ & $\begin{array}{l}* * \text { Throughout } \\
\text { this policy there } \\
\text { is a sex offender } \\
\text { checklist, and } \\
\text { although more } \\
\text { could be added } \\
\text { to it, it does } \\
\text { include aspects } \\
\text { of sex offender } \\
\text { desistance. }\end{array}$ & $\begin{array}{l}\text { Main risk } \\
\text { aspects here are } \\
\text { the idea that an } \\
\text { offender's } \\
\text { thoughts could } \\
\text { be very rooted in } \\
\text { anti-social } \\
\text { cognitions, for } \\
\text { example } \\
\text { (Andrews and } \\
\text { Bonta 2010) }\end{array}$ & $\begin{array}{l}\text { Aspects of both, } \\
\text { but more } \\
\text { desistance } \\
\text { paradigm } \\
\text { focused. }\end{array}$ \\
\hline $\begin{array}{l}\text { Legitimate } \\
\text { Pathways }\end{array}$ & $\begin{array}{l}\text { Desistance } \\
\text { factors in } \\
\text { relation to } \\
\text { employment } \\
\text { (Craig and } \\
\text { Foster 2013), } \\
\text { and education } \\
\text { (see McFarland } \\
\text { et al. 2018). }\end{array}$ & & $\begin{array}{l}\text { Can be risk } \\
\text { based since } \\
\text { education can } \\
\text { contribute to } \\
\text { living a crime } \\
\text { free life (see } \\
\text { Hansen } 2003 \text { for } \\
\text { example), and so } \\
\text { can education } \\
\text { (Benda, Harm, } \\
\text { and Toombs, } \\
\text { 2005). }\end{array}$ & Both. \\
\hline $\begin{array}{l}\text { Criminal } \\
\text { Experiences }\end{array}$ & $\begin{array}{l}\text { The desistance } \\
\text { paradigm is } \\
\text { included in that } \\
\text { there is mention } \\
\text { of age (Laub and } \\
\text { Sampson 2001). }\end{array}$ & & $\begin{array}{l}\text { Many aspects } \\
\text { here including } \\
\text { how past } \\
\text { offences and } \\
\text { previous } \\
\text { supervision } \\
\text { could be rooted } \\
\text { in risk factors } \\
\text { such as history } \\
\text { of anti-social } \\
\text { personality or } \\
\text { anti-social } \\
\text { cognitions } \\
\text { (Andrews and }\end{array}$ & $\begin{array}{l}\text { Aspects of both, } \\
\text { but more risk } \\
\text { paradigm } \\
\text { focused. }\end{array}$ \\
\hline
\end{tabular}




\begin{tabular}{|l|l|l|l|}
\hline & & & $\begin{array}{l}\text { Bonta 2010). } \\
\text { Time between } \\
\text { incarceration is } \\
\text { desistance based } \\
\text { and relates to the } \\
\text { idea that } \\
\text { desistance is a } \\
\text { process (Maruna } \\
\text { and Farrall } \\
\text { 2004). }\end{array}$ \\
\hline $\begin{array}{l}\text { Connections to } \\
\text { Society }\end{array}$ & $\begin{array}{l}\text { Focus on support } \\
\text { including } \\
\text { aspects like } \\
\text { marriage (see } \\
\text { Laub and } \\
\text { Sampson 2003 } \\
\text { for example, and } \\
\text { social } \\
\text { bonds/support } \\
\text { (Cullen 1994). }\end{array}$ & $\begin{array}{l}\text { More desistance } \\
\text { based but can be } \\
\text { both because } \\
\text { relationships for } \\
\text { example can } \\
\text { reduce risk of } \\
\text { offending (see } \\
\text { Lo and Zhong } \\
\text { 2006) for } \\
\text { example. }\end{array}$ & $\begin{array}{l}\text { Aspects of both, } \\
\text { but more } \\
\text { desistance } \\
\text { paradigm } \\
\text { focused. }\end{array}$ \\
\hline
\end{tabular}

\section{715-1: Community Supervision}

This policy included seven primary codes and three focused codes. The focused codes were "connections to society", "deviant behaviours", and "comprehension of realities". This part of the discussion section will, like above, relate these codes to the concept of desistance. Of note, as has already been said throughout this paper, the $C D-715$ series policies are shorter and make reference to $C D$ 705-6, therefore this discussion on this policy may refer to the discussion of $C D$ 705-6.

\section{"Connections to Society"}

This focused code included the primary codes of "support" and "current situational factors". Of note is that this theme also emerged in CD 705-6 and will also be a theme in CD 715-3.

Informal Social Control 
In terms of support, in Annex C (Rating Reassessment Framework) one of the four criteria for intervention based on static factors is talking to collateral contacts that could help with supervision (CSC Website, CD 715-1). The Rating Reassessment Framework also takes into consideration the SIR-R1 (Annex B), and the Static Factors Assessment (Annex D) of $C D$ 705-6 (CSC Website, CD 715-1). And furthermore, in looking at dynamic factors of intervention it is stated in this policy that the parole officer should "look at changes in personal situation" and this could include aspects such as support (CSC Website, CD 715-1, 13). This policy also states that when looking at dynamic factors the parole officer should look at "progress related to the correctional plan" (CSC Website, CD 715-1, 13).

The outline for the correctional plan is in $C D$ 705-6 and includes the Static Factors Assessment (Annex D), and the DFIA-R (Annex E) (CSC Website, CD 705-6). Therefore, in $C D$ 715-1 the same in-depth questions are not re-covered. In relation to support, given that $C D$ 715-1 references Annex B, D and $\mathrm{E}$ of $C D$ 705-6 there is not much that has not been covered if one counts the policies together (CSC Website, $C D$ 705-6, CSC Website, $C D$ 715-1). But, specifically in relation to $C D$ 715-1 it would be ideal to expand on collateral contacts and actually list "friends, family, community members" (this could also be done in a yes or no format, if desired) (CSC Website, $C D$ 715-1). This is because family and friends can provide support in relation to desistance (King 2013; Kras 2019). A small change that could also be made to CD 715-1 is actually expanding on what "personal situation" means when trying to reassess based on dynamic factors (CSC Website, CD 715-1, 13).

When looking at situational factors, there are some aspects that relate to social bonds. For example, $C D 715-1$ is supposed to ask what the offender's "proximity to criminal/gang 
activity" is and if they live in an area that is "restricted to outside intervention" (CSC Website, $C D 715-1,11)$. Asking about gang activity is a gateway to understanding the types of people the offender associates with, and therefore has connections with. This is ideal in relation to desistance because although friends are an important part of a social network for offenders (Kras 2019), it has also been pointed out that sometimes an offender's friends have anti-social tendencies and have committed crimes themselves, which is not ideal for someone who is on community supervision and who wants to desist (Visher and Courtney 2007).

Furthermore, inquiring about if the offender lives somewhere remote or restricted is beneficial because these factors can affect desistance (CSC Website, CD 715-1). For example, employment can contribute to desistance (Craig and Foster 2013; Verbruggen, Blokland, and Geest 2012), but if an offender lives somewhere remote, having access to a place where they can be employed could be difficult. Furthermore, if they live in an isolated area this could also affect their social life; it will be harder for them to create social bonds in the first place, which could hinder desistance. In this way, $C D$ 715-1 does an adequate job of asking questions that encompass aspects of the desistance paradigm (CSC Website, CD 715-1).

\section{Formal Control}

This focused code does not include many formal control aspects. Above, I mention how asking about "restricted access to outside intervention" includes aspects of informal social control such as social bonds (CSC Website, CD 715-1, 11). This is true, however, my criticism of this question is that it does not outline what "intervention" means, and who exactly is intervening (CSC Website, $C D$ 715-1, 11). In other words, does intervention in this context mean access to community services including treatment? Or, could it relate to intervention such as parole officers, and their ability to access an offender if they need to 
make a home visit?

Assuming that this question is referring to intervention as treatment or community services, then the question does relate to desistance in that treatment can help foster desistance, therefore it would be beneficial for an offender to live somewhere wherein they could get treatment (Mann, Devendran, and Lundrigan 2019). Furthermore, if intervention relates to the ability of parole officers to make home visits and check up on their clients, then this question also incorporates elements of formal social control and desistance, as the rules of the criminal justice system can shape and change offender behaviour (Paternoster and Bushway 2009).

\section{"Deviant Behaviours"}

This focused code encompassed the primary codes of "history of illegal behaviours" and "current behaviours perceived as negative". In reality these codes bring together aspects of an offender's prior criminal life, and their current status.

\section{Informal Social Control}

This policy covers if the offender has "history of violence, weapons use, predatory behaviour and previous hostility or assault on staff" (CSC Website, CD 715-1, 10-11). All of these aspects are important, and in $C D$ 705-6, Annex B (SIR-R1) touches on the historical offence factors more so than this policy which is asking questions to elicit a yes or no answer (CSC Website, $C D$ 705-6). At the same time, in order to have more thorough questions in the assessments in $C D$ 715-1 I recommend that there would be some more context included in these questions, as the continuity of offending is not only important for research on desistance, but is also a factor in the desistance process (Robins 1966).

Social bonds are also prevalent when analyzing the informal social control aspects of 
$C D$ 715-1. Specifically, this policy asks if the offender "has links to organized crime/gangs, etc." (CSC Website, CD 715-1, 11). Like mentioned above, the question around gangs, and whether the offender is linked to gangs or is in proximity to gangs is important because said activities could not only hinder desistance, but association with people who are part of organized crime and gangs are not conducive to prosocial behaviour. This policy also asks if the offender's collateral contacts are "hostile" or "uncooperative" (CSC Website, CD 715-1, 11). Although this does not have to do with the offender specifically this question does highlight aspects of social bonds in that that collateral contact could be friends or family, or someone from the community.

Regardless of who they are, this question is beneficial, but could potentially be followed by follow up questions. These questions could be directed at the offender (i.e., asking them why they think their community contact is hostile), or at the contact themselves (i.e., asking them why they are hostile). I understand that this assessment is not a narrative in that longer answers are not required and yes or no answers are ideal, but $C D$ 705-6 does not cover many aspects of collateral contacts, therefore this is important. I maintain it is important from an offender's perspective because it could have the ability to foster secondary desistance; something that was also mentioned under the "reactions and thoughts" focused code for $C D$ 705-6, wherein I discuss how personal reflective questions could kickstart the secondary desistance narrative shift (Maruna 2001; CSC Website, CD 705-6).

Lastly, this policy asks about the "instability of intimate relationships" in a yes or no manner (CSC Website, CD 715-1, 11). I would argue that this should be expanded, however, given that $C D$ 705-6 discusses intimate relationships successfully, I do not feel it is needed in this case. Another reason for this is the fact that asking about intimate relationships requires 
more than a few follow up questions unlike those that I suggested above, such as expanding on what intervention means, or expanding the scope of collateral contacts (CSC Website, $C D$ $715-1)$.

Formal Control

In terms of formal control, this code for $C D$ 715-1 does not present with many thorough elements. However, what can be noticed is that there are questions that ask about "the relationship between intoxicants and violent behaviour" and if the offender has "mental health issues" (CSC Website, CD 715-1, 10-11). None of these ask about intervention or past intervention blatantly, but they could lend themselves to aspects of formal control. In other words, although these are yes or no questions, a yes answer to one of these questions could explicitly lead a parole officer to requesting that an offender attend treatment while in the community. Treatment has been discussed above as having mixed results when it comes to desistance, because it can be another avenue wherein an offender can be stigmatized (Lacombe 2008; Levins and Crewe 2015).

\section{"Comprehension of Realities"}

This focused code includes the primary codes of "personal understanding about event/personal behaviours", "learning/behaviour adaptations" and "responsivity and learning styles".

\section{Informal Social Control}

Informal social control aspects are the most prominent in this policy because the information that corresponds with these codes falls into the Accountability, Motivation, and Engagement sections of Annex C in CD 715-1 (CSC Website, CD 715-1). In my analysis section I describe in detail what is included in these sections, therefore, in this discussion 
instead of repeating said justifications, I will focus more on how they contribute or do not contribute to desistance.

To start, these three mini sections in Annex $\mathrm{C}$ focus on if the offender can understand what they did is wrong, if they can point out their behaviours that are not acceptable, if they want to change, and how they are progressing with that change (CSC Website, $C D$ 715-1). I would not go as far as saying that these assessment statements could foster secondary desistance within the offender, like I argued above for aspects of $C D$ 705-6, despite the fact that these sections incorporate some aspects of personal reflection (Maruna 2001; CSC Website, $C D$ 705-6; CSC Website, $C D$ 715-1). Some of the statements such as "institutional adjustment and/or behaviour under community supervision", "understanding and commitment to their relapse prevention" and "level of comfort with problem and its impact on the offender's life" do, however give the parole officers insight into their state of mind (CSC Website, $C D$ 715-1,14). This could help the parole officer communicate to the offender in ways that could not only perpetuate knowledge or willingness around identity change, but around next steps on how to get there. Unlike the pointed and reflective questions in $C D$ 705-6 that were directed at the offender, these statements in $C D$ 715-1 are less invasive on the offender's life, which is why they may not directly foster secondary desistance (Maruna 2001; CSC Website, CD 705-6; CSC Website, CD 715-1). Thus, the difference here comes down to the level of detail in $C D$ 715-1, versus $C D$ 705-6 in relation to reflective questions or statements. Given that this level of detail is presented well in $C D$ 705-6, I uphold that there is not a need to change this section of $C D$ 715-1.

Formal Social Control

In $C D$ 715-1, the factors listed for responsivity are identical as in $C D 705-6$, minus 
the potential interview prompts (CSC Website, $C D$ 715-1; CSC Website, $C D$ 705-6). In $C D$ 715-1 Annex C is intended for the parole officer to reassess what was already assessed from the Intake Assessment Process (including the SIR-R1, Static Factors Assessment, DIFA-R) in $C D$ 705-6 (CSC Website, $C D$ 715-1; CSC Website, $C D$ 705-6). Thus, having the responsivity factors listed without the detail of the interview prompts is adequate for this policy as parole officers can refer to $C D$ 705-6 if they have prompts that they would like to re-ask (CSC Website, CD 715-1). With this being said, my criticism from above (CD 705-6) still stands (i.e., policies should inquire about an offender's current academic level), however the Community Supervision policy is not the policy to which to add these additions, as its reference point is $C D$ 705-6 (CSC Website, $C D$ 715-1).

\section{Sex Offender Desistance}

CD 715-1 does not have a dedicated sex offender section. Therefore, this section will discuss if there are aspects of sex offender desistance present in this policy despite the fact that there is no section to reference on the topic. Of note, however, is that since this Community Supervision policy has a reassessment section (Annex C), parole officers are told to review aspects of $C D$ 705-6 including ratings "on the Statistical Information on Recidivism Scale, criminal history record, offence severity record, sex offence history, detention criteria" which "produces a reliable estimate of the probability and severity of re-offending" (CSC Website, CD 715-1, 12). Thus, the Sex Offender Offence History Checklist is included as something that the parole officer should reference when filling out sections of CD 715-1 (CSC Website, $C D$ 715-1). With this in mind, my previous analysis on $C D$ 705-6's Sex Offence History Checklist still stands (CSC Website, CD 705-6).

To compliment that above analysis of this policy, I have noticed two factors that are 
present in $C D$ 715-1 that would be relevant to discuss as they would be relevant questions to ask sex offenders. To start, $C D 715-1$ asks if the offender is in a "remote location" or has "restricted access to outside intervention" (Annex B) (11). Both of these questions incorporate aspects that would be prevalent for sexual offenders, in that sex offenders could live in remote locations because they legitimately cannot go anywhere else due to sex offender registries (or other geographical restrictions), coupled with other stigmas associated with their offence (Tewksbury 2005; Mann, Devendran and Lundrigan's 2019; Griffiths 2015). Hanson and Morton-Bourgon (2004) discuss how sex offenders recidivism predictors could include having an unstable life and living in a remote area could contribute to a lifestyle that is not stable (it would also be very hard to establish a routine if you are living in a rural area).

Thus, I suggest that this question be expanded more. I do not think there is a need to create a sex offender "section" in this policy, but I do believe that factors that relate to sex offenders should be noticed, and at least expanded on slightly. Therefore, for this assessment criteria the parole officer could expand as they see fit (and this could include simply asking the offender if there is a reason they live in a remote area). Given that Annex C tells the parole officer to take into account sex offending criteria, Annex B questions do not have to be that in depth other than a simple follow up (CSC Website, CD 715-1).

Lastly, having "restricted access to outside intervention" could also be the reality for sex offenders because of registries (CSC Website, CD 715-1, 11). This understandably could limit their ability to reintegrate, but is also a barrier to reintegration. Above, I interrogate and question what intervention could mean in this context. If it means treatment, this could be a good question to ask sex offenders because if they do have restricted access to outside 
intervention that means that they may not have access to treatment. Although research is mixed as to whether treatment is beneficial to sex offenders (see Brown 2005 for research on sex offender treatment and how offenders feel not participating could be seen as negative, and Harris 2017 for research on how treatment is beneficial for desistance in sex offenders), it could be worth it to ask sex offenders if they feel having restricted access to intervention is going to hinder their reintegration, or if they feel it is going to be a barrier for them going forward in the community. I realize that Annex $\mathrm{C}$ already discusses taking sex offender history into account, but I suggest that $C D$ 715-1 could incorporate more aspects of sex offender desistance throughout (like expanding on the specific criteria mentioned above), rather than just relying on $C D$ 705-6 (CSC Website, $C D$ 715-1).

With this being said, this policy does have at least some aspects of sex offender desistance present throughout even though they are not labelled as such.

\section{Summary CD 715-1}

This section will summarize the discussion portion of $C D$ 715-1 to highlight the main points as they relate to desistance.

Informal Social Control

This policy should expand on both collateral contacts, and what a personal situation is (CSC Website, CD 715-1). But more importantly, in relation to collateral contacts, it would be beneficial if the policy asked the offender about their relationship with the collateral contacts to foster an aspect of reflection and a further narrative shift (CSC Website, CD 715-1; Maruna 2001). This policy also does a good job at inquiring about social bonds especially in relation to people offenders could associate with that would not foster desistance (i.e., those in gangs) (CSC Website, $C D$ 715-1). Furthermore, inquiring about where the offender lives also 
incorporates aspects of social bonds as living in remote areas removes the possibility of social interaction, and the possibility of situations that could positively affect reintegration, such as employment (Craig and Foster 2013; Verbruggen, Blokland, and Geest 2012; CSC Website, CD 715-1). Lastly, this policy does well at asking the basics around intimate relationships, especially given that $C D$ 705-6 does an in-depth job at this task (CSC Website, $C D$ 715-1).

To conclude, this policy adequately inquires about history of offending, but could go a step further and ask about age at first offence or age at any offence as that could be beneficial from a research perspective, even though $C D$ 705-6 covers this information as well (CSC Website, $C D$ 715-1). Annex C covers personal questions that do not necessarily have the same reflective aspect of those in $C D$ 705-6 that inquire about an offender's personal thoughts but have the ability for the parole officer to gauge where personal identity change could take place (CSC Website, CD 715-1).

Formal Social Control

In terms of formal control, $C D$ 715-1 discusses "intervention", and in this discussion section I interrogate what "intervention" means in terms of if it refers to treatment, or refers to accessibility so that the parole officer can access the offender if need be (CSC Website, $C D$ $715-1,11)$. If intervention refers to treatment then this policy covers aspects of formal control in that parole officers could gain insight into if it would be beneficial for the offender to get treatment from the policy (Farmer, McAlinden and Maruna 2015; Harris 2014; Wakeling et al. 2005). Obviously, this is an aspect of formal control, as a parole officer as a criminal justice professional can instruct an offender to complete treatment if they see fit. Lastly, this policy focuses on education less than $C D$ 705-6 which makes sense given $C D$ 705-6 has an indepth dynamic factors section, however $C D$ 715-1 could also benefit (just as $C D$ 705-6 could) 
from asking the offender about their current education level (CSC Website, CD 705-6; CSC Website, $C D$ 715-1).

Sex Offender Desistance

As reiterated above there is not a sex offender specific section in this policy. With this being said, the questions in the policy about "remote location" and restriction for interventions incorporate aspects that offenders could face in the community that could hinder desistance due to sex offender registries and stigma (i.e., not being able to see their children or family) (CSC Website, CD 715-1, 11; Mann, Devendran, and Lundrigan 2019; Giffiths 2015). The only criticism in this regard is that the questions could be followed up with some additional ones that could help contextualize the Sex Offence History Checklist questions that they need to take into account in Annex C.

Risk

In $C D$ 715-1 there are not as many codes as in $C D$ 705-6, and since some of the codes are the same or extremely similar to that of $C D$ 705-6, the discussion around risk for this policy will be lesser to ensure there is not as much repetition between the sections (CSC Website, $C D$ 715-1). To reiterate again, a discussion of these codes as they pertain to the risk paradigm will be done in the order that they appear in the analysis section. However, it is important to note that aspects such as support, learning, and offence history can also relate to the concept of desistance as indicated by scholars such as McCord (1980), Kras (2019), Hansen (2003), Runell (2017), and Laub and Sampson (2003).

To start, "history of illegal behaviours" has a risk component simply because those behaviours could be a direct result of anti-social behaviours, personality, or cognitions (CSC Website, CD 715-1; Andrews and Bonta 2010). In this way this code is focused on what the 
offender is doing wrong and what needs to be fixed. This fits into the idea of risk being focused on offender deficits (Nee and Vernham 2016; des Vries Robbé et al. 2015; Maruna and LeBel 2003). Obviously, there is no way to know for sure, however, it is not unreasonable to assume that some factors that are inherent to illegal behaviours could be derived from the factors that increase risk for those behaviours. Further "current situational factors" as they pertain to the physical environment the offender is in involves risk simply because that environment could include aspects such as anti-social associates (CSC Website, CD 715-1; Andrews and Bonta 2010; Boduszek et al. 2013).

The primary code "support" relates to the risk paradigm because not only is the lack of support detrimental in many ways, but having pro-social support largely depends on who the offender is getting support from; the risk of offence could understandably go up especially if the individual is associating with a support network that is involved in deviant behaviours or who can be classified as anti-social associates (Whited et al. 2015). Furthermore, "personal understanding about an event/personal behaviours", if done in a pro-social way, can mean that the offender is coming to terms with what they have done. At the same time, however, antisocial cognitions (as explained by Walters (2003)) can play a role in individuals not recognizing what they have done wrong and not taking responsibility for it, and it is in this way that it fits into risk.

To continue, "current behaviours perceived as negative" included both substance abuse and instability of relationships (CSC Website, CD 715-1). Substance abuse can increase risk of offence (Vaughn 2011; White and Gorman 2000) and having unstable relationships can also affect offence rates given that having stable pro-social relationships decrease offence rates (Huebner 2005; Sampson, Laub and Wimer 2006). 
"Learning/behaviours adaptations" is a code that lends itself to the desistance paradigm. However, this code's underlying aspects can be seen as having a risk element because the reasons for not being able to adjust properly can be seen as stemming from having a history of anti-social behaviour, or having an anti-social personality, or having issues with family, anti-social associates or substance abuse (Andrews and Bonta 2010). Lastly, "responsivity and learning styles" can also have a risk element. The parole officer inquiring about learning is beneficial so that the offender can be placed in programming that will help them (CSC Website, CD 715-1). However, in assessing learning styles, if the offender is having issues with aspects of learning this could point to the fact that they did not complete school, which is a risk for offending behaviours (Hansen 2003; Lochner 2004). This can be seen as a positive aspect because if a parole officer realizes that the offender has not finished school, it means that parole officers have the ability to catch offenders up in terms of schooling curriculum.

In relation to sex offending, although there is not a sexual offender checklist in this policy, I make note that more questions on remote locations and restrictions to interventions are needed especially for sex offenders (CSC Website, CD 715-1). Risk is somewhat already incorporated into this policy simply because, for example, living in a remote location means that there is not access to leisure or community, and this could affect risk, as leisure time can be known to decrease risk of reoffence (Williams 2006; Williams and Walker 2006). Even if these aspects are not mentioned in much detail, it is still important to note that they are present.

Code Summary

Just like in CD 705-6, in this policy I discuss the ways in which the focused codes for 
CD 715-1 encompass aspects that relate to the desistance and risk paradigms. The summary table below provides an explanation of this, along with including reasoning as to if the codes are more desistance or risk paradigm based.

Table 11: $C D$ 715-1 Code Summary

\begin{tabular}{|c|c|c|c|c|}
\hline $\begin{array}{l}C D 715-1 \\
\text { Focused Codes }\end{array}$ & $\begin{array}{l}\text { Main } \\
\text { Desistance } \\
\text { Paradigm } \\
\text { Factors } \\
\text { Included } \\
\end{array}$ & $\begin{array}{l}\text { Sex Offender } \\
\text { Desistance }\end{array}$ & $\begin{array}{l}\text { Main Risk } \\
\text { Paradigm } \\
\text { Factors } \\
\text { Included }\end{array}$ & $\begin{array}{l}\text { Desistance or } \\
\text { Risk Paradigm } \\
\text { Dominated? } \\
\text { Or Both? }\end{array}$ \\
\hline $\begin{array}{l}\text { Connections to } \\
\text { Society }\end{array}$ & $\begin{array}{l}\text { Similar to the } \\
\text { previous policy } \\
\text { in that this } \\
\text { policy mentions } \\
\text { a lot about } \\
\text { support in the } \\
\text { community, } \\
\text { including friends } \\
\text { (see King 2013). }\end{array}$ & $\begin{array}{l}* * \text { No sex } \\
\text { offender } \\
\text { checklist, but } \\
\text { aspects like } \\
\text { mentioning } \\
\text { remote location } \\
\text { for example can } \\
\text { relate to sex } \\
\text { offenders } \\
\text { because of } \\
\text { geographical } \\
\text { restrictions (see } \\
\text { Tewksbury } \\
\text { 2005). }\end{array}$ & $\begin{array}{l}\text { Relates to the } \\
\text { risk paradigm } \\
\text { because if the } \\
\text { offender has no } \\
\text { support, this } \\
\text { could lead to } \\
\text { deviant } \\
\text { behaviours } \\
\text { (Whited et al. } \\
2015 \text { ). }\end{array}$ & $\begin{array}{l}\text { Aspects of both, } \\
\text { but more } \\
\text { desistance } \\
\text { paradigm } \\
\text { focused. }\end{array}$ \\
\hline $\begin{array}{l}\text { Deviant } \\
\text { Behaviours }\end{array}$ & $\begin{array}{l}\text { Does highlight } \\
\text { aspects of social } \\
\text { bonds when } \\
\text { discussing } \\
\text { collateral } \\
\text { contacts. }\end{array}$ & & $\begin{array}{l}\text { More risk } \\
\text { focused in that } \\
\text { what } \\
\text { encompasses } \\
\text { deviant } \\
\text { behaviours can } \\
\text { relate to anti- } \\
\text { social cognitions } \\
\text { or personality } \\
\text { (Andrews and } \\
\text { Bonta 2010). }\end{array}$ & $\begin{array}{l}\text { Aspects of both, } \\
\text { but more risk } \\
\text { paradigm } \\
\text { focused. }\end{array}$ \\
\hline $\begin{array}{l}\text { Comprehension } \\
\text { of Realities }\end{array}$ & $\begin{array}{l}\text { Extremely } \\
\text { desistance based } \\
\text { because of the } \\
\text { focus on } \\
\text { personal } \\
\text { reflection in } \\
\text { terms of the } \\
\text { questions that } \\
\text { are asked in } \\
\text { relation to this }\end{array}$ & & $\begin{array}{l}\text { Much of what is } \\
\text { included in this } \\
\text { code is } \\
\text { desistance based, } \\
\text { but it could be } \\
\text { related to the } \\
\text { risk paradigm } \\
\text { because having a } \\
\text { hard time } \\
\text { adapting }\end{array}$ & $\begin{array}{l}\text { Aspects of both, } \\
\text { but more } \\
\text { desistance } \\
\text { paradigm } \\
\text { focused. }\end{array}$ \\
\hline
\end{tabular}




\begin{tabular}{|l|l|l|l|}
\hline Maruna 2001). & & behaviours or \\
& & learning, could \\
stem from & \\
having a history & \\
of anti-social & \\
behaviour, for & & example \\
& & (Andrews and & \\
& & Bonta 2010). & \\
\hline
\end{tabular}

\section{715-2: Post-Release Decision Process}

This policy is used for when an offender is suspended and when their conditions change (CSC Website, $C D 715-2$ ). Within this policy it is stated that "the assessment is based upon information and analysis derived from other key case management documents, but in particular the Criminal Profile, Correctional Plan or Correctional Plan Update and the Community Strategy" (CSC Website, CD 715-2, 13-14). Because of this, this policy is shorter and covers information in broader strokes. Thus, this policy only had three primary codes, which were not turned into secondary codes. This also means that the discussion around this policy will not be as in depth given its nature. The three primary codes are "history/offence history", "relationships/support/community", and "responses to interventions including situations".

\section{"History/Offence History"}

This code relates to the offender's conviction history or criminal history.

\section{Informal Social Control}

This policy starts by asking about the criminal behaviour of the offender, and states that the parole officer should "assess relevant aspects of the criminal history and conditional release history" and also should "assess the offenders' overall behaviour in the institutional or community setting" (CSC Website, CD 715-2,15). These assessments can largely be done by 
going back to $C D$ 715-1 and re-looking at Annex B (Staff Safety Assessment) and Annex C

(Rating Reassessment Framework) (CSC Website, $C D$ 715-1). Also, given that $C D$ 705-6 has a very thorough Annex D (Static Factors Assessment), and Annex E (DFIA-R) there is not much that can be added to this section of the policy, as it is made clear that parole officers should refer elsewhere for this information (CSC Website, CD 705-6; CSC Website, CD 7152). These aspects mentioned above could also fit under formal social control, however I opted to discuss them under the Informal Social Control section as they have a community element. But nonetheless, I understand that looking at conditional release and institutional behaviour at its core relates to the criminal justice system as an apparatus of formal social control.

Moreover, in Annex C (Correctional Plan Update-Community Progress- Release Maintained-Report Guide) there is a focus on what the parole officer should consider when updating the correctional plan (CSC Website, $C D$ 715-2). Other than offense history and offender profile, of interest is that this policy asks the parole officer to describe "the circumstances of the suspension/increase in risk" (CSC Website, CD 715-2, 17). Although this makes sense, and they can refer to other policies for this information, it does seem vague (CSC Website, CD 715-2). However, not every offender is the same and gets suspended for the same reasons, therefore it also makes sense that this policy does not list potential reasons that the parole officer should consider or investigate further when providing a case status (CSC Website, $C D 715-2$ ). Of note is the use of the word risk and the way the quote above reads. I think it is interesting to note that the policy mentions investigating the reason for an increase in risk, and other than mentioning the word risk, the way this quote is phrased definitely could make parole officers think about how offenders are at fault or how their behaviour is problematic and thus, in my opinion incorporates a deficit approach to 
assessment, in my opinion (see Nee and Vernham 2016, for example). But, at the same time desistance can be discussed here despite this (i.e., what can be done socially to help the offender). Lastly, in relation to history and offence history this policy makes it clear that the parole officer should inquire about how the offender understands their offence cycle; as I have mentioned above several times, this type of inquiry, that requires the offender to be able to self-reflect, could be beneficial to starting a desistance process wherein there is an attitude change (Maruna 2001; CSC Website, CD 715-2).

\section{Formal Social Control}

Under Annex D in $C D$ 715-2 is a Risk Assessment Framework which is intended for the parole officer to review when a condition has been breached (CSC Website, CD 715-2). This Annex includes mentions of offence patterns and type of breaches committed, however, of interest is how this specific question instructs parole officers that when reviewing critical risk factors they should consider "actuarial/clinical measures of risk and any other information from psychological, psychiatric or supplementary assessments" (CSC Website, CD 715-2, 19). This is grouped under formal social control under the assumption that going to a psychologist or psychiatrist for assessment would be something that the criminal justice system had ordered of the offender. Although actuarial tools have a high predictive accuracy (Hanson and Morton- Bourgon 2007), it is interesting how this policy narrows in on risk. I have posed suggestions in the above policies around making desistance narratives more prominent, but this is the first policy wherein risk instruments are the focus in an assessment criterion (CSC Website, $C D$ 715- 2). If this policy wanted to take a purely desistance paradigm approach according to researchers such as Ward and Maruna (2007), risk narratives would not be part of the discussion. However, I will interrogate this concept at the end of this 
discussion section where I discuss the difference between risk factors and desistance factors.

\section{"Relationships/Support/Community"}

This code is quite self-explanatory and relates to the ways in which the offender has a support system around them in the community.

Informal Social Control

This code encompasses many aspects of other policies repeated in a less in-depth way. In terms of support, this policy mostly looks at the community. Specifically, this policy looks at how long the offender has been in the community, and how much stability they have in the community (CSC Website, $C D$ 715-2). The emphasis on stability is vital because the relationships that offenders build in the community can help with the desistance process (Kras 2019; Mallik-Kane and Visher 2008). However, I struggle to conceptualize how one measures "level of stability in the community" (CSC Website, CD 715-2, 20). This could be done simply by inquiring about how many friends the offender has, who their friends are, what they do in the community, and how attached they are to the community. But, at the same time, I assume that it would not be beneficial to ask the same questions to every offender when trying to measure stability. The fact of the matter is that one offender could be really connected to the community through volunteering for example, but maybe does not have a family relationship that they can turn to, while another offender is very close to family and friends, but not the community. Further, just because an offender is close to their family or the community, this also does not mean that those relationships are pro-social, therefore judging on that type of scale may actually not lead to information on stability. Thus, it would seem that there is not one way to measure stability, which means that the vagueness of this criteria is warranted given the multitude of factors that can influence it. 
The next assessment criteria focuses on collateral contacts and assessing if the offender has had relationship struggles (breakdowns), including family violence (CSC Website, $C D$ 715-2). Above I criticize $C D$ 715-1 for not expanding what collateral contacts mean in relation to who could help the offender during their supervision, and who is included in them (i.e. friends or family) (CSC Website, $C D$ 715-1). Although the assessment criteria in $C D 715$ 2 is not dealing with who the collateral contacts are and if they are able to support the offender while on supervision, there is better attention paid to what sort of information the parole officer should inquire about from the collateral contact (CSC Website, CD 715-2). Additionally, if the collateral contact is a friend or family member that could help with supervision, the assessment criteria lends itself to the parole officer asking the collateral contact if they have recently had relationship strain with the offender. All in all, this is important to gauge whether potential support systems are going to be positive or detrimental to the offender's desistance process as sometimes these relationships are not always clear cut (Visher and Courtney 2007; Kras 2019).

Formal Social Control

The only aspect of formal social control mentioned in this policy in relation to support is that the parole officer should seek "recommendations from supervision team members e.g., community-based residential facility, program facilitators, police, etc." (CSC Website, CD 715-2, 20). Talking to community-based residential facilities and police fit more under formal control as those institutions are part of the criminal justice system. Paternoster and Bushway (2009) discuss formal sanctions as being positive because offenders do not want to violate the rules so they will play by the rules instead. Going to a community-based residential facility could be seen as a formal sanction as part of a condition, therefore although this code 
incorporates social bonds and community, there is an aspect of formal social control present as well. In terms of desistance, every offender's relationship to formal social control will be different and the information the parole officer receives in relation to the aspects of formal social control will also be different.

Thus, this assessment criteria (although vague), does well at leaving this as an openended question that incorporates different aspects of community and relationships, and formal control.

\section{"Responses to Interventions Including Situations"}

This code has some aspects that deal with support, while others look at specific interventions such as programs.

Informal Social Control

In $C D$ 705-6 I comment that secondary desistance processes can be yielded from personal questions within the policy that make offenders think about not only what they did, but their current life situation and how they could or have changed it (Maruna 2001; CSC Website, $C D$ 705-6). In $C D 715-2$, much of this is the same in that the parole officer should not only refer to $C D$ 705-6 for Correctional Planning, but should investigate attitudes and behaviours that have changed since the start of the sentence, and "what effect have these changes had on the offender's risk level?" (CSC Website, CD 715-2, 14). Of interest here specifically is how risk is mentioned; but this phrase as a whole does incorporate desistance aspects although not quite as explicit as the mention of risk.

Of note is that this policy does do an adequate job of inquiring about interventions as they relate to dynamic factors. Although not explicit in the policy, in mentioning progress with dynamic factors it would not be unreasonable for the parole officer to reference the 
DFIA-R in Annex E of $C D$ 705-6. With this in mind there are no specific aspects that need to be added in $C D 715-2$ as they relate to situations.

Formal Social Control

The one aspect of formal social control that is present under this code in relation to $C D 715-2$ is the mention of interventions. Specifically, the parole officer is to investigate how "the available programs and/or interventions mitigate risk?" (CSC Website, CD 715-2, 14). Here not only is risk mentioned again, but risk management seems to be the goal of these programs (CSC Website, $C D$ 715-2). In $C D$ 715-1 I question what intervention means in the context of access that offenders will have to said intervention, but nonetheless argue that this question around access to intervention is still beneficial because a parole officer can gain insights into an offender's physical ability to access treatment (CSC Website, CD 715-1).

In terms of $C D$ 715-2 this question can be seen as a background question based on answers from questions in $C D$ 705-6 about criminal history, and in $C D$ 715-1 about intervention. Of note is that incorporating aspects of education as a formal control method (like was done in $C D 705-6$ ) is present in this question, because an offender's past experiences from available programming and intervention could be beneficial for the parole officer to know about, and could be the information gathered from this question. However, it is important to also note that some offenders attend treatment to seem lower risk or to get a decent risk assessment score, and going to treatment can be stigmatizing for some offenders (Mann, Devendran, and Lundrigan 2019; Brown 2005; Lacombe 2008; Levins and Crewe 2015), therefore their learning experiences from treatment or intervention may not be a good measure of management in the community.

Nonetheless it is understandable that this policy would want to touch on programming 
as a whole, and since this policy is more about the parole officer assessing the offender based on the Criminal Profile and Correctional Plan already in place rather than interviewing an offender for an intake assessment like in $C D$ 705-6, this question does not necessarily need to be more specific (CSC Website, CD 715-2). I do, however, question if the policy needs to mention risk at all as that does not necessarily add to the question as it relates to desistance. Given that this question incorporates treatment and intervention along with a hidden aspect of education it means that formal control aspects of desistance are present that do not need elaboration (Mann, Devendran, and Lundrigan 2019; Harris 2017). Again, this is a situation wherein risk can be explicitly stated in the assessment criteria, but at the same time can and does incorporate aspects of desistance.

This policy also asks about "previous response to interventions" (CSC Website, $C D$ $715-2,20)$. Just as I criticize $C D 715-1$ for not adequately explaining what an intervention is in the context of access, the same criticism is valid here (CSC Website, $C D$ 715-1). In other words, does CSC mean correctional interventions? Behaviour interventions? Interventions for drugs and alcohol? Some clarity would be favourable so the parole officer could gain some clarity and context.

\section{Sex Offender Desistance}

This policy, just like $C D$ 715-1, does not have a dedicated sex offender checklist or section (CSC Website, $C D$ 715-2). My suggestion for $C D$ 715-1 was that it could expand on some already existing aspects that are prevalent for sex offenders (CSC Website, CD 715-1). Since $C D$ 715-2 mostly focuses on breaches and change of conditions, it is not unreasonable to assume that the parole officer would have information from the Sex Offender History Checklist in $C D$ 705-6 on file especially if they are assessing the offender for their parole 
conditions (CSC Website, CD 715-2). This is made clear in Annex C wherein the parole officer is to take offence history into account "from the intake Correctional Plan", which is CD 705-6 (CSC Website, $C D$ 715-2, 17).

Furthermore, the Sex Offender History Checklist is in Annex D (Static Factors Assessment) of $C D$ 705-6. In Annex C, section 1 of $C D$ 715-2 (Ratings Reassessment and Correctional Plan Progress) the parole officer is told to reference $C D$ 715-1 Annex C (Rating Reassessment Framework) which clearly states that the parole officer should take into account static factors including sex offence history which is located in CD 705-6 Annex D (CSC Website CD 715-2; CSC Website, CD 715-1; CSC Website, CD 705-6).

Although this is a roundabout way to get to talking about sexual offences, it is not as though $C D$ 715-2 did not take sex offending into account whatsoever (CSC Website, $C D$ 7152). My one recommendation would be that within section 1 of Annex $\mathrm{C}$ of $C D 715-2$, sex offending should have its own point wherein it is explained to the parole officer to not only look at offence history, but specifically sex offense history (CSC Website, CD 715-2). Although this is a small recommendation, it would help with the continuity of the policies, and would help emphasize that sexual offenders should receive more attention because of the unique barriers they face in every facet of life, from treatment (Lacombe 2008; Levins and Crewe 2015), to employment (Graffam, Shinkfield, and Hardcastle 2008; Varghese et al. 2010) to reintegration and restrictions as a result of stigma from their offences (Mann, Devendran, and Lundrugan 2019; Hipp, Petersilia, and Turner 2010; Giffiths 2015).

I recognize that my research questions address each policy and how they incorporate or do not incorporate sex offender desistance. However, it is important to note that as CSC is one organization, the policies do not have to be repetitive in every sense, but rather need 
to adequately convey important aspects around topics such as sex offending and desistance, which is easier to do when policies relate to one another.

\section{Summary CD 715-2}

This section will summarize what was discussed above in relation to $C D$ 715-2.

Informal Social Control

In $C D$ 715-2 criminal history and offence history are well explained and the parole officer is told to reference CD 715-1 (Annex B and C), and the Static Assessment and DIFA-R in $C D$ 705-6 (Annex D and E) (CSC Website, $C D$ 715-2). Furthermore, when inquiring about aspects of suspension, the assessment portion in the policy seems vague, but this makes sense since the circumstances of suspension are not uniform across the board (CSC Website, $C D$ 715-2). Moreover, the way in which this policy frames discussions about suspension and the offence cycle brings forth a self-reflection aspect that could kickstart a personal identity change for the offender (i.e., consistent with secondary desistance), which is also a theme in CD 715-1 (Maruna 2001).

This policy also looks at social bonds, specifically in the community (CSC Website, $C D$ 715-2). When assessing for these aspects, I maintained that measuring stability in the community would be difficult, but since stability can look different for every offender the fact the assessment criteria does not go into more detail is appropriate. The discussion around what sorts of information a parole officer should gather from a collateral contact is also adequate as it can give insight into social bonds and relationships, both of which are important for desistance in that they can be positive, or hinder the process (Kras 2019; Visher and Courtney 2007).

Although this is similar to above, this policy is heavy on the assessments of attitude 
change since the start of the sentence (CSC Website, CD 715-2). This type of direct questioning can foster the process of secondary desistance (CSC Website, CD 715-2; Maruna 2001). An interesting aspect to note is how attitude change corresponds to risk level in this policy which is something that was noteworthy (CSC Website, CD 715-2). Lastly, this policy does a good job of mentioning dynamic risk factors (CSC Website, CD 715-2).

\section{Formal Control}

Of particular note in the policy is the mention of actuarial tools for risk assessment purposes (CSC Website, CD 715-2). I mention that although they are accurate tools of measure, (Hanson and Morton-Bourgon 2007), it is interesting how they are specifically mentioned in this policy, despite the fact the policy covers many aspects of the desistance paradigm. Furthermore, this policy asks parole officers to gather information from formal control institutions such as the police or community-based residential facilities, which within itself can influence the desistance of offenders because once they are in the system they could want to obey the rules and change their behaviour positively (CSC Website, CD 715-2; Paternoster and Bushway 2009).

Lastly, programming is mentioned within this policy, but in relation to risk not desistance (CSC Website, $C D$ 715-2). This policy also asks about responses to interventions but ceases to clarify what this means (CSC Website, $C D$ 715-2). Therefore, an explanation would be beneficial.

Sex Offender Desistance

Sex offender desistance, although not extremely explicit in this policy, is still present as the policy references $C D 715-1$, and makes note of the importance of referring to $C D$ 705-6 for offence history, which not only includes Annex D (Static Factors Assessment), but also 
includes the Sex Offence History Checklist (CSC Website, CD 715-2). The one suggestion made for this policy, however, is that specifying "sex offence history" in $C D$ 715-2 Annex $\mathrm{C}$, section 1 would just make it clearer that that is an additional aspect of offence history that needs specific attention especially given the unique needs of sex offenders (CSC Website, $C D$ 715-2).

Risk

For this policy the discussion on risk will also be shorter given that there are only three primary codes. This will act as a summary to what is said in the analysis section. As indicated above when discussing the other policies, it is important to understand that risk and desistance do not seem to be singular within themselves, and this will be discussed later in the discussion section. To start, "history/offence history" can relate to the risk paradigm in the sense that the information in this code highlights risk to parole officers and communities (CSC Website, $C D$ 715-2). The information in this code also mentions risk factors deemed important by Andrews and Bonta (2010) such as substance abuse (CSC Website, CD 715-2).

The next code "relationships/support/community" incorporates aspects of the risk paradigm because it discusses the breakdown of relationships (relationships can help lower recidivism (Lo and Zhong 2006)), and asks about the community, which can relate to leisure activities, and connections the individual has to the community, which can lower crime (Williams 2006; Williams and Walker 2006).

Lastly, "responses to interventions including situations" incorporates aspects of the risk paradigm because within this policy there is talk of changes in attitudes, and that could mean changing attitudes that are considered at risk for offending or recidivism such as anti-social cognitions (CSC Website, CD 715-2; also see Healy and O’Donnell 2000; Palmer and Hollin 
2004). The mention of negative aspects of environment lends itself to aspects such as deviant recreational activities (see Atkinson 2014, for example). In terms of sex offenders, given the way this policy is structured there is no suggestion of how risk is incorporated into this policy given that this policy makes note of referring to $C D$ 705-6 for sex offender information (CSC Website, $C D$ 715-2).

Code Summary

This policy was only coded in terms of primary codes, thus the table presented below summarizes the important aspects of those primary codes, and then discusses them in relation to the risk and desistance paradigms.

\begin{tabular}{|c|c|c|c|c|}
\hline$C D$ 715-2 Primary Codes & $\begin{array}{l}\text { Main } \\
\text { Desistance } \\
\text { Paradigm } \\
\text { Factors } \\
\text { Included }\end{array}$ & $\begin{array}{l}\text { Sex } \\
\text { Offender } \\
\text { Desistance }\end{array}$ & $\begin{array}{l}\text { Main Risk } \\
\text { Paradigm } \\
\text { Factors } \\
\text { Included }\end{array}$ & $\begin{array}{l}\text { Desistance } \\
\text { or Risk } \\
\text { Paradigm } \\
\text { Dominated? } \\
\text { Or Both? }\end{array}$ \\
\hline History/Offence History & $\begin{array}{l}\text { There is a lot } \\
\text { of mention of } \\
\text { treatment in } \\
\text { this code, } \\
\text { which is a } \\
\text { formal social } \\
\text { control } \\
\text { element in } \\
\text { relation to } \\
\text { desistance } \\
\text { (see Farmer, } \\
\text { McAlinden, } \\
\text { and Maruna } \\
\text { 2015). }\end{array}$ & $\begin{array}{l}* * \text { No sex } \\
\text { offender } \\
\text { section in } \\
\text { this policy, } \\
\text { but does } \\
\text { reference } \\
C D 715-1 \text {, } \\
\text { which says } \\
\text { that the } \\
\text { parole } \\
\text { officer } \\
\text { should take } \\
\text { into account } \\
\text { the sex } \\
\text { offender } \\
\text { checklist in } \\
C D 705-6 \text { ). }\end{array}$ & $\begin{array}{l}\text { Relates to the } \\
\text { risk paradigm } \\
\text { because } \\
\text { included in } \\
\text { this code is } \\
\text { mention of } \\
\text { risk factors } \\
\text { such as } \\
\text { substance } \\
\text { abuse } \\
\text { (Andrews and } \\
\text { Bonta 2010). } \\
\text { Can also } \\
\text { include other } \\
\text { factors such } \\
\text { as anti-social } \\
\text { personality } \\
\text { (Andrews and } \\
\text { Bonta 2010). }\end{array}$ & $\begin{array}{l}\text { Both, but } \\
\text { more risk } \\
\text { paradigm } \\
\text { focused. }\end{array}$ \\
\hline Relationships/Support/Community & $\begin{array}{l}\text { Similar to the } \\
\text { codes for the } \\
\text { policies }\end{array}$ & & $\begin{array}{l}\text { More } \\
\text { desistance } \\
\text { based, but }\end{array}$ & $\begin{array}{l}\text { Both but } \\
\text { more } \\
\text { desistance }\end{array}$ \\
\hline
\end{tabular}




\begin{tabular}{|c|c|c|c|}
\hline & $\begin{array}{l}\text { above, } \\
\text { mention of } \\
\text { relationships } \\
\text { and } \\
\text { community } \\
\text { are present } \\
\text { here, and } \\
\text { they can help } \\
\text { with the } \\
\text { desistance } \\
\text { process (see } \\
\text { Kras 2019). }\end{array}$ & $\begin{array}{l}\text { relates to the } \\
\text { risk paradigm } \\
\text { because } \\
\text { relationships } \\
\text { can relate to } \\
\text { lower } \\
\text { recidivism } \\
\text { (Lo and } \\
\text { Zhong 2006). }\end{array}$ & $\begin{array}{l}\text { paradigm } \\
\text { focused. }\end{array}$ \\
\hline $\begin{array}{l}\text { Responses to Interventions } \\
\text { Including Situations }\end{array}$ & $\begin{array}{l}\text { Similar to } \\
C D 705-6 \\
\text { there is a } \\
\text { reflective } \\
\text { element here } \\
\text { (Maruna } \\
\text { 2001). }\end{array}$ & $\begin{array}{l}\text { Could be a } \\
\text { change of } \\
\text { attitudes } \\
\text { which could } \\
\text { mean that } \\
\text { attitudes } \\
\text { related to the } \\
\text { risk paradigm } \\
\text { changed such } \\
\text { as anti-social } \\
\text { cognitions } \\
\text { (Palmer and } \\
\text { Hollin 2004). }\end{array}$ & Both. \\
\hline
\end{tabular}

\section{715-3: Community Assessments}

The purpose of this policy is for when a parole officer needs to complete a community assessment especially when "there is a new significant source of community information and/or support which needs to be assessed for release planning, including a temporary absence and work release location, or when the offender is in the community" (CSC Website, $C D$ 715-3, 2). Community assessments are also done when there is new information on file, or when the offender is no longer suspended, and is going to be released in another area (CSC Website, $C D$ 715-3). There are two focused codes in this policy, and they are "acceptance and understanding" and "connections to society". They will be explored below. 


\section{"Acceptance and Understanding"}

Under this policy this code includes the primary codes of "willingness and responsibility" and "criminal past/history/escape/current status". Therefore, there is an element of past acceptance of mistakes, and current abilities to recognize said mistakes.

Informal Social Control

In this policy there is again mention of what the parole officer should ask collateral contacts (or community contacts), about "the offender's motivation to engage in their Correctional Plan" (CSC Website, $C D$ 715-3, 7). This within itself relates to $C D$ 705-6, and since this policy is more focused on the assessment of those in the community, there is no need to expand this statement to include everything that is included in every aspect of the correctional plan (CSC Website, CD 705-6; CSC Website, CD 715-3). It is also safe to assume that said collateral contact could have been in contact with the parole officer before, and therefore would be familiar with what a correctional plan is. Thus, I do not recommend any additions for this part of the policy, given that aspects of the correctional plan have been critiqued above in the discussion of $C D$ 705-6.

In terms of community contacts, this policy also states that the parole officer should inquire about how the community contact can help the offender in programming (CSC Website, $C D$ 715-3). This both encompasses aspects of formal and informal control. In terms of informal control, if we assume that the community contact is a friend of the offender (or just a positive social bond or support network), then that is a factor of the desistance paradigm that could help the offender desist (Kras 2019; Lin 1986; Cullen 1994). In terms of community programs, that could be an aspect of formal control, especially if it is part of conditions for offenders. Community programs are not necessarily "treatment options" therefore, I do not 
believe that literature involving treatment is directly applicable. However, it is not unreasonable to assume that the same idea could persist; the offender could feel obligated to go to community programming because they think it could be frowned upon if they do not want to go (Brown 2005). I recognize that Brown (2005) talks about this in relation to sex offenders, but again, I think the same principle around judgement could apply to other offenders as well.

Furthermore, the parole officer should assess "all dynamic factors associated with the offender's criminality" (CSC Website, $C D$ 715-3, 7). As explained above, some dynamic factors such as relationships, friendships (etc.) have aspects of informal social control related to them if the relationships and social bonds are positive (Kras 2019). There is also mention in this policy of inquiring about how the offender accepts what they have done, and in what ways they do so (CSC Website, CD 715-3). This within itself has been a theme in this paper; the self-reflective lens in which the policies are written can lend themselves to secondary desistance, or at least get the offender thinking about the consequences of their actions (Maruna 2001). Given that these dynamic factors are mentioned in Annex E of CD 705-6 in a concrete amount of detail, the detail they are mentioned in $C D$ 715-3 is sufficient (CSC Website, $C D$ 715-3).

\section{Formal Social Control}

The one element that encompasses formal social control under this policy is where the parole officer is instructed to glean information about "whether the offender has refused to participate in a rehabilitation or reintegration program" (CSC Website, $C D$ 715-3, 10). Above, in discussing $C D$ 705-6, I criticize the policy for not making the questions about treatment personal in any way (CSC Website, CD 705-6). I maintain this criticism for this policy (CSC 
Website, $C D$ 715-3). This is because the offender could have refused to participate in treatment for a multitude of reasons including living too far, or having personal life situations wherein attending would not have been feasible (i.e., the offender does not drive, and in order to get to treatment they need to ask a friend or family member, but they are ashamed to do so). I also believe that phrasing this statement this way lends itself to focusing on the offender's "problems" which is very characteristic of risk assessment (Nee and Vernham 2016, 39) (in this case the offender's problem being the behaviour that has led them to offending).

This section in $C D 715-3$ could be addressed by adding a statement within the subsection that asks "why the offender has refused to participate in a rehabilitation or reintegration program", or a prompt can be added for the parole officer in which they are asked to simply ask the offender to expand on their treatment history (CSC Website, CD 7153). I understand the parole officer can take the information from $C D$ 705-6 as it pertains to rehabilitation, but that policy also does not have an in-depth explanation of factors that could affect this; therefore, the same suggestion stands (CSC Website, CD 705-6).

Lastly, of note, above I talk about community programs as not necessarily being treatment options, but as potentially having some of the same aspects around them in terms of the idea that offenders could be pressured to attend. In the discussion presented above, I took rehabilitation to lean more on the medical end of treatment (whether that would be behavioural or substance), however I argue that whether we are talking about community programs, rehabilitation programs, or reintegration programs, the same suggestion applies: there needs to be a more in-depth conversation around these aspects as it is not always clear cut as to why an offender may not have participated (CSC Website, $C D$ 715-3).

\section{"Connections to Society"}


This focused code has been present in every policy except for that of $C D$ 715-2. In this case, this code encompasses much of the same aspects as it did throughout the other policies, including "support/community" and "employment/aspects of employment".

\section{Informal Social Control}

In terms of community and support, this policy directly addresses these issues by having the parole officer assess if community resources are adequate for their needs when they are to be released in society (CSC Website, $C D$ 715-3). This policy also asks for the parole officer to take into account what sorts of support the offender needs (financial or social etc.) (CSC Website, $C D$ 715-3). Through my analysis of $C D$ 705-6 I mention that the policy (specifically Annex E (DFIA-R)) does adequately discuss relationships and also inquires about the offender's connection to the community (CSC Website, CD 705-6). CD 715-3 is doing the same thing, just not to the same detailed extent as it is covered elsewhere (CSC Website, $C D$ 715-3). Although this information being covered elsewhere is not a reason not to suggest additional information be covered in $C D$ 715-3, repetition is not effective, and $C D$ 715-3, in its cross references section makes note that other policies the parole officer should reference include $C D$ 715-1 (CSC Website, $C D$ 715-3). And, as expressed above, in $C D$ 715-1 there is written instructions for the parole officer to address aspects of the offender's life that are covered in $C D$ 705-6 (CSC Website, $C D$ 715-1). Therefore, there is a lot of interconnectedness between the policies.

Under this code there is also mention of social services in this policy, in that the parole officer should assess "availability of social services for problems with drugs, alcohol, mental health, income support, etc." (CSC Website, $C D$ 715-3, 8). Although this can be seen as an aspect of formal control because of the mention of drugs and alcohol and the way it is phrased 
as though it is referring to treatment, I think it is more social support focused because on page 10 of this policy they actually address "rehabilitation" (CSC Website, $C D$ 715-3, 10). Thus, this falls under what I mentioned above in regard to community resources and is adequate enough given that the parole officer can refer to $C D 715-1$, and $C D$ 705-6 if they require more information.

Secondly, this focused code focuses on "employment/aspects of employment". This is an interesting part of this policy because part of the reason for a community assessment could be for the offender to be released on a work release (CSC Website, CD 715-3). This policy asks the parole officer to assess "the community employer's understanding of the offence cycle and willingness to accept the offender on work release" and "any concerns expressed by the employer" (CSC Website, CD 715-3, 7). With regard to the first statement, it makes sense the parole officer needs to assess this because it is known that people with criminal records have a harder time obtaining a job (Graffam, Shinkfield, and Hardcastle 2008). Thus, the employer understanding the offence cycle could help maintain a truthful and honest relationship between the employer and the offender which could break the stigma around hiring offenders.

It is also known that jobs can help in the desistance process (Craig and Foster 2013; Verbruggen, Blokland, and Geest 2012), therefore within itself this policy covers employment and desistance. However, I have a suggestion as to how this policy could better address employment (CSC Website, $C D$ 715-3). I think it would be beneficial if the parole officer could also assess if the employer has other offenders who work for them. This most likely could be a confidentiality issues, and the point would not be to ask about what exactly the other offenders did, but to gauge if the offender seeking employment would have a 
support network there. This could be beneficial as not only do offenders struggle in the community when it comes to getting a job (Brown 2004), but social networks could be positive for offenders (Lin 1986), and said support could come in the form of friends who the offender is working with, who understand their struggles and relate to them personally. I also understand that having several offenders at the same place of employment could hinder desistance (Visher and Courtney 2007). Thus, my suggestion is not faultless, but it is something to consider especially if the offender is being released into the community, and might need extra support.

\section{Sex Offender Desistance}

This policy does not have a dedicated sex offender desistance section and does not directly make reference to $C D$ 705-6 where there is a Sex Offender History Checklist (CSC Website, $C D$ 705-6). In some ways it would make sense if this policy where to add a sex offender section in that it could be beneficial to know an offender's history prior to a Community Assessment (CSC Website, CD 715-3). With that said, however, since this policy is focused on community assessment for the purpose of reintegration and release, I do not think a Sex Offender History Checklist needs to be added. However, I think it is important to consider that if a parole officer is completing this assessment for a sex offender there are legitimate factors to consider. I observed that this policy does incorporate aspects of the desistance paradigm but does not go the extra step to incorporate statements or thoughts within the assessment that would be pertinent for sex offenders (CSC Website, CD 715-3). I argue earlier in this paper that sex offender desistance should be seen as different because of the weight that label holds in society. The pertinence of the Not in My Backyard Movement (Griffiths 2015) is why it is at least important to consider sex offender factors within this 
policy.

I discuss how this policy talks about how the parole officer should understand and look into the community resources available for the offender upon release (CSC Website, $C D$ 715-3), and I discuss how this is adequate because of $C D$ 705-6 Annex $\mathrm{E}$ and how factors of support and community are mentioned in depth in that policy (CSC Website, CD 705-6). I maintain that this is true, and that it is adequate, but I believe that $C D$ 715-3 should add (either in brackets or under another bullet point) "consider special programming for sex offenders". This would be useful for multiple reasons. First, since sex offenders are stigmatized against, thinking about special programming would be beneficial if they were to be released. But, secondly (and more importantly), programs such as CoSA are not only effective in reducing recidivism (Wilson, Picheca, and Prinzo 2005; Wilson, Cortoni, and McWhinnie 2009), but also include community members in the program (Hannem and Petrunik 2007). Therefore, even though the policy does not have to mention CoSA specifically, it could be beneficial to make a note about special programming.

Above, I discuss how employment and desistance are related (Craig and Foster 2013; Verbruggen, Blokland, and Geest 2012), and suggest that parole officer could go more in depth with an employer to discuss if they have other offenders working for them. In $C D$ 705-6 I suggest that the aspects of the Sex Offender History Checklist that should be added include asking an offender how they would navigate a conversation about their sex offences if it came up in relation to employment (CSC Website, $C D$ 705-6). Although $C D$ 715-3 is less direct (i.e., the parole officer is looking to community individuals to provide assessment on the offender), I believe it would be beneficial for the policy to include the parole officer not only asking the employer about who works for them (like mentioned above), but also about the 
community the workplace is in (CSC Website, CD 715-3). This could at least somewhat help the parole officer contextualize what would happen if the news got out that a specific employer was hiring sex offenders. Given that the parole officer is to talk to a perspective employer in this policy, it is safe to assume that the workplace would not conflict with any conditions the offender would have (i.e., it would not be near a school), therefore location in that sense would not be worth bringing up in this policy (CSC Website, $C D$ 715-3).

I also mention how treatment within this policy, specifically in relation to rehabilitation needs to come with a "why" question when assessing if an offender has refused treatment in the past (CSC Website, $C D$ 715-3). This policy could ask more questions regarding rehabilitation that are sex offender specific, but I feel as though the why question, coupled with the fact that the parole officer would know if the offender has a sexual offence history, is adequate in this case.

Overall, these suggestions are not necessarily large, but gives the policy more complexity to consider not only general desistance factors, but also sex offender desistance factors.

\section{Summary CD 715-3}

This section will discuss and summarize the discussion portion of this policy.

\section{Informal Control}

$C D$ 715-3 mentions the importance of the correctional plan, which is adequate given that CD 705-6 touches on this in detail, thus there is no need to expand (CSC Website, CD 7153). The mention of assessing dynamic factors is also adequate because it is clear that the policy recognizes how important it is to consider them; also, $C D$ 705-6 goes in depth especially in Annex E around these factors, so no elaboration is necessary (CSC Website, 
CD 715-3; CSC Website, CD 705-6). Furthermore, in my opinion asking community contacts if they can help with programming for the offender is positive and could act as a strong and positive social bond for the offender.

This policy does inquire about different aspects of support for the offender, but, as mentioned above, not in as much detail as $C D$ 705-6 does, but that is not relevant as the interconnectedness of $C D$ 715-3, $C D$ 715-1 and $C D$ 705-6 means this topic is covered (CSC Website, $C D$ 715-3). Lastly, in terms of employment this policy could do a better job at engaging with community employers about who works for them in hopes of potentially having work be an aspect of positive social interaction (CSC Website, CD 715-3).

Formal Control

In terms of formal control in this policy, the same criticism mentioned in relation to $C D$ 705-6 stands. When discussing treatment, $C D$ 715-3 lacks asking "why" in regard to reasons an offender refused treatment (CSC Website, $C D$ 715-3). The fact it does not ask why fits into the risk paradigm in that there is a larger focus on the offender's "problem" instead of getting to the root of why they did not attend (Nee and Vernham 2016, 39). Including the question why in the assessment would help the parole officer gain a fuller picture of the obstacles the offender faces in life that could hinder treatment (CSC Website, $C D$ 715-3).

Sex Offender Desistance

This policy needs to make note of, or at least make it known that the parole officer should consider special sex offender programming (such as CoSA) when completing the community assessment, as this could be important for sex offenders to be integrated into the community with a strong support system (CSC Website, CD 715-3). Lastly, inquiring about 
the community that a sex offender could be working in could also be beneficial as this could help the parole officer glean insight shall public stigma prevail.

Risk

Risk aspects within $C D$ 715-3 are included in the code "criminal past/history/escape/current legal status" particularly as included in this code are dynamic factors which could include risk factors as identified by Andrews and Bonta (2010) (CSC Website, $C D$ 715-3). Also, aspects within this policy such as escape, and criminal associates fall into risk factors within the risk paradigm such as anti-social cognitions and anti-social associates (Andrews and Bonta 2010).

Furthermore, for the code "support/community" there is mention of access to community services which could be considered under leisure and recreation especially if community services become something that the offender attends regularly (Andrews and Bonta 2010; CSC Website, CD 715-3). Also, the mention of substance abuse support in this code also relates to risk in that substance abuse is a factor that could contribute to recidivism (Håkansson and Berglund 2012).

Within the code "willingness and responsibility" the major aspects that relate to risk within the policy and code come from the expectation that the offender will start to recognize what they did, and how it affected people (CSC Website, CD 715-3). However, anti-social cognitions can have an effect on taking responsibility for actions, and since anti-social cognitions are a risk factor identified by Andrews and Bonta (2010), this code has a risk element. Lastly, as mentioned above in previous policies, employment decreases risk of offence (Benda, Harm and Toombs 2005), therefore under the code for this policy "employment/aspect of employment", the fact that the policy recognizes this as important 
means that they have recognized its value in relation to risk.

In terms of sexual offenders, I mention that this policy needs to make more of a mention of programming for sexual offenders. This within itself does not necessarily relate to risk. However, the fact the policy does not inquire about programming leads me to make the connection that if a parole officer does not ask about programming this could hinder the offender's ability to associate with pro-social associates instead of anti-social ones, and to change any anti-social cognitions they may have (Andrews and Bonta 2010). Thus, in this situation not asking about programming hinders desistance, but also could increase risk.

In $C D$ 715-3 aspects such as support and employment also relate to desistance as much as they relate to risk (Cullen 1994; Lin 1986; Craig and Foster 2013; Hansen 2003). This will be highlighted more at the end of the discussion, but just as mentioned in the policies above, it is important to take note of the simultaneous nature of risk and desistance.

\section{Code Summary}

Just like for the previous two policies, below is a table that summarizes how the focused codes for this policy incorporate aspects of the desistance and risk paradigms. This table also touches on if the codes are more risk or desistance paradigm dominated.

Table 13: $C D$ 715-3 Code Summary

\begin{tabular}{|l|l|l|l|l|}
\hline $\begin{array}{l}\text { CD 715-3 } \\
\text { Focused Codes }\end{array}$ & $\begin{array}{l}\text { Main } \\
\text { Desistance } \\
\text { Paradigm } \\
\text { Factors } \\
\text { Included }\end{array}$ & $\begin{array}{l}\text { Sex Offender } \\
\text { Desistance }\end{array}$ & $\begin{array}{l}\text { Main Risk } \\
\text { Paradigm } \\
\text { Factors } \\
\text { Included }\end{array}$ & $\begin{array}{l}\text { Desistance or } \\
\text { Risk Paradigm } \\
\text { Dominated? } \\
\text { Or Both? }\end{array}$ \\
\hline $\begin{array}{l}\text { Acceptance and } \\
\text { Understanding }\end{array}$ & $\begin{array}{l}\text { Focus on } \\
\text { dynamic factors } \\
\text { that are mostly } \\
\text { mentioned in } C D \\
\text { 705-6 but } \\
\text { covered in } \\
\text { enough detail in } \\
\text { this policy. }\end{array}$ & $\begin{array}{l}\text { ** This policy } \\
\text { does not have a } \\
\text { dedicated sex } \\
\text { offender section } \\
\text { and could make } \\
\text { note of certain } \\
\text { aspects such as } \\
\text { special }\end{array}$ & $\begin{array}{l}\text { Included in this } \\
\text { code is offence } \\
\text { history, therefore } \\
\text { aspects such as } \\
\text { anti-social } \\
\text { cognitions for } \\
\text { example, are } \\
\text { prevalent here }\end{array}$ & $\begin{array}{l}\text { Both, but more } \\
\text { desistance } \\
\text { paradigm } \\
\text { focused. }\end{array}$ \\
\hline
\end{tabular}




\begin{tabular}{|c|c|c|c|c|}
\hline & $\begin{array}{l}\text { There is also the } \\
\text { mention of } \\
\text { programming in } \\
\text { this policy, } \\
\text { which can also } \\
\text { relate to the } \\
\text { desistance } \\
\text { paradigm } \\
\text { (Farmer, } \\
\text { McAlinden and } \\
\text { Maruna (2015). } \\
\text { Willingness and } \\
\text { Responsibility is } \\
\text { a primary code } \\
\text { that is under this } \\
\text { focused code, } \\
\text { and could also } \\
\text { have a reflective } \\
\text { element to it that } \\
\text { leads to } \\
\text { secondary } \\
\text { desistance } \\
\text { (Maruna 2001) }\end{array}$ & $\begin{array}{l}\text { programming for } \\
\text { sex offenders. }\end{array}$ & $\begin{array}{l}\text { (Andrews and } \\
\text { Bonta 2010). }\end{array}$ & \\
\hline $\begin{array}{l}\text { Connections to } \\
\text { Society }\end{array}$ & $\begin{array}{l}\text { Mention of } \\
\text { social services } \\
\text { (which relates to } \\
\text { social support) } \\
\text { in this code that } \\
\text { could be } \\
\text { provided to the } \\
\text { offender, along } \\
\text { with } \\
\text { employment } \\
\text { which is also } \\
\text { related to } \\
\text { desistance } \\
\text { (Cullen 1994, } \\
\text { Craig and Foster } \\
\text { 2013). }\end{array}$ & & $\begin{array}{l}\text { A connection to } \\
\text { society could } \\
\text { relate to risk } \\
\text { aspects such as } \\
\text { and offender } \\
\text { engaging in } \\
\text { leisure and } \\
\text { recreation } \\
\text { (Andrews and } \\
\text { Bonta 2010). }\end{array}$ & $\begin{array}{l}\text { Both, but more } \\
\text { of a risk } \\
\text { paradigm focus. }\end{array}$ \\
\hline
\end{tabular}

Policy Comparisons in Relation to Desistance

In my analysis section I grouped together focused codes in order to highlight

Charmaz's (2006) question around comparing texts that deal with similar topics as part of 
CGT. Given that this is present in my analysis section, I felt as though this should also be a prevalent question to address in my discussion section. As seen above, in the summary sections of my discussion, I summarize my suggestions and commentaries on desistance. Therefore, this section will serve as summarizing the main points as they pertain to informal social control, formal social control, and sex offender desistance. My discussion above, and the summary that goes along with said discussion, incorporates some of the smaller and larger trends I found when looking for desistance in the CSC policies. However, this policy comparison section is different because I will only be discussing the bigger and most frequent themes found across policies. At the end of this subsection I will discuss some of the common themes within policies where aspects of the risk paradigm are also prevalent.

\section{Informal Social Control}

$C D$ 705-6, $C D 715-1$, and $C D 715-2$ all to some extent have a personalized element to the ways in which they ask offenders about their personal thoughts in regard to their offences, their subsequent actions from the offence and the consequences that have resulted because of their offences and actions (CSC Website, CD 705-6; CSC Website, CD 715-1; CSC Website, $C D$ 715-2; Maruna 2001). Employment is mentioned in $C D$ 705-6, $C D$ 715-1, and $C D$ 715-3, and its lack of mention in $C D 715-2$ is not as big of a deal as is not like these policies have ignored the importance of employment altogether (CSC Website, CD 705-6; CSC Website, CD 715-1; CSC Website, CD 715-2; CSC Website, CD 715-3). In CD 705-6 employment is talked about in depth in terms of skills but could still bear to incorporate an understanding of non-formal employment (CSC Website, CD 705-6; Harris 2016). In the other two policies employment is mentioned in relation to social bonds (i.e., location is inquired about in $C D$ 715-1, and in $C D$ 715-3 community employers are being talked to), and although I maintain 
that CD 715-3 could go further in their questions with the community employer, employment aspects are still mentioned throughout (CSC Website, CD 715-1, CSC Website, CD 715-3).

All four policies incorporate several aspects of social bonds within their assessment sections. For example, $C D$ 705-6 has a detailed questionnaire around family and relationships, $C D$ 715-1 inquires about the offender's associates, $C D$ 715-2 discusses social bonds especially in relation to community and stability, and $C D 715-3$ incorporates community contacts in a way that is indicative of social bonds (CSC Website, CD 705-6; CSC Website, CD 715-1; CSC Website, CD 715-2; CSC Website, CD 715-3).

\section{Formal Social Control}

Firstly, a theme every policy has in common is that they are created by a criminal justice organization, and parole officers who assess offenders on the basis of these policies are criminal justice actors, and thus possess an aspect of formal control (CSC Website, CD 705-6; CSC Website, CD 715-1; CSC Website, CD 715-2; CSC Website, CD 715-3; Brogden and Harkin 2000). Furthermore, education is mentioned in both $C D$ 705-6, and $C D$ 715-1; in $C D$ 705-6 there are many questions around education and learning styles, and in $C D$ 715-1 inquiring about education is mentioned, just with significantly less detail (CSC Website, $C D$ 705-6; CSC Website, CD 715-1). Both of these policies could benefit from asking about the offender's current education level.

Another major theme present across all four policies was treatment or interventions (CSC Website, CD 705-6; CSC Website, CD 715-1; CSC Website, CD 715-2; CSC Website, $C D$ 715-3). These questions should not only be clearer (i.e., my suggestion around defining what intervention means in $C D$ 715-1 and $C D$ 715-2), but much of the treatment discussion within these policies would benefit from a more personalized element, as treatment 
experiences can vary from offender to offender.

\section{Sex Offender Desistance}

Of all the policies only $C D$ 705-6 had a specific sex offender section (CSC Website, CD 705-6). My suggestions for this section is that it should inquire more about social bonds (in terms of if the offender has support in the community), it should prepare the offender more for the potential of social outcry within the community, should have more questions about treatment and the offender's past experiences, and should also inquire more about accommodations (CSC Website, $C D$ 705-6). CD 715-1 despite not having a sex offender section, does incorporate aspects that are relatable for sex offenders such as living in a remote location-however this policy should follow these questions up more thoroughly (CSC Website, $C D$ 715-1). $C D$ 715-2 also does not have a sex offender section but mentioning sex offender history in this policy would help acknowledged the different needs sex offenders have (CSC Website, $C D$ 715-2). Lastly, $C D$ 715-3 has the same issue as $C D$ 715-1-the policy would benefit from acknowledging that programming, for example would be different for sex offenders, and therefore putting a statement about this in their policy could at least acknowledge this difference (CSC Website, CD 715-3).

Although there is not necessarily one theme that is present throughout each policy in regard to sex offenders (in terms of informal and formal social control), the interesting part here is that $C D 715-1$ and $C D 715-2$ both incorporate some aspects of sex offender desistance without having a sex offender section, but still required further suggestions on how to better integrate sex offender desistance (CSC Website, CD 715-1; CSC Website, CD 715-2). Furthermore, for $C D$ 715-3 the suggestions made were minor and had more to do with wording and special considerations for sex offenders, but the factors that these suggestions 
were attached to could be related to sex offenders, thus there were no elements that simply did not relate (CSC Website, CD 715-3).

Hence, I would argue that although these policies in relation to sex offender desistance have no major themes that run concretely in them (i.e., like education or treatment), the alternative theme here is straightforward: regardless of having a sex offender section within the policy or not, these policies would all benefit from going into detail about certain aspects of sex offender desistance. That detail will differ given that each policy is different. Hence, although each policy has sex offender desistance aspects, no one policy covers these aspects flawlessly.

\section{Risk}

In my discussion section I already summarized what was discussed in my analysis section in relation to the risk paradigm. To avoid more repetition, in this policy comparison section I am simply going to list the trends that were captured throughout every policy that have risk components consistent with the central eight risk factors outlined by Andrews and Bonta (2010). Every policy discusses to some extent: current offences, relationships (including support), drugs and alcohol (sometimes referenced as substance abuse), employment, and situations (whether that would be personal interpretations of situations or reactions and responses to the criminal act) (CSC Website, CD 705-6; CSC Website, CD 715-1; CSC Website, $C D$ 715-2; CSC Website, $C D$ 715-3). These are just the bigger themes that have been consistent throughout the policies, this is not to say that the other codes I discussed do not incorporate important risk factors as well. In terms of sex offending in particular and its connection to risk, the policies are all a bit different but touch on aspects that affect risk and recidivism such as treatment, anti-social peers, and leisure (CSC Website, CD 705-6; CSC 
Website, $C D$ 715-1; CSC Website, $C D$ 715-2; CSC Website, CD 715-3; Andrews and Bonta 2010).

\section{Summary}

The major themes across these policies include employment, education, social bonds, interaction from criminal justice personnel, and treatment and interventions (CSC Website, $C D$ 705-6; CSC Website, $C D$ 715-1; CSC Website, $C D$ 715-2; CSC Website, $C D$ 715-3). Sex offender desistence was an encompassing aspect throughout each of the four policies, but, again, could benefit from the addition of additional aspects (CSC Website, $C D$ 705-6; CSC Website, CD 715-1; CSC Website, CD 715-2; CSC Website, CD 715-3). In terms of themes across the policies that included aspects of the risk paradigm, they include: current offences, relationships, substance abuse, employment and situations (CSC Website, CD 705-6; CSC Website, CD 715-1; CSC Website, CD 715-2; CSC Website, CD 715-3; Andrews and Bonta 2010).

Final Thoughts: Desistance versus Risk

Throughout the analysis and discussion portions of this paper, I point to instances wherein the word risk is used in the assessment criteria. For example, in $C D$ 715-2 when risk is mentioned in relation to questioning how an offender's behaviour change has impacted their "risk level" (CSC Website, $C D$ 715-2, 14). Of note here, is that of the times I mentioned risk in this paper in relation to the policies, I was able to follow this up with discussion on how despite using "risk" as a term in the policies, there were still some aspects of the desistance paradigm present (CSC Website, $C D 715-2,14)$. This within itself is an interesting trend because it shows that risk and desistance narratives can coexist and aspects of both of these paradigms can be present. 
In relation to the desistance paradigm, I talk about how these policies incorporate social bonds and support (family, relationships, and friends) in a way that is consistent with how the desistance literature frames the importance of these factors for the desistance process (see Laub and Sampson 1993; Kras 2019; Laub and Sampson 2003; Berg and Huebner 2011). The relationship an offender has to the community is also inquired about in these policies and is further related to the desistance paradigm, and how community bonds can help foster prosocial relationships that the offender will have with the community (including support) (Lin 1986; CSC Website, CD 705-6). Education, including skill set and learning styles were mentioned most frequently in $C D$ 705-6 and $C D$ 715-1 which relates to formal social control, and education can also relate to employability (see Hansen 2003; Machin, Marie, and Vujić 2011; Blomberg et al. 2011; Lockwood et al. 2012). Employment was also mentioned in these policies, and employment can be a factor of desistance (Craig and Foster 2013; Verbruggen, Blokland, and Geest 2012).

Treatment is also discussed in all four of these policies (CSC Website, CD 705-6; CSC Website, CD 715-1; CSC Website, CD 715-2; CSC Website, CD 715-3), and is related to desistance because treatment programs have been shown to kickstart a shift in the offender towards understanding their negative behaviour, but is also shown to foster positive support networks (Mann, Devendran, and Lundrigan 2019). Further, substance abuse treatment is also shown to positively influence reintegration (Davis, Bahr, and Ward 2012).

Of more immediate importance, however, is that throughout these policies I was also able to relate almost every primary code to the risk paradigm in some way (in accordance with Andrews and Bonta's (2010) central eight risk factors). This also included discussing aspects 
such as the relationship the offender has to the community, education, employment, substance abuse, and incorporating aspects of personality and personal situation into the discussion around risk (CSC Website, CD 705-6; CSC Website, CD 715-1; CSC Website, CD 715-2; CSC Website, $C D$ 715- 3). It is also important to note that sex offender desistance aspects also had risk aspects closely correlated with them in the policies (CSC Website, CD 705-6; CSC Website, $C D$ 715-1; CSC Website, $C D$ 715-2; CSC Website, $C D$ 715-3).

Thus, at the end of this analysis and discussion I am left questioning if the need to move towards a more desistance focused and less risk focused paradigm is needed to assess offender's for community reintegration. If there is such a considerable amount of overlap/interconnectedness between the risk paradigm and desistance paradigm is there really a benefit of going towards one over another? Should the focus then move to balancing both risk and desistance? This is an important time to remember that there have been training programs for parole officers that incorporate both paradigms, therefore this idea of overlapping has been considered before (Horan 2015; Serin and Lloyd 2017). There are also assessment tools that take both into account (Horan, Wong, and Szifris 2019).

The next section of this thesis will conclude this paper and discuss the limitations and the future direction of research for this topic. 


\section{Conclusion}

This thesis explored CSC policies $C D$ 705-6, $C D$ 715-1, $C D$ 715-2, and $C D$ 715-3

through a combination of policy analysis, thematic analysis, CDA and CGT in order to assess if there were aspects of the desistance paradigm present within them. Through this analysis it was found that these policies all present with aspects of informal and formal social control that can contribute to the desistance process, including aspects such as employment, social bonds, education, and treatment (CSC Website, CD 705-6; CSC Website, CD 715-1; CSC Website, $C D$ 715-2; CSC Website $C D$ 715-3). Further, the policies had themes present between all four of them that related to the risk paradigm, such as drugs and alcohol, employment, relationships (including support), and situational factors.

To summarize in more detail, I will go over the main points of my analysis of each policy as it relates to general desistance (informal and formal social control). In terms of informal social control, $C D$ 705-6 does a respectable job of asking questions that are reflective for offenders, which paves the way for secondary desistance, and does a good job of discussing social bonds (CSC Website, CD 705-6). This policy should include non-formal aspects of work (Harris 2016), and pay more attention to age at first offence (CSC Website, CD 705-6). In terms of formal control this policy could do a better job at asking questions in terms of education and current abilities, should also take into account the previous relationship offenders have had with their parole officers, and should inquire further about past treatment (CSC Website, CD 705-6).

In $C D$ 715-1, in terms of general desistance and informal social control, the policy should really focus on relationships more (specifically collateral contacts) (CSC Website, CD 715-1). Overall, this policy does a good job at inquiring about social bonds (CSC Website, CD 715-1). In terms of informal social control, this policy does an adequate job of discussing treatment, but 
could, like $C D$ 705-6, ask more about education (CSC Website, CD 715-1; CSC Website, CD 705-6).

$C D$ 715-2 does an effective job at accounting for offence history, especially in the way the policy talks about the offence cycle (CSC Website, CD 715-2). The policy also does a good job at presenting what sort of information the parole officer should gather from collateral contacts (CSC Website, CD 715-2). In terms of formal social control, the policy requires the parole officers to gather information from other actors in the criminal justice system in relation to an offender, which is a positive aspect of the policy (CSC Website, $C D$ 715-2). The policy could explain more clearly what intervention means (CSC Website, CD 715-2). Lastly, CD 715 3, does a good job of inquiring about the correctional plan, and about the community (CSC Website, $C D$ 715-3). It could do a better job of talking with community employers about offenders to ensure a positive work environment (CSC Website, $C D$ 715-3). In terms of formal social control, this policy should inquire more about why an offender refused treatment (CSC Website, $C D$ 715-3).

The analysis and discussion for this thesis specifically focused on looking at how sex offender desistance was incorporated into these policies. All of the policies incorporated sex offender desistance elements to different extents, regardless of if there was a specified sex offender section within them (CSC Website, CD 705-6; CSC Website, CD 715-1; CSC Website, $C D$ 715-2; CSC Website $C D$ 715-3). Specifically, in $C D$ 705-6 this is not very thorough, but more importantly the treatment section needs to be expanded to really understand what sex offenders may be feeling regarding going to treatment (CSC Website, CD 705-6). However, at the same time, it does address social bonds quite well, regardless of the fact that I mention it should really include more questions about if the offender has offended towards family (CSC 
Website, $C D$ 705-6). Housing and accommodations should also be addressed more within this policy (CSC Website, CD 705-6). Lastly, this policy needs more questions around employment especially for the offender to conceive how they would navigate issues relating to their offence, shall they come up in the professional sense (CSC Website, $C D$ 705-6). In $C D$ 715-1 there is no sex offender checklist, however, I discuss how this policy does mention aspects related to sex offenders such as location (i.e., being in a remote location), and I suggest that parole officers can expand on this especially if they know the offender is a sex offender (CSC Website, $C D$ 715-1). The policy mentions being restricted when it comes to intervention, and I comment on how this could be important to ask sex offenders given the stigma they face in relation to treatment (Lacombe 2008; Levins and Crewe 2015; CSC Website, CD 715-1).

$C D$ 715-2 also does not have a dedicated sex offender checklist, and the one point I have for this policy was in regard to Annex C (Ratings Reassessment and Correctional Plan Progress) where a sex offence history point should be added for parole officers to consider (CSC Website, $C D$ 715-2). Lastly, in $C D$ 713-3, the policy needs to make note of sex offender programming as something the parole officer should consider for the offender (i.e., like CoSA), should inquire further about why an offender has refused treatment in the past (CSC Website, CD 715-3). Lastly, this policy should also make note of having the parole officer ask employers about the social and physical environment of the work place (CSC Website, CD 715-3).

Even though this project was focusing more so on the desistance paradigm, I ended up discussing aspects of both the risk and desistance paradigms in-depth. At the end of my discussion, I pose several questions that could be important to answer. Although this project cannot answer all of these questions, I believe that it paved the way for more discussions around balancing risk and desistance as concepts in relation to re-offending. By nature of the 
way my discussion upfolded, it is clear that a lot of my suggestions of where aspects of desistance could be included into the policies simply were a matter of adding more to what was already existing. In most cases, once I did this, I was able to talk about the codes I developed through a desistance paradigm and risk paradigm lens. Thus, in my mind, the conclusion that has naturally come from this project is the fact that not only can risk factors and desistance factors coexist, but, if written in enough detail, they can complement one another.

Scholars such as Maruna and LeBel (2003), Ttofi et al. (2016), Ward and Maruna (2007), de Vries Robbé, de Vogel, and de Spa (2011), de Vries Robbé et al. 2015, and Thornton (2013) advocate for the fact that we should be looking at an offender's strengths when considering re-offending and reintegration, which is what separates desistance from risk. But, in my analysis, I make references several times to the fact that even though "risk" is explicitly mentioned in policies (see $C D$ 715-2) it does not take away from desistance aspects that are mentioned (CSC Website, CD 715-2). Although scholars seem to focus on how risk is more negative than desistance when it comes to how they present the offender's realities (see Maruna and LeBel 2003; Ttofi et al. 2016; Ward and Maruna 2007, for example), it seems factors of these paradigms co-exist quite well in CSC policies.

Like I mentioned previously, the overlapping of these two paradigms in the form of both training programs and assessment tools does exist (Horan 2015; Serin and Lloyd 2017; Horan, Wong, and Szifris 2019). To expand, I would argue that this paper did encapsulate the whole picture from what was said in my analysis. For example, in $C D$ 705-6, there is only one question about a drug and alcohol program (CSC Website, $C D$ 705-6). I suggested not only asking more questions, but having those questions be centered around asking the offender what worked for 
them and if they had support during this process. In $C D$ 715-1 I say that focusing on responsivity factors is good, but if the parole officer asks the offender where the offender thinks they are at academically, this could also be helpful (CSC Website, $C D$ 715-1). In $C D$ 715-2 I mention how even though the parole officer has to ask about how attitude changes have affected the offender's risk level, attitude change could be an avenue to secondary desistance (CSC Website, CD 715-2; Maruna 2001). Finally, in $C D$ 715- 3, I mention how it would be ideal if offenders knew if other offenders worked at their place of employment as this could foster social bonds (CSC Website, CD 715-3; Lin 1986). However, drug and alcohol programs, responsivity (education), and attitudes all also relate to aspects of the risk paradigm (Andrews and Bonta 2010). Drugs and alcohol correlate to substance abuse, responsivity correlates to education, and attitudes can correlate to both anti- social cognitions and anti-social attitudes (Andrews and Bonta 2010).

At the end of my discussion, I ask these two questions: if there is such a considerable amount of overlap/interconnectedness between the risk paradigm and desistance paradigm is there really a benefit of going towards one over another? I would argue that there is no benefit of going towards one or the other, and that they should both be balanced within correctional policies, despite the ideas presented by Maruna and LeBel (2003), Ttofi et al. (2016), Ward and Maruna (2007), de Vries Robbé, de Vogel, and de Spa (2011) and Thornton (2013) that a risk approach is inherently negative.

There are several reasons as to why I believe that the concepts of both risk and desistance should be balanced within policies. Firstly, parole officers may interpret policies different ways because each parole officer is going to have a different style. Although this can be seen as a limitation of policies (i.e., one can question if having subjective policies is a good thing), the flexibility of interpretation allows for variability in supervision style. 
Secondly, and more to the point, however, is that policies are supposed to be neutral in the sense that they are meant for public consumption. Given this, having a policy that presents and includes multiple aspects of reintegration (desistance and risk) is important so that parole officers who have different styles can still interpret the policies with correct intentions, and so multiple aspects are presented.

Thirdly, not every offender is at the stage where they are ready to desist. If this is the case, then if a parole officer interpreted the policy with aspects of risk in mind instead of desistance, this could actually greatly help the offender minimize risks in their lives, and, eventually get to the point wherein desistance is possible. Finally, the flipside of this is that some offenders may be ready for desistance (depending on their personal characteristics and history). With that in mind having a policy that is considerably risk and recidivism focused could be detrimental to the offender and their desistance journey. Thus, since policies should be somewhat uniform and clear (i.e., having two policies called $C D$ 705-6 but having one focusing on the desistance paradigm and one focusing on the risk paradigm could get confusing for parole officers especially if they did not know which one to reference in a given situation), it makes sense that the policies incorporate elements of both the risk and desistance paradigms.

The three reasons above articulate why desistance and risk should co-exist in reintegration policies. There are other aspects to consider as to why going towards one or the other is not beneficial and why the simultaneous approach is beneficial. Above, I talk about why these two aspects should co-exist mostly from the point of view of parole officers and their interpretation of policy (in relation to offenders), however, offenders, and the effect policies have on them should be considered. Thus, I argue that one of the biggest arguments in 
favour of why aspects of the desistance and risk paradigms should co-exist in policies is because they could allow for offenders to see where they are at in their correctional program. I recognize this assumes that offenders have a good relationship with their parole officer, and also assumes that parole officers would use the terms "risk" and "desistance" when talking about progress (this may not be the case and could depend on the offender's learning level). However, I make this argument because there is the possibility that an offender could inquire about where they are in their correctional program, and if a parole officer uses the policies as a point of reference to explain this to them, then this could lead to an understanding of desistance. In a perfect scenario it could also lead to desistance.

Although we do not know how the explanation of where an offender is at in their program would go (as this also depends heavily on parole officers, their style, and on the offender's capability to understand), having a policy that has elements of the risk and desistance paradigms present could be beneficial personally for offenders, whether that would be to compare against their progress and/or correctional program, or to educate them around what the next steps are. This adds to my third point above as to why risk and desistance should co-exist, and the positive implications of this.

However, one must also engage with the limitations and reasons why aspects of the desistance and risk paradigms should not co-exist (or some of the downsides of their coexistence). One of the reasons I mention above as to why both paradigms should co-exist is that in some instances offenders may not be ready for desistance, thus having only a risk approach within the policies could be beneficial. However, what I think is important to realize here is that there is a possibility that the offender never gets to the desistance stage while on parole. Therefore, just because aspects of the desistance and risk paradigms co-exist, and just 
because this could be beneficial for the parole officer's style (and for offenders if they do desist), it is important to recognize that with the co-existence of these elements comes the assumption that the offender will desist eventually, which may not be the case. However, I maintain that even though this is an assumption, there is still no harm having both of these elements present.

Furthermore, another argument as to why these elements should not exist together in policies is the idea that maybe it is only a good thing that they exist together if parole officers know about their co-existence. This is very much so the flipside to one of my main reasonings as to why these elements should exist together (i.e., the idea that they account for differing parole officer styles). But I still wonder if accounting for different parole officer styles could only become effective if the policies were structured in a way that really highlights their desistance and risk paradigm elements, simply as a way to offer guidance for parole officers to assist their clients. I do not actually recommend that CSC restructure their policies to take this into consideration (since the policy accounts for aspects of both paradigms anyways), but I do believe this point highlights the interplay between parole officer knowledge, and the way policies are written, and offers a point of thought around some of the potential disadvantages of having a policy that interweaves these two aspects quite well. But, although there are pros and cons to consider when a risk and desistance approach are present in policies, I argue that it is still beneficial that they co-exist.

My last point in relation to reintegration policies is the idea that CSC has an obligation to the public and public safety. Thus, there should be a focus on the offender (in the individualized fashion that Serin and Lloyd (2017) mention that RNR incorporates) because individual factors could be predictive of how community reintegration will go. Furthermore, 
risk needs to be considered as it pertains to community reintegration because it is not unfair to assume that the public will care about an offender's risk level. Knowing what the offender's risk level is has the possibility to either make the public feel safe, or unsafe. I think there are also other factors to consider here, such as the media. How the media responds to offenders or certain offenders in the community is important as it can inform how safe the public feels in relation to offenders being in the community.

However, it is also important to understand that there is a spectrum of possible public reactions. Certain cases would likely inspire very extreme reactions, but others would inspire more moderate ones (based on the crimes committed). In my opinion, the tricky part lies with deciding which offenders transition into the community. Should it be based on whether their likelihood to desist intersects with the likelihood of a moderate reaction? This is not a question I know the answer to, but nonetheless I think it is something to consider.

In my introduction I explain how this project is important because it could help CSC in developing a more revised and current policy that can better target not only sexual offenders, but aspects of the desistance paradigm instead of the risk paradigm. However, as stated above, after the analysis of the policies and conclusions gathered, it seems that these two paradigms are both present in the policies. This is a positive aspect of Correctional Service Canada's policy on reintegration, and, thus, the revision of current policy based on the conclusions of this paper is not needed at this time.

To formally conclude, this paper not only analyzed $C D 705-6, C D 715-1, C D 715-2$ and $C D$ 715-3 for the presence of general and sex offender desistance, but in doing so looked specifically at aspects of the risk and desistance paradigms, and recognized how they complement one another, especially in these policies. This paper suggested that this is a 
positive matter, and the coexistence of desistance and risk can not only help offenders in the system achieve pro-social integration but is also beneficial to parole officers who have the option to read the policies as they see fit. This paper also came to the conclusion that aspects of the risk and desistance paradigm are intertwined significantly throughout Correctional Service Canada policies.

Before discussing future research, it is important to consider the limitations of this research project as a way to recognize the aspects of the project that could be different or changed.

\section{Limitations}

This project presents with several limitations that differ in gravity. First, this project could have taken more policies into account as they relate to the community and reintegration. For example, this project could have included CD 710-1 (Progress Against the Correctional Plan), or $C D$ 710-7 (Work Releases) in the analysis of this thesis. Although the information in these policies is somewhat covered by the other policies that were analyzed, they could have been additional inclusions that could have added more validity to the themes developed and to the comparison sections of the policies that were analyzed.

Another limitation of this research is that it is very time specific. Although I mentioned in the analysis section that the fact these policies were all written at the same time was beneficial for consistency, I also wonder how looking at the policies throughout time would aid in this analysis. For example, an analysis of $C D$ 705-6, $C D$ 715-1, $C D$ 715-2, and $C D$ 715-3 from the time each of them was adopted at CSC, to current day iterations of the same policies could help trace how and if aspects of the desistance paradigm have been part of CSC policy over time. Even if these policies were not named as such back then, looking at parole or 
reintegration policies from years ago could still be helpful. Moreover, doing an analysis of policy over time could also be useful in making connections between any significant social changes in society over time, and how said changes could mirror the ways in which offenders, reintegration, and parole are discussed in policy. Although this is a more drawn-out process, it could aid in having a better grasp of the implications and change of policy at any time.

A third limitation of this research has to do with the use of CGT. CGT, although being the appropriate method to use for this paper (see Charmaz 2006), bears a certain aspect of subjectivity throughout. This is not necessarily negative across the board, but what it means is that I coded the themes presented to me in policy by what I saw in the policy. Different people could theoretically derive different themes from an analysis using CGT. More to the point, however, is that policy, although constructed to be adhered to, does not rid itself from also being subjective to a certain extent. Throughout the analysis in this paper, I stopped to question not only word choice, but ideas within the assessment of the policy that could take on different meanings or were not clear. This is not to say that policy should not be analyzed, rather, there needs to be a recognition that in some instances there is no correct way to undertake a qualitative analysis that involves coding.

The last limitation of this project is that it did not consider women, or Indigenous status. Including these demographics would have meant including multiple other $C D s$ which would have made this paper considerably longer. However, I also recognize the need to explore how $C D s$ that pertain to women and Indigenous offenders incorporate aspects of the risk and desistance paradigm.

\section{Next Steps and Future Research}

There are multiple next steps for research of this nature. Above I mention how more 
policies could have been analyzed in the realm of CSC within this project. Given the conclusion that this project has come to, I maintain that more policies that incorporate community reintegration should be coded and analyzed for themes, as this would increase the validity of this type of analysis and be an interesting point of investigation. To expand, however, it could also be beneficial to examine other policies from other countries that have similar correctional processes at the federal level as Canada, in order to see how risk and desistance factors are present in policies, and if there are actual instances where they co-exist.

Another avenue that could be taken is similar to my original idea for this project: interviewing a subset of past federal offenders who have been incarcerated and have also been in the community on parole. These interviews would consist of asking the ex-offenders what they thought about the assessments that were used for correctional planning while they were in the community. Questions could consist of asking the ex-offenders if they found the assessments to be helpful, and if they thought the assessments captured aspects of their life that either positively or negatively impacted offending behaviour. Questions here would have to be specific, such as "do you think the assessments that you undertook with your parole officer asked you relevant questions about your family/employment/relationships? Are there any questions or topics that you think should be added?".

A study set up in this way would get an ex-offender's view of assessment content. Combining this with a thematic analysis could further help researchers understand how offenders contextualize what is important for reintegration. They could also help researchers further suggest aspects that are missing from assessments by having firsthand accounts of the reality of reintegration from people who have been subject to the assessment process. A discussion of the risk and desistance paradigms would also play a part in this project in that 
what comes of this proposed project could help researchers understand the importance of how risk and desistance play out in the ex-offender's mind (i.e., how do ex-offenders talk about reintegration? What particular questions or assessments helped them, and did they help them because they took into account risk or desistance, or both? How did the parole officer play a role in this?).

I mention above how a limitation of this project is how it does not include women or Indigenous offenders in the analysis. This limitation is an opportunity for further research, as I believe it would bring to light another layer that needs to be considered when investigating the ways in which policy accounts for the two paradigms.

This thesis came to the conclusion that aspects of the risk and desistance paradigm overlap in the policies ways that that are beneficial, but through the coding process provided concrete examples of this in $C D$ 705-6, $C D$ 715-1, CD 715-2, and $C D 715-3$. Although there is room for this specific research to advance and include other actors such as parole officers and ex-offenders, this project demonstrated that policies related to the Canadian federal prison system in regard to reintegration provide an adequate balance of aspects of the risk and desistance paradigms throughout.

To formally conclude, my hope is that this research not only provided satisfactory discussion on risk and desistance, but also showcased the multi-dimensional, multi-layered and complex nature of parole policies. My goal for future research is to continue this work in a larger capacity whether that would be academically or in a work setting. 


\section{References}

Abeling-Judge, David. 2019. "Stopping Out and Going Back: The Impact of Educational Attainment on Criminal Desistance Among Stopped-Out Offenders." Crime and Delinquency 65 (4): $527-554$.

Akers, Ronald L. 1998. Social learning and social structure: A general theory of crime and deviance. Boston, MA: Northeastern University Press.

Akers, Ronald L. 2000. Criminological theories: Introduction and evaluation (3rd ed.). Los Angeles, CA: Roxbury.

Ambrose, Mallory A., and Jeffrey W. Rosky. 2013. "Prisoners' round: Examining the literature on recreation and exercise in correctional facilities." International Journal of Criminology and Sociology 2: 362-370.

Andrews, Donald, and James Bonta. 2003. The psychology of criminal conduct ( $3^{\text {rd }}$ ed). Cincinnati, $\mathrm{OH}$ : Anderson.

Andrews, Donald, and James Bonta. 2006. The psychology of criminal conduct ( $4^{\text {th }}$ ed). Newark, NJ: LexisNexis/Matthew Bender.

Andrews, Donald, and James Bonta. 2010. The psychology of criminal conduct ( $5^{\text {th }}$ ed). Cincinnati, $\mathrm{OH}$ : Anderson.

Andrews, Donald, and James, Bonta. 1998. The psychology of criminal conduct ( $2^{\text {nd }}$ ed). Cincinnati, $\mathrm{OH}$ : Anderson.

Andrews, Donald, James Bonta, and Robert Hoge. 1990. "Classification for Effective Rehabilitation: Rediscovering Psychology.” Criminal Justice and Behavior 17: 19-52.

Andrews, Donald, James Bonta, and Stephen Wormith. 2010. "The Level of Service (LS) Assessment of adults and older adolescents." In R. Otto \& K. Douglas (Eds.), Handbook of violence risk assessment tools (pp. 199-225). New York, NY: Routledge.

Atkinson, Rowland. 2014. Shades of deviance. London, England: Routledge.

Attrill, G., and Liell, G. 2007. "Offenders views on risk assessment." In N. Padfield (Ed.), Who to release? Parole, fairness and criminal justice, (pp. 191-201). Cullompton, UK: Willan.

Bacchi, Carol. 2000. "Policy as Discourse: What Does It Mean? Where Does It Get Us?" Discourse: Studies in the Cultural Politics of Education 21 (1): 45-57.

Bahr, Stephen J., Paul E. Harris, Janalee H. Strobell, and Bryan M. Taylor. 2012. "An Evaluation of a Short-Term Drug Treatment for Jail Inmates." International Journal of Offender Therapy and Comparative Criminology 57 (10): 1275-1296.

Bates, Andrew, Ron Macrae, Dominic Williams, and Carrie Webb. 2012. "Ever-Increasing Circles: A Descriptive Study of Hampshire and Thames Valley Circles of Support and Accountability 2002-09." Journal of Sexual Aggression 18 (3): 355-373. 
Batiuk, Mary Ellen, Karen F Lahm, Matthew Mckeever, Norma Wilcox, and Pamela Wilcox. 2005. "Disentangling the Effects of Correctional Education: Are Current Policies Misguided? An Event History Analysis." Criminal Justice 5 (1): 55-74.

Benda, Brent B. 2005. "Gender Differences in Life-Course Theory of Recidivism: A Survival Analysis." International Journal of Offender Therapy and Comparative Criminology 49 (3): 325-342.

Benda, Brent B., Nancy J. Harm, and Nancy J. Toombs. 2005. "Survival Analysis of Recidivism of Male and Female Boot Camp Graduates Using Life-Course Theory." Journal of Offender Rehabilitation 40 (3-4): 87-113.

Bennett, Trevor, and Katharine K. Holloway. 2009. "The Causal Connection Between Drug Misuse and Crime." British Journal of Criminology 49 (4): 513-531.

Bennett, Trevor, Katy Holloway, David Farrington. 2008. "The Statistical Association Between Drug Misuse and Crime: A Meta-Analysis." Agression and Violent Behavior 13 (2): $107-$ 118.

Berg, Mark T., and Beth M. Huebner. 2011. "Reentry and the Ties that Bind: An Examination of Social Ties, Employment, and Recidivism." Justice Quarterly 28 (2): 382-410

Blasko, Brandy L., Peter D. Friedmann, Anne Giuranna Rhodes, and Faye S. Taxman. 2015. "The Parolee-Parole Officer Relationship as a Mediator of Criminal Justice Outcomes." Criminal Justice and Behavior 42 (7): 722-740.

Blomberg, Thomas G., William D. Bales, Karen Mann, Alex R. Piquero, and Richard A. Berk. 2011. "Incarceration, Education and Transition from Delinquency." Journal of Criminal Justice 39 (4): 355-365.

Boduszek, Daniel, Gary Adamson, Mark Shevlin, Philip Hyland, and Ashling Bourke. 2013. "The Role of Criminal Social Identity in the Relationship Between Criminal Friends and Criminal Thinking Style Within a Sample of Recidivistic Prisoners." Journal of Human Behavior in the Social Environment 23 (1): 14-28.

Bonta, James, Suzanne Wallace-Capretta, and Jennifer Rooney. 2000. "A quasi-experimental evaluation of an intensive rehabilitation supervision program." Criminal Justice and Behavior 27: 312-329.

Bouffard, Leana and John H. Laub. 2004. "Jail or the Army: Does Military Service Facilitate Desistance from Crime?" In S. Maruna and R. Immarigeon (Eds.), After Crime and Punishement: Pathways to Offender Reintegration, (pp 129-151). Cullompton: Willan.

Bowen, Glenn A. 2003. Social Funds as a Strategy for Poverty Reduction in Jamaica: An Exploratory Study. Dissertation Abstracts International. University Microfilms ATT 3130413, Doctoral Dissertation, Florida International University, A 65/04, 1557.

Bowen, Glenn A. 2009. "Document Analysis as a Qualitative Research Method." Qualitative Research Journal 9 (2): 27-40. 
Brogden, Mike, and Sharon Harkin. 2000. "Community Rules Preventing Re-Offending by Child Sex Abusers-A Life History Approach." International Journal of the Sociology of Law 28 (1): 45-68.

Brown, Jason. 2004. "Challenges facing Canadian federal offenders newly released to the community: A Concept Map.” Journal of Offender Rehabilitation, 39, 19-35.

Brown, Sarah. 2005. Treating Sex Offenders: An Introduction to Sex offender Treatment Programs. Cullompton: Willan Publishing.

Bryman, Allan. 2016. Social Research Methods. Oxford: Oxford University Press.

Burnett, Ros. 2004. “One-to-one ways of promoting desistance: In search of an evidence base." In R. Burnett and C. Roberts (Eds.), What Works in Probation and Youth Justice: Developing Evidence-Based Practice (pp 180-197). Cullompton: Willan.

Bushway, Shawn D., Alex R. Piquero, Lisa M. Broidy, Elizabeth Cauffman, and Paul Mazerolle. 2001. "An Empirical Framework for Studying Desistance as a Process." Criminology 39 (2): 491-513.

Carach, Carlos and Simon Leverett. 1999. Recidivism among juvenile offenders: An analysis of times to reappearance to court. Canberra: Australian Institute of Criminology. Australian Institute of Criminology Research and Public Policy Series No. 17.

Carlsson, Christoffer. 2012. "Using 'Turning Points' to Understand Processes of Change in Offending." The British Journal of Criminology 52 (1): 1-16.

Caspi, Avshalom. 2000. "The child is father of the man: Personality continuities from childhood to adulthood." Journal of Personality and Social Psychology 78 (1): 158-172.

Caudy, Michael S., Johanna B. Folk, Jeffrey B. Stuewig, Alese Wooditch, Andres Martinez, Stephanie Maass, June P. Tangney, and Faye S. Taxman. 2015. "Does Substance Misuse Moderate the Relationship Between Criminal Thinking and Recidivism?" Journal of Criminal Justice 43 (1): 12-19.

Caudy, Michael S., Joseph M. Durso, and Faye S. Taxman. 2013. "How Well Do Dynamic Needs Predict Recidivism? Implications for Risk Assessment and Risk Reduction." Journal of Criminal Justice 41 (6): 458-466.

Chappell, Cathryn. 2004. "Post-Secondary Correctional Education and Recidivism: A MetaAnalysis of Research Conducted 1990-1999." Journal of Correctional Education 55 (2): $148-169$.

Charmaz, Kathy. 2006. Constructing grounded theory: A practical guide through qualitative analysis. London: SAGE Publications.

Charmaz, Kathy. 2008. "Constructionism and the Grounded Theory Method." In Handbook of Constructionist Research (Eds). by James A. Holstein and Jaber F. Gubrium, (pp. 397-412). New York: The Guildford Press.

Cooley, Brooke N., Sara E. Moore, and Lisa L. Sample. 2017. "The Role of Formal Social Control 
Mechanisms in Deterring Sex Offending as Part of the Desistance Process." Criminal Justice Studies 30 (2): 136-157.

Craig, Jessica, and Holly Foster. 2013. "Desistance in the Transition to Adulthood: The Roles of Marriage, Military, and Gender." Deviant Behavior 34 (3): 208-223.

Creswell, John W., and Vicki L. Plano Clark. 2011. Designing and Conducting Mixed Methods Research. Los Angeles: SAGE Publications.

CSC Website 2019. Commissioner's Directive 715-2. "Post-Release Decision Process.” Correctional Service of Canada. Last Modified April 11, 2019. https://www.cscscc.gc.ca/politiques-et-lois/715-2-cd-en.shtml

CSC Website. 2012. Commissioner's Directive 715-4. "Case Preparation and Supervision of Women Offenders With Children Residing at a Community-Based Residential Facility." Correctional Service Canada. Last Modified June 13, 2012. https://www.csc-scc.gc.ca/actsand-regulations/715-4-cd-eng.shtml

CSC Website. 2013. Commissioner's Directive 702. “Aboriginal Offenders.” Correctional Service Canada. Last Modified November 12, 2013. https://www.csc-scc.gc.ca/acts-andregulations/702-cd-eng.shtml

CSC Website. 2014. Commissioner's Directive 710-7. "Work Releases." Correctional Service of Canada. Last Modified July 24, 2014. https:/www.csc-scc.gc.ca/politiques-et-lois/710-7-cdeng.shtml

CSC Website. 2016. “Our Priorities.”. Correctional Service Canada. Last Modified May 13, 2016. https://www.csc-scc.gc.ca/about-us/006-0002-eng.shtml

CSC Website. 2019. “The Federal Offender Population Profile.” Correctional Service Canada. Last Modified May 7, 2019. https://www.csc-scc.gc.ca/publications/005007-3033-en.shtml

CSC Website. 2019. Commissioner's Directive 577. "Staff Protocol in Women offender Institutions." Correctional Service Canada. Last Modified May 30, 2019. https://www.cscscc.gc.ca/acts-and-regulations/577-cd-en.shtml

CSC Website. 2019. Commissioner's Directive 578. "Intensive Intervention Strategy in Women Offender Institutions/Units.” Correctional Service Canada. Last Modified November 30, 2019. https://www.csc-scc.gc.ca/acts-and-regulations/578-cd-en.shtml

CSC Website. 2019. Commissioner's Directive 705-6. “Correctional Planning and Criminal Profile." Correctional Service of Canada. Last Modified April 3, 2019. https://www.cscscc.gc.ca/politiques-et-lois/705-6-cd-en.shtml

CSC Website. 2019. Commissioner's Directive 710-1. "Progress Against the Correctional Plan." Correctional Service of Canada. Last Modified November 9, 2018. https://www.cscscc.gc.ca/politiques-et-lois/710-1-cd-en.shtml

CSC Website. 2019. Commissioner's Directive 715-1. “Community Supervision.” Correctional Service of Canada. Last Modified April 4, 2019. https://www.csc-scc.gc.ca/politiques-etlois/715-1-cd-en.shtml 
CSC Website. 2019. Commissioner's Directive 715-3. "Community Assessments." Correctional Service of Canada. Last Modified April 25, 2019. https://www.csc-scc.gc.ca/politiques-etlois/715-3-cd-en.shtml

Cullen, Francis T. 1994. "Social Support as an Organizing Concept for Criminology: Presidential Address to the Academy of Criminal Justice Sciences." Justice Quarterly 11 (4): 527-559.

Danto, Elizabeth. 2008. "Historical Research.” In T. Triodi (Ed.), Pocket Guides to Social Work Research Methods (pp. 3-157). New York: Oxford University Press.

Davis, Celeste, Stephen J. Bahr, and Carol Ward. 2012. "The Process of Offender Reintegration: Perceptions of What Helps Prisoners Reenter Society." Criminology \& Criminal Justice 13 (4): 446-469.

de Vries Robbé, Michiel, Ruth E. Mann, Shadd Maruna, David Thornton, Calvin M. Langton, and James R. Worling. 2015. "An Exploration of Protective Factors Supporting Desistance From Sexual Offending.” Sexual Abuse: A Journal of Research and Treatment 27 (1): 16-33.

de Vries Robbé, Michiel, Vivienne de Vogel, and Eva de Spa. 2011. "Protective Factors for Violence Risk in Forensic Psychiatric Patients: A Retrospective Validation Study of the SAPROF." International Journal of Forensic Mental Health 10 (3): 178-186.

Diem, Sarah, Michelle D. Young, Anjalé D. Welton, Katherine C. Mansfield, and Pei-Ling Lee. 2014. "The Intellectual Landscape of Critical Policy Analysis." International Journal of Qualitative Studies in Education 27 (9): 1068-1090.

Dunrose, Matthew R., Alexia D. Cooper, and Howard. N. Snyder. 2014. Recidivism of prisoners released in 30 States in 2005: Patterns from 2005 to 2010. U.S. Department of Justice: Bureau of Justice Statistics, NCJ 244205.

Duwe, Grant. 2012. "Can Circles of Support and Accountability (COSA) Work in the United States? Preliminary Results from a Randomized Experiment in Minnesota." Sexual Abuse: A Journal of Research and Treatment 25 (2): 143-165.

Evans, Douglas N., and Jeremy R. Porter. 2015. "Criminal History and Landlord Rental Decisions: A New York Quasi-Experimental Study." Journal of Experimental Criminology 11 (1): 2142.

Fairclough, Isabela, and Norman Fairclough. 2012. Political Discourse Analysis: A Method for Advanced Students. Abington, Oxon: Routledge.

Fairclough, Norman. 1989. Language and power. London: Longman.

Fairclough, Norman. 2013. "General Introduction". In N. Fairclough (Ed.), Critical Discourse Analysis: The Critical Study of Language (2nd ed), (pp. 1-23). New York: Routledge.

Farmer, Mark, Anne-Marie McAlinden, and Shadd Maruna. 2015. "Understanding Desistance from Sexual Offending: A Thematic Review of Research Findings." Probation Journal 62 (4): 320-335. 
Farrall, Stephen, Gilly Sharpe, Ben Hunter, and Adam Calverley. 2011. "Theorizing Structural and Individual-Level Processes in Desistance and Persistence: Outlining an Integrated Perspective." Australian \& New Zealand Journal of Criminology 44 (2): 218-234.

Farrington, David P., and J. David Hawkins. 1991. "Predicting Participation, Early Onset, and Later Persistence in Officially Recorded Offending." Criminal Behaviour and Mental Health (1): 1-33.

Fereday, Jennifer and Eimear Muir-Cochrane. 2006. "Demonstrating Rigor using Thematic Analysis: A Hybrid Approach of Inductive and Deductive Coding and Theme Development." International Journal of Qualitative Methods 5 (1): 80-92.

Finlay, Linda. 2003. “The reflexive journey: Mapping multiple routes”. In L. Finlay and B. Gough (Eds.), Reflexivity: A practical guide for researchers in health and social sciences (pp 3-20). London: Blackwell.

Frey, James H., and Time Delaney. 1996. "The role of leisure participation in prison: A report from consumers.” Journal of Offender Rehabilitation 23: 79-89.

Gadd, David, and, Stephen Farrall. 2004. "Criminal Careers, Desistance and Subjectivity: Interpreting Men's Narratives of Change." Theoretical Criminology 8 (2): 123-156.

Gendreau, Paul, Paula Smith, and Shelia French 2006. "The theory of effective correctional intervention: Empirical status and future directions." In F. Cullen, J. Wright, \& M. Coleman (Eds.), Taking stock: The status of criminological theory (pp. 419-446). Piscataway, NJ: Transaction Press.

Giordano, Peggy C., Patrick M. Seffrin, Wendy D. Manning, and Monica A. Longmore. 2011. "Parenthood and Crime: The Role of Wantedness, Relationships with Partners, and SES." Journal of Criminal Justice 39 (5): 405-416.

Giordano, Peggy C., Stephen A. Cernkovich, and Jennifer L. Rudolph. 2002. "Gender, Crime, and Desistance: Toward a Theory of Cognitive Transformation." The American Journal of Sociology 107 (4): 990-1064.

Glaser, Barney, and Anselm L. Strauss. 1967. The Discovery of Grounded Theory: Strategies for Qualitative Research. Chicago: Aldine.

Glaser, Daniel. 1969. The Effectiveness of a Prison and Parole System. Indianapolis, IN: BobbsMerrill.

Glueck, Sheldon, and Eleanor Glueck. 1943. Criminal Careers in Retrospect. New York: Commonwealth Fund.

Göbbels, Svenja, Tony Ward, and Gwenda M. Willis. 2012. "An Integrative Theory of Desistance from Sex Offending." Aggression and Violent Behavior 17 (5): 453-462.

Gordon, Karen E. 2013. "The Registered Sex Offender Population as a Marker of Social Disorganisation." The Howard Journal of Criminal Justice 52 (5): 527-542.

Gottfredson, Michael R., and Travis Hirschi. 1990. A General Theory of Crime. Stanford, 
California: Stanford University Press.

Gough, Harrison G., Ernest A. Wenk, and Vitali V. Rozynko. 1965. "Parole outcome as predicted from the CPI, the MMPI, and a base expectancy table." Journal of Abnormal Psychology 70: $432-441$.

Graffam, Joseph, Alison J. Shinkfield, and Lesley Hardcastle. 2008. "The perceived employability of ex-prisoners and offenders." International Journal of Offender Therapy and Comparative Criminology 52 (6): 673-85.

Grattet, Ryken, Jeffrey Lin, and Joan Petersilia. 2011. "Supervision Regimes, Risk, and Official Reactions to Parolee Deviance." Criminology 49 (2): 371-399.

Grieger, Lena, and Daniela Hosser. 2014. "Which Risk Factors Are Really Predictive?: An Analysis of Andrews and Bonta's 'Central Eight' Risk Factors for Recidivism in German Youth Correctional Facility Inmates." Criminal Justice and Behavior 41 (5): 613-634.

Griffith, Jakari N., and Nicole C. Jones Young. 2017. "Hiring ex-offenders? the case of ban the box." Equality, Diversity and Inclusion: An International Journal 36 (6): 501-18.

Griffiths, C. T. 2015. Canadian criminal justice: A primer (Fifth ed.). Toronto: Nelson Education.

Groot, Wim, and Henriëtte Maassen van Den Brink. 2010. "The Effects of Education on Crime.” Applied Economics 42 (3): 279-289.

Guillemin, Marilys, and Lynn Gillam. 2004. "Ethics, Reflexivity and "Ethically Important Moments" in Research." Qualitative Inquiry 10 (2): 261-280.

Gunnison, Elaine, and Jacqueline B. Helfgott. 2011. "Factors that hinder offender reentry success: A view from community corrections officers." International Journal of Offender Therapy and Comparative Criminology 55 (2): 287-304.

Håkansson, Anders and Mats Berglund. 2012. "Risk Factors for Criminal Recidivism - a Prospective Follow-up Study in Prisoners with Substance Abuse." BMC Psychiatry 12 (1): $111-118$.

Hannah-Moffat, Kelly. 2008. "Re-imagining Gendered Penalities: The Myth of Gender Responsivity.” In P. Carlen (Ed.), Imaginary Penalities (pp 193-219). London: Willan Press.

Hannem, Stacey and Michael Petrunik. 2004. "Canada's Circles of Support and Accountability: A Community Justice Initiative for High-Risk Sex Offenders." Corrections Today 66 (7): 98.

Hannem, Stacey, and Michael Petrunik. 2007. "Circles of Support and Accountability: A Community Justice Initiative for the Reintegration of High Risk Sex Offenders." Contemporary Justice Review 10 (2): 153-171.

Hannem, Stacey. 2011. "Experiences in Reconciling Risk Management and Restorative Justice: How Circles of Support and Accountability Work Restoratively in the Risk Society." International Journal of Offender Therapy and Comparative Criminology 57 (3): 269-288. 
Hansen, Kirstine. 2003. "Education and the Crime-Age Profile." The British Journal of Criminology 43 (1): 141-168.

Hanson, Karl R. 2005. Stability and change: Dynamic risk factors for sexual offenders. In W. L. Marshall, Y. M. Fernandez, L. E. Marshall, \& G. A. Serran (Eds.), Sexual offender treatment: Issues and controversies (pp. 17-31). West Sussex, UK: John Wiley.

Hanson, Karl R., and David, Thornton. 2000. "Improving risk assessments for sex offenders: A comparison of three actuarial scales." Law and Human Behavior, 24, 119-136.

Hanson, Karl R., and Kelly Morton-Bourgon, K. E. 2007. The accuracy of recidivism risk assessments for sexual offenders: A meta-analysis (ResearchRep. No. 2007-01). Ottawa; Canada: Public Safety and Emergency Preparedness.

Hanson, Karl R., and Kelly Morton-Bourgon, K. E. 2009. "The accuracy of recidivism risk assessments for sexual offenders: A meta-analysis of 118 prediction studies." Psychological Assessment, 21(1), 1-21.

Hanson, Karl R., and Kelly Morton-Bourgon, K.E. 2004. Predictors of Sexual Recidivism: An Updated Meta-Analysis (ResearchRep. No. 2004-02). Ottawa; Canada: Public Safety and Emergency Preparedness.

Hanson, Karl R., Andrew J.R. Harris, Terri-Lynne Scott, and Leslie Helmus. 2007. Assessing the risk of sexual offenders on community supervision: The dynamic supervision project. (Research PS3-1/2007-5). Ottawa; Canada: Public Safety Canada.

Hanson, Karl R., Guy Bourgon, Leslie Helmus and Shannon Hodgon. 2009. A meta-analysis of the effectiveness of treatment for sexual offenders: Risk, need, and responsivity. Vol. 2009-01; 2009-01; Ottawa: Public Safety Canada.

Hanson, R. Karl, and Andrew J. R. Harris. 2000. "Where should we Intervene?: Dynamic Predictors of Sexual Offense Recidivism." Criminal Justice and Behavior 27 (1): 6-35.

Hare, Robert D. 1991. The Hare Psychopathy Checklist- Revised. Torronto: Multi-Health Systems.

Hare, Robert D. 1993. Without conscience: The disturbing world of the psychopaths among us. New York: Pocket Books.

Hare, Robert D. 1996. "Psychopathy: A clinical construct whose time has come." Criminal Justice and Behavior 23: 25-54.

Harris, Andrew J.R., and Karl R. Hanson. 2004. Sex Offender Recidivism: A simple question. (User Report 2004-03). Ottawa: Public Safety Canada.

Harris, Danielle Arlanda. 2014. "Desistance from Sexual Offending: Findings from 21 Life History Narratives." Journal of Interpersonal Violence 29 (9): 1554-1578.

Harris, Danielle Arlanda. 2016. "A Descriptive Model of Desistance from Sexual Offending: Examining the Narratives of Men Released from Custody." International Journal of Offender Therapy and Comparative Criminology 60 (15): 1717-1737. 
Harris, Danielle Arlanda. 2017. "Desistance from Sexual Offending: Behavioral Change without Cognitive Transformation." Journal of Interpersonal Violence 32 (20): 3049-3070.

Healy, Deirdre, and Ian O’Donnell. 2006. "Criminal Thinking on Probation: A Perspective From Ireland." Criminal Justice and Behavior 33, (6): 782-802.

Healy, Deirdre. 2012. "Advise, Assist and Befriend: Can Probation Supervision Support Desistance?" Social Policy \& Administration 46 (4): 377-394.

Hertz, R. 1997. “Introduction: Reflexivity and Voice.” In R. Hertz (Ed.), Reflexivity and voice (pp. vi-xviii). Thousand Oaks, CA: Sage.

Hipp, John R., Joan Petersilia, and Susan Turner. 2010. "Parolee Recidivism in California: The Effect of Neighborhood Context and Social Service Agency Characteristics." Criminology 48 (4): 947-979.

Hjalmarsson, Randi. 2008. "Criminal Justice Involvement and High School Completion." Journal of Urban Economics 63 (2): 613-630.

Höing, Mechtild, Bas Vogelvang, and Stefan Bogaerts. 2017. "'I Am a Different Man Now"-Sex Offenders in Circles of Support and Accountability: A Prospective Study." International Journal of Offender Therapy and Comparative Criminology 61 (7): 751-772.

Homey, Julie D., Wayne Osgood, and Ineke Haen Marshall. 1995. "Criminal Careers in the ShortTerm: Intra-individual Variability in Crime and Its Relation to Local Life Circumstances." American Sociological Review (60) :655- 73.

Horan, Rachel N. 2015. "Restorative Justice: The Relevance of Desistance and Psychology." Safer Communities 14 (3): 147-155.

Horan, Rachel, Kevin Wong, and Kirstine Szifris. 2019. "Enabling Change: An Assessment Tool for Adult Offenders That Operationalises Risk Needs Responsivity and Desistance Principles." European journal of probation 12 (1): 1-16.

Huebner, Beth M. 2005. "The Effect of Incarceration on Marriage and Work Over the Life Course." Justice Quarterly 22 (3): 281-303.

Katsiyannis, Antonis, and Teara Archwamety. 1997. "Factors Related to Recidivism Among Delinquent Youths in a State Correctional Facility." Journal of Child and Family Studies 6 (1):43-56.

King, Ryan D., Michael Massoglia, and Ross Macmillan. 2007. "The Context of Marriage and Crime: Gender, the Propensity to Marry, and Offending in Early Adulthood." Criminology 45 (1): 33-65.

King, Sam. 2013. "Early Desistance Narratives: A Qualitative Analysis of Probationers' Transitions Towards Desistance." Punishment \& Society 15 (2): 147-165.

Knight, Barry J., Seven G. Osborn, and Donald J. West. 1977. "Early Marriage and Criminal Tendency in Males." British Journal of Criminology 17 (3). 
Kras, Kimberly R. 2019. "Can Social Support Overcome the Individual and Structural Challenges of being a Sex Offender? Assessing the Social Support-Recidivism Link." International Journal of Offender Therapy and Comparative Criminology 63 (1): 32-54.

Kras, Kimberly R., and Brandy L. Blasko. 2016. "Pathways to Desistance among Men Convicted of Sexual Offenses: Linking Post Hoc Accounts of Offending Behavior and Outcomes." International Journal of Offender Therapy and Comparative Criminology 60 (15): 1738-1755.

Kronick, Rachel, and Cécile Rousseau. 2015. "Rights, Compassion and Invisible Children: A Critical Discourse Analysis of the Parliamentary Debates on the Mandatory Detention of Migrant Children in Canada." Journal of Refugee Studies 28 (4): 544-569.

Lacombe, Dany. 2008. "Consumed with Sex: The Treatment of Sex Offenders in Risk Society." The British Journal of Criminology 48 (1): 55-74.

Laub, John H., and Robert J. Sampson. 1993. "Turning Points in the Life Course: Why Change Matters to the Study of Crime." Criminology (31): 301-25.

Laub, John H., and Robert J. Sampson. 2001. "Understanding Desistance from Crime." Crime and Justice 28: 1-69.

Laub, John H., and Robert J. Sampson. 2003. Shared Beginnings, Divergent Lives: Delinquent Boys to Age 70. Cambridge, Mass: Harvard University Press.

Laub, John H., Daniel S. Nagin, and Robert J. Sampson. 1998. "Trajectories of Change in Criminal Offending: Good Marriages and the Desistance Process." American Sociological Review (63): $225-38$

Laverty, Louise, and Rebecca Harris. 2018. "Can Conditional Health Policies Be Justified? A Policy Analysis of the New NHS Dental Contract Reforms." Social Science \& Medicine 207: 46-54.

Lee, Raymond M. 2000. Unobtrusive Methods in Social Research. Philadelphia: Open University Press.

Levins, Alice, and Ben Crewe. 2015. "'Nobody's Better than You, Nobody's Worse than You': Moral Community among Prisoners Convicted of Sexual Offences." Punishment \& Society 17 (4): 482.

Lin, Nan. 1986. “Conceptualizing social support.” In N. Lin, A. Dean, and W. Edsel (Eds.), Social support, life events, and depression (pp. 17-30). Orlando, FL: Academic Press.

Lo, Celia C., and Hua Zhong. 2006. "Linking Crime Rates to Relationship Factors: The Use of Gender-Specific Data.” Journal of Criminal Justice 34 (3): 317-329.

Lochner, Lance. 2004 "Education, Work, and Crime: A Human Capital Approach." International Economic Review 45 (3): 811-843.

Lockwood, Susan, John M. Nally, Taiping Ho, and Katie Knutson. 2012. "The Effect of Correctional Education on Postrelease Employment and Recidivism: A 5-Year Follow-Up 
Study in the State of Indiana." Crime \& Delinquency 58 (3): 380-396.

Loeber, Rolf, and Marc LeBlanc. 1990. "Toward a Developmental Criminology”. In M. Tonry and N. Morris (Eds). Crime and Justice: A Review of Research (pp. 375-468). Chicago: University of Chicago Press.

Loeber, Rolf. 1990. "Development and Risk Factors of Juvenile Antisocial Behavior and Delinquency.” Clinical Psychology Review 10 (1): 1-41.

Lucken, Karol, and Lucille M. Ponte. 2008. "A just measure of forgiveness: Reforming occupational licensing regulations for Ex-Offenders using BFOQ analysis." Law \& Policy 30 (1): 46-72.

Lueger, Robert J., and William Cadman. 1982. "Variables Associated with Recidivism and Program-termination of Delinquent Adolescents." Journal of Clinical Psychology 38 (4): 861-863.

Lytle, Robert, Danielle J. S. Bailey, and Tusty ten Bensel. 2017. "We Fought Tooth and Toenail: Exploring the Dynamics of Romantic Relationships among Sex Offenders Who have Desisted." Criminal Justice Studies 30 (2): 117-135.

Machin, Stephen, Olivier Marie, and Sunčica Vujić. 2011. "The Crime Reducing Effect of Education." The Economic Journal 121 (552): 463-484.

Mackieson, Penny, Aron Shlonsky, and Marie Connolly. 2019. "Increasing Rigor and Reducing Bias in Qualitative Research: A Document Analysis of Parliamentary Debates using Applied Thematic Analysis." Qualitative Social Work 18 (6): 965-980.

Mallik-Kane, K., and Christy A. Visher. 2008. Health and prisoner reentry: How physical, mental, and substance abuse conditions shape the process of reintegration. Washington, DC: Justice Policy Center, Urban Institute.

Mandracchia, Jon T., Robert D. Morgan, Sheila Garos, and J. Travis Garland. 2007. "Inmate Thinking Patterns: An Empirical Investigation." Criminal Justice and Behavior 34 (8): 10291043.

Mann, Natalie, Priya N. Devendran, and Samantha Lundrigan. 2019. "'You're Never really Free': Understanding the Barriers to Desistance for Registered Sexual Offenders in the Community." Criminology \& Criminal Justice 00 (0): 1-18.

Mann, Ruth E., Stephen D. Webster, Caroline Schofield, and William L. Marshall. 2004. "Approach Versus Avoidance Goals in Relapse Prevention with Sexual Offenders." Sexual Abuse: A Journal of Research and Treatment 16 (1): 65-75.

Maruna, Shadd, and Stephen Farrall. 2004. "Desistance From Crime: A Theoretical Reformulation." Kvlner Zeitschrift fur Soziologie und Sozialpsychologie 43: 171-94.

Maruna, Shadd and Thomas T. LeBel. 2003. "Welcome home? Examining the "re-entry court" concept from a strengths-based perspective." Western Criminology Review 4: 91-107.

Maruna, Shadd, and Kevin Roy. 2007. "Amputation Or Reconstruction? Notes on the Concept of 
"Knifing Off" and Desistance from Crime." Journal of Contemporary Criminal Justice 23 (1): 104-124.

Maruna, Shadd, Russ Immarigeon, and Thomas P. LeBel. 2004. "Ex-offender reintegration: Theory and practice." In S. Maruna and R. Immarigeon (Eds.), After Crime and Punishment: Pathways to Offender Reintegration (pp 3-26). Cullompton: Willan.

Maruna, Shadd. 1997. "Going Straight: Desistance from crime life narratives of reform.” In A. Lieblich and R. Josselson (Eds.), The Narrative Study of Our Lives (pp 59-93). Thousand Oaks, California: SAGE Publications.

Maruna, Shadd. 2001. Making Good. Washington, DC: APA Press.

Maruna, Shadd. 2017. “Desistance as a Social Movement." Irish Probation Journal 14(1): 5-20.

Mason, Jennifer. 1996. Qualitative researching. London: Sage.

Matza, David. 1964. Delinquency and Drift. New York: Wiley.

Mauthner, Natasha S., and Andrea Doucet. 2003. "Reflexive Accounts and Accounts of Reflexivity in Qualitative Data Analysis." Sociology 37 (3): 413-431.

May, Peter, Geralyn Hynes, Philip Mccallion, Sheila Payne, Philip Larkin, and Mary Mccarron. 2013. "Policy Analysis: Palliative Care in Ireland." Health policy 115 (1): 69-74.

McAlinden, Anne-Marie, Mark Farmer, and Shadd Maruna. 2017. "Desistance from Sexual Offending: Do the Mainstream Theories Apply?" Criminology \& Criminal Justice 17 (3): 266-283.

McCloskey, Rose. 2008. An Institutional Exploration of the Transitional Experience of Nursing Home Residents to and from a Hospital Emergency Room. PhD Dissertation, Interdisciplinary Studies, University of New Brunswick, Fredericton, Canada.

McCord, Joan. 1980. "Patterns of Deviance." In S. Sells, R. Crandall, M. Roff, J. Strauss and W. Pollin (Eds.), Human Functioning in Longitudinal Perspective (pp. 157-162). Baltimore: Williams.

McFarland, Joel., Jiashan Cui, Amy Rathbun, and Juliet Holmes. 2018. Trends in high school dropout and completion rates in the United States: 2018. Washington, DC: National Center for Education Statistics, Institute of Education Sciences.

McGurk, Barry J., Alexander W. McEwan, and F. Graham. 1981. "Personality Types and Recidivism Among Young Delinquents. (Great Britain)." British Journal of Criminology 21 (2): 159-165.

Meek, Rosie, and Gwen Eleanor Lewis. 2014. "Promoting Well-Being and Desistance Through Sport and Physical Activity: The Opportunities and Barriers Experienced by Women in English Prisons." Women \& Criminal Justice 24 (2): 151-172.

Meloy, Michelle L. 2005. "The Sex Offender Next Door: An Analysis of Recidivism, Risk Factors, and Deterrence of Sex Offenders on Probation." Criminal Justice Policy Review 16 (2): 211- 
236.

Merriam, Sharan. 1988. Case Study Research In Education: A Qualitative Approach. San Fransico: Jossey-Bass.

Mills, Alice, and Helen Codd. 2008. "Prisoners' Families and Offender Management: Mobilizing Social Capital." Probation Journal 55 (1): 9-24.

Moffitt, Terrie E., Avshalom Caspi, Nigel Dickson, Phil Silva, Warren Stanton. 1996. “Childhoodonset versus adolescent-onset antisocial conduct problems in males: Natural history from ages 3 to 18 years." Development and Psychopathology 8: 399-424.

Morash, Merry, Deborah A. Kashy, Sandi W. Smith, and Jennifer E. Cobbina. 2015. "The Effects of Probation Or Parole Agent Relationship Style and Women Offenders' Criminogenic Needs on Offenders' Responses to Supervision Interactions." Criminal Justice and Behavior 42 (4): 412-434.

Moscovici, Serge, and Marisa Zavalloni. 1969. "The Group as a Polarizer of Attitudes.” Journal of Personality and Social Psychology 12 (2): 125-135.

Motiuk, Laurence L., and Shelley L. Brown. 1996. Factors related to recidivism among released federal sex offenders. (Research Report No. R-49). Ottawa, Canada: Correctional Service of Canada.

Mustaine, Elizabeth Ehrhardt, Richard Tewksbury, and Kenneth M. Stengel. 2006. "Social Disorganization and Residential Locations of Registered Sex Offenders: Is this a Collateral Consequence?" Deviant Behavior 27 (3): 329-350.

Nee, Claire, and Zarah Vernham. 2016. "Expertise and Its Contribution to the Notion of Protective Factors in Offender Rehabilitation and Desistance." Aggression and Violent Behavior 32: 3744.

Palmer, Emma J., and Clive R. Hollin. 2004. "The Use of the Psychological Inventory of Criminal Thinking Styles with English Young Offenders." Legal and Criminological Psychology 9 (2): $253-263$.

Parole Board of Canada. 2018. "Types of Conditional Release." Last Modified October 19, 2018. https://www.canada.ca/en/parole-board/services/parole/types-of-conditional-release.html

Paternoster, Ray, and Shawn Bushway. 2009. "Desistance and the "Feared Self": Toward an Identity Theory of Criminal Desistance." The Journal of Criminal Law and Criminology (1973-) 99 (4): 1103-1156.

Pollack, Shoshana L. 2000. “Outsiders Inside: The Social Context of Women's Lawbreaking and Imprisonment”. ProQuest Dissertations Publishing. 1-211.

Pozzulo, Joanna, Craig Bennell, and Adelle E. Forth. 2015. Forensic Psychology. Fourth ed. Don Mills, Ontario: Pearson Canada Inc.

Prendergast, Michael L., Frank S. Pearson, Deborah Podus, Zachary K. Hamilton, and Lisa Greenwell. 2013. "The Andrews' Principles of Risk, Need, and Responsivity as Applied in 
Drug Abuse Treatment Programs: Meta-Analysis of Crime and Drug Use Outcomes.” Journal of experimental criminology 9 (3): 275-300.

Public Safety Canada. 2017. "Corrections and Conditional Release Statistical Overview (CCRSO).” https://www.publicsafety.gc.ca/cnt/rsrcs/pblctns/ccrso-2017/ccrso-2017-en.pdf

Public Safety Canada. 2018. "Corrections and Conditional Release Statistical Overview (CCRSO).” https://www.publicsafety.gc.ca/cnt/rsrcs/pblctns/ccrso-2018/ccrso-2018-en.pdf

Ralph, Nicholas, Melanie Birks, and Ysanne Chapman. 2014. "Contextual Positioning: Using Documents as Extant Data in Grounded Theory Research." SAGE Open 4 (3): 1-7.

Rand, Alicia. 1987. "Transitional Life Events and Desistance from Delinquency and Crime." In From Boy to Man, from Delinquency to Crime, edited by Marvin E. Wolfgang, Terence P. Thornberry, and Robert M. Figlio Chicago: University of Chicago.

Reed, Paige. 2017. "Punishment beyond incarceration: The negative effects of sex offender registration and restrictions." Journal of Law and Criminal Justice 5(2): 16-30.

Robbers, Monica L. P. 2009. "Lifers on the Outside: Sex Offenders and Disintegrative Shaming." International Journal of Offender Therapy and Comparative Criminology 53 (1): $5-28$.

Robins, Lee. 1966. Deviant Children Grown Up. Baltimore: Williams \& Wilkins.

Rodermond, Elanie, Candace Kruttschnitt, Anne-Marie Slotboom, and Catrien CJH Bijleveld. 2016. "Female Desistance: A Review of the Literature." European Journal of Criminology 13 (1): 3-28.

Runell, Lindsey Livingston. 2017. "Identifying Desistance Pathways in a Higher Education Program for Formerly Incarcerated Individuals." International Journal of Offender Therapy and Comparative Criminology 61 (8): 894-918.

Salisbury, Emily. J., Breanna Boppre, and Bridget Kelly. 2016. "Gender-responsive risk and need assessment: Implications for the treatment of justice-involved women.” In F. Taxman (Ed.), Division on Corrections and Sentencing, volume 1, Risk and Need Assessment: Theory and Practice (pp 220- 243). London, UK: Taylor and Francis/Routledge.

Sampson, Robert J., and John H. Laub. 1995. "Understanding Variability in Lives through Time: Contributions of Life-Course Criminology." Studies on Crime and Crime Prevention (4): $143-58$.

Sampson, Robert J., and John H. Laub. 1998. "Integrating Quantitative and Qualitative Data." In J. Z. Giele and G. H. Elder (Eds.), Methods of Life Course Research: Qualitative and Quantitative Approaches (pp.213-30). Thousand Oaks: Sage Publications.

Sampson, Robert J., and John H. Laub. 2003. "Life-course Desisters? Trajectories of Crime among Delinquent Boys Followed to Age 70." Criminology 41 (3): 555-592.

Sampson, Robert J., and John H. Laub. 2005. "A Life-Course View of the Development of Crime." The Annals of the American Academy of Political and Social Science 602 (1): 12-45. 
Sampson, Robert J., John H. Laub, and Christopher Wimer. 2006. "Does Marriage Reduce Crime? A Counterfactual Approach to Within-Individual Casual Effects." Criminology 44 (3): 465508.

Saris, Patti B., Charles R. Breyer, Dabney L. Friedrich, Rachel E. Barkow, William H. Pryor Jr., Patricia Wilson Smoot. 2016. Recidivism among federal offenders: A comprehensive overview. Washington D.C.: United States Sentencing Commission.

Schulenberg, Jennifer L. 2016. The Dynamics of Criminological Research. Don Mills, Ontario: Oxford University Press.

Schwartz, Jennifer. 2006. "Effects of Diverse Forms of Family Structure on Female and Male Homicide." Journal of Marriage and the Family 68 (5): 1291-1312.

Seewald, Katharina, Astrid Rossegger, Juliane Gerth, Frank Urbaniok, Gary Phillips, and Jérôme Endrass. 2018. "Effectiveness of a risk-need-responsivity-based treatment program for violent and sexual offenders: Results of a retrospective, quasi-experimental study." Legal and Criminological Psychology 23 (1): 85-99.

Serin, Ralph C., and Donna L. Mailloux. 2003. "Assessment of sex offenders: Lessons learned from the assessment of non-sex offenders." Annals of the New York Academy of Sciences 989 (1): 185-97.

Serin, Ralph C., and Caleb D. Lloyd. 2017. "Understanding the Risk, Need, and Responsivity (RNR) Model and Crime Desistance Perspective and Integrating them into Correctional Practice." Carleton University and the Centre for Forensic Behavioural Science, Swinburne University of Technology: 1-13.

Sevigny, Eric, and Phyllis Coontz. 2008. "Patterns of Substance Involvement and Criminal Behavior: A Gender-Based Cluster Analysis of Pennsylvania Arrestees." International Journal of Offender Therapy and Comparative Criminology 52 (4): 435-453.

Simonoff, Emily, James Elander, Janet Holmshaw, Andrew Pickles, Robin Murray, and Michael Rutter. 2004. "Predictors of Antisocial Personality: Continuities from Childhood to Adult Life." British Journal of Psychiatry 184: 118-127.

Simons, Ronald L., Eric Stewart, Leslie C. Gordon, Rand D. Conger, and Glen H. Elder Jr. 2002. "A Test of Life-Course Explanations for Stability and Change in Antisocial Behavior from Adolescence to Young Adulthood." Criminology 40 (2): 401-434.

Smid, Wineke. J., Jan H. Kamphuis, Edwin C. Wever, and Maud C. F. M. Verbruggen. 2015. "Risk levels, treatment duration, and drop out in a clinically composed outpatient sex offender treatment group." Journal of Interpersonal Violence 30 (5): 727-43.

Smith, Paula, Paul Gendreau, and Kristin Swartz. 2009. "Validating the Principles of Effective Intervention: A Systematic Review of the Contributions of Meta-Analysis in the Field of Corrections." Victims \& Offenders: Effective Correctional Intervention 4 (2): 148-169.

Solomon E. Asch. 1955. "Opinions and Social Pressure.” Scientific American 193, (5): 31-35. 
Staller, Karen M. 2015. "Qualitative Analysis: The Art of Building Bridging Relationships." Qualitative Social Work 14 (2): 145-153.

Stearns, Elizabeth, and Elizabeth J. Glennie. 2006. "When and Why Dropouts Leave High School." Youth \& Society 38 (1): 29-57.

Stebbins, Robert. 1996. Tolerable differences: Living with deviance. Toronto, Ontario, Canada: McGraw-Hill Ryerson.

Steffensmeier, Darrell J., Emile Andersen Allan, Miles D. Harer, and Cathy Streifel. 1989. "Age and the Distribution of Crime." American Journal of Sociology 94: 803-31.

Stewart, Lynn A., Geoff Wilton, Sebastian Baglole, and Ryan Miller. 2019. A Comprehensive Study of Recidivism Rates among Canadian Federal Offenders. Ottawa; Canada. (ResearchRep.) No. 2019 No. R-426. Correctional Service Canada.

Sweeten, Gary, Shawn D. Bushway, and Raymond Paternoster. 2009. "Does Dropping Out of School Mean Dropping into Delinquency?" Criminology 47 (1): 47-91.

Taheri, Sema A., and Brandon C. Welsh. 2016. "After-School Programs for Delinquency Prevention: A Systematic Review and Meta-Analysis." Youth Violence and Juvenile Justice 14 (3): 272-290.

Tewksbury, Richard. 2005. "Collateral Consequences of Sex Offender Registration." Journal of Contemporary Criminal Justice 21 (1): 67-81.

Thomas, Natalie, and Melissa Bull. 2018. "Representations of Women and Drug Use in Policy: A Critical Policy Analysis.” International Journal of Drug Policy 56: 30-39.

Thornberry, Terence P., Alan J. Lizotte, Marvin D. Krohn, Margaret Farnworth, and Sung Joon Jang. 1994. "Delinquent Peers, Beliefs, and Delinquent Behavior: a Longitudinal Test of Interactional Theory." Criminology 32 (1): 47-83.

Thornton, David. 2013. "Implications of Our Developing Understanding of Risk and Protective Factors in the Treatment of Adult Male Sexual offenders." The International Journal of Behavioral Consultation and Therapy 8 (3-4): 62-65.

Tracy, Sarah J. 2010. "Qualitative Quality: Eight "Big-Tent" Criteria for Excellent Qualitative Research." Qualitative Inquiry 16 (10): 837-851.

Tracy, Sarah J. 2013. Qualitative research methods: Collecting evidence, crafting analysis, communicating impact. Chichester, West Sussex, UK: Wiley-Blackwell.

Tripodi, Stephen J., Johnny S. Kim, and Kimberly Bender. 2010. “Is Employment Associated With Reduced Recidivism?: The Complex Relationship Between Employment and Crime." International Journal of Offender Therapy and Comparative Criminology 54 (5): 706-720.

Ttofi, Maria M., David P. Farrington, Alex R. Piquero, and Matthew Delisi. 2016. "Protective Factors Against Offending and Violence: Results from Prospective Longitudinal Studies." Journal of Criminal Justice 45: 1-3. 
Tully, Ruth J., Shihning Chou, and Kevin D. Browne. 2013. "A systematic review on the effectiveness of sex offender risk assessment tools in predicting sexual recidivism of adult male sex offenders." Clinical Psychology Review 33 (2): 287-316.

Uggen, Christopher, and Candace Kruttschnitt. 1998. "Crime in the Breaking: Gender Differences in Desistance." Law \& Society Review 32 (2): 339-366.

Uggen, Christopher. 2000. "Work as a turning point in the life course of criminals: A duration model of age, employment, and recidivism”. American Sociological Review, 65, 529-546

van den Hoonaard, Deborah K. 2015. Qualitative research in action: A Canadian primer. Second ed. Don Mills, Ontario: Oxford University Press.

Varghese, Femina P., Erin E. Hardin, Rebecca L. Bauer, and Robert D. Morgan. 2010. "Attitudes toward hiring offenders: The roles of criminal history, job qualifications, and race." International Journal of Offender Therapy and Comparative Criminology 54 (5): 769782.

Vaughan, Barry. 2007. "The Internal Narrative of Desistance." The British Journal of Criminology 47 (3): 390-404.

Vaughn, Michael. 2011. "Addiction and Criminal Justice: Empirical Findings and Theory for Advancing Public Safety and Health.” Journal of Criminal Justice 39 (3): 205-206.

Verbruggen, Janna, Arjan A. J. Blokland, and Victor R. van der Geest. 2012. "Effects of Employment and Unemployment on Serious Offending in a High-Risk Sample of Men and Women from Ages 18 to 32 in the Netherlands." The British Journal of Criminology 52 (5): 845-869.

Viglione, Jill. 2019. “The Risk-Need-Responsivity Model: How Do Probation Officers Implement the Principles of Effective Intervention?" Criminal Justice and Behavior 46 (5): 655-673.

Vilorio, Dennis. 2016. Education matters. Washington, DC: U.S. Bureau of Labor Statistics.

Visher, Christly A., Carly Knight, Aaron Chalfin, and John Roman. 2009. The impact of marital and relationship status on social outcomes for returning prisoners. Washington, DC: Justice Policy Center, Urban Institute.

Visher, Christy A., and Jeremy Travis. 2003. "Transitions from Prison to Community: Understanding Individual Pathways." Annual Review of Sociology 29 (1): 89-113.

Visher, Christy A., and Shannon M. E. Courtney. 2007. One Year Out: Experiences of Prisoners Returning to Cleveland: Urban Institute.

Voorhis, Patricia Van. 2012. "On Behalf of Women Offenders: Women's Place in the Science of Evidence-Based Practice.” Criminology \& Public Policy 11 (2): 111-145.

Wakeling, Helen C., Stephen D. Webster, and Ruth E. Mann. 2005. "Sexual Offenders' Treatment Experience: A Qualitative and Quantitative Investigation." Journal of Sexual Aggression 11 (2): 171-186. 
Walters, Glenn D. 1990. The Criminal Lifestyle: Patterns of Serious Criminal Conduct. Thousand Oaks, CA: SAGE Publications, Inc.

Walters, Glenn D. 2003. "Predicting Institutional Adjustment and Recidivism with the Psychopathy Checklist Factor Scores: a Meta-Analysis." Law and Human Behavior 27 (5): $541-558$.

Ward, Tony, and Claire Stewart. 2003. "Criminogenic Needs and Human Needs: A Theoretical Model." Psychology, Crime and Law 9 (2): 125-143.

Ward, Tony, and Shadd Maruna. 2007. Rehabilitation. London, UK: Routledge.

Wartna, Bouke, Martine Blom, and, Nikolaj Tollenaar. 2011. The Dutch recidivism monitor, 4th revised edition. The Hague, The Netherlands: Research and Documentation Centre of the Ministry of Security and Justice, 2011-03a.

Watt, Bruce, Kevin Howells, and Paul Delfabbro. 2004. "Juvenile Recidivism: Criminal Propensity, Social Control and Social Learning Theories." Psychiatry, Psychology and Law 11 (1): 141-153.

Weaver, Beth. 2019. "Understanding Desistance: A Critical Review of Theories of Desistance." Psychology, Crime and Law 25 (6): 641-658.

Weitekamp, Elmar G. M., and Hans-Jurgen Kerner. 1994. "Epilogue: Workshop and Plenary Discussions, and Future Directions." In E. Weitekamp and H.J. Kerner (Eds), Cross-National Longitudinal Research on Human Development and Criminal Behavior (pp. 439-449). Dordrecht: Kluwer Academic.

Welte, John W., Grace M. Barnes, Joseph H. Hoffman, William F. Wieczorek, and Lening Zhang. 2005. "Substance Involvement and the Trajectory of Criminal Offending in Young Males." The American Journal of Drug and Alcohol Abuse 31 (2): 267-284.

White, Helen R., and Dennis M. Gorman. 2000. Dynamics of the drug-crime relationship. Criminal justice 2000 volume 1 . The nature of crime: continuity and change. Washington, DC: U.S. Department of Justice.

Whited, William H., Laura Wagar, Jon T. Mandracchia, and Robert D Morgan. 2015. "Partners or Partners in Crime? The Relationship Between Criminal Associates and Criminogenic Thinking." International Journal of Offender Therapy and Comparative Criminology 61 (5): $1-17$.

Wierson, Michelle, and Rex Forehand. 1995. "Predicting Recidivism in Juvenile Delinquents: The Role of Mental Health Diagnoses and the Qualification of Conclusions by Race." Behaviour Research and Therapy 33 (1): 63-67.

Wilcox, Bradford W., William J. Doherty, Helen Fisher, William A. Galston, Norval D. Glenn, John Gottman, Robert Lerman, Annette Mahonet, Barbara Markey, Howard K. Markman, Steven Nock, David Popenoe, Gloria G. Rodriguez, Scott M. Stanley, Linda J. Waite, and Judith Wallerstein. 2005. Why Marriage Matters, Second Edition: Twenty-Six Conclusions from the Social Sciences. A Report from Family Scholars. Institute for American Values. New York, NY. 
Williams, D J. 2006. "Forensic Leisure Science: A New Frontier for Leisure Scholars.” Leisure Sciences 28 (1): 91-95.

Williams, D. J. 2005. "Functions of Leisure and Recreational Activities Within a Sexual Assault Cycle: A Case Study." Sexual Addiction \& Compulsivity 12 (4): 295-309.

Williams, D. J., and Gordon J. Walker. 2006. "Leisure, deviant leisure, and crime: Caution: Objects may be closer than they appear." Leisure/Loisir 30: 193-218.

Wilson, David B., Catherine A. Gallagher, and Doris L. Mackenzie. 2000. "A Meta-Analysis of Corrections-Based Education, Vocation, and Work Programs for Adult Offenders." Journal of Research in Crime and Delinquency 37 (4): 347-368.

Wilson, Robin J., Franca Cortoni, and Andrew J. McWhinnie. 2009. "Circles of Support \& Accountability: A Canadian National Replication of Outcome Findings." Sexual Abuse: A Journal of Research and Treatment 21 (4): 412-430.

Wilson, Robin J., Picheca, Janice E., and Michelle Prinzo. 2005. Circles of Support \& Accountability: An Evaluation of the Pilot Project in South-Central Ontario. (Research Report No. R-168). Ottawa, Canada" Correctional Service of Canada.

Wolfgang, Marvin, Terence Thornberry, and Robert Figlio. 1987. From Boy to Man: From Delinquency to Crime. Chicago: University of Chicago.

Wong, Stephen C. P., and Audrey Gordon. 2006. "The Validity and Reliability of the Violence Risk Scale: A Treatment-Friendly Violence Risk Assessment Tool." Psychology, Public Policy, and Law 12 (3): 279-309.

Wooldredge, John, and Amy Thistlethwaite. 2003. "Neighborhood Structure and Race-Specific Rates of Intimate Assault.” Criminology 41 (2): 393-422. 


\title{
Appendix A: CD 705-6- Correctional Planning and Criminal Profile
}

\section{Commissioner's Directive 705-6 Correctional Planning and Criminal Profile}

\author{
Commissioner's Directive \\ Number: $705-6$ \\ In Effect: 2019-04-15 \\ Related links \\ Policy Bulletin 517 (517-pb-eng.shtml) \\ Policy Bulletin 554 (554-pb-eng.shtml) \\ Policy_Bulletin 586 ( $\underline{586-p b-e n . s h t m l)}$ \\ Policy Bulletin 619 (619-pb-en.shtml) \\ Policy Bulletin 633 (633-pb-en.shtml)
}

\section{Authorities}

- Corrections and Conditional Release Act (https://laws-lois.justice.gc.ca/eng/acts/C-44.6) (CCRA), sections $\underline{3}$ (http://lawslois.justice.gc.ca/eng/acts/C-44.6/section-3.html), 3.1 (http://laws-lois.justice.gc.ca/eng/acts/C-44.6/section-3.1.html), 4 (http://lawslois.justice.gc.ca/eng/acts/C-44.6/section-4.html), 15.1 (http://laws-lois.justice.gc.ca/eng/acts/C-44.6/section-15.1.html), 54 (http://lawslois.justice.gc.ca/eng/acts/C-44.6/section-54.html), 84 (http://laws-lois.justice.gc.ca/eng/acts/C-44.6/section-84.html), 84.1 (http://lawslois.justice.gc.ca/eng/acts/C-44.6/section-84.1.html) and Schedule I (http://laws-lois.justice.gc.ca/eng/acts/C-44.6/page-32.html) and II (http://laws-lois.justice.gc.ca/eng/acts/C-44.6/page-33.html).

- Corrections and Conditional Release Regulations (http://laws.justice.gc.ca/eng/regulations/SOR-92-620/) (CCRR), sections 54-57 (http://laws-lois.justice.gc.ca/eng/regulations/SOR-92-620/section-54.html) and 102 (http://laws-lois.justice.gc.ca/eng/regulations/SOR92-620/section-102.html)

\section{Purpose}

To outline the process for the completion of offenders' Correctional Plans and Criminal Profiles

\section{Application}

Applies to staff responsible for the completion of the Criminal Profile Report and the Correctional Plan

\section{Contents}

- Responsibilities

- Procedures

- Timeframes

- Intake Assessment Process

- Custody Rating Scale

- Revised Statistical Information on Recidivism Scale

- Static Factors Assessment Report

- Dynamic Factors Assessment Report

- Domain Motivation Level

- Criminal Profile Report

- Correctional Plan

- Offender Accountability. 
$11 / 26 / 2019$

Correctional Planning and Criminal Profile

- Offender Motivation

- Responsivity Factors

- Offender Engagement

- Reintegration Potential

- Psychological/Psychiatric/Mental Health Information

- Offence Cycle

- Correctional and Sentence Planning

- Offender Readmissions/Offenders With New Convictions Pre or Post-Release

- Annex A: Cross-References and Definitions

- Annex B: Revised Statistical Information on Recidivism Scale

- Annex C: Criminal Risk Index

- Annex D: Static Factors Assessment

- Criminal History Record

- Offence Severity Record

- Sex Offence History Checklist

- Annex E: Dynamic Factor Identification and Analysis, Revised (DFIA-R)

- Employment/Education Domain Indicators

- Marital/Family_Domain Indicators

- Associates Domain Indicators

- Substance Abuse Domain Indicators

- Community Functioning Domain Indicators

- Personal/Emotional Domain Indicators

- Attitude Domain Indicators

- Responsivity.

- Overall Dynamic Factor Rating Guidelines

- Annex F: Criminal Profile - Report Outline

- Annex G: Correctional Plan - Report Outline

- Annex H: Dynamic Factors and Aboriginal Social History.

\section{Responsibilities}

1. The Institutional Head/District Director will ensure that:

a. the Criminal Profile Report, the Correctional Plan and all related reports are completed within the prescribed timeframes.

b. procedures are in place to assist the offender in obtaining appropriate pieces of identification such as birth certificate, Indian Status card, Metis card, citizenship/permanent resident card, health coverage, Social Insurance Number.

2. The Parole Officer Supervisor/Manager, Assessment and Interventions, will :

a. determine the intake assessment process required for all admissions, including the Compressed Offender Intake Assessment

b. provide quality control for the Custody Rating Scale, Revised Statistical Information on Recidivism, Criminal Profile Report, amended Criminal Profile Report and Correctional Plan

C. ensure completion of the Primary Information Sharing Checklist (CSC/SCC 1199) and the Procedural Safeguard Declaration (CSC/SCC 1198).

3. The Parole Officer will:

a. assist and support the offender during the intake process

b. complete, as required, actuarial and risk assessment tools, static and dynamic factors assessment

c. complete the Criminal Profile Report

d. complete, if required, the assessments for offender security level and penitentiary placement

e. complete the Correctional Plan, Annex G in consultation with the offender and the Case Management Team, and :

i. determine the key ratings including offender accountability, motivation, responsivity and engagement.

ii. review current pieces of identification and confirm validity

iii. determine the requirement for the offender to obtain outstanding pieces of identification

iv. explain the application process to obtain outstanding pieces of identification to the offender and provide assistance, when necessary 
v. document the above information in the Correctional Plan along with the offender's plan for acquiring needed identification, including a health card when/if possible (refer to Appendices F and $\mathrm{H}$ of the National Essential Health Services Framework).

4. The offender is expected to:

a. participate in the intake assessment process

b. participate in the development of Correctional Plan

c. comply with the requirement to submit to urinalysis in accordance with section 54 (http://laws.justice.gc.ca/eng/acts/c44.6/section-54.html) of the CCRA and/or supervision requirements.

\section{Procedures}

5. The Parole Officer and, if required, members of the Case Management Team will interview the offender prior to completing the intake assessment reports. If the offender refuses to participate, or is unable to participate (e.g. illness), the completed report will include a notation of the circumstances.

\section{Timeframes}

6. The Criminal Profile Report and the Correctional Plan will be completed within the following timeframes:

a. Compressed Offender Intake Assessment - within 60 days after admission for offenders who:

i. are serving a sentence of four years or less for a non-violent offence

ii. have limited criminal history (five or less prior convictions, including those as a young offender) or no criminal history

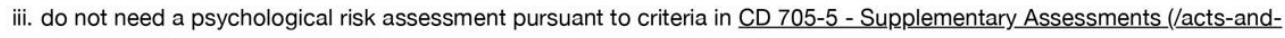
regulations/705-5-cd-eng.shtml).

iv. are not likely to be referred for detention

v. do not have a long-term supervision order

b. within 70 days after admission:

i. for all other offenders serving four years or less

ii. for young.persons transferred to a penitentiary pursuant to sections 76 (https://laws-lois.justice.gc.ca/eng/acts/Y-1.5/section76.html), 89 (https://laws-lois.justice.gc.ca/eng/acts/Y-1.5/section-89.html), 92 (https://laws-lois.justice.gc.ca/eng/acts/Y1.5/section-92.html) or 93 (https://laws-lois.justice.gc.ca/eng/acts/Y-1.5/section-93.html) of the Youth Criminal Justice Act (https://laws-lois.justice.gc.ca/eng/acts/Y-1.5/index.html)

c. within 90 days after admission date, for all other offenders serving sentences of more than four years (including indeterminate and life).

\section{Intake Assessment Process}

7. The Parole Officer will complete the intake assessment documents and initial Correctional Plan using at least the minimum required information sources, pursuant to $\underline{\mathrm{CD}}$ 705-2 - Information Collection (/acts-and-regulations/705-2-cd-eng.shtml).

8. Upon receipt of additional official information and if required, the Parole Officer will update the intake assessment documents and the Correctional Plan.

\section{Custody Rating Scale}

9. The Custody Rating Scale will be completed for all offenders, pursuant to $\mathrm{CD}$ 705-7 - Security Classification and Penitentiary Placement (/acts-and-regulations/705-7-cd-eng.shtml), prior to determining the level of intervention based on static factors.

\section{Revised Statistical Information on Recidivism Scale}

10. The Revised Statistical Information on Recidivism Scale will be completed, pursuant to Annex B, for all offenders (except Aboriginal offenders, women offenders, and provincial offenders) prior to determining the level of intervention based on static factors.

11. The Revised Statistical Information on Recidivism Scale needs to be reviewed and updated if necessary following receipt of new information, revocation and/or new conviction.

Static Factors Assessment Report 
12. The Static Factors Assessment in OMS will be completed for all offenders at intake pursuant to $\underline{A n n e x ~} \mathrm{D}$. If the criteria for Compressed Offender Intake Assessment outlined above are met, the Criminal History Record section of the Static Factors Assessment will be completed at intake to determine the Criminal Risk Index score pursuant to Annex C. The overall Static Factors Assessment will be contained within the Correctional Plan.

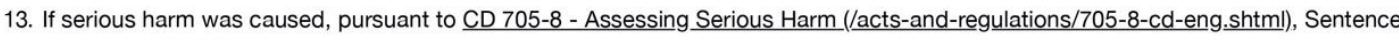
Management will be advised.

14. The guidelines for determining the overall rating for level of intervention based on static factors are:

a. a rating of High reflects cases in which:

i. the Criminal History Record reflects considerable involvement with the criminal justice system, or

ii. the Offence Severity Record reflects considerable harm to society in general, and victims in particular, or

iii. the Sex Offence History Checklist reflects considerable sex offending

b. a rating of Low reflects cases where all of the following conditions are met:

i. the Criminal History Record reflects little or no involvement with the criminal justice system

ii. the Offence Severity Record reflects little or no harm to society in general, and victims in particular

iii. the Sex Offence History reflects little or no sex offending

iv. a review against detention criteria, as well as the score on the Revised Statistical Information on Recidivism, if applicable, supports all of the aforementioned indices

c. a rating of Medium signifies that the offender is clearly not a Low criminal risk and there exists sufficient latitude to not rate the offender as High.

\section{Dynamic Factors Assessment Report}

15. The Dynamic Factor Identification and Analysis Revised Assessment Report will be completed at intake using the Dynamic Factor

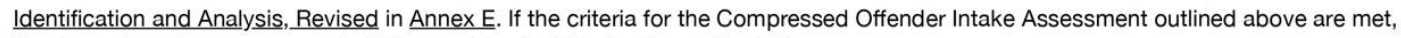
the dynamic factors assessment will be contained within the Correctional Plan.

16. The Parole Officer will determine dynamic contributing factors and prioritize the domain needs.

17. Within the domain analysis contained in the Dynamic Factors Assessment Report, or the Correctional Plan, the reasons why the specific dynamic factor is rated as contributing must be provided. The results from available supplementary assessments will be included in the rationale. For Aboriginal offenders, explain how the Aboriginal Social History may have impacted each specific dynamic factor rated as contributing. Refer to Annex $\mathrm{H}$ - Dynamic Factors and Aboriginal Social History for guidance.

18. Participation in Adult Basic Education must be included in the offender's Correctional Plan pursuant to $\underline{C D} 720$ - Education Programs and Services for Inmates (/acts-and-regulations/720-cd-eng.shtml) when:

a. the grade level achieved by the offender is below grade twelve or the equivalent, or

b. upgrading is required for participation in correctional programming or vocational training (CORCAN).

19. For dynamic factors not directly related to criminal behaviour, but where intervention will improve safe and timely reintegration, provide a clear explanation of why such factors require intervention.

20. If a domain has no bearing on the offender's criminal behaviour, this should be indicated.

21. The guidelines for determining the overall rating for the level of intervention based on dynamic factors are:

a. Low

i. No identified dynamic factors (i.e. factors seen as an asset to community adjustment and/or no immediate need for improvement)

ii. Relatively few identified dynamic factors and rated as low or medium need for improvement

b. High

i. Few identified dynamic factors but rated as high need for improvement

ii. Multiple dynamic factors identified, (regardless of degree or severity of needs)

c. Medium

i. Any combination of dynamic factor severity and number that lie outside of either the low or high guidelines as identified above. 
$11 / 26 / 2019$

\section{Domain Motivation Level}

22. The domain motivation level is assessed for eight need areas: education, employment, marital/family, associates, substance abuse, community functioning, personal/emotional orientation, and attitude using the following criteria:

a. High

The offender fully recognizes a need requiring intervention and is fully ready to start intervention. They haves committed to change and may have already started actively engaging in behaviours related to change. While still recognizing external benefits for pursuing intervention (e.g., securing early release), they have primarily motivated for internal reasons (e.g., doing it for themselves, "I'm tired of the lifestyle or I want a change").

b. Medium

The offender may not fully accept or recognize need area as deficit but is willing to participate in recommended programs or other interventions. Genuine commitment to change may still be absent. While the offender may commit to intervention, they may only be doing so for external reasons (e.g., to secure early release or be transferred to a lower security institution).

\section{c. Low}

The offender would benefit from motivational interviewing prior to programming. There is absolutely no recognition that a need exists in this area. There is no genuine commitment to change.

\section{Criminal Profile Report}

23. The Criminal Profile Report will be completed for all offenders pursuant to Annex $F$.

24. An amended Criminal Profile Report is completed when:

a. outstanding appeals or charges are processed

b. additional documents are received that impact on the outcome of the Criminal Profile, including:

i. Crown information

ii. police reports

iii. judge's reasons for sentence and relevant court orders

iv. psychiatric and/or psychological assessments completed for trial

v. post-assessment/treatment reports completed for the purpose of developing an offence cycle

c. the offender is convicted of new offences while incarcerated or while under community supervision

d. the offender is readmitted with new conviction(s).

25. The operational unit that is responsible for the offender at the time of the receipt of new information or convictions, or upon revocation, will amend the Criminal Profile Report.

\section{Correctional Plan}

26. The Correctional Plan will be completed in consultation with the offender and the Case Management Team, pursuant to Annex G. The Correctional Plan will contain the following:

a. level of intervention with respect to the offender's needs

b. objectives for the offender's behaviour (i.e. conduct that demonstrates respect for other persons and property, penitentiary rules, and conditions of any release)

c. programs and interventions required to manage risk

d. court-ordered obligations (i.e. restitution to victims or child support).

\section{Offender Accountability}

27. The guidelines for establishing the overall accountability rating are:

a. High

i. The offender accepts responsibility for actions and recognizes problems.

ii. Willingness to self disclose, displays guilt and victim empathy with evidence indicating a low level of cognitive distortions.

b. Medium

i. The offender may not fully accept responsibility for actions but recognizes some problems. 
c. Low

i. The offender rejects responsibility for actions and fails to recognize problems.

ii. Does not disclose emotional states, display guilt or victim empathy with evidence indicating a high level of denial and cognitive distortions.

\section{Offender Motivation}

28. The guidelines for establishing the overall motivation rating are:

a. High

The offender is self-motivated and is actively addressing problem areas.

b. Medium

The offender may not fully accept overall assessment, but will participate in recommended programs or other interventions.

c. Low

The offender strongly rejects the need for change.

\section{Responsivity Factors}

29. Identify the offender's responsivity_factors and consider barriers or facilitators, if applicable, pursuant to Annex E.

\section{Offender Engagement}

30. Engagement is determined by combining ratings on motivation, accountability and responsivity. In order to be engaged there must be a rating of either medium or high in both accountability and motivation.

\section{Reintegration Potential}

31. Reintegration potential of male, non-Aboriginal offenders is determined by using the Custody Rating Scale, the Revised Statistical Information on Recidivism and the Static Factor Rating.

32. Reintegration potential of women offenders and Aboriginal offenders is determined by using the Custody Rating Scale, the Static Factor Rating and the Dynamic Factor Rating.

33. The reintegration potential is calculated as follows:

a. a low reintegration potential is assigned to offenders who received a high score in two or more of the three tools

b. a moderate reintegration potential is assigned to offenders who received one high score in any one tool and a moderate score in at least one of the other two tools, or who received a moderate score on all three tools

c. a high reintegration potential is assigned to all other offenders, i.e. all those who did not score high in any of the three tools, or scored high in one of the tools and no worse than low in the other two tools.

34. When the Parole Officer disagrees with the determined reintegration potential, a clear rationale must be documented in the Correctional Plan, based on the following:

a. High

Offenders with high reintegration potential should not normally require formal correctional interventions. If required, these interventions should preferably be provided in the community. Other correctional interventions, services and work placements (including employability skills development) may be used, as well as any other risk management strategies, other than programs, in both institutions and the community.

\section{b. Medium}

Offenders with medium reintegration potential should require institutional correctional interventions based on the dynamic factors and the offender's level of risk and need(s). These interventions can also be provided in the community during the period of day parole or unescorted temporary absence program for personal development prior to full parole release.

c. Low

Offenders with low reintegration potential require institutional correctional interventions based on the dynamic factors and the offender's level of risk and need(s). Other risk management strategies are to be provided in institutions prior to release, and continued in the community as required.

\section{Psychological/Psychiatric/Mental Health Information}


35. In the Correctional Plan, include the offender's psychological, psychiatric, mental health and/or physical health information on risk, risk management strategies, and recommended interventions.

\section{Offence Cycle}

36. Summarize the offence cycle and the offender's understanding of the cycle. For Aboriginal offenders, their offence cycle must be explained within the context of their Aboriginal Social History.

\section{Correctional and Sentence Planning}

37. Correctional programs will be prioritized as the first correctional intervention for those who meet the referral criteria as set out in GL $726-$ 2 - National Correctional Programs Referral Guidelines (/acts-and-regulations/726-2-gl-eng.shtml).

38. Education programs will be prioritized as the second correctional intervention for those who meet the criteria as set out in $\mathrm{GL} 720-1$ Guidelines for Education Programs (/acts-and-regulations/720-1-gl-eng.shtml).

39. Employment programs will be prioritized as the third correctional intervention for those who meet the eligibility criteria for all correctional interventions. If the offender has:

a. limited cooperative work skills or employment history is absent, a referral to Employability Program will be made

b. limited marketable job skills obtained through experience, formal training or is dissatisfied with job skills, a referral to Vocational Training will be made.

40. Sentence planning in the Correctional Plan will identify the objectives and significant events for the offender to gain support for reduced security classification, temporary absences, work release and/or conditional release.

41. These objectives and significant events will be individualized, structured and timeframed. They will initially focus on the next review period while setting the framework for managing the offender's sentence.

42. These objectives and significant events will be prioritized based on public safety, institutional adjustment and adaptation, interventions required and safe reintegration.

43. The Case Management Team, in consultation with the offender, will identify clear goals and expected results that support progress against the Correctional Plan.

44. Sentence planning for offenders serving sentences of 10 years or more will include the four phases, pursuant to Annex $\mathrm{G}$ - Correctional Plan - Report Outline. The initial focus is on adaptation and integration to the institutional environment. Offenders classified as medium security must be in the "preparation for release" or "reintegration to the community" phase to be eligible for placement in, or transfer to, an environment without a secure and directly controlled perimeter pursuant to $\underline{C D}$ - 706 - Classification of Institution (/acts-andregulations/706-cd-en.shtml).

45. In cases where the offender's reintegration potential is rated as low and the Case Management Team is not supporting the release, a Community Strategy is not required unless the offender is:

a. pursuing a release under the provisions of section 84 (https://laws-lois.justice.gc.ca/eng/acts/C-44.6/section-84.html)or section 84.1 (http://laws-lois.justice.gc.ca/eng/acts/C-44.6/section-84.1.html) of the CCRA

b. being released on statutory release, or

c. being released at warrant expiry and is subject to a long-term supervision order

46. For offenders serving three years or less who have applied for day parole or are eligible for full parole within six months of completion of intake, a Community Strategy is required. Following completion of the intake assessment, the institutional Parole Officer, Intake Assessment Unit, will request the Community Strategy from the proposed release destination pursuant to Annex G - Correctional Plan Report Outline.

\section{Offender Readmissions/Offenders With New Convictions Pre or Post-Release}

47. Offenders who are readmitted without having committed a new offence do not normally require a comprehensive reassessment.

48. For offenders who are readmitted with one or more new convictions, or following an escape, the Criminal Profile Report and the Revised Statistical Information on Recidivism Scale will be amended and the Correctional Plan will be reviewed to determine if the current Correctional Plan remains appropriate, or if a comprehensive reassessment is required.

49. In the case of an escaped offender, the region in which the offender has been recaptured becomes responsible for completing all reviews and updates to the Criminal Profile Report and the Correctional Plan.

50. A decision to refer an offender readmitted with new convictions to the Intake Assessment Unit for a more comprehensive re-evaluation of the offender's static and dynamic factors could be made under the following circumstances: 
a. the offender's criminal behaviour has taken a significant shift (e.g., a property offender has committed violent offence(s), an offender previously not identified as a sex offender has committed a sexual offence) and there is no information in the offender's previous assessment or in the file that would assist in the development of a strategy to deal with that shift

b. there is no comprehensive Correctional Plan on the offender

c. the Correctional Plan does not provide the level or quality of information necessary to plan an adequate strategy for dealing with the offender, or

d. the offender has been on conditional release or at large for five years or more, and the new offence(s) or other relevant information lead staff to consider that a review of the offender's previous assessment is necessary to determine an appropriate strategy.

51. For offenders who commit new offences while incarcerated, use the same criteria found in the previous paragraphs to determine whether to refer the offender to the Intake Assessment Unit for reassessment. The transfer process, pursuant to $\mathrm{GL} 710-2-3-\operatorname{Inmate}$ Transfer Processes (/acts-and-regulations/710-2-3-gl-en.shtml), is required and a decision should take place within 30 days of readmission or within 30 days from the date the offender is convicted of a new offence committed while incarcerated.

52. If an offender is returned to the Intake Assessment Unit for reassessment, staff should review the previous assessment and only change or reassess those areas where the offender's situation has changed.

Commissioner,

Original Signed by:

Anne Kelly

\section{Annex A}

Cross-References and Definitions

\section{Cross-References}

CD 001 - Mission, Values and Ethics Framework of the Correctional Service of Canada (/acts-and-regulations/001-cd-en.shtml) CD 700 - Correctional Interventions (/acts-and-regulations/700-cd-eng.shtml)

CD 701 - Information Sharing_(/acts-and-regulations/701-cd-eng.shtml)

CD 702 - Aboriginal Offenders (/acts-and-regulations/702-cd-eng.shtml).

CD 703 - Sentence Management (/acts-and-regulations/703-cd-eng.shtml).

CD 705-1 - Preliminary Assessments and Post-Sentence Community Assessments (/acts-and-regulations/705-1-cd-eng.shtml).

CD 705-2 - Information Collection (/acts-and-regulations/705-2-cd-eng.shtml)

CD 705-3 - Immediate Needs Identification and Admission Interviews (/acts-and-regulations/705-3-cd-eng.shtml)

$\mathrm{CD} 705-4$ - Orientation (/acts-and-regulations/705-4-cd-eng.shtml)

CD 705-5 - Supplementary Assessments (/acts-and-regulations/705-5-cd-eng.shtml).

CD 705-7 - Security Classification and Penitentiary Placement (/acts-and-regulations/705-7-cd-eng.shtml)

CD 705-8 - Assessing Serious Harm (/acts-and-regulations/705-8-cd-eng.shtml)

CD 710-2 - Transfer of Inmates (/acts-and-regulations/710-2-cd-en.shtml)

GL 710-2-3 - Inmate Transfer Processes (/acts-and-regulations/710-2-3-gl-en.shtml)

CD 720 - Education Programs and Services for Inmates (/acts-and-regulations/720-cd-eng.shtml)

GL 720-1 - Guidelines for Education Programs (/acts-and-regulations/720-1-gl-eng.shtml).

CD 726 - Correctional Programs (/acts-and-regulations/726-cd-eng.shtml)

GL 726-2 - National Correctional Programs Referral Guidelines (/acts-and-regulations/726-2-gl-eng.shtml).

CD 784 - Victim Engagement (/acts-and-regulations/784-cd-eng,shtml)

CD 800 - Health Services (/acts-and-regulations/800-cd-eng.shtml)

CD 843 - Interventions to Preserve Life and Prevent Serious Bodily_(lacts-and-regulations/843-cd-eng.shtml)

Access to Information Act (http://laws-lois.justice.gc.ca/eng/acts/A-1/)

Canadian Charter of Rights and Freedom (https://laws-lois.justice.gc.ca/eng/Const/page-15.html).

Canadian Human Rights Act (http://laws-lois.justice.gc.ca/eng/acts/H-6/index.html)

Controlled Drugs and Substances Act (http://laws-lois.justice.gc.ca/eng/acts/C-38.8)

Immigration and Refugee Protection Act (http://laws-lois.justice.gc.ca/eng/acts/l-2.5/)

Official Languages Act (http://laws-lois.justice.gc.ca/eng/acts/O-3.01/index.html)

Privacy_Act (http://laws-lois.justice.gc.ca/eng/acts/P-21/)

Youth Criminal Justice Act (http://laws-lois.justice.gc.ca/eng/acts/Y-1.5/) 
$11 / 26 / 2019$

Integrated Mental Health Guidelines

Aboriginal Social History Tool

National Essential Health Services Framework
Correctional Planning and Criminal Profile

\section{Definitions}

Accountability: the level of involvement of the offender in their Correctional Plan in relation to the obligation to modify behaviours identified as being problematic. Attitude, behaviour, and insight are critical components to offender accountability.

Case Management Team: the individuals involved in managing an offender's case, which include at a minimum the Parole Officer and the offender, and in institutions, the Correctional Officer II/Primary Worker.

Criminal Risk Index: a research based tool used to assess static risk and guide offender intervention levels, which is derived from the Criminal History Record section of the Static Factors Assessment.

Custody Rating Scale: a research-based tool used to assist in assessing the most appropriate level of security for the penitentiary placement of an offender.

Domain Analysis: a concise narrative of a specific domain which qualifies or expands on the factors identified during the intake assessment process. This analysis provides a better understanding of how each area relates to the present offence and the offender's overall criminality. For Aboriginal offenders, each domain analysis must consider the impact of the offender's Aboriginal Social History.

Dynamic Factor Identification and Analysis, Revised: primary instrument for assessing dynamic factors upon offender's admission to federal custody. Its main function is to identify and prioritize criminogenic needs according to seven dynamic risk areas (employment and education, marital/family, associates, substance abuse, community functioning, personal/emotional and attitudes) so as to focus correctional intervention on factors that, when appropriately addressed, reduce the likelihood of re-offending.

Engagement: the demonstrated willingness of an offender:

a. to actively participate in their assigned Correctional Plan

b. be free of criminal and gang activity while under sentence

C. display conduct that demonstrates respect

d. obey the penitentiary rules and/or supervision requirements.

Healing component: a component of the Correctional Plan that allows for consideration to be given to the circumstances and background of Aboriginal offenders following a healing path.

Motivation: the desire or willingness to change.

Responsivity: the presence of a characteristic(s) that influences the offender's capacity to benefit from the targeted intervention(s).

Revised Statistical Information on Recidivism: a statistically derived tool for predicting recidivism, which combines measures of demographic characteristics and criminal history.

Serious harm: severe physical injury or severe psychological damage, as defined in section 99 (http://laws-lois.justice.gc.ca/eng/acts/C44.6/page-12.html\#h-41) of the CCRA.

Young person: a person who is or, in the absence of evidence to the contrary, appears to be twelve years old or older, but less than eighteen years old and, if the context requires, includes any person who is charged under the Youth Criminal Justice Act (http://laws-

lois.justice.gc.ca/eng/acts/Y-1.5/index.html) with having committed an offence while they were a young person or who is found guilty of an offence under this Act.

\section{Annex B \\ Revised Statistical Information on Recidivism Scale (SIR-R1)}

In the SIR screen in the Offender Management System (OMS), assign an individual score to each of the 15 items using the scoring guidelines and notes that follow:

1. Current offence

2. Age at admission

3. Previous incarceration

4. Revocation or forfeiture 
5. Act of escape

6. Security classification

7. Age at first adult conviction

8. Previous convictions for assault

9. Marital status at most recent admission

10. Interval at risk since last offence

11. Number of dependants at most recent admission

12. Current total aggregate sentence

13. Previous convictions for sex offences

14. Previous convictions for break and enter

15. Employment status at arrest.

\section{Scoring Guidelines}

1. An item score may be positive, zero, or negative. Read each of the descriptions under an item. If one of them applies to the offender, enter the corresponding value in the OMS field. If no descriptions apply, then enter a value of zero. OMS calculates an offender's total score by adding the 15 individual item scores together.

2. Ensure that all information about the offender is accurate. Verify the information through all available sources (file review, offender, collateral contacts, etc.). However, it is important that each of the 15 items be scored. So, if accurate data is not available, it is preferable to make an approximation rather than omitting the item or entering a value of zero by default.

3. When scoring the items, include Young Offender Act or Youth Criminal Justice Act involvement (e.g., convictions, incarcerations, escapes, etc.) if the offender was 16 or over. Also, as a general principle, do not ignore information that is not on the official record. For example, where the FPS indicates assault, but other reliable sources allow us to determine that the offender actually committed a sexual assault, treat the offence as a sexual assault and score accordingly.

4. To avoid confrontation at a hearing, the Parole Board of Canada should be alerted if the offender disputes the score. The Board should also know if the score is approximated.

5. This scoring tool is to be used only for federal non-Aboriginal male offenders.

6. Aboriginal, women, and provincial offenders are excluded from SIR use. However, to date there is no reason to exclude other groups from this scoring tool.

7. Absolute and/or conditional discharges do not count as a conviction for purposes of the scale. 
$11 / 26 / 2019$

Correctional Planning and Criminal Profile

1

Current Offence

Notes

- Includes all offences under the current total aggregate sentence.

- If more than one offence, score the offender according to the one that is the "most negative score". If the offender has two convictions at the same time, choose the conviction where the "rate of recidivism" is the "most negative".

- Scores define the association between the likelihood of recidivism as associated with certain offences when this offence is the current offence.

- Where an offence has not been defined within these lists, it is because the likelihood of recidivism for these offences was equal to the general average. These offences did not allow researchers to define the offenders as more or less likely to recidivate. In addition, there were certain offences where the frequency of occurrence was too low to be useful. " 0 " in this item is not a valued score, simply a default to assure that the item has been considered.

Definition of "homicide"

- Refers to Criminal Code definition of murder and manslaughter.

Score on this item may not be static

- If there are outstanding charges at time of incarceration and the charges are subsequently dealt with, these new convictions become part of the "current offence" category.

- If offender has been revoked with new offences, both the new and the original offences are considered "current offences".

Scores

Escape (includes any conviction for escape or attempted escape from a federal or provincial correctional facility or court, or from an escort; does not include unlawfully at large)

Break and enter (includes B. \& E. and commit with intent), forcible entry, unlawfully in dwelling, illegal possession of

firearm, carrying concealed weapon

Theft (receiving or possession of stolen goods)

None of the offence descriptions apply (armed robbery has a score of 0 )

Unarmed robbery, kidnapping, arson, hijacking, criminal negligence in operation of vehicle, abduction, dangerous driving, +2 obstruct peace officer

Homicide (any act resulting in death, except by automobile), narcotics offences (Food \& Drug Act, Narcotic Control Acts, +3 Controlled Drugs and Substances Act)

Incest, sexual intercourse with the underage, seduction, gross indecency

Item Description

Scoring

2

Age at Admission

Notes

Refers to "Admission" on the current total aggregate sentence (i.e. at original warrant of committal admission).

Does not apply to readmission as a result of a revocation, termination, etc.

\section{Scores}

20 or under

Between 21 and 39

Over 39 
$11 / 26 / 2019$

Correctional Planning and Criminal Profile

3

Previous Incarceration

Notes

"Previous" refers to a period of incarceration that expired (i.e. warrant expiry date) before the current total aggregate sentence.

An incarceration is a separate original admission to a custodial place.

"Penal institution" refers to jail, prison, or penitentiary, in each case.

If offender was on the street through parole or statutory release (or mandatory supervision) and has been revoked with or without a new conviction, this is not a new period of incarceration. The revocation is still part of the original sentence.

Scores

Has served sentences in jail, prison or penitentiary five or more times before.

$-2$

Has served sentences in jail, prison or penitentiary three or four times before.

Has served sentences in jail, prison or penitentiary one or two times before.

First time incarcerated.

Item Description

Scoring

4 Previous Revocation or Forfeiture

Notes

This does not include terminations.

Scores

Has previously had a term of day parole, full parole or statutory release revoked or forfeited (does not include termination).

$-2$

Has not previously had a term of day parole, full parole or statutory release revoked or forfeited.

Item Description

Scoring

5 Previous Escape

Notes

Includes current or previous acts of escape or attempted escape from a federal or provincial correctional facility or court, or from an escort, whether or not this act resulted in a conviction. A conviction for unlawfully at large for any of the above should be treated as an escape.

Scores

Has escaped or attempted to escape on one or more occasions.

Has never escaped or attempted to escape.

Item Description

6

\section{Security Classification}

Notes

If completed at admission, this score $=0$ as it refers only to security level at time of parole hearing.

Multi-level institution did not exist when scale was developed; therefore, at this time they score " 0 ". 


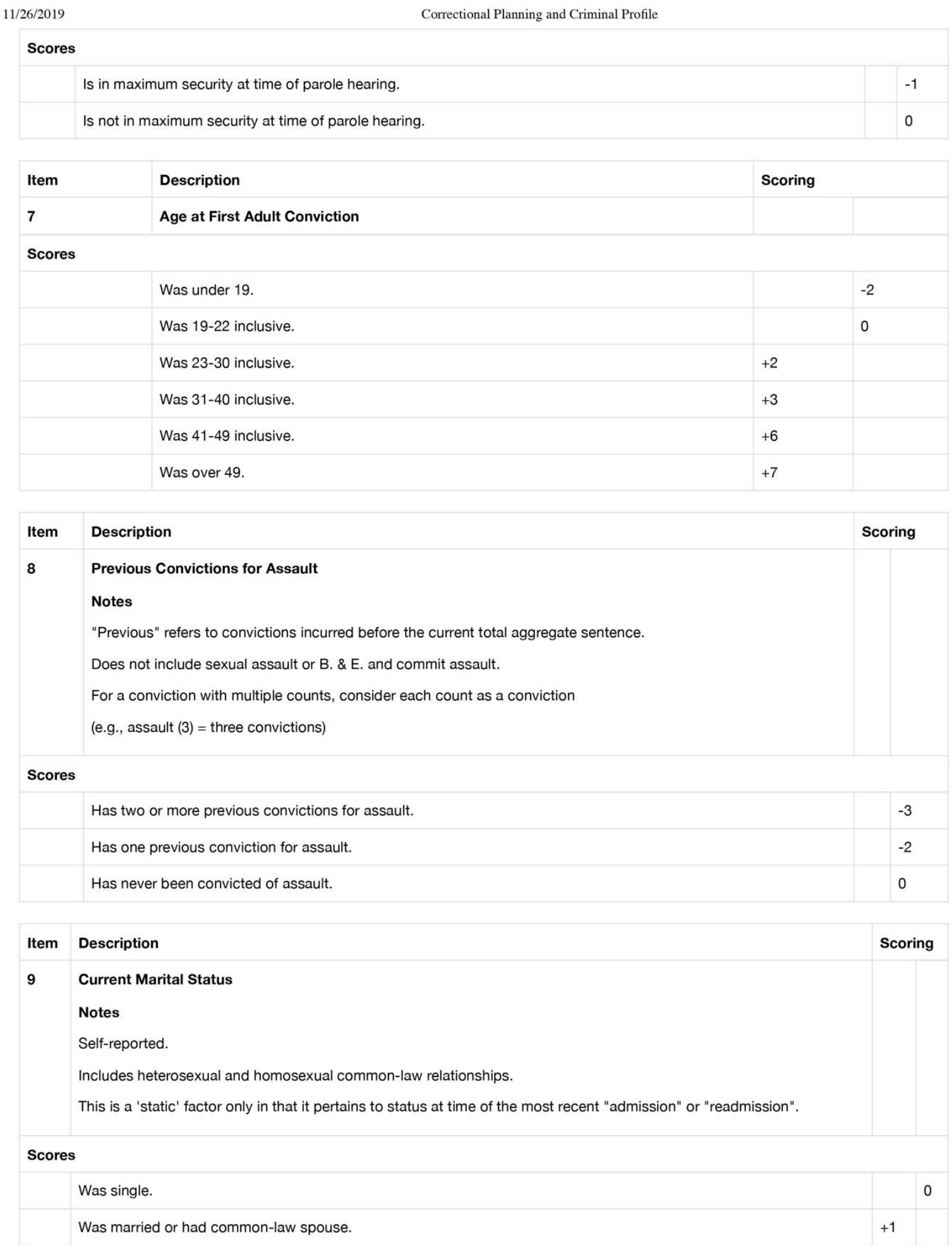




\begin{tabular}{|c|c|c|c|}
\hline$/ 2019$ & Correctional Planning and Criminal Profile & & \\
\hline Item & Description & \multicolumn{2}{|c|}{ Scoring } \\
\hline 10 & $\begin{array}{l}\text { Interval at Risk Since Last Offence } \\
\text { Notes } \\
\text { Defined as the period from when an offender is released from imprisonment (on a form of conditional release or free of } \\
\text { supervision) until reincarceration (on breach of conditional release or new conviction). } \\
\text { If exact data on offender is not available, make the best possible approximation. } \\
\text { Key here is "interval at risk" - interval on the street. } \\
\text { While on day parole, offender is still on the registry of an institution; therefore, this does not count as time at risk. } \\
\text { If suspended, and suspension cancelled, bail granted, or suspended sentence, the time at risk is still seen as time since } \\
\text { original release. } \\
\text { Terminations or revocations terminate the interval at risk. } \\
\text { Does not apply to periods of escape or unlawfully at large. }\end{array}$ & & \\
\hline \multicolumn{4}{|c|}{ Scores } \\
\hline & Less than six months between current conviction/reincarceration and last release & & -1 \\
\hline & Six months to two years between current conviction/reincarceration and last release & & 0 \\
\hline & Two years or more between current conviction/reincarceration and last release & +2 & \\
\hline Item & Description & \multicolumn{2}{|c|}{ Scoring } \\
\hline 11 & $\begin{array}{l}\text { Number of Dependants (under one roof) } \\
\text { Notes } \\
\text { This is a "static" factor only in that it pertains to status at time of the most recent "admission" or "readmission". } \\
\text { The intent was to define a statement to mainly cover dependent children who lived, at time of admission, with the } \\
\text { offender "under the same roof" and who had been "economically" dependent on the offender. }\end{array}$ & & \\
\hline \multicolumn{4}{|c|}{ Scores } \\
\hline & Had less than three dependants (including dependants from common-law marriage). & & 0 \\
\hline & Had three or more dependants (including dependants from common-law marriage). & +2 & \\
\hline Item & Description & \multicolumn{2}{|c|}{ Scoring } \\
\hline 12 & $\begin{array}{l}\text { Aggregate Sentence } \\
\text { Notes } \\
\text { Measure from the date of the original sentence, not the remnant. } \\
\text { Must be calculated from beginning of this sentence (i.e., from the original commencement of the total aggregate } \\
\text { sentence). }\end{array}$ & & \\
\hline \multicolumn{4}{|c|}{ Scores } \\
\hline & Aggregate sentence is less than five years. & & 0 \\
\hline & Aggregate sentence is five years and up to six years. & +3 & \\
\hline & Aggregate sentence is six years or more. & +2 & \\
\hline
\end{tabular}




\begin{tabular}{|c|c|c|}
\hline / $/ 2019$ & \multicolumn{2}{|l|}{ Correctional Planning and Criminal Profile } \\
\hline Item & Description & Scoring \\
\hline 13 & $\begin{array}{l}\text { Previous Convictions (Violent Sex Offence) } \\
\text { Notes } \\
\text { "Previous" refers to convictions incurred before the current total aggregate sentence. } \\
\text { Includes sexual assault and aggravated sexual assault (and rape). } \\
\text { Present offence could be either a sexual offence or any other type of offence (e.g., B. \& E.). Reference FPS to see if there } \\
\text { is a conviction for any of the defined sexual offences. } \\
\text { For a conviction with multiple counts, consider each count as a conviction (e.g., sexual assault (11) = 11 convictions). }\end{array}$ & \\
\hline \multicolumn{3}{|c|}{ Scores } \\
\hline & $\begin{array}{l}\text { Has two or more previous convictions for any of rape, attempted rape, indecent assault, sexual assault or aggravated } \\
\text { sexual assault. }\end{array}$ & -4 \\
\hline & $\begin{array}{l}\text { Has never been convicted or has only one conviction for rape, attempt rape, indecent assault or aggravated sexual } \\
\text { assault. }\end{array}$ & 0 \\
\hline Item & Description & Scoring \\
\hline 14 & $\begin{array}{l}\text { Previous Convictions For Break And Enter } \\
\text { Notes } \\
\text { "Previous" refers to convictions incurred before the current total aggregate sentence. } \\
\text { Break and enter includes B. \& E. with intent to commit, and B. \& E. \& commit. } \\
\text { Multiple counts of offences are considered separate convictions (e.g., B. \& E. (9) = nine convictions). } \\
\text { Convictions listed separately at the same time are also separate convictions. } \\
\text { B. \& E. (2) } \\
\text { B. \& E. (4) = nine convictions } \\
\text { B. \& E. (3) }\end{array}$ & \\
\hline \multicolumn{3}{|c|}{ Scores } \\
\hline & Has five or more previous convictions for break and enter. & -6 \\
\hline & Has three or four previous convictions for break and enter. & -3 \\
\hline & Has one or two previous convictions for break and enter. & -2 \\
\hline & Had no previous convictions for break and enter. & +2 \\
\hline Item & Description & Scoring \\
\hline 15 & $\begin{array}{l}\text { Employment Status at Arrest } \\
\text { Notes } \\
\text { Includes either part-time or full-time legal employment. } \\
\text { Self-reported at time of arrest. } \\
\text { Current offences are those associated with the original commencement of the current total aggregate sentence. } \\
\text { Paid for retraining is considered employment. } \\
\text { Going to school is not considered employment unless being paid for through programs such as employment insurance. }\end{array}$ & \\
\hline
\end{tabular}




11/26/2019
\begin{tabular}{|l|l|}
\hline Scores & Correctional Planning and Criminal Profile \\
\hline Was not employed at time of arrest for current offence(s) (full time or part time). \\
\hline Was employed at time of arrest for current offence(s) (full time or part time). & 0 \\
\hline
\end{tabular}

\section{Success Rates Based on SIR Scores}

\begin{tabular}{ll}
+6 to +27 & Four out of every five offenders will not commit an indictable offence after release. \\
\hline+1 to +5 & Two out of every three offenders will not commit an indictable offence after release. \\
\hline-4 to 0 & One out of every two offenders will not commit an indictable offence after release. \\
\hline-8 to -5 & Two out of every five offenders will not commit an indictable offence after release. \\
-30 to -9 & One out of every three offenders will not commit an indictable offence after release.
\end{tabular}

\section{Annex C \\ Criminal Risk Index}

The Criminal Risk Index (CRl.(Criminal.Risk Index)) score is generated when the Criminal History Record section of the Static Factors Assessment is completed at intake.

Each indicator marked as applying in the Criminal History Record of the Static Factors Assessment will have a value of one and will contribute to the final $\mathrm{CRI}$ score and resulting grouping.

In the Static Factors Assessment screen in the Offender Management System (OMS.(Offender.Management System)), provide a "Yes" response to all of the Criminal History Record indicators that apply using the scoring guidelines and notes that follow:

\section{Scoring Guidelines}

Some of the indicators apply if any element within a numerical range is true. For example, if the indicator question specifies a range of $10-14$ inclusive, this includes all the numbers $(10 / 11 / 12 / 13 / 14)$.

When reporting on the number of convictions, count the total number even if they formed part of same court proceeding and sentence. For example an offender convicted of Robbery $\times 3$ on a certain date would count as three separate convictions.

\section{Criminal History Record}

\section{Previous Offences - Youth Court}

The indicators in this section apply to offences committed by the offender as a young offender. This applies to individuals who are under eighteen (18) years old at the time the crime was committed.

\section{Number of Convictions:}

Count the number of convictions on the youth record (i.e., offender found guilty of the offence).

Check all indicators that apply.

\begin{tabular}{|l|l|}
\hline Indicator & Description \\
\hline $\begin{array}{l}\text { Previous offences } \\
\text { youth court? }\end{array}$ & Check if the offender has had any previous convictions in youth court. \\
\hline $\begin{array}{l}\text { Fifteen or more } \\
\text { convictions? }\end{array}$ & Check if the offender has previously been convicted of 15 or more offences in youth court. \\
\hline $\begin{array}{l}\text { Ten to fourteen } \\
\text { convictions? }\end{array}$ & $\begin{array}{l}\text { Check if the offender has previously been convicted of more than } 14 \text { offences or there are between } 10 \\
\text { and } 14 \text { offences (inclusive) in youth court. }\end{array}$ \\
\hline $\begin{array}{l}\text { Five to nine } \\
\text { convictions? }\end{array}$ & $\begin{array}{l}\text { Check if the offender has previously been convicted of more than } 9 \text { offences or there are between } 5 \text { and } \\
9 \text { offences (inclusive) in youth court. }\end{array}$ \\
\hline
\end{tabular}




\begin{tabular}{|l|l|}
\hline $\begin{array}{l}\text { Two to four } \\
\text { convictions? }\end{array}$ & $\begin{array}{l}\text { Check if the offender has previously been convicted of more than } 4 \text { offences or there are between } 2 \text { and } \\
4 \text { offences (inclusive) in youth court. }\end{array}$ \\
\hline One conviction? & Check if the offender has previously been convicted of 1 or more offences in youth court. \\
\hline
\end{tabular}

\section{Type of Convictions:}

Refers to the current schedules of offences listed in the Corrections and Conditional Release Act (CCRA - Schedules I and II).

\begin{tabular}{|l|l|}
\hline Indicator & Description \\
\hline $\begin{array}{l}\text { Scheduled } \\
\text { convictions? }\end{array}$ & $\begin{array}{l}\text { Check if any of the convictions in Youth court were for offences listed in Schedules I and/or II of the } \\
\text { CCRA. }\end{array}$ \\
\hline
\end{tabular}

Youth Court Dispositions:

This refers to the sentence received from a youth court for the conviction of a youth offence.

Check all that apply.

If the offender had a number of separate convictions as a youth and received all types of sentences, check all the indicators that apply.

\begin{tabular}{|l|l|}
\hline Indicator & Description \\
\hline $\begin{array}{l}\text { Community } \\
\text { supervision? }\end{array}$ & $\begin{array}{l}\text { Check if the offender was sentenced by the court to a period of supervision in the community (i.e., probation, } \\
\text { community service order, house arrest). }\end{array}$ \\
\hline Open custody? & $\begin{array}{l}\text { Check if the offender was sentenced to a term of confinement in an open custody facility (community } \\
\text { residential facility, group home, wilderness camp). }\end{array}$ \\
\hline Secure custody? & $\begin{array}{l}\text { Check if the offender was sentenced to a term of confinement in a secure custody facility (locked secure } \\
\text { facilities). }\end{array}$ \\
\hline
\end{tabular}

Disposition Outcomes:

This section refers to the offender's behaviour/performance during a sentence imposed by a youth court.

This does not include conditional releases granted during a sentence.

\begin{tabular}{|c|c|c|}
\hline Indicator & Description & Score \\
\hline $\begin{array}{l}\text { Failure during } \\
\text { community-based } \\
\text { supervision? }\end{array}$ & $\begin{array}{l}\text { Check if the offender had any failures during a sentence of community supervision imposed by a youth } \\
\text { court (i.e., breach of probation, failure to complete community service order, further conviction while serving } \\
\text { a sentence of community supervision). }\end{array}$ & \\
\hline $\begin{array}{l}\text { Disciplinary } \\
\text { transfers from open } \\
\text { to secure? }\end{array}$ & $\begin{array}{l}\text { Check if the offender was sentenced by a youth court to an open custody facility and transferred to a secure } \\
\text { custody facility during this sentence. }\end{array}$ & \\
\hline $\begin{array}{l}\text { Disciplinary reports } \\
\text { while in secure } \\
\text { custody? }\end{array}$ & Check if the offender has received any disciplinary reports while serving a sentence in secure custody. & \\
\hline $\begin{array}{l}\text { Attempt } \\
\text { escape/UAL/escape } \\
\text { from secure } \\
\text { custody? }\end{array}$ & $\begin{array}{l}\text { Check if the offender previously attempted to escape, has escaped or was unlawfully at large during any } \\
\text { sentence previously imposed in youth court. This includes escape/UAL incidents during an escorted } \\
\text { absence from secure custody. This indicator is applicable even if the offender was not convicted of the } \\
\text { offence but file information reveals that the incident occurred. }\end{array}$ & \\
\hline $\begin{array}{l}\text { Transfer from } \\
\text { secure custody to } \\
\text { adult facility? }\end{array}$ & $\begin{array}{l}\text { Check if the offender was sentenced by a youth court to a term of confinement in secure custody and was } \\
\text { transferred to an adult facility during the sentence. }\end{array}$ & \\
\hline
\end{tabular}

\section{Previous Offences - Adult Court}


$11 / 26 / 2019$

Correctional Planning and Criminal Profile

This section gathers information involving previous convictions as an adult (18 years or older).

Number of Convictions:

Count the number of convictions on the adult record.

Check all that apply.

\begin{tabular}{|l|l|}
\hline Indicator & Description \\
\hline $\begin{array}{l}\text { Previous offences adult } \\
\text { court? }\end{array}$ & Check if the offender has had any previous convictions in adult court. \\
\hline $\begin{array}{l}\text { Fifteen or more } \\
\text { convictions? }\end{array}$ & Check if the offender has previously been convicted of 15 or more offences in adult court. \\
\hline $\begin{array}{l}\text { Ten to fourteen } \\
\text { convictions? }\end{array}$ & $\begin{array}{l}\text { Check if the offender has previously been convicted of more than } 14 \text { offences or between } 10 \text { and } 14 \\
\text { offences (inclusive) in adult court. }\end{array}$ \\
\hline $\begin{array}{l}\text { Five to nine } \\
\text { convictions? }\end{array}$ & $\begin{array}{l}\text { Check if the offender has previously been convicted of more than } 9 \text { offences or between } 5 \text { and } 9 \\
\text { offences (inclusive) in adult court. }\end{array}$ \\
\hline $\begin{array}{l}\text { Two to four } \\
\text { convictions? }\end{array}$ & $\begin{array}{l}\text { Check if the offender has previously been convicted of more than } 4 \text { offences or between } 2 \text { and } 4 \\
\text { offences (inclusive) in adult court. }\end{array}$ \\
\hline One conviction? & Check if the offender has previously been convicted of 1 or more offences in adult court. \\
\hline
\end{tabular}

\section{Types of Convictions:}

Refers to the current schedules of offences listed in the Corrections and Conditional Release Act (CCRA - Schedule I and II).

\begin{tabular}{|l|l|l|}
\hline Indicator & Description & Score \\
\hline Scheduled convictions? & Check if the offender has any previous offences listed in Schedules I and/or II of the CCRA. \\
\hline
\end{tabular}

\section{Adult Court Sanctions:}

Refers to sentences previously imposed on the offender for convictions in adult court.

\begin{tabular}{|l|l|}
\hline Indicator & Description \\
\hline $\begin{array}{l}\text { Community } \\
\text { supervision? }\end{array}$ & $\begin{array}{l}\text { Check if the offender previously received a sentence of community supervision in adult court (i.e., probation, } \\
\text { community service order, house arrest, electronic monitoring or any other form of sentence imposed that did not } \\
\text { involve incarceration). }\end{array}$ \\
\hline $\begin{array}{l}\text { Provincial } \\
\text { terms? }\end{array}$ & Check if the offender previously received a sentence in adult court of less than two years in prison. \\
\hline $\begin{array}{l}\text { Federal } \\
\text { terms? }\end{array}$ & Check if the offender previously received a sentence in adult court of two years or more in penitentiary. \\
\hline
\end{tabular}

\section{Sanction Outcomes:}

These refer to the offender's behaviour/performance during any previous sentences imposed by adult court.

These include sentences or orders imposed by the court to community-based supervision and/or periods of incarceration.

\begin{tabular}{|l|l|}
\hline Indicator & Description \\
\hline $\begin{array}{l}\text { Failure during } \\
\text { community-based } \\
\text { supervision? }\end{array}$ & $\begin{array}{l}\text { Check if the offender has had any failures during a previous sentence of community supervision imposed } \\
\text { by an adult court (i.e., probation, house arrest or long term supervision order). This may have been } \\
\text { caused by further criminal behaviour or for a breach of a condition attached to community supervision } \\
\text { order. }\end{array}$ \\
\hline
\end{tabular}


$11 / 26 / 2019$

Correctional Planning and Criminal Profile

\begin{tabular}{|l|l|}
\hline Indicator & Description \\
\hline $\begin{array}{l}\text { Segregation for } \\
\text { disciplinary } \\
\text { infractions? }\end{array}$ & $\begin{array}{l}\text { Check if the offender has previously been placed in segregation during any period of incarceration in an } \\
\text { adult facility (either provincial or federal) for disciplinary reasons. }\end{array}$ \\
\hline $\begin{array}{l}\text { Attempt } \\
\text { escape/UAL/escapes? }\end{array}$ & $\begin{array}{l}\text { Check if the offender previously attempted to escape, has escaped or was unlawfully at large during any } \\
\text { sentence previously imposed in adult court. This includes attempt escape/UAL or escape incidents during } \\
\text { an escorted absence. This indicator is applicable even if the offender was not convicted of the offence but } \\
\text { file information reveals that the incident occurred. }\end{array}$ \\
\hline $\begin{array}{l}\text { Reclassified to higher } \\
\text { levels of custody? }\end{array}$ & $\begin{array}{l}\text { Check if the offender has previously been transferred to increased security while serving a custodial } \\
\text { sentence resulting from previous convictions in adult court. }\end{array}$ \\
\hline $\begin{array}{l}\text { Failures during } \\
\text { conditional release? }\end{array}$ & $\begin{array}{l}\text { Check if the offender has any previous failures of conditional release (release to the community during a } \\
\text { sentence of incarceration - i.e., temporary absence, work release, day parole, full parole, statutory } \\
\text { release). This indicator also applies to failures on bail. The indicator applies for any reason that the } \\
\text { conditional release was not completed as a result of the behaviour of the offender. It does not apply if the } \\
\text { release was terminated for reasons outside of the offender's control (i.e., extreme weather conditions, } \\
\text { technical issues with the release permit). }\end{array}$ \\
\hline
\end{tabular}

\section{Crime-Free Period:}

\begin{tabular}{|l|l|}
\hline Indicator & Description \\
\hline $\begin{array}{l}\text { Less than six months } \\
\text { since last } \\
\text { incarceration? }\end{array}$ & Check if the offender's date of offence was within 6 months of a release from any form of incarceration. \\
\hline $\begin{array}{l}\text { No crime-free period of } \\
\text { one year or more? }\end{array}$ & $\begin{array}{l}\text { Check if the offender's history indicates the absence of any periods of one year or more without being } \\
\text { convicted of an offence since the commencement of their adult criminal history (18 years or older). }\end{array}$ \\
\hline
\end{tabular}

\section{Current Offences}

Refers to the offences for which the offender is currently serving time in the federal system.

\section{Number of Convictions:}

Count the number of convictions on the warrant of committal.

Where there is a requirement to obtain or update the Criminal History Record section of the Static Factors Assessment component of the Offender Intake Assessment for offenders who are supervised on a Long-Term Supervision Order (LTSO), use only the convicted offences that correspond to the sentence containing the LTSO. However, for offenders whose LTSO has been interrupted by another sentence, use only the convicted offences corresponding to the interrupting sentence: the offences that correspond to the initial sentence or previous interrupting sentences are to be considered as previous offences

Check all that apply.

\begin{tabular}{|l|l|}
\hline Indicator & Description \\
\hline $\begin{array}{l}\text { Fifteen or more current } \\
\text { convictions? }\end{array}$ & Check if the offender is currently serving a sentence for 15 or more convictions. \\
\hline $\begin{array}{l}\text { Ten to fourteen current } \\
\text { convictions? }\end{array}$ & $\begin{array}{l}\text { Check if the offender is currently serving a sentence for more than } 14 \text { convictions or ten to } \\
\text { fourteen inclusive. }\end{array}$ \\
\hline $\begin{array}{l}\text { Five to nine current } \\
\text { convictions? }\end{array}$ & $\begin{array}{l}\text { Check if the offender is currently serving a sentence for more than } 9 \text { convictions or } 5 \text { to } 9 \\
\text { inclusive. }\end{array}$ \\
\hline $\begin{array}{l}\text { Two to four current } \\
\text { convictions? }\end{array}$ & $\begin{array}{l}\text { Check if the offender is currently serving a sentence for more than } 4 \text { convictions or } 2 \text { to } 4 \\
\text { inclusive. }\end{array}$ \\
\hline One current conviction? & Check if the offender is currently serving a sentence for one or more convictions. \\
\hline
\end{tabular}


$11 / 26 / 2019$

Correctional Planning and Criminal Profile

Types of Convictions:

Refers to the current schedules of offences listed in the Corrections and Conditional Release Act (CCRA - Schedule I and II).

\begin{tabular}{|l|l|l|}
\hline Indicator & Description & Score \\
\hline Scheduled current convictions? & Check if the offender has any current offences listed in Schedules I and/or II of the CCRA. \\
\hline
\end{tabular}

\section{Score Groupings}

Once the Criminal History Record has been completed, the system will generate a total Criminal History Record score. The total score is used to place the offender into the appropriate score grouping based on gender as per the following tables:

\begin{tabular}{|c|c|}
\hline Score & Case Management Statement - Men \\
\hline 1 to 7 & $\begin{array}{l}X \text { scored \# on the Criminal Risk Index. Research found that } 6 \% \text { of men federal offenders in this category (range: } 1-7) \text { committed an } \\
\text { offence within } 3 \text { years of release. }\end{array}$ \\
\hline $\begin{array}{l}8 \text { to } \\
13\end{array}$ & $\begin{array}{l}X \text { scored \# on the Criminal Risk Index. Research found that } 13 \% \text { of men federal offenders in this category (range: } 8-13 \text { ) committed } \\
\text { an offence within } 3 \text { years of release. }\end{array}$ \\
\hline $\begin{array}{l}14 \text { to } \\
17\end{array}$ & $\begin{array}{l}\text { X scored \# on the Criminal Risk Index. Research found that } 22 \% \text { of men federal offenders in this category (range: } 14-17) \\
\text { committed an offence within } 3 \text { years of release. }\end{array}$ \\
\hline $\begin{array}{l}18 \text { to } \\
21\end{array}$ & $\begin{array}{l}X \text { scored \# on the Criminal Risk Index. Research found that } 30 \% \text { of men federal offenders in this category (range: 18-21) } \\
\text { committed an offence within } 3 \text { years of release. }\end{array}$ \\
\hline $22+$ & $\begin{array}{l}X \text { scored \# on the Criminal Risk Index. Research found that } 37 \% \text { of male federal offenders in this category (range: } 22 \text { or greater) } \\
\text { committed an offence within X years of release. }\end{array}$ \\
\hline Score & Case Management Statement - Women \\
\hline 1 to 4 & $\begin{array}{l}X \text { scored \# on the Criminal Risk Index. Research found that } 5 \% \text { of women federal offenders in this category (range: } 1-4) \text { committed } \\
\text { an offence within } 3 \text { years of release. }\end{array}$ \\
\hline 5 to 8 & $\begin{array}{l}X \text { scored \# on the Criminal Risk Index. Research found that } 7 \% \text { of women federal offenders in this category (range: } 5-8) \text { committed } \\
\text { an offence within } 3 \text { years of release. }\end{array}$ \\
\hline $\begin{array}{l}9 \text { to } \\
13\end{array}$ & $\begin{array}{l}\text { X scored \# on the Criminal Risk Index. Research found that } 14 \% \text { of women federal offenders in this category (range: 9-13) } \\
\text { committed an offence within } 3 \text { years of release. }\end{array}$ \\
\hline $\begin{array}{l}14 \text { to } \\
18\end{array}$ & $\begin{array}{l}\text { X scored \# on the Criminal Risk Index. Research found that } 16 \% \text { of women federal offenders in this category (range: 14-18) } \\
\text { committed an offence within } 3 \text { years of release. }\end{array}$ \\
\hline $19+$ & $\begin{array}{l}X \text { scored \# on the Criminal Risk Index. Research found that } 30 \% \text { of women federal offenders in this category (range: } 19 \text { or greater) } \\
\text { committed an offence within } 3 \text { years of release. }\end{array}$ \\
\hline
\end{tabular}

\section{Professional Discretion}

The Criminal Risk Index is a reliable tool to assess static risk and to guide intervention levels. Nevertheless, there will be certain cases in the federal system whereby professional discretion is to be used in assessing the offender's overall risk level and potential program and/or intervention placement. For example, a first time offender sentenced to life for multiple murders may score low on the CRI due to the lack of previous criminal history and/or previous periods of custody/supervision. In these cases, the Parole Officer (in conjunction with their supervisor) will need to exercise professional discretion in reliance on the CRI in determining intervention levels. Discretion will also be required in other assessment decisions referring to Aboriginal Social History, information about the degree of harm caused to victims, whether sexual offending occurred as well as information from the Dynamic Factor Identification and Analysis - Revised and other available assessment tools.

The $\mathrm{CRI}$ is used as a static risk assessment and is applied in conjunction with other assessment tools to manage individual offenders and guide the development of correctional plans and supervision strategies to manage the risk to re-offend. Once the offender is released to the community, the degree to which the $\mathrm{CRI}$ influences the supervision levels will decrease the longer the offender is succeeding and performing in line with their Correctional Plan while under community supervision. 
Annex D

Static Factors Assessment

\section{Criminal History Record}

\section{Previous Offences - Youth Court}

\section{Number of Convictions}

- Previous offences youth court?

- Fifteen or more convictions?

- Ten to fourteen convictions?

- Five to nine convictions?

- Two to four convictions?

- One conviction?

Type of Convictions

- Scheduled convictions?

Youth Court Dispositions

- Community supervision?

- Open custody?

- Secure custody?

Disposition Outcomes

- Failure during community-based supervision?

- Disciplinary transfers from open to secure?

- Disciplinary reports while in secure custody?

- Attempt escape/UAL/escape from secure custody?

- Transfer from secure custody to adult facility?

\section{Previous Offences - Adult Court}

Number of Convictions

- Previous offences adult court?

- Fifteen or more convictions?

- Ten to fourteen convictions?

- Five to nine convictions?

- Two to four convictions?

- One conviction?

Type of Convictions

- Scheduled convictions?

Adult Court Sanctions

- Community supervision?

- Provincial terms?

- Federal terms?

Sanction Outcomes

- Failure during community-based supervision?

- Segregation for disciplinary infractions?

- Attempt escape/UAL/escapes?

- Reclassified to higher levels of custody?

- Failures on conditional release?

Crime-Free Period

- Less than six months since last incarceration?

- No crime-free period of one year or more? 
$11 / 26 / 2019$

Correctional Planning and Criminal Profile

\section{Current Offences}

Number of Convictions

- Fifteen or more current convictions?

- Ten to fourteen current convictions?

- Five to nine current convictions?

- Two to four current convictions?

- One current conviction?

Type of Convictions

- Scheduled current convictions?

\section{Offence Severity Record}

\section{Previous Offences}

Type of Convictions

- Previous offences?

- Previous serious offences?

- Drug cultivation?

- Drug trafficking?

- Drug importation?

- Arson/fire-setting?

- Use of prohibited weapons?

- Discharge firearms?

- Forcible confinement/kidnapping?

- Violence (assault, robbery)?

- Sexual offences?

- Attempted murder?

- Homicide

- Conspire to any of the above?

- Break and enter with commission of any of the above?

Type of Victim

- Victims were children?

- Victims were handicapped/infirm?

- Victims were elderly?

- Three or more victims?

- Two victims?

- One victim?

Degree of Force Used on Victim

- Use of power/position/authority on victim?

- Threat of violence to victim?

- Threaten victim with a weapon?

- Violence used against victim?

- Weapons used against victim?

Degree of Physical Harm to Victim

- Caused death of victim?

- Serious injury (wounding, maiming, disfiguring) to victim?

- Minor injury (hitting, slapping, striking) to victim?

Degree of Psychological Harm to Victim

- Serious psychological harm to victim?

- Moderate psychological harm to victim?

- Mild psychological harm to victim?

Sentence Length

- Sentence length over 24 years? 
- Sentence length 10 to 24 years?

- Sentence length 5 to 9 years?

- Sentence length 1 day to 4 years?

\section{Current Offences}

Type of Conviction

- Current serious offences?

- Drug cultivation?

- Drug trafficking?

- Drug importation?

- Arson/fire-setting?

- Use of prohibited weapons?

- Discharge firearms?

- Forcible confinement/kidnapping?

- Violence (assault, robbery)?

- Sexual offences?

- Attempted murder?

- Homicide?

- Conspire to any of the above?

- Break and enter with commission of any of the above?

Types of Victims

- Victims were children?

- Victims were handicapped/infirm?

- Victims were elderly?

- Three or more victims?

- Two victims?

- One victim?

Degree of Force Used on Victims

- Use of power/position/authority on victim?

- Threat of violence to victim?

- Threaten victim with a weapon?

- Violence used against victim?

- Weapons used against victim?

Degree of Physical Harm to Victims

- Caused death of victim?

- Serious injury (wounding, maiming, disfiguring) to victim?

- Minor injury (hitting, slapping, striking) to victim?

Degree of Psychological Harm to Victims

- Serious psychological harm to victim?

- Moderate psychological harm to victim?

- Mild psychological harm to victim?

Sentence Length

- Sentence length over 24 years?

- Sentence length 10 to 24 years?

- Sentence length 5 to 9 years?

- Sentence length 1 day to 4 years?

\section{Sex Offence History Checklist}

Sex Offender Status

- Sex offence history (current or past)?

- Is currently serving a sentence for a sex offence?

- Has been convicted in the past for one or more sex offences? 


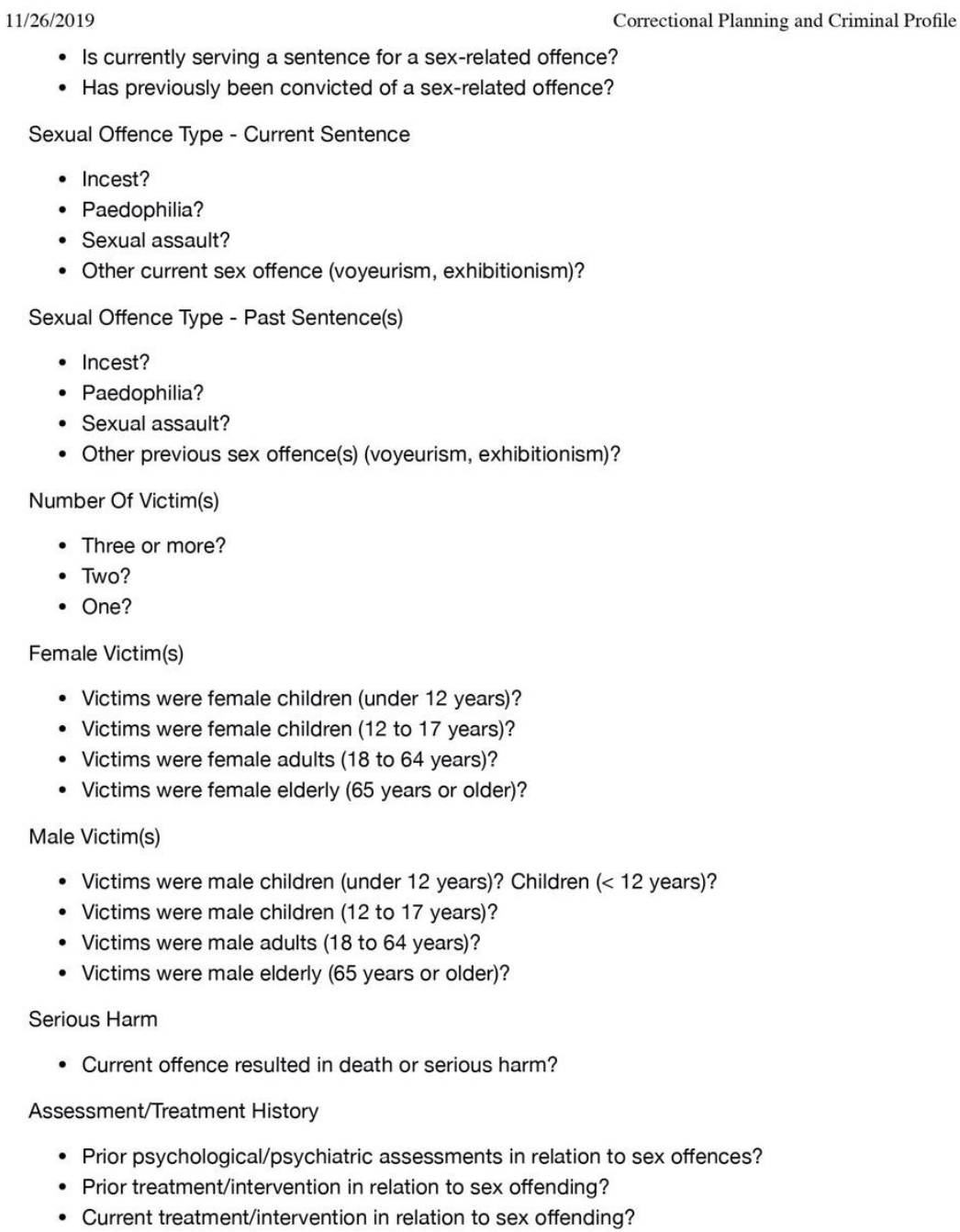

- Is currently serving a sentence for a sex-related offence?

- Has previously been convicted of a sex-related offence?

Sexual Offence Type - Current Sentence

- Incest?

- Paedophilia?

- Sexual assault?

- Other current sex offence (voyeurism, exhibitionism)?

Sexual Offence Type - Past Sentence(s)

- Incest?

- Paedophilia?

- Sexual assault?

- Other previous sex offence(s) (voyeurism, exhibitionism)?

Number Of Victim(s)

- Three or more?

- Two?

- One?

Female Victim(s)

- Victims were female children (under 12 years)?

- Victims were female children (12 to 17 years)?

- Victims were female adults (18 to 64 years)?

- Victims were female elderly (65 years or older)?

Male Victim(s)

- Victims were male children (under 12 years)? Children ( $<12$ years)?

- Victims were male children (12 to 17 years)?

- Victims were male adults (18 to 64 years)?

- Victims were male elderly (65 years or older)?

Serious Harm

- Current offence resulted in death or serious harm?

Assessment/Treatment History

- Prior psychological/psychiatric assessments in relation to sex offences?

- Prior treatment/intervention in relation to sex offending?

- Current treatment/intervention in relation to sex offending?

\section{Annex E}

Dynamic Factor Identification and Analysis, Revised (DFIA-R)

\section{Employment/Education Domain Indicators}

\begin{tabular}{l|l|l|} 
Employment/ Interview Prompts & Help Messages \\
Education \\
Domain \\
Indicators
\end{tabular}

Academic History 


\begin{tabular}{|c|c|c|}
\hline \multicolumn{2}{|l|}{$1 / 26 / 2019$} & Correctional Planning and Criminal Profile \\
\hline $\begin{array}{l}\text { Has less than } \\
\text { grade } 10 \text { or } \\
\text { equivalent? }\end{array}$ & $\begin{array}{l}\text { How far did you go in } \\
\text { school? What is the last } \\
\text { grade you completed? } \\
\text { Have you done any } \\
\text { upgrading since then? } \\
\text { If so, what? }\end{array}$ & $\begin{array}{l}\text { Level achieved either through the regular school system, upgrading, night school, } \\
\text { correspondence courses, or some other method of obtaining grade } 10 \text { level standing. In order to } \\
\text { be rated No the offender must have completed all required grade } 10 \text { credits or, in Quebec, } \\
\text { Secondary-IV. GED completers must have taken final exams and received official } \\
\text { diploma/certificate. Current functioning as determined by the CAAT (Canadian Adult } \\
\text { Achievement Test) or other tests should be included in the narrative section if applicable. For } \\
\text { Aboriginal offenders, consider any geographical limitations (such as isolated/remote community; } \\
\text { high school out of area; etc.) that may have had an impact on their access to educational } \\
\text { resources. }\end{array}$ \\
\hline $\begin{array}{l}\text { Has less than } \\
\text { high school } \\
\text { diploma or } \\
\text { equivalent? }\end{array}$ & $\begin{array}{l}\text { How far did you go in } \\
\text { school? What is the last } \\
\text { grade you completed? } \\
\text { Have you done any } \\
\text { upgrading since then? } \\
\text { If so, what? }\end{array}$ & $\begin{array}{l}\text { Diploma obtained either through the regular school system, upgrading, night school, } \\
\text { correspondence courses, or some other method of obtaining grade } 12 \text { level standing. In order to } \\
\text { be rated No, the offender must have completed all required grade } 12 \text { credits or, in Quebec, } \\
\text { Secondary-V. Current functioning as determined by the CAAT (Canadian Adult Achievement } \\
\text { Test) or other tests should be included in the comments section if applicable. For Aboriginal } \\
\text { offenders, consider any geographical limitations (such as isolated/remote communities; high } \\
\text { school out of area; etc.) that may have had an impact on their access to educational resources. }\end{array}$ \\
\hline \multicolumn{3}{|l|}{ Work History } \\
\hline $\begin{array}{l}\text { Employment } \\
\text { history is } \\
\text { absent? }\end{array}$ & $\begin{array}{l}\text { What kind of work have } \\
\text { you done in the past? } \\
\text { What is the longest you } \\
\text { have ever been } \\
\text { employed? Have you } \\
\text { ever been unemployed } \\
\text { for six or more } \\
\text { consecutive months? }\end{array}$ & $\begin{array}{l}\text { Rate Yes if the offender has never worked for more than } 6 \text { months in a row (full or part time } \\
\text { during adulthood). Employment must have been in the community (e.g., roofing, undeclared } \\
\text { daycare). Young offenders who have not yet gained employment experience are automatically } \\
\text { rated Yes. If the offender has only worked full time in the home, particularly as the primary } \\
\text { caregiver, this should be considered employment; however, it is important to distinguish } \\
\text { between offenders who actually performed these duties within the home versus those who led } \\
\text { unstable lifestyles (e.g., were not actually looking after the home and/or children). For Aboriginal } \\
\text { offenders, consider the lack of employment opportunities in their home community and/or the } \\
\text { movement to an urban city area without skills sets or education that may have had an impact on } \\
\text { their work history. For Aboriginal offenders, a history of traditional and cultural work or activities } \\
\text { to support their family or community should be considered a form of employment. Document if } \\
\text { the offender had been supporting themselves by working in the sex trade. }\end{array}$ \\
\hline $\begin{array}{l}\text { Unemployed } \\
\text { at the time of } \\
\text { arrest? }\end{array}$ & $\begin{array}{l}\text { Were you employed/in } \\
\text { school at the time of } \\
\text { your arrest? How long } \\
\text { had you been working } \\
\text { at that job? For } \\
\text { individuals working in } \\
\text { the home: Describe a } \\
\text { typical day at home. } \\
\text { What types of activities } \\
\text { did you do with the } \\
\text { children/around the } \\
\text { home? }\end{array}$ & $\begin{array}{l}\text { Rate Yes if the offender was unemployed at the time of arrest. For young offenders, being in } \\
\text { school is considered equivalent with being employed. If the young offender was suspended or } \\
\text { expelled from school at the time of arrest and was not employed in the workforce, rate Yes. } \\
\text { Young offenders who were suspended or expelled but were nonetheless working merit a rating } \\
\text { of No. With regards to offenders who are parents, if the offender was working full time in the } \\
\text { home, particularly as the primary caregiver, this should be considered employment; however, it } \\
\text { is important to distinguish between offenders who actually performed these duties within the } \\
\text { home versus those who were not actually looking after the home and/or children. Medical or } \\
\text { health related leave from employment should be rated No. For Aboriginal offenders, consider the } \\
\text { lack of employment opportunities in their home community and/or the movement to an urban } \\
\text { city area without skills sets or education that may have had an impact on their work history. For } \\
\text { Aboriginal offenders, a history of traditional or cultural work or activities to support their family or } \\
\text { community should be considered a form of employment. }\end{array}$ \\
\hline $\begin{array}{l}\text { Job history } \\
\text { has been } \\
\text { unstable? }\end{array}$ & $\begin{array}{l}\text { How many different } \\
\text { jobs have you had } \\
\text { during your lifetime? } \\
\text { Have you ever quit a } \\
\text { job without knowing } \\
\text { where your next pay } \\
\text { cheque was coming } \\
\text { from? What's the } \\
\text { shortest job you have } \\
\text { ever had? What's the } \\
\text { longest? What's the } \\
\text { longest time you have } \\
\text { been without work? }\end{array}$ & $\begin{array}{l}\text { Rate Yes if there is evidence of significant unemployment (six months or more in two years) or } \\
\text { has walked off several jobs without having another job in sight. For young offenders, school is } \\
\text { considered employment. With regards to offenders who are parents, particularly primary } \\
\text { caregivers, consider to what extent the offender managed the household on a regular basis. } \\
\text { Additionally, if there is evidence that the offender also worked outside the home, consider } \\
\text { whether or not the work history was unstable and sporadic. Note: When scoring this item, } \\
\text { consider the offender's entire life history not just the past year prior to arrest. For Aboriginal } \\
\text { offenders, consider the lack of employment opportunities in their home community and/or the } \\
\text { movement to an urban city area without skills sets or education that may have had an impact on } \\
\text { their work history. For Aboriginal offenders, a history of traditional and cultural work or activities } \\
\text { to support their family or community should be considered a form of employment. }\end{array}$ \\
\hline
\end{tabular}




\section{Work Skill Set}

Marketable job skills obtained through experience are limited?

\begin{tabular}{|l} 
\\
\hline \\
\hline Marketable \\
job skills \\
obtained \\
through \\
formal \\
training are \\
limited?
\end{tabular}

[lf not already answered for the previous indicator] What type of work have you done in the past? How many days/months/years did you spend working as a (e.g., roofer,

mechanic, sales clerk, administrative assistant, etc.)? Have you received any on-the-job training for anything we haven't talked about yet?

Have you ever received any kind of formal training, certificate or diploma? If so, what for and how long ago?
Dissatisfied with job skills?
Are you satisfied with the type of work you have done in the past? Do you wish that you could have done something different? How often do you think about changing the nature of work you have done in the past? Were the benefits acceptable? Was the salary sufficient? Were you happy with the degree of job security?

Co-operative How would you work skills are describe your past limited? relationships with coworkers (or classmates), and supervisors? Have you had difficulties with coworkers or supervisors in the past? For those who have not worked: Do you think you would have any difficulties working with others or reporting to someone?
Rate Yes if the offender has not obtained any job-related skills during on-the-job training in any law-abiding area, trade or profession. Skill set must be considered useful in current context (for Aboriginal offenders, particularly Inuit offenders, take current community into consideration, isolated area where traditional and cultural skills would be considered marketable). Note: Managing a household including raising children may not count as a marketable job skill unless it can be readily linked to formal employment (e.g., cleaning services, daycare).
Rate Yes if the offender has never received formal training (e.g., does not have a ticket, official certificate, diploma, apprenticeship) in any law-abiding area, trade or profession. Skill set must be judged useful given current market demands.
Rate Yes if the offender expresses personal dissatisfaction with current skill set/trade/profession or employment history. Individuals rated Yes for this indicator will typically talk negatively about the work they have done in the past. The offender may also comment that the salary was insufficient, the employment benefits were poor and the job lacked security. Offenders who are satisfied with their job skills typically have higher self-esteem. This item also applies to parents who have never had an opportunity to work outside the home due to caregiver responsibilities and would like to pursue employment opportunities outside of the home.
Rate Yes if there is evidence of conflict or friction with co-workers or supervisors (e.g., problems with authority). Individuals rated Yes on this item generally view teamwork in a negative light and believe that it is unimportant to plan and make decisions with others. They also believe that it is unimportant to respect the opinions and feelings of others in the workplace. For individuals who have never worked outside the home or who have never worked, consider volunteer work, or any situation where the individual was required to accomplish some task with at least one other person (e.g., sharing of parental responsibilities with other family members).

Work Attitudes 


\begin{tabular}{|c|c|c|}
\hline $11 / 26 / 2019$ & \multicolumn{2}{|r|}{ Correctional Planning and Criminal Profile } \\
\hline $\begin{array}{l}\text { Belief in } \\
\text { oneself to } \\
\text { improve } \\
\text { employability } \\
\text { is low? }\end{array}$ & $\begin{array}{l}\text { Have you ever been } \\
\text { fired or let go from a } \\
\text { job? Why/why not? If } \\
\text { you were fired/let go, } \\
\text { how did that make you } \\
\text { feel? Do you think you } \\
\text { can be employed? Do } \\
\text { you think you are able } \\
\text { to improve your future } \\
\text { job options? }\end{array}$ & $\begin{array}{l}\text { This indicator is meant to measure the extent to which an offender believes they are incapable of } \\
\text { improving their future employment options. Offenders rated Yes on this indicator do not believe } \\
\text { that they are capable of learning new job skills or that they will be able to adjust to working with } \\
\text { new people or meet the expectations of future employers. If mainly unemployed during the one- } \\
\text { year period prior to arrest, rate whether or not the offender was actively seeking employment. }\end{array}$ \\
\hline $\begin{array}{l}\text { Work ethic } \\
\text { can be } \\
\text { described as } \\
\text { poor? }\end{array}$ & $\begin{array}{l}\text { Do you believe it is } \\
\text { important to work hard } \\
\text { regardless of who is } \\
\text { watching? Do you } \\
\text { believe that you should } \\
\text { be the best at what you } \\
\text { do no matter what? } \\
\text { Can you think of } \\
\text { reasons for working, } \\
\text { above and beyond } \\
\text { receiving a pay } \\
\text { cheque? Are you ever } \\
\text { late for work (or for } \\
\text { class if in school)? }\end{array}$ & $\begin{array}{l}\text { Offenders rated Yes on this indicator generally do not believe that hard work is fulfilling in and of } \\
\text { itself. They do not believe in the value of steady work or a steady income. They do not see value } \\
\text { in work, above and beyond the pay cheque (e.g., making a contribution to society). They may } \\
\text { believe that it is okay to rely on the system for financial support regardless of whether or not } \\
\text { someone is capable of working. In regards to household work, the offender does not believe it is } \\
\text { important to maintain an organized and clean house nor do they put much value in providing } \\
\text { and caring for their children. Evidence for a poor work ethic may also be taken from poor work } \\
\text { performance (e.g., must be prompted to start working, house is described as poorly maintained, } \\
\text { they are often late or hung over at work, school or home, may have been fired from several jobs } \\
\text { for poor work performance). }\end{array}$ \\
\hline \multicolumn{3}{|c|}{ Past Interventions } \\
\hline $\begin{array}{l}\text { Has } \\
\text { previously } \\
\text { been referred } \\
\text { to programs } \\
\text { addressing } \\
\text { deficit(s) } \\
\text { under this } \\
\text { domain? }\end{array}$ & $\begin{array}{l}\text { Have you ever } \\
\text { participated in a course } \\
\text { to upgrade your level of } \\
\text { education? Have you } \\
\text { ever participated in an } \\
\text { employment program? }\end{array}$ & $\begin{array}{l}\text { Rate Yes if the offender has previously been referred to programs addressing deficit(s) under the } \\
\text { education/employment domain. }\end{array}$ \\
\hline $\begin{array}{l}\text { Employment } \\
\text { Need Rating }\end{array}$ & \multicolumn{2}{|c|}{ Employment Need Domain Rating Guidelines } \\
\hline $\begin{array}{l}\text { Factor seen } \\
\text { as an asset } \\
\text { to } \\
\text { community } \\
\text { adjustment }\end{array}$ & \multicolumn{2}{|c|}{$\begin{array}{l}\text { A rating of "Factor seen as an asset to community adjustment" indicates that employment has been stable and has } \\
\text { played an important role for the offender. In the domain analysis, note how this area will contribute/facilitate community } \\
\text { reintegration. }\end{array}$} \\
\hline $\begin{array}{l}\text { No } \\
\text { immediate } \\
\text { need for } \\
\text { improvement }\end{array}$ & \multicolumn{2}{|c|}{$\begin{array}{l}\text { A rating of "No immediate need for improvement" indicates that neither employment, under employment, sporadic } \\
\text { employment, nor chronic unemployment have interfered with daily functioning. }\end{array}$} \\
\hline $\begin{array}{l}\text { Low need for } \\
\text { improvement }\end{array}$ & \multicolumn{2}{|c|}{$\begin{array}{l}\text { An offender receives a rating of "Low need for improvement" if any of the aforementioned have caused minor adjustment } \\
\text { problems while in the community. Need could be addressed through community-based programming. }\end{array}$} \\
\hline $\begin{array}{l}\text { Moderate } \\
\text { need for } \\
\text { improvement }\end{array}$ & \multicolumn{2}{|c|}{$\begin{array}{l}\text { A rating of "Moderate need for improvement" indicates that any of the aforementioned have caused moderate } \\
\text { adjustment problems. }\end{array}$} \\
\hline
\end{tabular}




\begin{tabular}{|c|c|}
\hline $26 / 2019$ & Correctional Planning and Criminal Profile \\
\hline $\begin{array}{l}\text { High need } \\
\text { for } \\
\text { improvement }\end{array}$ & $\begin{array}{l}\text { A rating of "High need for improvement" indicates that the employment situation has caused serious adjustment } \\
\text { problems. }\end{array}$ \\
\hline $\begin{array}{l}\text { Current } \\
\text { Motivation } \\
\text { Level - } \\
\text { Education }\end{array}$ & $\begin{array}{l}\text { Are you interested in treatment/upgrading? Why/why not? How would it help you/not help you? Who else benefits from the } \\
\text { intervention? On a scale of } 1 \text { to } 5 \text {, where } 5 \text { represents "extremely motivated", how motivated are you to upgrade your } \\
\text { education? }\end{array}$ \\
\hline Low & $\begin{array}{l}\text { The offender would benefit from motivation interviewing prior to programming. There is absolutely no recognition that they } \\
\text { have a need in this area. There is no genuine commitment to change. }\end{array}$ \\
\hline Medium & $\begin{array}{l}\text { The offender may not fully accept or recognize need areas as deficit but is willing to participate in recommended programs } \\
\text { or other interventions. Genuine commitment to change may still be absent. While the offender may commit to intervention, } \\
\text { they may only be doing so for external reasons (e.g., to secure early release, to be transferred to a lower security } \\
\text { institution). }\end{array}$ \\
\hline High & $\begin{array}{l}\text { The offender fully recognizes a need requiring intervention and is fully ready to start intervention. They have committed to } \\
\text { change and may have already started actively engaging in behaviours related to change. While still recognizing external } \\
\text { benefits for pursuing intervention (e.g., securing early release), they are primarily motivated for internal reasons (e.g., doing } \\
\text { it for themselves, "I'm tired of the lifestyle or I want a change"). }\end{array}$ \\
\hline $\begin{array}{l}\text { Not } \\
\text { applicable }\end{array}$ & No need in this area. \\
\hline $\begin{array}{l}\text { Current } \\
\text { Motivation } \\
\text { Level - } \\
\text { Employment }\end{array}$ & $\begin{array}{l}\text { Are you interested in treatment/upgrading? Why/why not? How would it help you/not help you? Who else benefits from the } \\
\text { intervention? On a scale of } 1 \text { to } 5 \text {, where } 5 \text { represents "extremely motivated", how motivated are you to upgrade your } \\
\text { employment? }\end{array}$ \\
\hline Low & $\begin{array}{l}\text { The offender would benefit from motivation interviewing prior to programming. There is absolutely no recognition that they } \\
\text { have a need in this area. There is no genuine commitment to change. }\end{array}$ \\
\hline Medium & $\begin{array}{l}\text { The offender may not fully accept or recognize need areas as deficit but is willing to participate in recommended programs } \\
\text { or other interventions. Genuine commitment to change may still be absent. While the offender may commit to intervention, } \\
\text { they may only be doing so for external reasons (e.g., to secure early release, to be transferred to a lower security } \\
\text { institution). }\end{array}$ \\
\hline High & $\begin{array}{l}\text { The offender fully recognizes a need requiring intervention and is fully ready to start intervention. They have committed to } \\
\text { change and may have already started actively engaging in behaviours related to change. While still recognizing external } \\
\text { benefits for pursuing intervention (e.g., securing early release), they are primarily motivated for internal reasons (e.g., doing } \\
\text { it for themselves, "I'm tired of the lifestyle or I want a change"). }\end{array}$ \\
\hline $\begin{array}{l}\text { Not } \\
\text { applicable }\end{array}$ & No need in this area. \\
\hline $\begin{array}{l}\text { Domain } \\
\text { Analysis }\end{array}$ & $\begin{array}{l}\text { Provide narrative summary explaining how this need area relates to the present offence and the offender's overall } \\
\text { criminality. Indicate whether or not the individual is a primary caregiver. Report strengths if applicable (e.g., volunteer work). } \\
\text { Identify whether the offender's income was principally derived from illegal or legal means (e.g., theft, fraud and drug sales). } \\
\text { Indicate the reasons why the specific dynamic factor is rated as contributing (directly linked to the criminal behaviour). For } \\
\text { dynamic factors not directly related to criminal behaviour, but where intervention will improve safe and timely reintegration, } \\
\text { provide a clear explanation of why such factors require intervention. For Aboriginal offenders, explain how the Aboriginal } \\
\text { Social History may have impacted this dynamic factor. Refer to Annex H - Dynamic Factors and Aboriginal Social History } \\
\text { for guidance. }\end{array}$ \\
\hline
\end{tabular}

\section{Marital/Family Domain Indicators}

\begin{tabular}{|l|l|l|}
\hline Marital/Family & Help Messages \\
\hline $\begin{array}{l}\text { Domain } \\
\text { Indicators }\end{array}$ & & \\
\hline
\end{tabular}




\begin{tabular}{|c|c|c|}
\hline /2019 & & rectional Planning and Criminal Profile \\
\hline \multicolumn{3}{|l|}{ Childhood } \\
\hline $\begin{array}{l}\text { Limited } \\
\text { attachment to } \\
\text { family unit } \\
\text { during } \\
\text { childhood? }\end{array}$ & $\begin{array}{l}\text { Who raised you when you were growing } \\
\text { up? How old were you when you left } \\
\text { home? Did you move around a lot when } \\
\text { you were young? Did you ever spend time } \\
\text { in a foster home, group home, or } \\
\text { residential school when you were growing } \\
\text { up? Is there at least one person you would } \\
\text { consider a parent? }\end{array}$ & $\begin{array}{l}\text { Rate Yes if several foster home placements or residential school } \\
\text { placements occurred during early childhood that resulted in no particular } \\
\text { ties or bonding to any one family unit (e.g., parents, aunts, uncles, } \\
\text { grandparents) or if cared for by several different family members during } \\
\text { early childhood. For Aboriginal offenders, consider whether they were } \\
\text { directly or indirectly impacted by placement in residential schools. } \\
\text { Consider the impact of family members attending residential schools; the } \\
\text { offender growing up in foster care or raised by other relatives; sixties scoop } \\
\text { etc. on the offender's childhood. }\end{array}$ \\
\hline $\begin{array}{l}\text { Relations with } \\
\text { parental figure } \\
\text { were negative } \\
\text { during } \\
\text { childhood? }\end{array}$ & $\begin{array}{l}\text { How did you get along with your primary } \\
\text { caregiver(s)? Would you characterize the } \\
\text { relationship as loving? Would you describe } \\
\text { your relationship as positive or negative? } \\
\text { Were the Children's Aid Society or other } \\
\text { government authorities ever involved in } \\
\text { your life? If so, how? }\end{array}$ & $\begin{array}{l}\text { Rate Yes if there is evidence that the relationship between the offender and } \\
\text { their primary caregiver(s) (mother and/or father figures such as parents, } \\
\text { aunts, uncles, grandparents) was chronically negative (e.g., characterized } \\
\text { by abuse, neglect, prolonged absences, poor supervision, absence of } \\
\text { emotional closeness). Describe the exact nature of the conflict in the } \\
\text { narrative section. For Aboriginal offenders, consider any historic and/or } \\
\text { current family violence; the direct and indirect impact of residential schools; } \\
\text { the offender growing up in foster care or raised by other relatives; sixties } \\
\text { scoop that resulted in family fragmentation such as the offender's relations } \\
\text { with parental figures. }\end{array}$ \\
\hline $\begin{array}{l}\text { Abused during } \\
\text { childhood? }\end{array}$ & $\begin{array}{l}\text { Was your family ever investigated by a } \\
\text { child welfare agency (e.g., Children's Aid } \\
\text { Society) or the police? If yes, for what? } \\
\text { What was the outcome? Did anyone in } \\
\text { your family ever push, shove, slap, or hit } \\
\text { you? If so, why? How often? Were you ever } \\
\text { afraid of your parents/caregiver? If yes, } \\
\text { describe. Were you ever sexually abused? } \\
\text { If yes, would you like to talk about it? }\end{array}$ & $\begin{array}{l}\text { Rate Yes if admitted by offender or documented in another official source. } \\
\text { Includes physical abuse (pushing, shoving, slapping, hitting, etc.), sexual } \\
\text { abuse or emotional abuse (threatening, demeaning or insulting behaviour) } \\
\text { from an immediate family member (e.g., father, mother, sibling), extended } \\
\text { family member (e.g., uncle, aunt, grandparent), or a non-family member. } \\
\text { For Aboriginal offenders, consider the direct and indirect impact of } \\
\text { residential schools; sixties scoop on the offender's abuse during childhood. }\end{array}$ \\
\hline $\begin{array}{l}\text { Witnessed } \\
\text { family violence } \\
\text { during } \\
\text { childhood? }\end{array}$ & $\begin{array}{l}\text { Did you ever see your parents/primary } \\
\text { caregivers push, shove, slap or hit one } \\
\text { another? If so, how often? Did you ever } \\
\text { hear them argue, yell or threaten to hurt } \\
\text { one another? If yes, describe. }\end{array}$ & $\begin{array}{l}\text { Rate Yes if admitted by offender or documented in another source (e.g., } \\
\text { Community Assessment, pre-sentence report). Family violence includes } \\
\text { physical abuse (pushing, shoving, slapping, hitting, etc.), sexual abuse or } \\
\text { emotional abuse (threatening, stalking, demeaning, insulting, or financially } \\
\text { controlling behaviour) against any family member (e.g., siblings, father, } \\
\text { mother, or any other extended family member). For Aboriginal offenders, } \\
\text { consider the direct and indirect impact that residential schools; sixties } \\
\text { scoop; or family fragmentation could have had on the violence the offender } \\
\text { witnessed. }\end{array}$ \\
\hline $\begin{array}{l}\text { Family } \\
\text { members } \\
\text { criminally active } \\
\text { during } \\
\text { childhood? }\end{array}$ & $\begin{array}{l}\text { When you were young, were any of your } \\
\text { family members (parents, siblings, } \\
\text { extended family) arrested, charged or } \\
\text { convicted of a criminal offence? If yes, } \\
\text { describe. }\end{array}$ & Rate Yes if criminal activity occurred while the offender was under 18. \\
\hline \multicolumn{3}{|c|}{ Intimate Relationships } \\
\hline $\begin{array}{l}\text { Inability to } \\
\text { maintain an } \\
\text { enduring } \\
\text { intimate } \\
\text { relationship? }\end{array}$ & $\begin{array}{l}\text { Have you ever been divorced or } \\
\text { separated? If yes, how many times? For } \\
\text { individuals never married: How many } \\
\text { girlfriends/boyfriends would you say you } \\
\text { have had? For those never involved in a } \\
\text { long-term relationship: How many short- } \\
\text { term relationships have you had? }\end{array}$ & $\begin{array}{l}\text { Rate Yes if the offender has never had a long-term relationship or has only } \\
\text { been in short-term casual relationships with no evidence of commitment. } \\
\text { Consider offender's age and ethnocultural background when rating this } \\
\text { indicator (e.g., young offender versus } 50+\text { ). For Aboriginal offenders, } \\
\text { consider any historic and/or current family violence; the direct and indirect } \\
\text { impact of residential schools; the offender growing up in foster care or } \\
\text { raised by other relatives; sixties scoop; family fragmentation on the } \\
\text { offender's ability to maintain relationships. }\end{array}$ \\
\hline
\end{tabular}




\begin{tabular}{|c|c|c|}
\hline $1 / 26 / 2019$ & \multicolumn{2}{|r|}{ Correctional Planning and Criminal Profile } \\
\hline $\begin{array}{l}\text { Intimate } \\
\text { relationship(s) } \\
\text { have been } \\
\text { problematic? }\end{array}$ & $\begin{array}{l}\text { On average, how often do you and your } \\
\text { partner argue? About what (e.g., money, } \\
\text { suspected infidelity, children, sex)? How } \\
\text { does the argument(s) usually get resolved? } \\
\text { Have you ever thought about counseling? } \\
\text { Have friends or family ever suggested it to } \\
\text { you? Are/were you happy in your } \\
\text { relationship(s)? }\end{array}$ & $\begin{array}{l}\text { Rate Yes if offender's relationship(s) is best characterized by excessive } \\
\text { jealousy (e.g., continually suspicious and/or distrustful of partner under all } \\
\text { circumstances) or constant arguing (e.g., about money, sex, infidelity, or } \\
\text { children) resulting in serious consequences (e.g., temporary separation, } \\
\text { counseling, interference from other family members). Unhealthy co- } \\
\text { dependency is also rated yes - particularly salient for women. Please note } \\
\text { that the previous indicator (i.e., inability to maintain an enduring intimate } \\
\text { relationship) pertains to instability across different relationship(s) while this } \\
\text { indicator pertains to instability within a relationship(s). For Aboriginal } \\
\text { offenders, consider any historic and/or current family violence; the direct } \\
\text { and indirect impact of family members attending residential schools; the } \\
\text { offender growing up in foster care or raised by other relatives; sixties } \\
\text { scoop; the impact of family fragmentation on the offender's intimate } \\
\text { relationships. }\end{array}$ \\
\hline $\begin{array}{l}\text { Victimized by } \\
\text { spousal abuse? }\end{array}$ & $\begin{array}{l}\text { How do you normally solve disagreements } \\
\text { with your partner(s)? Have the police ever } \\
\text { been called to your house? If yes, why? } \\
\text { What was the outcome? Have you ever } \\
\text { gone to the hospital because of an injury } \\
\text { caused by your partner? If yes, describe. } \\
\text { Have you ever felt afraid of your partner(s)? } \\
\text { Why/why not? How do you make decisions } \\
\text { about money in your relationship/family? }\end{array}$ & $\begin{array}{l}\text { Rate Yes if self-reported or documented in another source (e.g., } \\
\text { Community Assessment, police reports). Spousal violence includes } \\
\text { physical abuse (pushing, shoving, slapping, hitting, etc.), sexual abuse or } \\
\text { emotional abuse (threatening, stalking, demeaning, insulting, financially } \\
\text { controlling behaviour). Includes same-sex partners. For Aboriginal } \\
\text { offenders, consider the historic and/or current family violence within the } \\
\text { context of the offender's Aboriginal Social History. }\end{array}$ \\
\hline $\begin{array}{l}\text { Perpetrated } \\
\text { spousal } \\
\text { violence? }\end{array}$ & $\begin{array}{l}\text { How do you normally solve disagreements } \\
\text { with your partner(s)? Have the police ever } \\
\text { been called to your house? If yes, why? } \\
\text { What was the outcome? Has your partner } \\
\text { ever gone to the hospital because of an } \\
\text { injury caused by you? If yes, describe. } \\
\text { Have you ever gotten the sense that your } \\
\text { partner(s) was/is afraid of you? Why/why } \\
\text { not? How do you usually make decisions } \\
\text { about money matters in your } \\
\text { relationship/family? }\end{array}$ & $\begin{array}{l}\text { Rate Yes if there is an official (past or present convictions) or unofficial } \\
\text { record (past or present charges) admitted by offender or reported by } \\
\text { another source such as Community Assessment or police reports. Spousal } \\
\text { violence includes physical abuse (pushing, shoving, slapping, hitting, etc.), } \\
\text { sexual abuse or emotional abuse (threatening, stalking, demeaning, } \\
\text { insulting, or financially controlling behaviour) against an intimate partner. } \\
\text { Includes same-sex partners. For Aboriginal offenders, consider historic } \\
\text { and/or current family violence and the impact that any family fragmentation } \\
\text { or lack of positive role models may have had as a direct or indirect result of } \\
\text { residential school attendance and/or sixties scoop. }\end{array}$ \\
\hline $\begin{array}{l}\text { Attitudes } \\
\text { support } \\
\text { spousal } \\
\text { violence? }\end{array}$ & $\begin{array}{l}\text { Do you believe that both partners should } \\
\text { have equal say in a relationship? Is it okay } \\
\text { to hurt or scare your partner if they get out } \\
\text { of line? Is it okay to hurt or scare your } \\
\text { partner to get them to do what you want? } \\
\text { Do you believe it is okay for the bread } \\
\text { winner to make all household spending } \\
\text { decisions? Do you believe that one spouse } \\
\text { has a right to force the other to have sex? }\end{array}$ & $\begin{array}{l}\text { Rate Yes if the offender demonstrates attitudes, values or beliefs } \\
\text { supportive of physical abuse (pushing, shoving, slapping, hitting, etc.), } \\
\text { sexual abuse or emotional abuse (threatening, stalking, demeaning, } \\
\text { insulting, or financially controlling behaviour). Prior convictions/charges do } \\
\text { Not merit an automatic Yes rating. For Aboriginal offenders, consider } \\
\text { historic and/or current family violence and the impact that any family } \\
\text { fragmentation or lack of positive role models may have had as a direct or } \\
\text { indirect result of residential school attendance and/or sixties scoop. }\end{array}$ \\
\hline \multicolumn{3}{|l|}{ Parenting } \\
\hline $\begin{array}{l}\text { Has no parental } \\
\text { responsibilities? }\end{array}$ & $\begin{array}{l}\text { Do you have children? If so, how often do } \\
\text { you see them (e.g., lived together, regular } \\
\text { visitations)? Who is currently looking after } \\
\text { the children? What is the status of any } \\
\text { court hearings in your case? }\end{array}$ & $\begin{array}{l}\text { Rate Yes if the offender Does not have biological or non-biological children } \\
\text { currently considered dependents under } 18 \text { years of age (i.e., the parent } \\
\text { provides or should be providing regular financial or instrumental support for } \\
\text { the child). }\end{array}$ \\
\hline $\begin{array}{l}\text { Has significant } \\
\text { difficulties } \\
\text { handling } \\
\text { parental } \\
\text { responsibilities? }\end{array}$ & $\begin{array}{l}\text { For individuals with children: How often do } \\
\text { you typically see your children? What is a } \\
\text { typical day like for you and your children? }\end{array}$ & $\begin{array}{l}\text { Rate Yes if there is evidence that the offender cannot or does not provide } \\
\text { for the physical or emotional needs of the child. If the offender does not } \\
\text { have children, rate No. For Aboriginal offenders, explain how the Aboriginal } \\
\text { Social History may have impacted the offender's parental responsibilities. }\end{array}$ \\
\hline
\end{tabular}




\begin{tabular}{|c|c|c|}
\hline $11 / 26 / 2019$ & \multicolumn{2}{|r|}{ Correctional Planning and Criminal Profile } \\
\hline $\begin{array}{l}\text { Parental } \\
\text { knowledge } \\
\text { and/or skill is } \\
\text { limited? }\end{array}$ & $\begin{array}{l}\text { Tell me what a typical week is like for you } \\
\text { and your child or children. For example, } \\
\text { how do you usually pass the time? What } \\
\text { does your child or children typically } \\
\text { eat/drink on any given day? If your child or } \\
\text { children are under } 12 \text { : Is there always } \\
\text { someone with your child or children? If } \\
\text { over 12: Do you like to know where your } \\
\text { child or children are at all times? Do they } \\
\text { have a curfew? What do you usually do } \\
\text { when your child or children do something } \\
\text { that makes you happy? What's the best } \\
\text { way to modify your child's behaviour - to } \\
\text { get them to do what you want? }\end{array}$ & $\begin{array}{l}\text { Rate Yes if any one of the following three situations applies: } \\
\text { 1) the offender does not use positive reinforcement (e.g., hugs, kisses, } \\
\text { praise, special privileges) on a regular basis to encourage good behaviour; } \\
\text { 2) the offender does not participate in activities with child or children (e.g., } \\
\text { sports, hobbies, games, crafts, reading, talking, playing); or 3) the offender } \\
\text { lacks information about basic childcare needs and childhood development } \\
\text { (e.g., has unrealistic expectations about child's abilities during different } \\
\text { stages of development, nutrition, sensory stimulation, and supervision } \\
\text { requirements). If the offender does not have children, rate No. For } \\
\text { Aboriginal offenders, explain how the Aboriginal Social History may have } \\
\text { impacted the offender's parental knowledge and/or skills (for example, } \\
\text { family fragmentation and lack of positive parental figures in the offender's } \\
\text { history may have contributed to current deficits in parental knowledge and } \\
\text { or skills). }\end{array}$ \\
\hline $\begin{array}{l}\text { Formally } \\
\text { investigated for } \\
\text { suspicion of } \\
\text { child abuse } \\
\text { and/or neglect? }\end{array}$ & $\begin{array}{l}\text { Have you or anyone else in your family ever } \\
\text { been seen by the Children's Aid Society? If } \\
\text { yes, when? What for? What was the } \\
\text { eventual outcome? }\end{array}$ & $\begin{array}{l}\text { Rate Yes if the offender self-reports or file information indicates that the } \\
\text { offender was investigated at least once by a child welfare agency for } \\
\text { suspicion of child abuse or neglect. Consider abuse or neglect of } \\
\text { dependents, biological children, non-biological children and/or any child } \\
\text { within or outside the family unit (extended family member, niece, nephew, } \\
\text { care of neighbour's children, etc.). For Aboriginal offenders, consider the } \\
\text { impact of family fragmentation and/or systemic racism and discrimination } \\
\text { that has resulted in higher interventions by child welfare agencies. } \\
\text { Additionally the potential lack of inherent parental skill sets based on their } \\
\text { historic experiences, and any direct or indirect impacts related to } \\
\text { residential school or the sixties scoop. }\end{array}$ \\
\hline $\begin{array}{l}\text { Uses excessive } \\
\text { force to } \\
\text { discipline child? }\end{array}$ & $\begin{array}{l}\text { What do you usually do when your child or } \\
\text { children do something you don't like (e.g., } \\
\text { temper tantrum, whine, poor school } \\
\text { grades, fight with siblings/friends, etc.)? } \\
\text { How do you usually discipline them? Have } \\
\text { you ever disciplined your child or children } \\
\text { by hitting, slapping, pushing or shoving } \\
\text { them? Have you ever restrained your child? } \\
\text { Have you used time outs? If so, for how } \\
\text { long? Has your child ever been bruised, } \\
\text { suffered broken bones as a result of } \\
\text { discipline? If yes, how often? Under what } \\
\text { circumstances? }\end{array}$ & $\begin{array}{l}\text { Rate Yes if the offender self-reports or file information indicates that the } \\
\text { offender has used excessive force (e.g., pushing, shoving, slapping, hitting, } \\
\text { or other extreme measures). Consider use of excessive force against } \\
\text { dependents, biological children, non-biological children and/or any child } \\
\text { within or outside the family unit (extended family member, niece, nephew, } \\
\text { care of neighbour's children, etc.). For Aboriginal offenders, consider } \\
\text { intergenerational family violence that may have resulted through direct and } \\
\text { indirect exposure to the residential school system and how they were } \\
\text { exposed to discipline and it may have shaped their point of view. }\end{array}$ \\
\hline \multicolumn{3}{|c|}{ Past Interventions } \\
\hline $\begin{array}{l}\text { Has previously } \\
\text { been referred to } \\
\text { programs } \\
\text { addressing } \\
\text { deficit(s) under } \\
\text { this domain? }\end{array}$ & $\begin{array}{l}\text { Have you ever participated in a course or } \\
\text { program addressing family violence, } \\
\text { parenting skills, etc.? }\end{array}$ & $\begin{array}{l}\text { Rate Yes if the offender has previously been referred to programs } \\
\text { addressing deficit(s) under the marital/family domain. }\end{array}$ \\
\hline $\begin{array}{l}\text { Martial/Family } \\
\text { Need Rating }\end{array}$ & \multicolumn{2}{|l|}{ Marital/Family Need Domain Rating Guidelines } \\
\hline $\begin{array}{l}\text { Factor seen } \\
\text { as an asset to } \\
\text { community } \\
\text { adjustment }\end{array}$ & \multicolumn{2}{|c|}{$\begin{array}{l}\text { For this category, a rating of "Factor seen as an asset to community adjustment" indicates that there is history of } \\
\text { positive and supportive relationships with either parents, relatives, spouse or children and there is no evidence of having } \\
\text { either experienced or perpetrated family violence. In the domain analysis, note how this area will contribute/facilitate } \\
\text { community reintegration. }\end{array}$} \\
\hline
\end{tabular}




\begin{tabular}{|c|c|}
\hline & Correctional Planning and Criminal Profile \\
\hline $\begin{array}{l}\text { No immediate } \\
\text { need for } \\
\text { improvement }\end{array}$ & $\begin{array}{l}\text { A rating of "No immediate need for improvement" indicates that there is evidence of a satisfying and caring relationship } \\
\text { within a marriage and/or family which has resulted in no current difficulties while in the community. }\end{array}$ \\
\hline $\begin{array}{l}\text { Low need for } \\
\text { improvement }\end{array}$ & $\begin{array}{l}\text { A rating of "Low need for improvement" indicates that there has been evidence of uncaring, hostility, arguments, fighting } \\
\text { or indifference in the marital/family relationships resulting in occasional instability (including relationships with children as } \\
\text { well as spouse). }\end{array}$ \\
\hline $\begin{array}{l}\text { Moderate } \\
\text { need for } \\
\text { improvement }\end{array}$ & $\begin{array}{l}\text { A rating of "Moderate need for improvement" indicates that there is a substantial problem in at least one area of this } \\
\text { domain that is resulting in a pattern of unstable relationships (e.g., unresolved issues pertaining to childhood abuse). }\end{array}$ \\
\hline $\begin{array}{l}\text { High need for } \\
\text { improvement }\end{array}$ & $\begin{array}{l}\text { A rating of "High need for improvement" is given if more than two of the aforementioned have been causing a very } \\
\text { unstable pattern of marital/family relationships. }\end{array}$ \\
\hline $\begin{array}{l}\text { Current } \\
\text { Motivation } \\
\text { Level - } \\
\text { Identified } \\
\text { Deficit }\end{array}$ & $\begin{array}{l}\text { Are you interested in treatment/upgrading? Why/why not? How would it help you/not help you? } \\
\text { Who else benefits from the intervention? }\end{array}$ \\
\hline Low & $\begin{array}{l}\text { The offender would benefit from motivation interviewing prior to programming. There is absolutely no recognition that they } \\
\text { have a need in this area. There is no genuine commitment to change. }\end{array}$ \\
\hline Medium & $\begin{array}{l}\text { The offender may not fully accept or recognize need areas as deficit but is willing to participate in recommended } \\
\text { programs or other interventions. Genuine commitment to change may still be absent. While the offender may commit to } \\
\text { intervention, they may only be doing so for external reasons (e.g., to secure early release, to be transferred to a lower } \\
\text { security institution). }\end{array}$ \\
\hline High & $\begin{array}{l}\text { The offender fully recognizes a need requiring intervention and is fully ready to start intervention. They have committed to } \\
\text { change and may have already started actively engaging in behaviours related to change. While still recognizing external } \\
\text { benefits for pursuing intervention (e.g., securing early release), they are primarily motivated for internal reasons (e.g., doing } \\
\text { it for themselves, "I'm tired of the lifestyle or I want a change"). }\end{array}$ \\
\hline $\begin{array}{l}\text { Not } \\
\text { applicable }\end{array}$ & No need in this area. \\
\hline $\begin{array}{l}\text { Domain } \\
\text { Analysis }\end{array}$ & $\begin{array}{l}\text { Provide a narrative summary explaining how this need area relates to the present offence and the offender's overall } \\
\text { criminality. For offenders with children, report current custody arrangement. Report strengths, if applicable. Indicate the } \\
\text { reasons why the specific dynamic factor is rated as contributing (directly linked to the criminal behaviour). For dynamic } \\
\text { factors not directly related to criminal behaviour, but where intervention will improve safe and timely reintegration, provide } \\
\text { a clear explanation of why such factors require intervention. For Aboriginal offenders, explain how the Aboriginal Social } \\
\text { History may have impacted this dynamic factor. Refer to Annex H- Dynamic Factors and Aboriginal Social History for } \\
\text { guidance. }\end{array}$ \\
\hline
\end{tabular}

\section{Associates Domain Indicators}

\begin{tabular}{|c|c|c|}
\hline $\begin{array}{l}\text { Associates } \\
\text { Domain } \\
\text { Indicators }\end{array}$ & Interview Prompts & Help Messages \\
\hline \multicolumn{3}{|l|}{ Criminal } \\
\hline $\begin{array}{l}\text { Associates with } \\
\text { substance } \\
\text { abusers? }\end{array}$ & $\begin{array}{l}\text { Do any of your friends, } \\
\text { acquaintances or family } \\
\text { members drink excessively or } \\
\text { use drugs? How often do you } \\
\text { see them? }\end{array}$ & $\begin{array}{l}\text { Rate Yes if there is evidence that the offender socializes with friends, family or } \\
\text { acquaintances who abuse drugs or alcohol. For Aboriginal offenders, consider the } \\
\text { impact of family and community fragmentation on the offender's associates. }\end{array}$ \\
\hline
\end{tabular}




\begin{tabular}{|c|c|c|}
\hline \multicolumn{2}{|l|}{$11 / 26 / 2019$} & Correctional Planning and Criminal Profile \\
\hline $\begin{array}{l}\text { Has many } \\
\text { criminal } \\
\text { acquaintances? }\end{array}$ & $\begin{array}{l}\text { How many of your } \\
\text { acquaintances have criminal } \\
\text { records or have been involved } \\
\text { with the police (e.g., none, few, } \\
\text { most)? }\end{array}$ & $\begin{array}{l}\text { Rate Yes if there is evidence that the offender socializes with criminal acquaintances. } \\
\text { For Aboriginal offenders, consider the impact of family and community fragmentation, } \\
\text { racial discrimination and gang affiliation on the offender's associates. }\end{array}$ \\
\hline $\begin{array}{l}\text { Has many } \\
\text { criminal } \\
\text { friends? }\end{array}$ & $\begin{array}{l}\text { How many of your friends have } \\
\text { criminal records or have been } \\
\text { involved with the police (e.g., } \\
\text { none, few, most)? }\end{array}$ & $\begin{array}{l}\text { Rate Yes if there is evidence that the offender has several criminal friends. For } \\
\text { Aboriginal offenders, consider the impact of family and community fragmentation, } \\
\text { racial discrimination and gang affiliation on the offender's associates. }\end{array}$ \\
\hline $\begin{array}{l}\text { Has contact } \\
\text { with criminal } \\
\text { family } \\
\text { members? }\end{array}$ & $\begin{array}{l}\text { How much contact have you } \\
\text { had with your family during the } \\
\text { last year? What about now? Do } \\
\text { any of them have criminal } \\
\text { records? }\end{array}$ & $\begin{array}{l}\text { Rate Yes if the offender has regular contact with family members who have been } \\
\text { involved or are currently involved in crime. For Aboriginal offenders, consider the } \\
\text { impact of family and community fragmentation, racial discrimination and gang } \\
\text { affiliation on the offender's associates. }\end{array}$ \\
\hline $\begin{array}{l}\text { Has a criminal } \\
\text { partner? }\end{array}$ & $\begin{array}{l}\text { Has your partner ever been } \\
\text { involved with the criminal } \\
\text { justice system? }\end{array}$ & $\begin{array}{l}\text { Rate Yes if the offender is married, or was living common-law, or is involved in a long- } \\
\text { term relationship (at least one year) with someone involved in crime (e.g., the person } \\
\text { has been charged and/or convicted of a criminal offence in the past or is currently } \\
\text { involved in crime). Includes same-sex partners. For Aboriginal offenders, consider the } \\
\text { impact of family and community fragmentation, racial discrimination and gang } \\
\text { affiliation on the offender's associates. }\end{array}$ \\
\hline $\begin{array}{l}\text { Suspected } \\
\text { affiliation with } \\
\text { street } \\
\text { gang/organized } \\
\text { crime? }\end{array}$ & $\begin{array}{l}\text { Do you know anyone who } \\
\text { belongs to a gang? Have you } \\
\text { ever socialized with a known } \\
\text { gang member or associate? } \\
\text { Have you ever belonged to a } \\
\text { gang? }\end{array}$ & $\begin{array}{l}\text { Rate Yes if any of the following apply: } \\
\text { 1) the offender was arrested while participating in a criminal activity with known gang } \\
\text { members or affiliates; } \\
\text { 2) the offender self-reports membership/affiliation; } \\
\text { 3) a judicial finding confirms membership/affiliation; } \\
\text { 4) tangible evidence (e.g., written, photographic) confirms membership/association; or } \\
\text { 5) unofficial information from a reliable source (e.g., informant, Community Assessment } \\
\text { report) confirms association. For Aboriginal offenders, consider the impact of family } \\
\text { and community fragmentation, racial discrimination and gang affiliation on the } \\
\text { offender's associates. }\end{array}$ \\
\hline $\begin{array}{l}\text { Resides in a } \\
\text { high crime } \\
\text { area? }\end{array}$ & $\begin{array}{l}\text { Did you live in a high crime } \\
\text { area? Did you feel safe at } \\
\text { night? Did you worry about your } \\
\text { children? Did you notice } \\
\text { criminal activity? Did the police } \\
\text { come to your neighbourhood } \\
\text { regularly? }\end{array}$ & $\begin{array}{l}\text { Rate Yes if the offender lives in a high crime area (e.g., prostitution, drug trafficking, } \\
\text { highly visible police presence). Consider offender's perception as well as official } \\
\text { information. For Aboriginal offenders, consider the impact of family and community } \\
\text { fragmentation, racial discrimination and gang affiliation on the offender's associates. }\end{array}$ \\
\hline \multicolumn{3}{|c|}{ Prosocial Deficits } \\
\hline $\begin{array}{l}\text { Prosocial } \\
\text { support from } \\
\text { an intimate } \\
\text { partner is } \\
\text { limited? }\end{array}$ & $\begin{array}{l}\text { How has your partner helped } \\
\text { you during the last year and } \\
\text { since your arrest? When was } \\
\text { the last time you spoke to } \\
\text { them? On the outside, how } \\
\text { frequently did you talk to them } \\
\text { (daily, weekly, monthly)? Do } \\
\text { they have a criminal record? }\end{array}$ & $\begin{array}{l}\text { Rate Yes if the offender does not receive support (instrumental or emotional) from a } \\
\text { prosocial partner (e.g., common-law partner, husband/wife, same-sex partner, long- } \\
\text { term non-cohabitating partner). Instrumental support includes tangible help (e.g., } \\
\text { housing, money) while emotional support includes non-tangible support (e.g., } \\
\text { someone to talk to). If applicable, indicate whether or not the offender has been } \\
\text { banished (Aboriginal offenders only) in the narrative section. Rate Yes if the offender } \\
\text { does not have an intimate partner. For Aboriginal offenders, consider whether the } \\
\text { impact of family and community fragmentation contributed to a lack of prosocial } \\
\text { support from an intimate partner. }\end{array}$ \\
\hline
\end{tabular}




\begin{tabular}{|c|c|c|}
\hline $11 / 26 / 2019$ & \multicolumn{2}{|r|}{ Correctional Planning and Criminal Profile } \\
\hline $\begin{array}{l}\text { Prosocial family } \\
\text { support is } \\
\text { limited? }\end{array}$ & $\begin{array}{l}\text { Are you close to your family? } \\
\text { Have they ever helped you out } \\
\text { when you needed it? When was } \\
\text { the last time you spoke to } \\
\text { them? On the outside, how } \\
\text { frequently did you talk to them } \\
\text { (daily, weekly, monthly)? Do } \\
\text { they have criminal records? }\end{array}$ & $\begin{array}{l}\text { Rate Yes if the offender does not receive support (instrumental or emotional) from } \\
\text { prosocial family member(s) (includes extended family members). Instrumental support } \\
\text { includes tangible help (e.g., housing, money) while emotional support includes non- } \\
\text { tangible support (e.g., someone to talk to). If applicable, indicate whether or not the } \\
\text { offender has been banished (Aboriginal offenders only) in the narrative section. For } \\
\text { Aboriginal offenders, consider whether the impact of family and community } \\
\text { fragmentation contributed to a lack of prosocial support from family. }\end{array}$ \\
\hline $\begin{array}{l}\text { Prosocial } \\
\text { support from } \\
\text { friends is } \\
\text { limited? }\end{array}$ & $\begin{array}{l}\text { Have your friends ever helped } \\
\text { you out when you needed it } \\
\text { (money, talk to them about a } \\
\text { problem)? When was the last } \\
\text { time you spoke to any of your } \\
\text { friends? On the outside, how } \\
\text { frequently did you talk to them } \\
\text { (daily, weekly, monthly)? Do } \\
\text { they have criminal records? }\end{array}$ & $\begin{array}{l}\text { Rate Yes if the offender does not receive support (instrumental or emotional) from } \\
\text { prosocial friends. Instrumental support includes tangible help (e.g., housing, money) } \\
\text { while emotional support includes non-tangible support (e.g., someone to talk to). If } \\
\text { applicable, indicate whether or not the offender has been banished (Aboriginal } \\
\text { offenders only) in the narrative section. For Aboriginal offenders, consider whether the } \\
\text { impact of family and community fragmentation contributed to a lack of prosocial } \\
\text { support from friends. }\end{array}$ \\
\hline \multicolumn{3}{|c|}{ Past Interventions } \\
\hline $\begin{array}{l}\text { Has previously } \\
\text { been referred } \\
\text { to programs } \\
\text { addressing } \\
\text { deficit(s) under } \\
\text { this domain? }\end{array}$ & $\begin{array}{l}\text { Have you ever participated in a } \\
\text { course or program about } \\
\text { criminal acquaintances and/or } \\
\text { socializing with friends that } \\
\text { abuse drugs or alcohol? }\end{array}$ & $\begin{array}{l}\text { Rate Yes if the offender has previously been referred to programs addressing deficit(s) } \\
\text { under the associates domain. }\end{array}$ \\
\hline $\begin{array}{l}\text { Associates } \\
\text { Need Rating }\end{array}$ & \multicolumn{2}{|c|}{ Associates Need Domain Rating Guidelines } \\
\hline $\begin{array}{l}\text { Factor seen } \\
\text { as an asset } \\
\text { to } \\
\text { community } \\
\text { adjustment }\end{array}$ & \multicolumn{2}{|c|}{$\begin{array}{l}\text { A rating of "Factor seen as an asset to community adjustment" indicates that there is evidence of the offender having } \\
\text { had positive prosocial support from either family, friends or spouse and no associations with criminal friends or } \\
\text { acquaintances. In the domain analysis, note how this area will contribute/facilitate community reintegration. }\end{array}$} \\
\hline $\begin{array}{l}\text { No } \\
\text { immediate } \\
\text { need for } \\
\text { improvement }\end{array}$ & \multicolumn{2}{|c|}{$\begin{array}{l}\text { A rating of "No immediate need for improvement" indicates that there is evidence of the offender having had mostly non- } \\
\text { criminal and positive associates. }\end{array}$} \\
\hline $\begin{array}{l}\text { Low need for } \\
\text { improvement }\end{array}$ & \multicolumn{2}{|c|}{$\begin{array}{l}\text { A rating of "Low need for improvement" indicates that there has been a lack of positive associates and/or some negative } \\
\text { companions (e.g., criminal). }\end{array}$} \\
\hline $\begin{array}{l}\text { Moderate } \\
\text { need for } \\
\text { improvement }\end{array}$ & \multicolumn{2}{|c|}{$\begin{array}{l}\text { A rating of "Moderate need for improvement" indicates that there is a substantial problem in that the offender has mainly } \\
\text { criminal associates but they may have some prosocial supports. }\end{array}$} \\
\hline $\begin{array}{l}\text { High need } \\
\text { for } \\
\text { improvement }\end{array}$ & \multicolumn{2}{|c|}{$\begin{array}{l}\text { A rating of "High need for improvement" is given if there is an absence of prosocial support coupled with a strong } \\
\text { criminal support system that has been interfering consistently with the offender's performance in the community. }\end{array}$} \\
\hline $\begin{array}{l}\text { Current } \\
\text { Motivation } \\
\text { Level - } \\
\text { Identified } \\
\text { Deficit }\end{array}$ & \multicolumn{2}{|c|}{$\begin{array}{l}\text { Are you interested in treatment/upgrading? Why/why not? How would it help you/not help you? Who else benefits from the } \\
\text { intervention? }\end{array}$} \\
\hline
\end{tabular}




\begin{tabular}{|c|c|}
\hline $6 / 2019$ & Correctional Planning and Criminal Profile \\
\hline Low & $\begin{array}{l}\text { The offender would benefit from motivation interviewing prior to programming. There is absolutely no recognition that they } \\
\text { have a need in this area There is no genuine commitment to change. }\end{array}$ \\
\hline Medium & $\begin{array}{l}\text { The offender may not fully accept or recognize need area as deficit but is willing to participate in recommended programs } \\
\text { or other interventions. Genuine commitment to change may still be absent. While the offender may commit to intervention, } \\
\text { they may only be doing so for external reasons (e.g., to secure early release, to be transferred to a lower security } \\
\text { institution). }\end{array}$ \\
\hline High & $\begin{array}{l}\text { The offender fully recognizes a need requiring intervention and is fully ready to start intervention. They have committed to } \\
\text { change and may have already started actively engaging in behaviours related to change. While still recognizing external } \\
\text { benefits for pursuing intervention (e.g., securing early release), they are primarily motivated for internal reasons (e.g., doing } \\
\text { it for themselves, "I'm tired of the lifestyle or I want a change"). }\end{array}$ \\
\hline $\begin{array}{l}\text { Not } \\
\text { applicable }\end{array}$ & No need in this area. \\
\hline $\begin{array}{l}\text { Domain } \\
\text { Analysis }\end{array}$ & $\begin{array}{l}\text { Provide a narrative summary explaining how this need area relates to the present offence and the offender's overall } \\
\text { criminality. Report strengths if applicable (e.g., prosocial support systems). Indicate the reasons why the specific dynamic } \\
\text { factor is rated as contributing (directly linked to the criminal behaviour). For other dynamic factors not directly related to } \\
\text { criminal behaviour, but where intervention will improve safe and timely reintegration, provide a clear explanation of why } \\
\text { such factors require intervention. For Aboriginal offenders, explain how the Aboriginal Social History may have impacted } \\
\text { this dynamic factor. Refer to Annex H - Dynamic Factors and Aboriginal Social History for guidance. }\end{array}$ \\
\hline
\end{tabular}

\section{Substance Abuse Domain Indicators}

\begin{tabular}{|c|c|c|}
\hline $\begin{array}{l}\text { Substance } \\
\text { Abuse } \\
\text { Domain } \\
\text { Indicators }\end{array}$ & Interview Prompts & Help Messages \\
\hline \multicolumn{3}{|l|}{ Alcohol Use } \\
\hline $\begin{array}{l}\text { Early age } \\
\text { alcohol use? }\end{array}$ & $\begin{array}{l}\text { How old were you when you first consumed alcohol? Who } \\
\text { were you with? How often did you drink (daily, weekly, } \\
\text { monthly)? How often were you hung over? Were you ever } \\
\text { suspended or expelled from school as a result of drinking? If } \\
\text { so, how many times? Tell me about it. Did your parents or } \\
\text { caregivers ever talk to you about your drinking? Were you } \\
\text { ever in counselling because of your drinking? }\end{array}$ & $\begin{array}{l}\text { Rate Yes if there is evidence that early-age drinking (under } \\
\text { age 16) interfered with any aspect of the offender's life (e.g., } \\
\text { expelled/suspended from school, in trouble with parents, } \\
\text { referred for an assessment). Also rate Yes if the offender } \\
\text { reports being intoxicated or hung over regularly (e.g., at } \\
\text { least once per week) at an early age. For Aboriginal } \\
\text { offenders, consider the impact of family history of } \\
\text { substance abuse; resorting to substances as a coping } \\
\text { mechanism in response to direct and indirect experiences } \\
\text { including residential schools or the sixties scoop, etc. on } \\
\text { the offender's early alcohol use and lifestyle. }\end{array}$ \\
\hline $\begin{array}{l}\text { Frequently } \\
\text { engages in } \\
\text { binge } \\
\text { drinking? }\end{array}$ & $\begin{array}{l}\text { During the last year, how often did you drink in bouts or } \\
\text { binges? Did you ever do it for more than two days in a row? } \\
\text { If so, how often (a few times a year, a few times a month, } \\
\text { every week)? }\end{array}$ & $\begin{array}{l}\text { Rate Yes if over the course of the last year: } \\
\text { 1) there is evidence that the offender had at least } 5 \text { (for } \\
\text { men) or } 4 \text { (for women) drinks in one sitting for at least two } \\
\text { days in a row; and } \\
\text { 2) this behaviour occurred at least twice per month. } \\
\text { For Aboriginal offenders, consider the impact of family } \\
\text { history of substance abuse; resorting to substances as a } \\
\text { coping mechanism in response to direct and indirect } \\
\text { experiences including residential schools or the sixties } \\
\text { scoop, etc. on the offender's binge drinking. }\end{array}$ \\
\hline
\end{tabular}




\begin{tabular}{|c|c|c|}
\hline 2019 & Correctional Planning & and Criminal Profile \\
\hline $\begin{array}{l}\text { Has } \\
\text { combined the } \\
\text { use of alcohol } \\
\text { and drugs? }\end{array}$ & $\begin{array}{l}\text { Have you ever used alcohol and drugs at the same time? } \\
\text { Describe the circumstances and frequency (a few times in } \\
\text { the last year, a few times per month, every week). }\end{array}$ & $\begin{array}{l}\text { Rate Yes if there is evidence that the offender combined the } \\
\text { use of alcohol and drugs at least a few times per month } \\
\text { (consider all information sources including the } \\
\text { Computerized Assessment of Substance Abuse, } \\
\text { Community Assessment reports, interview results). For } \\
\text { Aboriginal offenders, consider the impact of family history } \\
\text { of substance abuse; resorting to substances as a coping } \\
\text { mechanism in response to direct and indirect experiences } \\
\text { including residential schools or the sixties scoop, etc. on } \\
\text { the offender's combined use of alcohol and drugs. }\end{array}$ \\
\hline $\begin{array}{l}\text { Alcohol use } \\
\text { interferes } \\
\text { with } \\
\text { employment? }\end{array}$ & $\begin{array}{l}\text { Ever miss work/school because you were too hung over? } \\
\text { Were you ever drunk at work/school, or consume alcohol at } \\
\text { work/school? Have you ever been fired/expelled from a } \\
\text { job/school because of alcohol?" For individuals who work } \\
\text { within the home: Did you feel like your drinking ever affected } \\
\text { your household and/or children? Did anyone ever comment } \\
\text { that your drinking was interfering with your children or your } \\
\text { home? }\end{array}$ & $\begin{array}{l}\text { Rate Yes if there is evidence that the offender's alcohol use } \\
\text { interfered with their job or education in any way (e.g., fired } \\
\text { from job because of being drunk at work or hung over, } \\
\text { evidence of poor job performance as a result of drinking). } \\
\text { Note: Consider academic performance for young offenders } \\
\text { (if applicable) and management of household } \\
\text { responsibilities for individuals working within the home. For } \\
\text { Aboriginal offenders, consider the impact of family history } \\
\text { of substance abuse; resorting to substances as a coping } \\
\text { mechanism in response to direct and indirect experiences } \\
\text { including residential schools or the sixties scoop, etc. on } \\
\text { the offender's alcohol use and employment. }\end{array}$ \\
\hline $\begin{array}{l}\text { Alcohol use } \\
\text { interferes } \\
\text { with } \\
\text { interpersonal } \\
\text { relationships? }\end{array}$ & $\begin{array}{l}\text { Has anyone ever expressed concern about your alcohol } \\
\text { use? Did your family ever claim that you have a drinking } \\
\text { problem? For example, did your partner ever seek help for } \\
\text { your drinking or ask you to seek help? Has your drinking } \\
\text { ever resulted in arguments or physical fights with other } \\
\text { people? If yes, with whom and how often (rarely, } \\
\text { occasionally, frequently)? }\end{array}$ & $\begin{array}{l}\text { Rate Yes if there is evidence that the offender's alcohol use } \\
\text { has negatively impacted interpersonal relationships with } \\
\text { significant others including intimate partners, family } \\
\text { members, or friends (e.g., lost friends over drinking, } \\
\text { drinking resulted in divorce/separation, caused problems in } \\
\text { general with intimate partner, children or other family } \\
\text { members). For Aboriginal offenders, consider the impact of } \\
\text { family history of substance abuse; resorting to substances } \\
\text { as a coping mechanism in response to direct and indirect } \\
\text { experiences including residential schools or the sixties } \\
\text { scoop, etc. on the offender's alcohol use and interpersonal } \\
\text { relationships. }\end{array}$ \\
\hline $\begin{array}{l}\text { Alcohol use } \\
\text { interferes } \\
\text { with physical } \\
\text { or emotional } \\
\text { well-being? }\end{array}$ & $\begin{array}{l}\text { Have you ever been hospitalized (injured/hurt) as a result of } \\
\text { drinking? If yes, how often and what for (e.g., alcohol } \\
\text { poisoning, liver problems)? Have you ever felt guilty about } \\
\text { your drinking or lost sleep because of it? If yes, describe. } \\
\text { Have you ever received psychiatric help or help from anyone } \\
\text { else for an emotional problem related to your drinking (e.g., } \\
\text { mental health clinic, social worker, clergy, Elder)? If yes, } \\
\text { describe. }\end{array}$ & $\begin{array}{l}\text { Rate Yes if there is evidence that the offender's alcohol use } \\
\text { has caused problems with physical health (e.g., liver } \\
\text { problems, alcohol poisoning) or emotional health (e.g., } \\
\text { psychiatric intervention, evidence of guilt/sleeplessness or } \\
\text { feeling stressed about drinking). For Aboriginal offenders, } \\
\text { consider the impact of family history of substance abuse; } \\
\text { resorting to substances as a coping mechanism in } \\
\text { response to direct and indirect experiences including } \\
\text { residential schools or the sixties scoop, etc. on the } \\
\text { offender's alcohol use and emotional well-being. }\end{array}$ \\
\hline $\begin{array}{l}\text { Excessive } \\
\text { alcohol use is } \\
\text { part of the } \\
\text { offender's } \\
\text { lifestyle? }\end{array}$ & $\begin{array}{l}\text { Have you ever stumbled, staggered or weaved about as a } \\
\text { result of drinking? If yes, describe the circumstances and } \\
\text { frequency (daily, weekly, monthly). Have you ever felt } \\
\text { physically sick (e.g., vomits, stomach cramps) as a result of } \\
\text { drinking? If yes, describe the circumstances and frequency. } \\
\text { Have you ever 'blacked out' as a result of drinking? If yes, } \\
\text { describe the frequency and circumstances. Do you ever } \\
\text { drink in the morning or alone? If yes, describe frequency and } \\
\text { circumstances. Have you ever tried to quit drinking } \\
\text { completely or cut down the amount you were drinking? If } \\
\text { yes, describe. Did you ever attend Alcoholics Anonymous? If } \\
\text { so, describe the circumstances and frequency. }\end{array}$ & $\begin{array}{l}\text { Rate Yes based on the responses to the above indicators. } \\
\text { Also rate Yes if there is additional evidence that the } \\
\text { offender drinks to excess on a regular basis based on the } \\
\text { answers to the following questions. For Aboriginal } \\
\text { offenders, consider the impact of family history of } \\
\text { substance abuse; resorting to substances as a coping } \\
\text { mechanism in response to direct and indirect experiences } \\
\text { including residential schools or the sixties scoop, etc. on } \\
\text { the offender's alcohol use and lifestyle. }\end{array}$ \\
\hline
\end{tabular}




\begin{tabular}{|c|c|c|}
\hline $11 / 26 / 2019$ & \multicolumn{2}{|c|}{ Correctional Planning and Criminal Profile } \\
\hline \multicolumn{3}{|l|}{ Drug Use } \\
\hline $\begin{array}{l}\text { Early age } \\
\text { drug use? }\end{array}$ & $\begin{array}{l}\text { How old were you when you first experimented with drugs? } \\
\text { Who were you with? How often did you use drugs (daily, } \\
\text { weekly, monthly)? Were you ever suspended or expelled } \\
\text { from school as a result of drug use? If so, how often? Tell me } \\
\text { about it. Did your parents/caregivers ever talk to you about } \\
\text { your drug use? Were you ever in counselling because of your } \\
\text { drug use? }\end{array}$ & $\begin{array}{l}\text { Rate Yes if there is evidence of regular (at least twice per } \\
\text { month) drug use (includes illegal drugs, solvents, as well as } \\
\text { prescription drugs in excess of directions) that occurred } \\
\text { before the age of } 16 \text {. For Aboriginal offenders, consider the } \\
\text { impact of family history of substance abuse; resorting to } \\
\text { substances as a coping mechanism in response to direct } \\
\text { and indirect experiences including residential schools or the } \\
\text { sixties scoop, etc. on the offender's early drug use. }\end{array}$ \\
\hline $\begin{array}{l}\text { Has gone on } \\
\text { drug-taking } \\
\text { bouts or } \\
\text { binges? }\end{array}$ & $\begin{array}{l}\text { During the last year, did you ever use drugs for more than } \\
\text { two days in a row? If yes, how often (a few times a year, a } \\
\text { few times a month, every week)? }\end{array}$ & $\begin{array}{l}\text { Rate Yes if there is evidence that the offender has been } \\
\text { 'strung-out' on drugs for two or more days in a row on at } \\
\text { least two separate occasions in any given month. For } \\
\text { Aboriginal offenders, consider the impact of family history } \\
\text { of substance abuse; resorting to substances as a coping } \\
\text { mechanism in response to direct and indirect experiences } \\
\text { including residential schools or the sixties scoop, etc. on } \\
\text { the offender's drug binges. }\end{array}$ \\
\hline $\begin{array}{l}\text { Has } \\
\text { combined the } \\
\text { use of } \\
\text { different } \\
\text { drugs? }\end{array}$ & $\begin{array}{l}\text { Have you ever used more than two drugs (excluding alcohol) } \\
\text { at the same time? Describe circumstances and frequency (a } \\
\text { few times in the last year, a few times per month, every } \\
\text { week)? }\end{array}$ & $\begin{array}{l}\text { Rate Yes if there is evidence that the offender combined the } \\
\text { use of more than two drugs (excluding alcohol) on a } \\
\text { relatively regular basis (e.g., at least twice in any given } \\
\text { month during the last year). (Consider all information } \\
\text { sources including the Computerized Assessment of } \\
\text { Substance Abuse, Community Assessment reports, } \\
\text { interview results.) For Aboriginal offenders, consider the } \\
\text { impact of family history of substance abuse; resorting to } \\
\text { substances as a coping mechanism in response to direct } \\
\text { and indirect experiences including residential schools or the } \\
\text { sixties scoop, etc. on the offender's combined use of } \\
\text { different drugs. }\end{array}$ \\
\hline $\begin{array}{l}\text { Drug use } \\
\text { interferes } \\
\text { with } \\
\text { employment? }\end{array}$ & $\begin{array}{l}\text { Ever miss work/school because you were too hung over? } \\
\text { Were you ever high or stoned at work/school, or did you ever } \\
\text { take drugs at work/school? Have you ever been fired or } \\
\text { expelled from a job/school because of being high or stoned? } \\
\text { If Yes to any of the above questions, have the offender } \\
\text { discuss in further detail. For individuals who work within the } \\
\text { home: Did you feel like your being high or stoned ever } \\
\text { affected your household and/or children? Did anyone ever } \\
\text { comment that your drug use was interfering with your } \\
\text { children or your home? If yes, can you tell me more about it? }\end{array}$ & $\begin{array}{l}\text { Rate Yes if there is evidence that the offender's drug use } \\
\text { interfered with their job or education in any way (e.g., fired } \\
\text { from job because of being high or stoned at work, evidence } \\
\text { of poor job performance as the result of drug use). Note: } \\
\text { Consider academic performance for young offenders (if } \\
\text { applicable) and management of household responsibilities } \\
\text { for individuals working within the home. For Aboriginal } \\
\text { offenders, consider the impact of family history of } \\
\text { substance abuse; resorting to substances as a coping } \\
\text { mechanism in response to direct and indirect experiences } \\
\text { including residential schools or the sixties scoop, etc. on } \\
\text { the offender's drug use and employment. }\end{array}$ \\
\hline $\begin{array}{l}\text { Drug use } \\
\text { interferes } \\
\text { with } \\
\text { interpersonal } \\
\text { relationships? }\end{array}$ & $\begin{array}{l}\text { Has anyone ever expressed concern about your drug use? } \\
\text { Did your family ever claim that you have a drug problem? For } \\
\text { example, did your spouse/partner ever seek help for your } \\
\text { drinking or ask you to seek help? Has your drug use ever } \\
\text { resulted in arguments or physical fights with other people? If } \\
\text { yes, with whom and how often (rarely, occasionally, } \\
\text { frequently)? }\end{array}$ & $\begin{array}{l}\text { Rate Yes if there is evidence that the offender's drug use } \\
\text { has negatively impacted interpersonal relationships with } \\
\text { significant others including intimate partners, family } \\
\text { members, or friends (e.g., lost friends over drug use, drug } \\
\text { use resulted in divorce/separation, caused problems in } \\
\text { general with intimate partner, children or other family } \\
\text { members). For Aboriginal offenders, consider the impact of } \\
\text { family history of substance abuse; resorting to substances } \\
\text { as a coping mechanism in response to direct and indirect } \\
\text { experiences including residential schools or the sixties } \\
\text { scoop, etc. on the offender's drug use and interpersonal } \\
\text { relationships. }\end{array}$ \\
\hline
\end{tabular}




\begin{tabular}{|c|c|c|}
\hline 1/26/2019 & \multicolumn{2}{|c|}{ Correctional Planning and Criminal Profile } \\
\hline $\begin{array}{l}\text { Drug use } \\
\text { interferes } \\
\text { with physical } \\
\text { or emotional } \\
\text { well-being? }\end{array}$ & $\begin{array}{l}\text { Have you ever been hospitalized as a result of taking drugs? } \\
\text { If yes, how often and what for (e.g., alcohol poisoning, liver } \\
\text { problems)? Have you ever felt guilty about your drug use or } \\
\text { lost sleep because of it? If yes, describe. Have you ever } \\
\text { received psychiatric help or help from anyone else for an } \\
\text { emotional problem related to your drug use (e.g., mental } \\
\text { health clinic, social worker, clergy, Elder)? If yes, describe. }\end{array}$ & $\begin{array}{l}\text { Rate Yes if there is evidence that the offender's drug use } \\
\text { has caused problems with physical health (e.g., liver } \\
\text { problems, alcohol poisoning) or emotional health (e.g., } \\
\text { psychiatric intervention, evidence of guilt/sleeplessness or } \\
\text { feeling stressed about drinking). For Aboriginal offenders, } \\
\text { consider the impact of family history of substance abuse; } \\
\text { resorting to substances as a coping mechanism in } \\
\text { response to direct and indirect experiences including } \\
\text { residential schools or the sixties scoop, etc. on the } \\
\text { offender's drug use and emotional well-being. }\end{array}$ \\
\hline $\begin{array}{l}\text { Regular drug } \\
\text { use is part of } \\
\text { the offender's } \\
\text { lifestyle? }\end{array}$ & $\begin{array}{l}\text { In the past year, how often have you used illegal drugs or } \\
\text { abused prescription drugs (never, yearly, monthly, weekly, } \\
\text { daily)? If answer is anything but "never", ask the individual to } \\
\text { describe the circumstances. Who were you with? Have you } \\
\text { ever tried to quit using drugs completely or cut down the } \\
\text { amount you were using? If yes, describe. Did you ever } \\
\text { attend Narcotics Anonymous? If so, describe the } \\
\text { circumstances and frequency. }\end{array}$ & $\begin{array}{l}\text { Rate Yes based on the responses to the above drug } \\
\text { indicators. Also rate Yes if there is additional evidence that } \\
\text { the offender uses drugs on a regular basis based on the } \\
\text { answers to the following questions. For Aboriginal } \\
\text { offenders, consider the impact of family history of } \\
\text { substance abuse; resorting to substances as a coping } \\
\text { mechanism in response to direct and indirect experiences } \\
\text { including residential schools or the sixties scoop, etc. on } \\
\text { the offender's drug use and emotional well-being. }\end{array}$ \\
\hline \multicolumn{3}{|c|}{ Alcohol/Drug Crime Link } \\
\hline $\begin{array}{l}\text { Alcohol or } \\
\text { drug use has } \\
\text { resulted in } \\
\text { law } \\
\text { violations? }\end{array}$ & $\begin{array}{l}\text { Have you ever been arrested, charged or convicted for any } \\
\text { offence that involved alcohol or drugs? }\end{array}$ & $\begin{array}{l}\text { Rate Yes if there is evidence that the offender has been } \\
\text { arrested, charged or convicted for alcohol/drug-related } \\
\text { offences. For Aboriginal offenders, consider the impact of } \\
\text { family history of substance abuse, offender's drug use, and } \\
\text { law violations. }\end{array}$ \\
\hline $\begin{array}{l}\text { Becomes } \\
\text { violent when } \\
\text { drinking or } \\
\text { using drugs? }\end{array}$ & $\begin{array}{l}\text { Has anyone ever accused you of becoming violent when you } \\
\text { drink or use drugs? }\end{array}$ & $\begin{array}{l}\text { Rate Yes if there is evidence that the offender becomes } \\
\text { violent (physical aggression) when using drugs and/or } \\
\text { alcohol. For Aboriginal offenders, consider the impact of } \\
\text { family history of substance abuse, offender's drug use, and } \\
\text { law violations. }\end{array}$ \\
\hline $\begin{array}{l}\text { Alcohol } \\
\text { and/or drug } \\
\text { use is part of } \\
\text { the offence } \\
\text { cycle? }\end{array}$ & $\begin{array}{l}\text { Have you ever been under the influence of alcohol/drugs } \\
\text { when you committed a crime? }\end{array}$ & $\begin{array}{l}\text { Rate Yes if there is evidence that the offender's alcohol } \\
\text { and/or drug use is clearly part of the offence cycle (e.g., if } \\
\text { offender is usually drunk/stoned while committing offence, } \\
\text { if the period preceding the offence is characterized by } \\
\text { excessive drinking and/or drug use). For Aboriginal } \\
\text { offenders, consider the impact of family history of } \\
\text { substance abuse, offender's drug use, and law violations. }\end{array}$ \\
\hline \multicolumn{3}{|c|}{ Past Intervention } \\
\hline $\begin{array}{l}\text { Has } \\
\text { previously } \\
\text { been referred } \\
\text { to programs } \\
\text { addressing } \\
\text { drugs or } \\
\text { alcohol } \\
\text { problems? }\end{array}$ & Have you ever participated in a drug or alcohol program? & $\begin{array}{l}\text { Rate Yes if the offender has previously been referred to } \\
\text { programs addressing substance abuse issues. }\end{array}$ \\
\hline $\begin{array}{l}\text { Substance } \\
\text { Abuse } \\
\text { Domain } \\
\text { Rating }\end{array}$ & \multicolumn{2}{|l|}{ Substance Abuse Domain Rating Guidelines } \\
\hline
\end{tabular}




\begin{tabular}{|c|c|}
\hline /26/2019 & Correctional Planning and Criminal Profile \\
\hline $\begin{array}{l}\text { No } \\
\text { immediate } \\
\text { need for } \\
\text { improvement }\end{array}$ & $\begin{array}{l}\text { "No immediate need for improvement" indicates that the extent, nature, and patterns of alcohol and/or drug } \\
\text { consumption by the offender while in the community has had no influence on their adjustment (e.g., abstinence, social } \\
\text { drinking). }\end{array}$ \\
\hline $\begin{array}{l}\text { Low need for } \\
\text { improvement }\end{array}$ & $\begin{array}{l}\text { An offender demonstrates "Low need for improvement" if alcohol and/or drug consumption has caused minor adjustment } \\
\text { problems while in the community. }\end{array}$ \\
\hline $\begin{array}{l}\text { Moderate } \\
\text { need for } \\
\text { improvement }\end{array}$ & $\begin{array}{l}\text { A rating of "Moderate need for improvement" means that while the offender's drinking has caused adjustment problems, } \\
\text { the extent of the problems has not been significant enough to merit a considerable need for improvement rating. }\end{array}$ \\
\hline $\begin{array}{l}\text { High need } \\
\text { for } \\
\text { improvement }\end{array}$ & Rate "High need for improvement" if substance abuse has caused serious adjustment problems while in the community. \\
\hline $\begin{array}{l}\text { Current } \\
\text { Motivation } \\
\text { Level - } \\
\text { Identified } \\
\text { Deficit }\end{array}$ & $\begin{array}{l}\text { Are you interested in treatment/upgrading? Why/why not? How would it help you/not help you? Who else benefits from the } \\
\text { intervention? }\end{array}$ \\
\hline Low & $\begin{array}{l}\text { The offender would benefit from motivation interviewing prior to programming. There is absolutely no recognition that they } \\
\text { have a need in this area. There is no genuine commitment to change. }\end{array}$ \\
\hline Medium & $\begin{array}{l}\text { The offender may not fully accept or recognize need area as deficit but is willing to participate in recommended programs } \\
\text { or other interventions. Genuine commitment to change may still be absent. While the offender may commit to intervention, } \\
\text { they may only be doing so for external reasons (e.g., to secure early release, to be transferred to a lower security } \\
\text { institution). }\end{array}$ \\
\hline High & $\begin{array}{l}\text { The offender fully recognizes a need requiring intervention and is fully ready to start intervention. They have committed to } \\
\text { change and may have already started actively engaging in behaviours related to change. While still recognizing external } \\
\text { benefits for pursuing intervention (e.g., securing early release), they are primarily motivated for internal reasons (e.g., doing } \\
\text { it for themselves, "I'm tired of the lifestyle or I want a change"). }\end{array}$ \\
\hline $\begin{array}{l}\text { Not } \\
\text { applicable }\end{array}$ & No need in this area. \\
\hline $\begin{array}{l}\text { Domain } \\
\text { Analysis }\end{array}$ & $\begin{array}{l}\text { Provide a narrative summary explaining how this need area relates to the present offence and the offender's overall } \\
\text { criminality. Report strengths if applicable (e.g., evidence of periods of sobriety in the past, evidence that treatment has } \\
\text { been successful in the past). Interview Prompts: Did you ever notice what or who helped you stop using drugs or alcohol? } \\
\text { Who are the most important people that could help you be alcohol or drug free? Indicate the reasons why the specific } \\
\text { dynamic factor is rated as contributing (directly linked to the criminal behaviour). For other dynamic factors not directly } \\
\text { related to criminal behaviour, but where intervention will improve safe and timely reintegration, provide a clear explanation } \\
\text { of why such factors require intervention. For Aboriginal offenders, explain how the Aboriginal Social History may have } \\
\text { impacted this dynamic factor. Refer to Annex H - Dynamic Factors and Aboriginal Social History for guidance. }\end{array}$ \\
\hline
\end{tabular}

\section{Community Functioning Domain Indicators}

\begin{tabular}{|l|l|l|}
\hline $\begin{array}{l}\text { Community } \\
\text { Functioning }\end{array}$ & Help Messages \\
\hline $\begin{array}{l}\text { Domain } \\
\text { Indicators }\end{array}$ & & \\
\hline
\end{tabular}

Accommodations 
$11 / 26 / 2019$

Unstable How many different places have you

accommodations? lived in the last year? Who have you lived with? Why have you changed residences so often?
Rate Yes if there is evidence that the offender frequently changed residences during the last year in the absence of a strong rationale. (Consider all information sources including the street instability rating from the Custody Rating Scale.) For Aboriginal offenders, consider the impact of their Aboriginal Social History such as family and community fragmentation, interventions by child welfare and poverty that may have contributed to unstable accommodations.

\begin{tabular}{|l|l|}
\hline Finances & \\
\hline $\begin{array}{l}\text { Financial } \\
\text { instability? }\end{array}$ & $\begin{array}{l}\text { Do you have a bank account? Do you } \\
\text { have any credit? Have you ever } \\
\text { declared bankruptcy, had furniture or } \\
\text { your car repossessed? Have you ever } \\
\text { owned a house? If so, have you ever } \\
\text { defaulted on your mortgage? How } \\
\text { often do you pay bills on time } \\
\text { (always, sometimes, rarely, never)? } \\
\text { Have you ever been evicted? Have } \\
\text { you ever had a collection agency after } \\
\text { you? Have you stressed about } \\
\text { money? Have you ever had to borrow } \\
\text { money illegally? }\end{array}$ \\
\hline
\end{tabular}

Has used social Have you ever been in receipt of assistance? social assistance? Please describe these circumstances. How frequent and for how long were you in receipt of social assistance?
Rate Yes if there is evidence of financial instability (e.g., no bank account, poor credit rating, no credit, no savings, defaulting on bills or loans, bankruptcy declaration, repossession by bank).
Rate Yes if there is evidence that the offender used social assistance in the last year. For Aboriginal offenders, rate Yes for those who may have been working for the band while receiving social assistance. Rate No for offenders receiving family benefits from their provincial governments.

\section{Leisure}

Constructive leisure activities are limited?
When you are not working or looking after your children, how do you spend your spare time? Do you have a membership anywhere? How often do you participate in this activity (daily, weekly, monthly, yearly)? Do you participate in cultural or spiritual activities? If yes, how often?
Rate Yes if regular involvement in hobbies or organized activity (e.g., car repair, sports/exercise, family activities, gardening, home improvement projects, crafts, camping, drawing, volunteering, singing, cultural/spiritual activities). First Nations specific activities include: circles, medicine bundles, drumming, pow-wows/feasts, sweat lodges, smudges, food, dress, music, craft, pipe ceremonies, and vision quests. Métis specific activities include: Sash weaving, bead making, jigging, and fiddling. Inuit specific activities include: throat singing, country food feasts, drum dancing and carving. Exclude all reported passive activities (e.g., parties, bars, hanging out with friends, sleeping, listening to music, watching television).

\section{Community}

Community attachment is limited?
What do you do in your spare time? Do you volunteer anywhere currently? Are you a member of any organization? Describe. Do you feel connected to the community? If yes, why? If no, why not?
Rate Yes if the offender is isolated or unattached to the community. Note that the reason for being unattached to the community should be discussed in the narrative section. For example, some offenders may choose to isolate themselves from the community. In contrast, others may wish to be part of the community but can't (e.g., sex offenders, banished offenders, unaware of available options). Examples of community attachment include: Big Brothers/Sisters, sports leagues, spiritual community activities, and volunteer work. Be aware of membership that facilitates criminal activity (e.g., sex offenders and organized community groups for children). For Aboriginal offenders, consider limited community attachment in the context of family/community fragmentation as a direct or indirect result of experiences with residential schools, child welfare interventions or the sixties scoop. 


\begin{tabular}{|c|c|c|}
\hline \multicolumn{2}{|l|}{ 11/26/2019 } & Correctional Planning and Criminal Profile \\
\hline $\begin{array}{l}\text { Use of commun } \\
\text { resources is } \\
\text { limited? }\end{array}$ & $\begin{array}{l}\text { Have you ever relied on the } \\
\text { community for support? Describe. Do } \\
\text { you know where to go if you needed } \\
\text { help for housing, food, etc.? }\end{array}$ & $\begin{array}{l}\text { Rate Yes if the offender is unaware of, chooses not to, or does not have } \\
\text { access to community resources. Provide reason in narrative section. Support } \\
\text { includes instrumental support (e.g., housing, money, drives, food), } \\
\text { informational support (e.g., how to get a SIN number, driver's license, } \\
\text { employment insurance application), and emotional support (e.g., telephone } \\
\text { help lines). If applicable, indicate in the narrative comment if the offender has } \\
\text { been banished. For Aboriginal offenders, consider limited community } \\
\text { resources in the context of family/community fragmentation as a direct or } \\
\text { indirect result of experiences with residential schools, child welfare } \\
\text { interventions or the sixties scoop. }\end{array}$ \\
\hline \multicolumn{3}{|c|}{ Past Intervention } \\
\hline $\begin{array}{l}\text { Has previously } \\
\text { been referred to } \\
\text { programs } \\
\text { addressing } \\
\text { deficit(s) under } \\
\text { this domain? }\end{array}$ & $\begin{array}{l}\text { Have you ever participated in a } \\
\text { leisure skills program, community } \\
\text { reintegration program, or any other } \\
\text { program addressing issues related to } \\
\text { your community involvement or } \\
\text { leisure activities? }\end{array}$ & $\begin{array}{l}\text { Rate Yes if the offender has previously been referred to programs addressing } \\
\text { deficit(s) under the community functioning domain. }\end{array}$ \\
\hline $\begin{array}{l}\text { Community } \\
\text { Functioning } \\
\text { Domain } \\
\text { Rating }\end{array}$ & \multicolumn{2}{|c|}{ Community Functioning Domain Rating Guidelines } \\
\hline $\begin{array}{l}\text { Factor seen } \\
\text { as an asset } \\
\text { to } \\
\text { community } \\
\text { adjustment }\end{array}$ & \multicolumn{2}{|c|}{$\begin{array}{l}\text { A rating of "Factor seen as an asset to community adjustment" indicates that the offender has been effectively } \\
\text { managing their situation (i.e., accommodation, deportment, health, finance, communication, leisure, support) while in the } \\
\text { community. In the domain analysis, note how this area will contribute/facilitate community reintegration. }\end{array}$} \\
\hline $\begin{array}{l}\text { No } \\
\text { immediate } \\
\text { need for } \\
\text { improvement }\end{array}$ & \multicolumn{2}{|c|}{$\begin{array}{l}\text { A rating of "No immediate need for improvement" indicates that knowledge and having the necessary skills for daily } \\
\text { living has not been causing the offender difficulties. }\end{array}$} \\
\hline $\begin{array}{l}\text { Low need for } \\
\text { improvement }\end{array}$ & \multicolumn{2}{|c|}{$\begin{array}{l}\text { A rating of "Low need for improvement" is given if any of the aforementioned has been causing the offender situational or } \\
\text { minor difficulties while in the community. }\end{array}$} \\
\hline $\begin{array}{l}\text { Moderate } \\
\text { need for } \\
\text { improvement }\end{array}$ & \multicolumn{2}{|c|}{$\begin{array}{l}\text { An offender exhibits "Moderate need for improvement" if the aforementioned has been causing them moderate } \\
\text { problems. }\end{array}$} \\
\hline $\begin{array}{l}\text { High need } \\
\text { for } \\
\text { improvement }\end{array}$ & \multicolumn{2}{|c|}{ An offender exhibits "High need for improvement" if community functioning has been causing them severe difficulties. } \\
\hline $\begin{array}{l}\text { Current } \\
\text { Motivation } \\
\text { Level - } \\
\text { Identified } \\
\text { Deficit }\end{array}$ & \multicolumn{2}{|c|}{$\begin{array}{l}\text { Are you interested in treatment/upgrading? Why/why not? How would it help you/not help you? Who else benefits from the } \\
\text { intervention? }\end{array}$} \\
\hline Low & \multicolumn{2}{|c|}{$\begin{array}{l}\text { The offender would benefit from motivation interviewing prior to programming. There is absolutely no recognition that they } \\
\text { have a need in this area. There is no genuine commitment to change. }\end{array}$} \\
\hline Medium & \multicolumn{2}{|c|}{$\begin{array}{l}\text { The offender may not fully accept or recognize need areas as deficit but is willing to participate in recommended programs } \\
\text { or other interventions. Genuine commitment to change may still be absent. While the offender may commit to intervention, } \\
\text { they may only be doing so for external reasons (e.g., to secure early release, to be transferred to a lower security } \\
\text { institution). }\end{array}$} \\
\hline
\end{tabular}




\begin{tabular}{|l|l|}
\hline High & \multicolumn{1}{|c}{ Correctional Planning and Criminal Profile } \\
\hline $\begin{array}{l}\text { The offender fully recognizes a need requiring intervention and is fully ready to start intervention. They have committed to } \\
\text { change and may have already started actively engaging in behaviours related to change. While still recognizing external } \\
\text { benefits for pursuing intervention (e.g., securing early release), they are primarily motivated for internal reasons (e.g., doing } \\
\text { it for themselves, "I'm tired of the lifestyle or I want a change"). }\end{array}$ \\
\hline Not & No need in this area. \\
\hline applicable & $\begin{array}{l}\text { Provide a narrative summary explaining how this need area relates to the present offence and the offender's overall } \\
\text { criminality. Include discussion of forced versus chosen isolation from community, which is particularly relevant for women } \\
\text { in abusive relationships and Aboriginal offenders who have been banished. Record strengths if applicable. Indicate the } \\
\text { reasons why the specific dynamic factor is rated as contributing (directly linked to the criminal behaviour). For other } \\
\text { dynamic factors not directly related to criminal behaviour, but where intervention will improve safe and timely reintegration, } \\
\text { provide a clear explanation of why such factors require intervention. For Aboriginal offenders, explain how the Aboriginal } \\
\text { Social History may have impacted this dynamic factor. Refer to Annex } H \text { - Dynamic Factors and Aboriginal Social History } \\
\text { for guidance. }\end{array}$ \\
\hline
\end{tabular}

\section{Personal/Emotional Domain Indicators}

\begin{tabular}{|c|c|c|}
\hline $\begin{array}{l}\text { Personal/Emotional } \\
\text { Domain Indicators }\end{array}$ & Interview Prompts & Help Messages \\
\hline \multicolumn{3}{|l|}{ Problem Solving Skills } \\
\hline $\begin{array}{l}\text { Displays narrow and } \\
\text { rigid thinking? }\end{array}$ & $\begin{array}{l}\text { Who do you think should be } \\
\text { primarily responsible for raising } \\
\text { children? Why/why not? }\end{array}$ & $\begin{array}{l}\text { Narrow and rigid thinkers are characterized by one-track thinking and close- } \\
\text { mindedness. They maintain their beliefs despite contrary evidence. They find it } \\
\text { difficult to see a situation from another viewpoint. In addition to collateral } \\
\text { information (e.g., previous assessments, Community Assessments, pre-sentence } \\
\text { reports, etc.), you may use the following method for determining whether or not } \\
\text { someone should be rated Yes for this indicator. Ask their opinion about a } \\
\text { mainstream issue(s) (e.g., working parents versus stay-at-home parents). Once } \\
\text { the individual has responded, try presenting counter arguments in favour of the } \\
\text { opposing view. Individuals who appear to see at least some merit in both sides } \\
\text { of the issue would not be considered narrow and rigid thinkers (e.g., "While I } \\
\text { think that women should stay home and raise the children, it is pretty difficult } \\
\text { nowadays given how expensive daycare can be."). For Aboriginal offenders, } \\
\text { consider whether their Aboriginal Social History including direct or indirect } \\
\text { experiences with residential schools, foster care, sixties scoop contributed to } \\
\text { their narrow and rigid thinking. }\end{array}$ \\
\hline $\begin{array}{l}\text { Problem recognition } \\
\text { skills are limited? }\end{array}$ & $\begin{array}{l}\text { Are there any aspects of your } \\
\text { life you would like to improve? If } \\
\text { so, what are they and why do } \\
\text { you want to do something about } \\
\text { them? If not, why not? [Continue } \\
\text { to probe if necessary.] What } \\
\text { about your family, your friends, } \\
\text { your job, your finances, your } \\
\text { emotions? Are you having any } \\
\text { problems in any of these areas? } \\
\text { Why/why not? }\end{array}$ & $\begin{array}{l}\text { Rate Yes if there is no evidence that the offender believes they have any } \\
\text { problem(s) that need to be addressed. The indicator is NOT meant to identify } \\
\text { individuals who deny or minimize responsibility for their criminal actions but } \\
\text { rather, it is meant to identify individuals who have difficulty recognizing problem } \\
\text { areas (e.g., the factors that brought them to prison). For Aboriginal offenders, } \\
\text { consider whether their limited problem recognition skills are related to a lack of } \\
\text { positive role modeling or learned behaviour growing up as a result of direct or } \\
\text { indirect family/community experience with residential schools, foster care and } \\
\text { the sixties scoop. }\end{array}$ \\
\hline $\begin{array}{l}\text { Ability to generate } \\
\text { choices is limited? }\end{array}$ & $\begin{array}{l}\text { How would you or how have you } \\
\text { dealt with the following situation } \\
\text { (e.g., you just had an argument } \\
\text { with your partner, you just lost } \\
\text { your job, your Parole Officer } \\
\text { recommends more } \\
\text { programming but you don't feel } \\
\text { you need anymore)? }\end{array}$ & $\begin{array}{l}\text { Rate Yes if there is evidence that the offender finds it difficult to generate a } \\
\text { number of different solutions when confronted with a problem (e.g., they are } \\
\text { unable to brainstorm). You may wish to consider how the offender responds to a } \\
\text { hypothetical problem situation. For Aboriginal offenders, consider whether their } \\
\text { limited ability to generate choices is related to a lack of positive role modeling or } \\
\text { learned behaviour growing up as a result of direct or indirect family/community } \\
\text { experience with residential schools, foster care and the sixties scoop. }\end{array}$ \\
\hline
\end{tabular}


$11 / 26 / 2019$

Ability to link actions to consequences is limited?

children? What will happen if
you don't follow your
Correctional Plan?

Has difficulty coping Describe a recent stressful even with stress? in your life (e.g., admission into prison)? How did you respond? How did others feel you were coping with the problem? Was there something you should have done to deal with the stress but didn't? ( $\$ \$$ oriented crimes)

\begin{tabular}{|l|l|}
\hline $\begin{array}{l}\text { Gives up easily when } \\
\text { challenged? }\end{array}$ & $\begin{array}{l}\text { What goals have you had for } \\
\text { yourself in the past? Have you } \\
\text { achieved them? If so, why? If } \\
\text { not, why not? Which adjective } \\
\text { best describes your goal- }\end{array}$ \\
& $\begin{array}{l}\text { seeking behaviour: 1) persistent, } \\
\text { 2) unshakable, 3) half-hearted, }\end{array}$ \\
4) ineffective. Why? Can you \\
give me an example? Are you \\
like a dog with a bone (you keep \\
trying until you get what you \\
want, obtain goal)? [Use \\
interview responses as well.]
\end{tabular}

\section{Self-Regulation}

Impulsive? Were your crimes planned or spur of the moment? Do you make decisions on the spot or do you like to have time to think things over before making a fina decision? Have you ever bought something on the spot and later regretted it? Do you live for today, live in the moment? Do you like to go with the flow?

Engages in thrill How do you feel when you are seeking behaviour? doing crime (excited, nervous)? Do you like to do risky things? Do you like fast driving? Are you the kind of person that dives right in and asks questions later? If you had a choice between sky-diving and watching a movie, what would you prefer? Why?
Correctional Planning and Criminal Profile

Rate Yes if there is evidence that the offender has difficulty linking actions (e.g., walk off job) to consequences (e.g., won't be able to pay bills, buy food, will produce conflict with partner). Consider both short-term and long-term consequences.

Rate Yes if there is evidence that the offender becomes aggressive, turns to substance abuse or avoids problem situations entirely when stressed (e.g., evidence of self-harming behaviour). Consider whether stress is linked to the crime cycle. Individuals who cope poorly with stress do not rely on others for support nor do they seek long-term solutions. Often their responses tend to worsen rather than improve the original problem (note: not all problems produce stress). For Aboriginal offenders, consider whether their difficulty coping with stress is related to a lack of positive role modeling or learned behaviour growing up as a result of direct or indirect family/community experience with residential schools, foster care and the sixties scoop.

Rate Yes if there is evidence that the offender is not persistent in goal-oriented behaviour. For example, the offender may have a history of verbally committing to achieve a particular goal but never follows through or makes few attempts to achieve goal. Consider file information if available. In addition, consider the answers to the following questions.
Rate Yes if any of the following apply: the offender typically fails to stop and think before acting, looks for immediate gratification, engages in impulsive behaviours (spur of the moment crimes, many jobs, many relationships, admits to making decisions too quickly that they later regret. Consider offender's answers to date particularly in regards to past relationships and employment history.

Rate Yes if the offender seeks situations (criminal or prosocial) that cause emotional excitement. These individuals may describe themselves as sensationseekers who become bored easily. They report getting a thrill or rush from crime. 
$11 / 26 / 2019$

Gambling has been problematic?
Have you ever placed bets at racetracks, casinos, or sporting events? Has anyone ever told you that you waste too much time or money gambling? Have you ever argued with anyone about gambling? Have you ever gone into debt because of gambling? Have you had to borrow to gamble? Have you been placed in protective custody as a result of gambling debts incurred while inside. What is the longest stint of gambling you've had? Do you gamble on the Internet?
Correctional Planning and Criminal Profile

Rate Yes if gambling has interfered with at least one aspect of life (work, finances, relationships, criminal justice system).

\section{Life Planning Skills}

Has difficulty setting long-term goals?

\begin{tabular}{|l|}
\hline \\
\hline $\begin{array}{l}\text { Has difficulty setting } \\
\text { realistic goals? }\end{array}$ \\
\hline
\end{tabular}

Do you have any long-term goals? Where would you like to be one year and five years from now? What are your plans for the next year?

What would you like to accomplish in the future in terms of work, living arrangements, other personal goals, relationships? Do you think these are realistic goals? Are there any obstacles to meeting these goals? Have you looked into it?

Time management skills are problematic?
Do you like to plan your time, or are you more day-to-day? Do you ever feel pressured for time? How would your former employers/partners comment on your time management skills? Has anyone ever indicated that you need to work on your timemanagement skills? If so, who? Can you tell me more about it? Do you plan tasks appropriately? Are you good at allocating the right amount of time towards specific tasks? Do you organize your time well?
Rate Yes if the offender lives day-to-day (in the moment), does not think about the future or generally lacks direction in life. Consider length of sentence. Can discuss community-focused or institution-based long-term goals. For Aboriginal offenders, consider the direct and indirect impact of residential schools, foster care and the sixties scoop and potential institutionalization that may have occurred.

Rate Yes if the offender's plans are inconsistent with current abilities or potential improvements. Consider whether or not the offender's lifestyle expectations appear to be consistent with their earning potential, educational background, employment background, and past experiences. Examples include unrealistic job expectations given educational level, employment history, and criminal history (e.g., a sex offender who wants to work with children).

Rate Yes if the offender is unable to set priorities and manage time appropriately.

Interpersonal Skills 


\begin{tabular}{|c|c|c|}
\hline \multicolumn{2}{|l|}{$26 / 2019$} & Correctional Planning and Criminal Profile \\
\hline $\begin{array}{l}\text { Assertiveness skills } \\
\text { are limited? }\end{array}$ & $\begin{array}{l}\text { In a group setting, would you } \\
\text { characterize yourself as the } \\
\text { person who likes to make the } \\
\text { rules or someone who doesn't } \\
\text { mind going by someone else's } \\
\text { rules? Would you characterize } \\
\text { yourself as an assertive person? }\end{array}$ & $\begin{array}{l}\text { Rate Yes if there is evidence that the offender has difficulty requesting or refusing } \\
\text { things in interactions with others, has difficulty stating their point of view, is easily } \\
\text { led by others and may have been influenced into problems by others in the past } \\
\text { (e.g., criminal associates, spouse, other relatives). For Aboriginal offenders, } \\
\text { consider the direct and indirect impact of residential schools, foster care and the } \\
\text { sixties scoop on their level of comfort to assert and their need to conform or } \\
\text { belong which can also be linked to family and community fragmentation. }\end{array}$ \\
\hline $\begin{array}{l}\text { Listening skills are } \\
\text { limited? }\end{array}$ & $\begin{array}{l}\text { If I asked your boss, wife, } \\
\text { mother, sister on a scale of } 1 \text { to } \\
10 \text { if you are a good listener or } \\
\text { not, what would they give you } \\
\text { and why? }\end{array}$ & $\begin{array}{l}\text { Rate Yes if the offender demonstrates poor listening skills during interview } \\
\text { process. }\end{array}$ \\
\hline $\begin{array}{l}\text { Has difficulty solving } \\
\text { interpersonal } \\
\text { problems? }\end{array}$ & $\begin{array}{l}\text { Describe a recent situation in } \\
\text { which you experienced some } \\
\text { form of conflict with another } \\
\text { person. What happened? How } \\
\text { was the situation resolved? } \\
\text { Were you happy with the } \\
\text { outcome? Why/why not? }\end{array}$ & $\begin{array}{l}\text { Rate Yes if the offender does not deal with interpersonal conflict (conflict with } \\
\text { other people) effectively. For instance, when presented with conflict involving } \\
\text { another person (e.g., argument with partner, disagreement with boss regarding } \\
\text { workload, disagreement about money with friend), the offender relies on short- } \\
\text { term solutions, uses drugs/alcohol, fails to address the problem entirely or reacts } \\
\text { in a manner that makes the problem worse (e.g., responds with aggression, } \\
\text { antagonizes the other person). }\end{array}$ \\
\hline $\begin{array}{l}\text { Manipulates others } \\
\text { to achieve goals? }\end{array}$ & $\begin{array}{l}\text { Has anyone ever accused you of } \\
\text { being untrustworthy or } \\
\text { manipulative? Are you a con } \\
\text { artist? Are you good at getting } \\
\text { people to do things you want } \\
\text { them to do? }\end{array}$ & $\begin{array}{l}\text { Rate Yes if there is evidence that the offender influences others through } \\
\text { deceptive or fraudulent means (e.g., fraud-related crimes, chronic lying, aliases). }\end{array}$ \\
\hline $\begin{array}{l}\text { Empathy skills are } \\
\text { limited? }\end{array}$ & $\begin{array}{l}\text { What effect has your crime(s) } \\
\text { had on the victim(s)? Has your } \\
\text { conviction(s) hurt anyone else? } \\
\text { If yes, describe who and how } \\
\text { so. Do you have any other } \\
\text { regrets in life that aren't directly } \\
\text { related to crime? If yes, } \\
\text { describe. }\end{array}$ & $\begin{array}{l}\text { Rate Yes if there is evidence that the offender does not consider the effects of } \\
\text { their actions on others or is incapable of understanding someone else's } \\
\text { perspective or feelings (consider convictions as well as other aspects of the } \\
\text { offender's life). Note: Remorse and feelings of guilt do not indicate empathy. }\end{array}$ \\
\hline \multicolumn{3}{|l|}{ General Aggression } \\
\hline $\begin{array}{l}\text { Frequently feels } \\
\text { intense anger? }\end{array}$ & $\begin{array}{l}\text { Have you ever experienced road } \\
\text { rage? Have you ever "seen red" } \\
\text { or felt so angry about something } \\
\text { that you almost blacked out? } \\
\text { Has anyone ever told you that } \\
\text { you have an anger control } \\
\text { problem? }\end{array}$ & $\begin{array}{l}\text { Rate Yes if there is evidence that the offender frequently (once a week or more) } \\
\text { feels enraged (self-reports "seeing red" or blacking out from intense rage) across } \\
\text { various situations (e.g., interpersonal conflict, minor mishaps). Also consider } \\
\text { whether or not the offender reports feeling rage for prolonged periods of time. } \\
\text { For Aboriginal offenders, consider whether the difficulty in emotional regulation is } \\
\text { related to direct or indirect experiences of intergenerational violence and trauma. }\end{array}$ \\
\hline $\begin{array}{l}\text { Frequently } \\
\text { suppresses anger? }\end{array}$ & $\begin{array}{l}\text { When you feel angry, what do } \\
\text { you typically do? Do you talk to } \\
\text { anyone about it? Do you act on } \\
\text { it, or are you more likely to think } \\
\text { about it a lot but never do } \\
\text { anything about it? }\end{array}$ & $\begin{array}{l}\text { Rate Yes if there is evidence that the offender frequently suppresses feelings of } \\
\text { anger. For Aboriginal offenders, consider whether the difficulty in emotional } \\
\text { regulation is related to direct or indirect experiences of intergenerational violence } \\
\text { and trauma. }\end{array}$ \\
\hline
\end{tabular}


$11 / 26 / 2019$

Frequently acts in an aggressive manner?

\begin{tabular}{|l|}
\hline \\
\hline \\
\hline $\begin{array}{l}\text { Has low frustration } \\
\text { tolerance? }\end{array}$ \\
\hline
\end{tabular}

\begin{tabular}{l|} 
Frequently interprets \\
neutral situations as \\
hostile?
\end{tabular}

hostile?
Has anyone ever described you as violent or aggressive? Have you ever slapped, hit or pushed anyone? If yes, can you tell me more about it? Have you ever verbally threatened anyone? Do you ever use your physical strength to intimidate people?

What things frustrate you on a daily basis? How do you respond? Would you describe yourself as patient and laidback?

Do your friends ever accuse you of over-reacting or reading too much into a given situation? Has anyone ever referred to you as short-tempered? Why?
Rate Yes if there is evidence that the offender is verbally and/or physically abusive or threatening towards others across various situations (work, relationships). Note: This indicator is related to actions rather than feelings; some individuals may feel anger but they may not act out on that anger. Include conviction record (e.g., uttering threats). For Aboriginal offenders, consider whether the difficulty in emotional regulation is related to direct or indirect experiences of intergenerational violence and trauma.

Rate Yes if there is evidence of a pattern of inappropriate responses (e.g., inpatient, behavioural indications of agitation - sighing/rolling eyes, slamming door) to daily life hassles (waiting too long for the elevator, missed bus, cancelled appointments, etc.). Also, consider the offender's behaviour during the interview.

Rate Yes if there is evidence that the offender interprets other people's actions as hostile, malicious or deliberately provocative regardless of the true motivation. Thus, in ambiguous situations (e.g., without more information it is impossible to know what the true motivation really is), the offender would attribute hostile intent. When rating this indicator, consider how the offender has responded to you throughout the interview.

\section{Sexual Aggression}

Has deviant sexual preferences?
[Refer to supplementary assessment results or official documentation.]
This indicator is only applicable to identified sex offenders. All other offenders should be rated No. Rate Yes if supplementary phallometric data or official documentation (police reports, Community Assessments, court documents) demonstrate that the offender has deviant sexual preferences (e.g., towards children, non-consensual sex between adults). For Aboriginal offenders, consider past sexual trauma and any direct or indirect impacts related to experiences in the residential school system, foster care or the sixties scoop.

This indicator is only applicable to identified sex offenders. All other offenders should be rated No. Rate Yes if the offender displays attitudes that support illegal sexual activity (e.g., non-consensual sex between adults; sex between adults and children).
Displays deviant sexual attitudes?
Do you believe it is okay to have sex with children? Does no really mean no?
Rate Yes if the offender has previously been referred to programs addressing deficit(s) under the personal/emotional domain. previously been referred to programs addressing deficit(s) under this domain?
Have you ever participated in a program addressing anger management, violence, cognitive skills or inappropriate sexual behaviour? 


\begin{tabular}{|c|c|}
\hline 26/2019 & Correctional Planning and Criminal Profile \\
\hline $\begin{array}{l}\text { Current Motivation } \\
\text { Level - Identified } \\
\text { Deficit }\end{array}$ & $\begin{array}{l}\text { Are you interested in treatment/upgrading? Why/why not? How would it help you/not help you? Who else benefits } \\
\text { from the intervention? }\end{array}$ \\
\hline Low & $\begin{array}{l}\text { The offender would benefit from motivation interviewing prior to programming. There is absolutely no recognition } \\
\text { that they have a need in this area. There is no genuine commitment to change. }\end{array}$ \\
\hline Medium & $\begin{array}{l}\text { The offender may not fully accept or recognize need areas as deficit but is willing to participate in recommended } \\
\text { programs or other interventions. Genuine commitment to change may still be absent. While the offender may } \\
\text { commit to intervention, they may only be doing so for external reasons (e.g., to secure early release, to be } \\
\text { transferred to a lower security institution). }\end{array}$ \\
\hline High & $\begin{array}{l}\text { The offender fully recognizes a need requiring intervention and is fully ready to start intervention. They have } \\
\text { committed to change and may have already started actively engaging in behaviours related to change. While still } \\
\text { recognizing external benefits for pursuing intervention (e.g., securing early release), they are primarily motivated for } \\
\text { internal reasons (e.g., doing it for themselves, "I'm tired of the lifestyle or I want a change"). }\end{array}$ \\
\hline Not applicable & No need in this area. \\
\hline Domain Analysis & $\begin{array}{l}\text { Provide a narrative summary explaining how this need area relates to the present offence and the offender's overall } \\
\text { criminality. Describe strengths if applicable. Indicate the reasons why the specific dynamic factor is rated as } \\
\text { contributing (directly linked to the criminal behaviour). For other dynamic factors not directly related to criminal } \\
\text { behaviour, but where intervention will improve safe and timely reintegration, provide a clear explanation of why such } \\
\text { factors require intervention. For Aboriginal offenders, explain how the Aboriginal Social History may have impacted } \\
\text { this dynamic factor. Refer to Annex H- Dynamic Factors and Aboriginal Social History for guidance. }\end{array}$ \\
\hline
\end{tabular}

\section{Attitude Domain Indicators}

\begin{tabular}{|c|c|c|}
\hline $\begin{array}{l}\text { Attitude Domain } \\
\text { Indicators }\end{array}$ & Interview Prompts & Help Messages \\
\hline \multicolumn{3}{|c|}{ General Criminal Attitudes } \\
\hline $\begin{array}{l}\text { Displays negative } \\
\text { attitudes towards the } \\
\text { criminal justice } \\
\text { system? }\end{array}$ & $\begin{array}{l}\text { Do you think the law is fair? Did your lawyer do } \\
\text { a good job defending you? Do you think the } \\
\text { police are trustworthy? }\end{array}$ & $\begin{array}{l}\text { Rate Yes if the offender demonstrates negative attitudes towards } \\
\text { any one of the following: the law, the police, the correctional } \\
\text { system (includes staff). For Aboriginal offenders, consider the } \\
\text { direct and indirect impact of residential school; sixties scoop; } \\
\text { historical and current community conflicts with government or } \\
\text { law enforcement agencies; family/community fragmentation on } \\
\text { offender's attitude towards the criminal justice system. }\end{array}$ \\
\hline $\begin{array}{l}\text { Displays negative } \\
\text { attitudes towards the } \\
\text { correctional system? }\end{array}$ & $\begin{array}{l}\text { Overall, what do you think about the } \\
\text { correctional system/prison? Do you think it } \\
\text { works? Why/why not? What do you think about } \\
\text { the people who work in the system (e.g., } \\
\text { Program Officers, Correctional Officers, } \\
\text { Psychologists, Parole Officers, Probation } \\
\text { Officers)? Are they trustworthy, effective, fair? } \\
\text { What about rehabilitation? }\end{array}$ & $\begin{array}{l}\text { Rate Yes if the offender displays negative attitudes towards any } \\
\text { aspect of the correctional system including community } \\
\text { supervision and treatment. For Aboriginal offenders, consider the } \\
\text { direct and indirect impact of residential school; sixties scoop; } \\
\text { historical and current community conflicts with government or } \\
\text { law enforcement agencies; family/community fragmentation on } \\
\text { offender's attitude towards the correctional system. }\end{array}$ \\
\hline $\begin{array}{l}\text { Takes pride in } \\
\text { criminal exploits? }\end{array}$ & $\begin{array}{l}\text { How do you feel about the crime(s) you have } \\
\text { committed? If your friends were planning a } \\
\text { crime, would they ask for your help in the } \\
\text { planning/execution of the crime? Why/why not? }\end{array}$ & $\begin{array}{l}\text { Rate Yes if the offender takes pride in criminal activities (e.g., } \\
\text { boasts or brags about criminal involvement, has high self-esteem } \\
\text { or a positive self-image because of criminal involvement, no } \\
\text { evidence of shame or embarrassment associated with criminal } \\
\text { conduct). }\end{array}$ \\
\hline
\end{tabular}


Displays nonconforming attitudes toward society?

Values a substance abusing lifestyle?
What do you think about things such as maintaining steady employment, marriage, owning a home? Are these things important to you? Why/why not? Is there anything about your cultural heritage that would be considered mainstream or commonly accepted within your culture but perhaps not so by mainstream society? If yes, describe it. What do you think about this practice?

What do you think about people who use drugs/alcohol excessively? What's good about it? What's bad about it?
Rate Yes if there is evidence that the offender does not conform to social convention or displays negative attitudes towards social convention. Social convention may include traditional values held by mainstream society (e.g., steady and satisfying employment, financial security, stable accommodation, meaningful relationships with friends/family, and an intimate partner). It may also include traditional values considered mainstream within specific cultures (e.g., Aboriginal, Asian, East Indian communities).

Rate Yes if there is evidence that the offender either enjoys or takes pride in the lifestyle associated with substance abuse (e.g. sleeping in late, staying up all night, hanging out in bars, being high/stoned, hung over at work). For Aboriginal offenders, consider the direct and indirect impacts of intergenerational substance abuse.

Property-Specific Attitudes

Disrespects personal What do you think about people who vandalize belongings? or steal from other people or other peoples' homes? Is it ever okay? Under what circumstances?

Disrespects public or commercial property?
What do you think about people who vandalize or steal from a public area or business? Is it ever okay? If so, under what circumstances?
Rate Yes if there is evidence that the offender supports the destruction or theft of personal property (e.g., self-reported attitudes or behavioural examples such as property-related convictions/charges involving private dwellings).

Rate Yes if there is evidence that the offender supports the destruction or theft of public or commercial property (e.g., selfreported attitudes or behavioural examples such as propertyrelated convictions/charges involving public or commercial property).

Violence-Specific Attitudes

Attitudes support instrumental/goaloriented violence?

\begin{tabular}{|l|l|}
\hline $\begin{array}{l}\text { Attitudes support } \\
\text { expressive/emotional } \\
\text { violence? }\end{array}$ \\
\hline
\end{tabular}

To what extent do you agree with the following statements: "Sometimes a physical fight is necessary to settle an argument. Sometimes the only way to get what you want is to physically fight for it. Violence is the means to an end."

Under what circumstances is violence acceptable? Why/why not? To what extent do you believe it's okay to hit someone if you just go crazy with anger? Is it okay to fight someone if they insults you?
Rate Yes if there is attitudinal evidence (the offender verbally expresses attitudes supportive of instrumental violence) or behavioural evidence (crimes involve instrumental violence) that the offender believes it is okay to use violence as a method of achieving a goal or getting what they want.

Rate Yes if there is attitudinal evidence (the offender verbally expresses attitudes supportive of expressive/emotional violence) or behavioural evidence (crimes involve emotional violence, e.g., violent crimes motivated by emotions such as anger, jealousy, fear) that the offender believes it is okay to use expressive violence. For Aboriginal offenders, consider whether the difficulty in emotional regulation is related to direct or indirect experiences of intergenerational violence and trauma as a coping mechanism.

\section{Rationalizations}

Denies crime or uses What effect has your crime(s) had? Who excuses to justify or was/were the victim(s)? How were they minimize crime? affected? Who do you think is responsible for what happened?
Rate Yes if the offender denies the crime completely OR if they minimize the extent of the harm (e.g., "there were no broken bones", "insurance covers the cost", "no one was home when I broke in", doesn't recognize emotional damage that was done) OR justifies their behaviour (e.g., "they deserved it", "I was drunk", "it happens all the time").

Past Interventions 


\begin{tabular}{|c|c|c|c|}
\hline \multicolumn{2}{|c|}{$11 / 26 / 2019$} & \multicolumn{2}{|c|}{ Correctional Planning and Criminal Profile } \\
\hline \multicolumn{2}{|c|}{$\begin{array}{l}\text { Has previously been } \\
\text { referred to programs } \\
\text { addressing deficit(s) } \\
\text { under this domain? }\end{array}$} & $\begin{array}{l}\text { Have you ever participated in a program } \\
\text { addressing general attitudes, or for example, } \\
\text { attitudes towards the use of violence? }\end{array}$ & $\begin{array}{l}\text { Rate Yes if the offender has previously been referred to programs } \\
\text { addressing deficit(s) under the attitudes domain. }\end{array}$ \\
\hline $\begin{array}{l}\text { Attitude } \\
\text { Domain } \\
\text { Rating }\end{array}$ & \multicolumn{3}{|c|}{ Attitude Domain Rating Guidelines } \\
\hline $\begin{array}{l}\text { Factor seen } \\
\text { as an asset } \\
\text { to } \\
\text { community } \\
\text { adjustment }\end{array}$ & \multicolumn{3}{|c|}{$\begin{array}{l}\text { In this category, a rating of "Factor seen as an asset to community adjustment" indicates that there has been evidence } \\
\text { of a very positive attitude and considerable involvement in prosocial activities (e.g., work, school, family, treatment, } \\
\text { supervision). In the domain analysis, note how this area will contribute/facilitate community reintegration. }\end{array}$} \\
\hline $\begin{array}{l}\text { No } \\
\text { immediate } \\
\text { need for } \\
\text { improvement }\end{array}$ & \multicolumn{3}{|c|}{$\begin{array}{l}\text { A rating of "No immediate need for improvement" indicates that the offender's attitudes towards justice, society, } \\
\text { property, violence and lifestyle have not been interfering with daily functioning in the community. }\end{array}$} \\
\hline $\begin{array}{l}\text { Low need for } \\
\text { improvement }\end{array}$ & \multicolumn{3}{|c|}{ An offender exhibits "Low need for improvement" if attitudes have caused minor interference while in the community. } \\
\hline $\begin{array}{l}\text { Moderate } \\
\text { need for } \\
\text { improvement }\end{array}$ & \multicolumn{3}{|c|}{ An offender has "Moderate need for improvement" if their attitudes have caused moderate interference in the community. } \\
\hline $\begin{array}{l}\text { High need } \\
\text { for } \\
\text { improvement }\end{array}$ & \multicolumn{3}{|c|}{$\begin{array}{l}\text { An offender exhibits "High need for improvement" if any of the aforementioned has seriously interfered with daily } \\
\text { functioning while in the community. }\end{array}$} \\
\hline $\begin{array}{l}\text { Current } \\
\text { Motivation } \\
\text { Level - } \\
\text { Identified } \\
\text { Deficit }\end{array}$ & \multicolumn{3}{|c|}{$\begin{array}{l}\text { Are you interested in treatment/upgrading? Why/why not? How would it help you/not help you? Who else benefits from the } \\
\text { intervention? }\end{array}$} \\
\hline Low & \multicolumn{3}{|c|}{$\begin{array}{l}\text { The offender would benefit from motivation interviewing prior to programming. There is absolutely no recognition that they } \\
\text { have a need in this area. There is no genuine commitment to change. }\end{array}$} \\
\hline Medium & \multicolumn{3}{|c|}{$\begin{array}{l}\text { The offender may not fully accept or recognize need areas as deficit but is willing to participate in recommended programs } \\
\text { or other interventions. Genuine commitment to change may still be absent. While the offender may commit to intervention, } \\
\text { they may only be doing so for external reasons (e.g., to secure early release, to be transferred to a lower security } \\
\text { institution). }\end{array}$} \\
\hline High & \multicolumn{3}{|c|}{$\begin{array}{l}\text { The offender fully recognizes a need requiring intervention and is fully ready to start intervention. They have committed to } \\
\text { change and may have already started actively engaging in behaviours related to change. While still recognizing external } \\
\text { benefits for pursuing intervention (e.g., securing early release), they are primarily motivated for internal reasons (e.g., doing } \\
\text { it for himself/herself, "I'm tired of the lifestyle or I want a change"). }\end{array}$} \\
\hline $\begin{array}{l}\text { Not } \\
\text { applicable }\end{array}$ & \multicolumn{3}{|c|}{ No need in this area. } \\
\hline
\end{tabular}




\begin{tabular}{|c|c|}
\hline 26/2019 & Correctional Planning and Criminal Profile \\
\hline $\begin{array}{l}\text { Domain } \\
\text { Analysis }\end{array}$ & $\begin{array}{l}\text { Provide a narrative summary explaining how this need area relates to the present offence and the offender's overall } \\
\text { criminality. Record strengths if applicable. Note: If the offender has been convicted of a hate crime against a minority or } \\
\text { someone with a disability, please indicate to what extent the person displays negative attitudes towards the minority group } \\
\text { in question. Provide the reasons why the specific dynamic factor is rated as contributing (directly linked to the criminal } \\
\text { behaviour). For other dynamic factors not directly related to criminal behaviour, but where intervention will improve safe and } \\
\text { timely reintegration, give a clear explanation of why such factors require intervention. For Aboriginal offenders, explain how } \\
\text { the Aboriginal Social History may have impacted this dynamic factor. Refer to Annex H - Dynamic Factors and Aboriginal } \\
\text { Social History for guidance. }\end{array}$ \\
\hline
\end{tabular}

\section{Responsivity}

\begin{tabular}{|c|c|c|}
\hline Responsivity & Interview Prompt & Help Messages \\
\hline $\begin{array}{l}\text { Language barriers } \\
\text { interfere with learning, } \\
\text { work or intervention? }\end{array}$ & $\begin{array}{l}\text { Do you think language barriers will affect your } \\
\text { performance in treatment/work, etc.? }\end{array}$ & $\begin{array}{l}\text { Rate Yes if English or French is the offender's second } \\
\text { language and they have problems writing or speaking in } \\
\text { English or French as indicated by the CAAT (Canadian Adult } \\
\text { Achievement Test) or as evidenced during the interview. } \\
\text { Consideration should be additionally given for Aboriginal and } \\
\text { ethnocultural offenders whose primary language may be } \\
\text { something other than English or French. }\end{array}$ \\
\hline $\begin{array}{l}\text { Basic reading and/or } \\
\text { writing skills are } \\
\text { problematic? }\end{array}$ & $\begin{array}{l}\text { How much difficulty, if any, did you have reading } \\
\text { safety information or written instructions at work? } \\
\text { How often, if at all, did you find it difficult to leave } \\
\text { written messages or instructions for your co- } \\
\text { workers or supervisors? }\end{array}$ & $\begin{array}{l}\text { Rate Yes if current functioning as determined by the CAAT } \\
\text { (Canadian Adult Achievement Test) or other tests is below } \\
\text { grade } 8 \text { (Secondary-II in Quebec). Results should be included } \\
\text { in the narrative section if applicable. If the CAAT scores are } \\
\text { unavailable, also consider whether or not the offender reports } \\
\text { having difficulties applying basic reading and writing skills in } \\
\text { the workplace. }\end{array}$ \\
\hline $\begin{array}{l}\text { Concentration } \\
\text { problems are evident? }\end{array}$ & $\begin{array}{l}\text { Has a teacher/employer ever told you that you } \\
\text { have a short attention span? Do you think you } \\
\text { have a short attention span? If yes, why? If no, } \\
\text { why not? Have you ever been officially diagnosed } \\
\text { or tested for ADD? }\end{array}$ & $\begin{array}{l}\text { Rate Yes if there is evidence that the offender has trouble } \\
\text { focusing for long periods of time. }\end{array}$ \\
\hline Introverted/shy? & $\begin{array}{l}\text { On a scale of } 1 \text { to } 5 \text {, to what extent will working in } \\
\text { a group cause you stress? To what extent do you } \\
\text { like being the center of attention? }\end{array}$ & $\begin{array}{l}\text { Consider behaviour during interview as well as file } \\
\text { information. Rate Yes if there is evidence that the offender's } \\
\text { anxiety, shyness or introversion would prevent them from } \\
\text { benefiting from group programming or impact their program } \\
\text { performance reports. }\end{array}$ \\
\hline $\begin{array}{l}\text { Displays chronic } \\
\text { antisociality? }\end{array}$ & Not applicable. & $\begin{array}{l}\text { Rate Yes if supplementary psychological assessment reports } \\
\text { that the offender scored either at or above the average-high } \\
\text { range of the Hare Revised Psychopathy Checklist (not } \\
\text { applicable to women). }\end{array}$ \\
\hline $\begin{array}{l}\text { May have a learning } \\
\text { disability (LD)? }\end{array}$ & $\begin{array}{l}\text { Did you ever have to repeat a grade? Did you ever } \\
\text { fail a subject or class? Did you ever cut/skip } \\
\text { class? Were you ever suspended for skipping } \\
\text { school? Did you ever receive special testing at } \\
\text { school that was not part of your regular class tests } \\
\text { or exams? Were you ever in special education } \\
\text { classes? Did you ever have a tutor? Did you use } \\
\text { devices to help you learn (e.g., books on tape)? }\end{array}$ & $\begin{array}{l}\text { Consider the following information when deciding whether or } \\
\text { not to rate this indicator Yes: underwent a } \\
\text { psycho/educational assessment at school; received special } \\
\text { assistance in school; evidenced poor school performance } \\
\text { (offender failed a grade or a subject), or reports frequently } \\
\text { missing school for no legitimate reason (e.g., cut classes } \\
\text { regularly) (note: exclude women who leave school on } \\
\text { account of pregnancy); diagnosed or told they were learning } \\
\text { disabled. }\end{array}$ \\
\hline Low self-esteem? & $\begin{array}{l}\text { Overall, how would you rate your self-esteem } \\
\text { (below average, average, above average)? Why? }\end{array}$ & $\begin{array}{l}\text { Rate Yes if there is evidence that the offender holds } \\
\text { themselves in low regard (e.g., feels worthless, negative self- } \\
\text { image). }\end{array}$ \\
\hline
\end{tabular}




\begin{tabular}{|c|c|c|}
\hline 6/2019 & Correctional Planni & $\mathrm{ng}$ and Criminal Profile \\
\hline Intellectually disabled? & Not applicable. & $\begin{array}{l}\text { Rate Yes if there is evidence that the offender is intellectually } \\
\text { challenged. Consider supplementary assessment (standard } \\
\text { IQ test) results if available. If there is reliable evidence } \\
\text { regarding the cause of the impairment (e.g., Fetal Alcohol } \\
\text { Spectrum Disorder), please discuss in the narrative section. }\end{array}$ \\
\hline $\begin{array}{l}\text { May have } \\
\text { personal/emotional/ } \\
\text { psychological/physical } \\
\text { issues that would } \\
\text { interfere directly or } \\
\text { indirectly with } \\
\text { correctional } \\
\text { programming? }\end{array}$ & $\begin{array}{l}\text { Is there any reason why you might find it difficult } \\
\text { to participate in correctional programs? This } \\
\text { includes, for example, paying attention during } \\
\text { sessions, completing homework assignments, and } \\
\text { actively contributing to group discussions. }\end{array}$ & $\begin{array}{l}\text { Rate Yes if the offender reports a potential issue. The nature } \\
\text { and severity of the issue and its potential impact on ability to } \\
\text { participate in programs should be assessed by a mental } \\
\text { and/or medical health professional. }\end{array}$ \\
\hline $\begin{array}{l}\text { Suicide attempts/self- } \\
\text { harm history? }\end{array}$ & $\begin{array}{l}\text { Have you ever felt that you wanted to hurt } \\
\text { yourself? Have you ever wanted to hurt yourself? } \\
\text { Have you ever tried? Why? What stopped you? }\end{array}$ & $\begin{array}{l}\text { Rate Yes if there is evidence that the offender has engaged in } \\
\text { self-injurious behaviour or has attempted suicide in the past. } \\
\text { Consider present behaviour, severity and potential impact on } \\
\text { ability to participate and complete correctional programming } \\
\text { (refer to psychiatric assessment if available). }\end{array}$ \\
\hline Grief and loss? & $\begin{array}{l}\text { What are the most important losses in your life? } \\
\text { Who or what contributed to these losses? }\end{array}$ & $\begin{array}{l}\text { Consider impact of loss of freedom, children, friends, family } \\
\text { members, etc. Consider consequences/repercussions of } \\
\text { residential schools, deaths, illness, separation, foster care, } \\
\text { divorce, etc. }\end{array}$ \\
\hline $\begin{array}{l}\text { Has unique cultural } \\
\text { communication style? }\end{array}$ & Not applicable. & $\begin{array}{l}\text { Rate Yes if passive communication styles are considered } \\
\text { appropriate in some cultures (e.g., Aboriginal community). } \\
\text { Thus, a passive, non-forthcoming style should not be } \\
\text { misinterpreted. }\end{array}$ \\
\hline
\end{tabular}

\section{Overall Dynamic Factor Rating Guidelines (Contributing Factors)}

A dynamic factor rating is the compilation of professional judgements derived from DFIA-R assessment results (i.e., degree or severity of need) on each of the seven target domains.

The number of target domains identified and severity of each need are considered.

For those offenders who have no identified needs (i.e., "Factors seen as asset to community adjustment" and/or "No immediate need for improvement") or relatively few identified needs which have been rated as "Low need for improvement", an overall case needs rating of Low is warranted.

Overall ratings of Medium or High case needs are determined from a systematic review of professional judgements identifying the need for intervention within each target domain (i.e., "Moderate need for improvement" and "High need for improvement").

Again, the number of target domains identified, both individually and in combination, and severity of each need are considered.

For those offenders assessed as having few identified needs but indicate "High need for improvement" in those areas, an overall rating of High case needs should be given.

Regardless of degree or severity of needs, offenders who have been identified to be multi-need individuals also warrant an overall rating of High case needs.

Where professional judgement concludes that the offender is clearly not a Low case needs and there exists sufficient latitude to not rate the offender as High, then an overall rating of Medium case needs is deemed appropriate.

\section{Annex $F$ \\ Criminal Profile - Report Outline}

\section{Case Status}

- Name, age, citizenship, sentence length and offence(s). 
- Confirm through Sentence Management court orders, outstanding appeals and outstanding charges including source and details (if it is confirmed that there are no outstanding charges, make a statement to that effect).

- If offender discloses information about outstanding charge(s), results can be incorporated into the Criminal Profile Report.

\section{Official Version of Index Offence(s)}

Concise official version of index offence(s) based on official documentation.

For multiple offences that were committed in a similar manner, do not describe the details of each individual offence but summarize pattern.

Note the following:

Reference source document(s) and include:

- date and place of offence(s)

- how the offence was perpetrated (who, what, where, when, how and why)

- offender's role in the offence

- nature and gravity of the offence and the degree of responsibility of the offender, including the degree of violence and the use of any weapons

- name, role and status of accomplices, co-accused and/or co-convicted

- date of arrest and level of cooperation by the offender with authorities following arrest

- whether or not the offender's version is consistent with the official version

- if offender's version in Preliminary Assessment changes, provide a brief comment about major discrepancies

- whether the offence(s) and/or conviction(s) received extensive publicity

- information concerning the offender's performance if released on bail

- sentencing judge's comments and/or recommendations.

\section{Assessment of Harm and Victim Impact}

- Victim Impact Statement(s) and description of physical and/or psychological harm and summary of victim impact.

- Determination of serious harm, as set out in the Corrections and Conditional Release Act (http://laws-lois.justice.gc.ca/eng/acts/C-44.6/). (CCRA) and $\underline{C D} 705-8$ - Assessing Serious Harm (/acts-and-regulations/705-8-cd-eng.shtml), in the current offence(s).

\section{Analysis of Criminal Behaviour}

\section{Criminal History}

Reference source document(s) and include a brief analysis of criminal behaviour, and if applicable, include:

- a concise summary of the offender's juvenile, young offender, and adult criminal history (include prior stayed, withdrawn and/or dismissed charges). For Aboriginal offenders, make links between the offender's offending and their Aboriginal Social History

- brief details of serious schedule I and II offences

- number of offences causing physical or psychological harm

- use of a weapon

- explicit threats of violence

- behaviour of a sexual nature associated with any offence

- the number of serious drug-related offences

- impact on victim(s)

- patterns of convictions

- escalation in offence severity

- information on crime free periods

- organized crime connections and/or gang affiliations

- terrorism-related convictions.

\section{Institutional History}

Provide a brief summary of past institutional history, reference source, and if applicable, include:

- synopsis of young offender and adult offender institutional adjustment

- most recent institutional (federal, provincial or territorial) adjustment

- behaviour and attitude while at the remand unit pending federal admission.

\section{Escape/Attempted Escape History}

Provide a brief summary of past attempted escape, conspiracy to escape, and/or escape behaviour/history, reference source, and if applicable, include: 
$11 / 26 / 2019$

Correctional Planning and Criminal Profile

- date of incident (unlawfully at large, escape custody of confinement, police, escort) location, how, with whom, reason and disposition.

Community Supervision History

Provide a brief summary of past community supervision history and pattern, reference source, and if applicable include:

- positive periods of community supervision

- previous bail supervision, youth and adult probation, community supervision orders, federal supervision

- breach of trust history (fail to comply, fail to appear, breach of recognizance).

Psychological/Psychiatric/Mental Health History

Summarize mental health screening results. If applicable, provide summary analysis of psychological and mental health assessments/reports, and psychiatric assessments from the courts or other sources.

Family Violence History

If applicable, provide a summary analysis of family violence concerns and/or the results of the Family Violence Risk Assessment. For Aboriginal offenders, consider the impact the offender's Aboriginal Social History had on family violence.

\section{Detention Criteria}

Based on the available information, make a preliminary statement whether the offender meets the criteria for a referral for detention.

\section{Analysis of the Offence Cycle}

Provide an analysis of the offence cycle based on the overall pattern of criminal behaviour, not only the current offence. All factors that lead to criminal behaviour(s) must be examined, including the offender's understanding of the behaviour and a description of the events or situations that lead to the commission of any offence. For Aboriginal offenders, the offence cycle must be explained within the context of the offender's Aboriginal Social History.

Consider the following:

- crisis situations (personal, financial problems, emotional loss, family, social)

- substance abuse (consumption with disinhibiting effect on thinking or emotions, exacerbated aggressiveness, crime used to support consumption)

- peer pressure (threats, provocation, incitement, seeking approval, association, debts)

- potential victims (victims are accessible, vulnerable)

- potential means (organization, information, weapons and accomplices)

- emotional states (frustration, aggressiveness, loss, negative feelings, mental health issues)

- cognitive processes (perceptions, interpretations, distortion, images, and errors in thought processes)

- adaptation processes (projection, denial, rationalization, and introjection)

- actions and motives (behaviour, impulsivity, etc.).

\section{Annex G}

\section{Correctional Plan - Report Outline}

\section{Case Status}

Include the offender's age, length of sentence, current offence(s), court-ordered obligations, outstanding charges or appeals, immigration, deportation or extradition status. Identify members of the Case Management Team and the offender's level of participation in the development of the Correctional Plan.

\section{Static Factors Assessment Rating - Low, Medium or High}

Provide a brief analysis of the offender's criminal history and level of intervention based on static factors.

\section{Dynamic Factors Assessment Rating - Low, Medium or High}

Provide a brief summary of each domain incorporating supplementary assessments and prioritizing areas of need. For all Aboriginal offenders, each domain must be explained within the context of their Aboriginal Social History. Refer to Annex $\mathrm{H}$ - Dynamic Factors and Aboriginal Social History for assistance making links between dynamic factors and an offender's Aboriginal Social History. 
$11 / 26 / 2019$

Correctional Planning and Criminal Profile

For contributing factor(s) or areas of need, identify the program(s) and/or intervention(s) required, including cultural and restorative options (such as interventions with an Elder), the domain level of motivation and the expected objectives and gains in measurable, positive goal statements.

Under personal/emotional orientation domain related to the offender's needs, include information pertaining to psychological, psychiatric, mental health information, and comments from an Elder if applicable.

Under the employment domain include an initial education, vocational and employment plan that will address the offender's needs and identify the expectations for behaviour, skill or knowledge development related to work placements and future community employment.

Indicate whether the offender has appropriate identification, such as Social Insurance Number, Indian Status Card, Métis card, Non-Insured Health Benefits (NIHB) N-Number, birth certificate/citizenship card, and health coverage, (refer to Appendices F and $\mathrm{H}$ of the National Essential Health Services Framework), and if not, outline the offender's plan for acquiring needed identification.

\section{For offenders following a Healing Plan}

Incorporate healing components through consultation with the Elder or Aboriginal Liaison Officer and referencing the Elder Review. Indicate the offender's understanding in relation to the four aspects of traditional healing, and how this may assist in the management of risk. Integrating the Aboriginal Continuum of Care, identify the Elder-supported short and long-term traditional goals.

Through consultation with the Elder and/or Aboriginal Liaison officer, and referencing the Elder's Review, outline the plans for each component over a specified period of time (e.g., until the change of season, next parole decision date or transfer to lower security).

Physical Aspect

What ceremonies/teachings/activities will address the physical aspects outlined in the Elder Review?

Emotional Aspect

What ceremonies/teachings/activities will address the emotional aspects outlined in the Elder Review?

Spiritual Aspect

What ceremonies/teachings/activities will address the spiritual aspects outlined in the Elder Review?

Mental Aspect

What ceremonies/teachings/activities will address the mental aspects outlined in the Elder Review?

\section{Accountability Rating - Low, Medium or High}

Provide a brief analysis considering the following:

- level of acceptance of responsibility for their criminal behaviour

- level of remorse and victim empathy

- institutional adjustment and/or behaviour under community supervision

- conduct that demonstrates respect for other persons and property

- communication to their Parole Officer of willingness to engage in their Correctional Plan

- active participation in setting and achieving the objectives of their Correctional Plan

- an understanding of their offence cycle

- an understanding and commitment to their relapse prevention

- the meeting of court-ordered obligations.

The overall rating of offender accountability is obtained by the following:

Low - Offender rejects responsibility for their actions and fails to recognize their problems. Does not disclose emotional states, display guilt or victim empathy with evidence indicating a high level of denial and cognitive distortions.

Medium - Offender may not fully accept responsibility for their actions but recognizes some of their problems. Displays some guilt and victim empathy with some evidence of denial and cognitive distortions.

High - Offender accepts responsibility for their actions and recognizes their problems. Willing to self-disclose, displays guilt and victim empathy with evidence indicating a low level of cognitive distortions.

\section{Motivation Rating - Low, Medium or High}

Provide a brief analysis considering the following:

- recognition that a problem exists with lifestyle, behaviour and resulting consequences

- level of comfort with problem and its impact on the offender's life

- level of feeling of personal responsibility for the problem(s)

- willingness to change, i.e. expression of wish to change, or of intention to fully participate in Correctional Plan

- possession of skills, knowledge required to effect change in behaviour, i.e. is ready to change 
- level of external support from family, friends or other community members

- the offender's past history related to demonstrating change.

The overall rating of offender motivation is obtained by the following:

Low - Offender strongly rejects the need for change.

Medium - Offender may not fully accept overall assessment but will participate in recommended programs or other interventions.

High - Offender is self-motivated and is actively addressing their problem areas.

\section{Responsivity Factor - Yes or No}

If responsivity factor(s) exists, provide a brief analysis. When determining whether the offender's responsivity is affected, consider the following:

- language barriers interfere with learning work or intervention

- basic reading and/or writing skills problematic

- concentration problems are evident

- introverted/shy

- displays chronic antisociality

- may have a learning disability

- low self-esteem

- intellectually disabled

- may have other issues that would interfere with programming

- suicide attempts/self-injury history

- grief and loss

- has unique cultural communication style

- any other factor.

\section{Engagement Rating - Yes or No}

Provide a brief analysis of the offender's engagement to:

- actively participate in their assigned Correctional Plan

- be free of criminal and gang activity while under sentence

- display conduct that demonstrates respect

- obey the penitentiary rules, lawful orders, and/or supervision requirements.

In order to be engaged, there must be a rating of either moderate or high in both accountability and motivation.

\section{Reintegration Potential Rating - High, Medium or Low}

Using the results of the relevant actuarial tools, the reintegration potential is calculated as follows:

a. a low reintegration potential is assigned to offenders who received a high score in two or more of the three tools

b. a moderate reintegration potential is assigned to offenders who received one high score in any one tool and a moderate score in at least one of the other two tools, or who received a moderate score on all three tools

c. a high reintegration potential is assigned to all other offenders, i.e. all those who did not score high in any of the three tools, or scored high in one of the tools and no worse than low in the other two tools.

When the Parole Officer disagrees with the determined reintegration potential, a clear rationale must be documented, based on the following:

High

Offenders with high reintegration potential should not normally require formal correctional interventions. If required, these interventions should preferably be provided in the community. Other correctional interventions, services and work placements (including employability skills development) may be used, as well as any other risk management strategies, other than programs, in both institutions and the community.

\section{Medium}

Offenders with medium reintegration potential should require institutional correctional interventions based on the dynamic factors and the offender's level of risk and need(s). These interventions can also be provided in the community during the period of day parole or unescorted temporary absence program for personal development prior to full parole release.

Low 
Offenders with low reintegration potential require institutional correctional interventions based on the dynamic factors and the offender's level of risk and need(s). Other risk management strategies are to be provided in institutions prior to release, and continued in the community as required.

\section{Psychological/Psychiatric/Mental Health Information (If Applicable)}

Include a brief analysis of psychological, psychiatric, or mental health information on risk, risk management strategies, and intervention recommendations, including interventions with an Elder. If applicable, incorporate the Integrated Management Plan.

\section{Offence Cycle}

Summarize the offence cycle and the offender's understanding of the cycle. For Aboriginal offenders, explain the offence cycle within the context of their Aboriginal Social History.

\section{Correctional and Sentence Planning}

Sentence planning for all offenders will identify the objectives and significant events to reach in order to gain support for reduced security and/or conditional release. These objectives and significant events will be individualized, structured, measurable, attainable, relevant and timebound, while setting the framework for managing the sentence. For Aboriginal offenders, objectives tied, for example, to Pathways initiative should be identified in consultation with the Elder and documented in the Healing Plan.

The objectives and significant events will be prioritized based on:

a. institutional adjustment and adaptation

b. interventions required

c. public safety, being the paramount consideration

d. safe reintegration.

The Case Management Team, in consultation with the offender, will identify clear goals and expected results that support progress against the Correctional Plan.

Sentence planning for offenders serving sentences of 10 years to life, who are not approaching release eligibility, is developed according to the four phases of a long-term sentence:

a. adaptation - coming to terms with the reality of confinement

b. integration to the prison environment - living within the context of that reality

c. preparation for release - preparing for release in a progressive manner. This can include consideration for placement or transfer to an institution without a secure and directly controlled perimeter

d. reintegration into the community - assuring a coherent and continuous process leading to safe reintegration. This can include consideration for placement or transfer to an institution without a secure and directly controlled perimeter assuring a coherent and continuous process leading to safe reintegration.

Indicate whether Community Strategy is being requested, and if not requested, provide a rationale.

\section{Analysis of Current Request (Only Required in Cases Where a Community Strategy is Being Requested)}

If release is being considered, summarize the offender's release plan, including the following:

- the outstanding risk factors requiring intervention in a community setting

- the community interventions that would be required to target the outstanding risk factors, and in the case of an Aboriginal offender following, or interested in following, a traditional path, also include any community cultural activities/ceremonies that will be undertaken which will help to assist the offender, and why they are necessary within the context of the offender's Aboriginal Social History, as well as any interventions noted in a section 84 (http://laws-lois.justice.gc.ca/eng/acts/C-44.6/section-84.html) or section 84.1 (http://lawslois.justice.gc.ca/eng/acts/C-44.6/section-84.1.html) agreement

- specifics of the proposed release plan, including destination (and, if applicable, whether section 84 (http://lawslois.justice.gc.ca/eng/acts/C-44.6/section-84.html) or section 84.1 (http://laws-lois.justice.gc.ca/eng/acts/C-44.6/section-84.1.html) of the Corrections and Conditional Release Act (CCRA) applies and any resulting agreement with the offender's home community or alternately another Aboriginal community that engages in a section 84 (http://laws-lois.justice.gc.ca/eng/acts/C-44.6/section-84.html) or section 84.1 (http://laws-lois.justice.gc.ca/eng/acts/C-44.6/section-84.1.html) with the offender), employment, accommodation, family support

- offender's current financial situation, if relevant to risk

- victim considerations, including possible restrictions on travel, requests from victims for non-association conditions and sentencing judge comments. 
If completing for statutory release or long-term supervision order at warrant expiry date, review the early discretionary release and

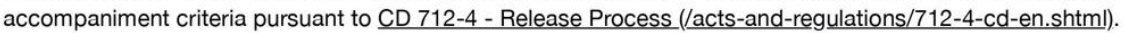

Annex H

\section{Dynamic Factors and Aboriginal Social History}

This table provides general examples of how to incorporate Aboriginal Social History within the dynamic factors and how different cultural and restorative options may be able to meet a need area. This table is not inclusive of all considerations or options, but provides an example.

\begin{tabular}{|c|c|c|c|c|}
\hline Dynamic Factor & Indicators & Links to ASH & Conventional Interventions & Aboriginal Interventions \\
\hline Employment/Education & $\begin{array}{l}\text { - Has less than high } \\
\text { school } \\
\text { - No employment } \\
\text { history } \\
\text { - Low confidence } \\
\text { regarding } \\
\text { employability }\end{array}$ & $\begin{array}{l}\text { - Reserve has } \\
\text { geographical } \\
\text { limitations (i.e. } \\
\text { isolated) } \\
\text { - High school is out } \\
\text { of area } \\
\text { - No tangible } \\
\text { employment } \\
\text { opportunities in } \\
\text { home community } \\
\text { - Lack of } \\
\text { opportunity to } \\
\text { develop } \\
\text { confidence } \\
\text { - Movement to an } \\
\text { urban inner city } \\
\text { area without skill } \\
\text { sets or education }\end{array}$ & $\begin{array}{l}\text { - Educational upgrading } \\
\text { - Institutional employment } \\
\text { - Skills/certification } \\
\text { training }\end{array}$ & $\begin{array}{l}\text { - Traditional } \\
\text { teachings/ceremonies } \\
\text { - One-on-one } \\
\text { counselling with an } \\
\text { Elder (Respect, } \\
\text { Traditional Learning, } \\
\text { Family and } \\
\text { Community) } \\
\text { - Pathways }\end{array}$ \\
\hline Marital Family & $\begin{array}{l}\text { - Perpetuates } \\
\text { violence against } \\
\text { partners } \\
\text { - Abused physically, } \\
\text { emotionally and } \\
\text { sexually as a child } \\
\text { - Children are in } \\
\text { foster care or } \\
\text { raised by relatives }\end{array}$ & $\begin{array}{l}\text { - Historic and/or } \\
\text { current family } \\
\text { violence } \\
\text { - Family members } \\
\text { attended } \\
\text { residential school } \\
\text { and have } \\
\text { scattered off } \\
\text { reserve and have } \\
\text { poor family links } \\
\text { - Offender grew up } \\
\text { in foster care or } \\
\text { raised by other } \\
\text { relatives } \\
\text { - Offender was } \\
\text { impacted by the } \\
\text { sixties scoop }\end{array}$ & $\begin{array}{l}\text { - Aboriginal Family } \\
\text { Violence Prevention } \\
\text { Program } \\
\text { - Aboriginal Integrated } \\
\text { Correctional Program } \\
\text { Model }\end{array}$ & $\begin{array}{l}\text { - Teachings/ceremonies } \\
\text { - One-on-one } \\
\text { counselling with an } \\
\text { Elder (The Role of } \\
\text { Men, The Role of } \\
\text { Women, The Role of } \\
\text { Elders and Children, } \\
\text { Responsibility and } \\
\text { Parenting, and/or } \\
\text { Respect, and/or } \\
\text { Grieving and/or } \\
\text { Healing) } \\
\text { - Pathways }\end{array}$ \\
\hline
\end{tabular}




\begin{tabular}{|c|c|c|c|c|}
\hline 26/2019 & & Correctional Planning & Criminal Profile & \\
\hline Associates & $\begin{array}{l}\text { - Associates with } \\
\text { known substance } \\
\text { users } \\
\text { - Associates with } \\
\text { criminally oriented } \\
\text { peers } \\
\text { - Is associated with } \\
\text { or is a member of } \\
\text { a security threat } \\
\text { group }\end{array}$ & $\begin{array}{l}\text { - Family and } \\
\text { community } \\
\text { fragmentation } \\
\text { (could be due to } \\
\text { intergenerational } \\
\text { impacts of } \\
\text { residential } \\
\text { schools, sixties } \\
\text { scoop) } \\
\text { - Racial } \\
\text { discrimination } \\
\text { - Gang affiliation }\end{array}$ & $\begin{array}{l}\text { Aboriginal Integrated } \\
\text { Correctional Program } \\
\text { Model }\end{array}$ & $\begin{array}{l}\text { - Teachings/ceremonies } \\
\text { - One-on-one } \\
\text { counselling with an } \\
\text { Elder (Respect, } \\
\text { Healthy Communities, } \\
\text { Healthy Families } \\
\text { and/or Healing) } \\
\text { - Pathways }\end{array}$ \\
\hline Substance Abuse & $\begin{array}{l}\text { - Substances are } \\
\text { interfering with } \\
\text { daily life } \\
\text { (employment and } \\
\text { family) } \\
\text { - Committed the } \\
\text { index offence } \\
\text { while under the } \\
\text { influence } \\
\text { - Violent when } \\
\text { under the } \\
\text { influence } \\
\text { - Started using at a } \\
\text { young age }\end{array}$ & $\begin{array}{l}\text { - Family history of } \\
\text { substance abuse } \\
\text { (could be the } \\
\text { result of } \\
\text { intergenerational } \\
\text { impacts of } \\
\text { residential } \\
\text { schools, sixties } \\
\text { scoop) } \\
\text { - Witnessed } \\
\text { parents abusing } \\
\text { substances while } \\
\text { growing up } \\
\text { - Moved to a foster } \\
\text { home at a young } \\
\text { age } \\
\text { - Suffered abuse at } \\
\text { a young age } \\
\text { - Resorted to } \\
\text { substances as a } \\
\text { coping } \\
\text { mechanism }\end{array}$ & $\begin{array}{l}\text { - Aboriginal Substance } \\
\text { Abuse Program } \\
\text { - Aboriginal Integrated } \\
\text { Correctional Program } \\
\text { Model }\end{array}$ & $\begin{array}{l}\text { - Teachings/ceremonies } \\
\text { - One-on-ones with an } \\
\text { Elder (Trauma, } \\
\text { Respect and } \\
\text { Traditional life, } \\
\text { Protocols, Spirituality, } \\
\text { Grieving and } \\
\text { Cleansing) } \\
\text { - Pathways }\end{array}$ \\
\hline $\begin{array}{l}\text { Community } \\
\text { Functioning }\end{array}$ & $\begin{array}{l}\text { - Unstable } \\
\text { accommodations } \\
\text { - Financially } \\
\text { unstable } \\
\text { - Community } \\
\text { attachment is } \\
\text { limited }\end{array}$ & $\begin{array}{l}\text { - Family and } \\
\text { community } \\
\text { fragmentation - } \\
\text { Removed from } \\
\text { home and culture } \\
\text { at a young age, } \\
\text { lost connection } \\
\text { with culture and } \\
\text { community (foster } \\
\text { homes and/or } \\
\text { sixties scoop) } \\
\text { - Limited } \\
\text { opportunities and } \\
\text { skill development } \\
\text { due to } \\
\text { geographical } \\
\text { location of home } \\
\text { community }\end{array}$ & $\begin{array}{l}\text { - Community Integration } \\
\text { Program } \\
\text { - Educational/employment } \\
\text { skills upgrading }\end{array}$ & $\begin{array}{l}\text { - Teachings/ceremonies } \\
\text { - One-on-one } \\
\text { counselling with an } \\
\text { Elder (Respect, } \\
\text { Traditional Life, and/or } \\
\text { Grieving and } \\
\text { Cleansing) } \\
\text { - Pathways }\end{array}$ \\
\hline
\end{tabular}




\begin{tabular}{|c|c|c|c|c|}
\hline 26/2019 & & Correctional Planning & Criminal Profile & \\
\hline Personal Emotional & $\begin{array}{l}\text { - Deals with stress } \\
\text { by using } \\
\text { substances } \\
\text { - Impulsive } \\
\text { - Problem solving } \\
\text { deficits } \\
\text { - Limited empathy } \\
\text { - Aggressiveness } \\
\text { - Low self-esteem }\end{array}$ & $\begin{array}{l}\text { - Intergenerational } \\
\text { impacts of } \\
\text { residential } \\
\text { schools, sixties } \\
\text { scoop } \\
\text { - Family } \\
\text { fragmentation } \\
\text { - Victim of sexual } \\
\text { and physical } \\
\text { abuse } \\
\text { - Foster care }\end{array}$ & $\begin{array}{l}\text { - Aboriginal Family } \\
\text { Violence Prevention } \\
\text { Program } \\
\text { - Aboriginal Basic Healing } \\
\text { Program } \\
\text { - Psychological } \\
\text { counselling } \\
\text { - Aboriginal Integrated } \\
\text { Correctional Program } \\
\text { Model }\end{array}$ & $\begin{array}{l}\text { - Teachings/ceremonies } \\
\text { - One-on-one } \\
\text { counselling with an } \\
\text { Elder (Patience, } \\
\text { Parenting, Preparation } \\
\text { of Feast Foods, } \\
\text { Protocols, Healing, } \\
\text { Preparation for } \\
\text { Fasting, Preparation } \\
\text { for Vision Quest) } \\
\text { - Pathways }\end{array}$ \\
\hline Attitude & $\begin{array}{l}\text { - Takes pride in } \\
\text { criminal exploits } \\
\text { - Distrust or } \\
\text { challenging } \\
\text { attitude toward } \\
\text { authority figures } \\
\text { - Values criminal } \\
\text { lifestyle } \\
\text { - Justifies/minimizes } \\
\text { crime }\end{array}$ & $\begin{array}{l}\text { - Intergenerational } \\
\text { residential school } \\
\text { impact and sixties } \\
\text { scoop } \\
\text { - Historical and } \\
\text { current } \\
\text { community } \\
\text { conflicts with } \\
\text { government or } \\
\text { law enforcement } \\
\text { agencies has lead } \\
\text { to a general } \\
\text { mistrust of } \\
\text { authority (for } \\
\text { example, } \\
\text { Ipperwash and } \\
\text { Oka crises) } \\
\text { - Family/community } \\
\text { fragmentation } \\
\text { - Struggle with } \\
\text { cultural/spiritual } \\
\text { identity }\end{array}$ & $\begin{array}{l}\text { - Aboriginal Integrated } \\
\text { Correctional Program } \\
\text { Model }\end{array}$ & $\begin{array}{l}\text { - Teachings/ceremonies } \\
\text { - One-on-one } \\
\text { counselling with an } \\
\text { Elder (Respect, } \\
\text { Traditional Family and } \\
\text { Community } \\
\text { Preparation of } \\
\text { Offerings and Feast } \\
\text { Food, Protocols, } \\
\text { Healing and Grieving) } \\
\text { - Pathways }\end{array}$ \\
\hline
\end{tabular}

*Please note that Elder interventions may vary from what is presented above depending on the Elder and their traditional teachings. The Elder interventions presented above are examples, with the purpose of illustrating how connections can be made between conventional and cultural interventions.

Date modified:

2019-04-03 


\title{
Appendix B: CD 715-1- Community Supervision
}

\section{Commissioner's Directive 715-1 Community Supervision}

\author{
Commissioner's Directive \\ Number: $715-1$ \\ In Effect: 2019-04-15 \\ Related links \\ Policy Bulletin 633 (633-pb-en.shtml)
}

\section{Authorities}

- Corrections and Conditional Release Act (https://laws-lois.justice.gc.ca/eng/acts/C-44.6/) (CCRA), sections $\underline{3.1}$ (http://laws-lois.justice.gc.ca/eng/acts/C-44.6/section-3.1.html), 4 (http://laws-lois.justice.gc.ca/eng/acts/C44.6/section-4.html), $\underline{5}$ (http://laws-lois.justice.gc.ca/eng/acts/C-44.6/section-5.html), 18 (http://lawslois.justice.gc.ca/eng/acts/C-44.6/section-18.html), 84 (https://laws-lois.justice.gc.ca/eng/acts/C-44.6/section-84.html), 84.1 (https://laws-lois.justice.gc.ca/eng/acts/C-44.6/section-84.1.html), 9 99(1)_(https://laws-lois.justice.gc.ca/eng/acts/C44.6/section-99.html), 100 (http://laws-lois.justice.gc.ca/eng/acts/C-44.6/section-100.html), 115 (http://lawslois.justice.gc.ca/eng/acts/C-44.6/section-115.html), 128 (http://laws-lois.justice.gc.ca/eng/acts/C-44.6/section128.html), 129 (http://laws-lois.justice.gc.ca/eng/acts/C-44.6/section-129.html), 133 (http://lawslois.justice.gc.ca/eng/acts/C-44.6/section-133.html) and 134 (http://laws-lois.justice.gc.ca/eng/acts/C-44.6/section134.html).

- Corrections and Conditional Release Regulations (http://laws.justice.gc.ca/eng/regulations/SOR-92-620/) (CCRR), sections 161 (http://laws.justice.gc.ca/eng/regulations/SOR-92-620/section-161.html) and 162 (http://laws.justice.gc.ca/eng/regulations/SOR-92-620/section-162.html)

- Criminal Code (http://laws-lois.justice.gc.ca/eng/acts/C-46/index.html), sections $\underline{672.34}$ (https://lawslois.justice.gc.ca/eng/acts/C-46/section-672.34.html) and 810 (https://laws-lois. justice.gc.ca/eng/acts/C-46/section810.html).

\section{Purpose}

To provide direction on assessing and managing an offender's transition to the community following release To provide direction on the completion of Staff Safety Assessments and application of tandem supervision

\section{Applications}

Applies to staff responsible for community supervision, including unescorted temporary absences and work releases

\section{Contents}

\author{
Responsibilities \\ Procedures \\ - Staff Safety and Tandem Supervision
}




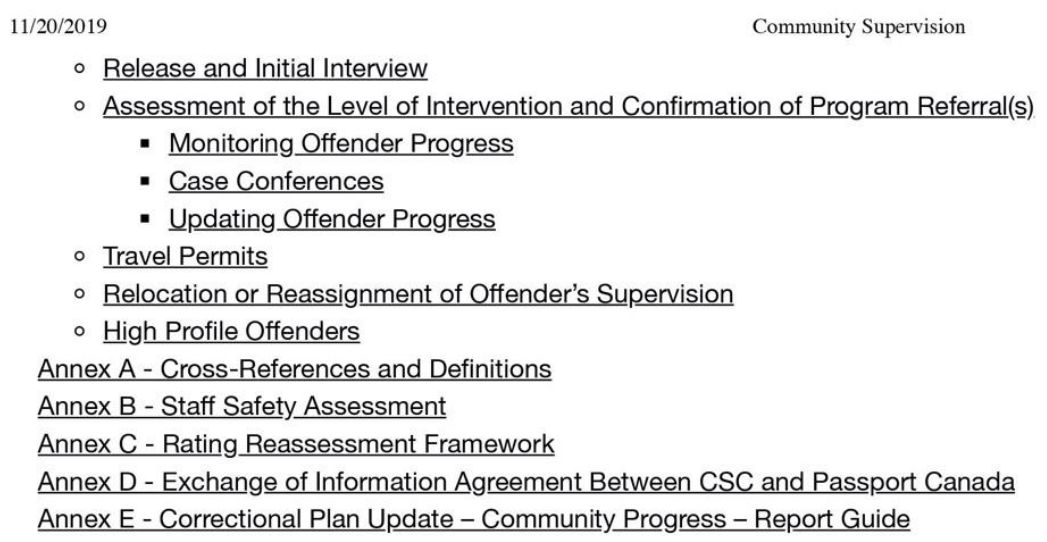

\section{Responsibilities}

1. The District Director will ensure:

a. procedures are in place to assist the offender in obtaining appropriate documentation/identification such as birth certificate, Indian Status card, Métis card, citizenship/permanent resident card, health coverage, Social Insurance Number

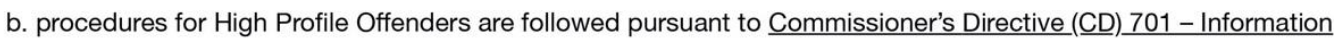
Sharing_(https://www.csc-scc.gc.ca/acts-and-regulations/701-cd-eng.shtml)

c. procedures outlined in $\mathrm{CD} 784$ - Victim Engagement (https://www.csc-scc.gc.ca/acts-and-regulations/784-cden.shtml) are followed

d. tandem supervision practices are respected

e. police receive relevant information pertaining to offenders' release activities.

2. The Area Director will:

a. ensure processes are in place to share offender related information with police

b. approve any submission to reduce levels of intervention during the first 90 days of release for offenders granted one-chance statutory release and for offenders subject to long-term supervision orders released at warrant expiry date

c. review submissions for an exception to the application of the tandem supervision requirement.

3. The Parole Officer Supervisor or Manager, Community_Correctional Centre ( $\underline{\mathrm{CCC}})$, will:

a. ensure continuity of the Correctional Plan

b. review and approve the offender's Correctional Plan Update and any change to their level of intervention.

4. The Parole Officer will:

a. maintain and update the Correctional Plan in consultation with the offender

b. assist and support the offender to actively participate in meeting the objectives of their Correctional Plan

c. monitor the offender's behaviour, release conditions and compliance with court-ordered obligations

d. obtain all relevant information from community-based residential facilities (d2) (CBRF) as identified in the contract requirements

e. develop and implement interventions which address and respond to the offender's risk and needs

f. confirm, with the offender, current pieces of identification upon release 
g. discuss and amend, if necessary, the offender's plan to obtain outstanding pieces of identification as soon as possible

h. assist the offender in obtaining outstanding pieces of identification, including their health card (refer to Appendices $\mathrm{F}$ and $\mathrm{H}$ of the National Essential Health Services Framework)

i. monitor the ongoing progress of the offender's plan in obtaining outstanding pieces of identification

j. document all actions taken to assist the offender (or the offender's refusal) in obtaining outstanding pieces of identification in a Casework Record entitled "Personal Documents - Post-Rel"

k. document all relevant information about the offender's circumstances, within established timeframes and parameters.

5. The offender is expected to:

a. participate in the consultation process for the maintenance of their Correctional Plan

b. actively participate in meeting the objectives identified in their Correctional Plan.

\section{Procedures}

\section{Staff Safety and Tandem Supervision}

6. The Staff Safety Assessment (Annex B) will be completed by the supervising Parole Officer prior to any community. supervision contact, excluding contacts at a community-based residential facility, and no later than 10 working days following:

a. an offender's initial release (including releases following a revocation)

b. case reassignment

c. a change in release type

d. the Parole Officer's determination that factors have arisen that may have a possible impact on staff safety, or

e. an offender's release from remand or immigration hold or the cancellation of a suspension in the case of offenders who went unlawfully at large and whose Staff Safety Assessment was not completed at the time of initial release.

7. A Staff Safety Assessment is not required pursuant to the above criteria in the case of offenders taken into provincial custody in relation to a remand order or an immigration hold, or for offenders who went unlawfully at large.

8. All staff members will ensure the Staff Safety Assessment is reviewed prior to the first meeting with an offender in the community (excluding contacts at a community-based residential facility) and the review is documented in a Casework Record.

9. If tandem supervision is required, all community supervision contacts, except those at a community-based residential facility or in public areas, will occur with an authorized tandem partner. This includes transporting an offender in a vehicle.

10. "Tandem partner" refers to the second individual authorized by policy or the District Director to complete tandem supervision. Authorized individuals include:
a. any CSC staff member
b. Peace Officers (including Police Officers and Provincial Probation/Parole Officers)
c. Community Assessment and Parole Supervision (CAPS) contractors
d. individuals authorized by the District Director by name.

11. These persons must meet both the following minimum standards:

a. have a valid Reliability Status 
b. have been briefed on the offender's criminal history and case dynamics as they relate to staff safety risk factors.

12. If, during the initial assessment or within the first 90 days, the tandem supervision criteria are met and there are no staff safety issues, the Area Director can make an exception to this requirement.

13. Tandem supervision can be reviewed and removed by the Area Director/Parole Officer Supervisor after the 90-day period has elapsed and the offender still meets tandem supervision criteria.

14. If an offender's release has been suspended within a 90-day tandem supervision period and the suspension is subsequently cancelled, the Case Management Team will consider whether to continue or restart the active tandem supervision period.

15. Offenders who are active tandem supervision cases are not permitted to participate in private home placements.

\section{Release and Initial Interview}

16. Within 24 hours of release, CSC will provide police with the following:

a. an up-to-date offender photograph

b. a copy of the release certificate, which includes the territorial boundaries noted under Special Instructions

c. the Standard Profile

d. the Parole Board of Canada (PBC) Decision Sheet (if applicable).

17. The Parole Officer will meet the offender within one working day of arrival at the release destination (excluding offenders who remain in custody on remand or an immigration hold/ removal order).

18. When this deadline cannot be met due to exceptional circumstances (e.g. release to remote area where the Parole Officer or contractor only travels once per week), upon approval of the Parole Officer Supervisor/CCC Manager, the meeting will take place as soon as possible and the reason for the delay will be documented in a Casework Record.

19. During the initial interview, the Parole Officer will review the offender's Correctional Plan and current circumstances and complete the Initial Interview Checklist (CSC/SCC 1331).

20. Levels of intervention are determined according to the criteria indicated below:

a. Level I (Intensive Supervision) - A minimum of eight face-to-face contacts per month between the Parole Officer and the offender is required when the following three criteria are met:

i. the offender is on statutory release

ii. their reintegration potential is rated as low at intake and at release

iii. their static or dynamic factors are assessed as high or when one of the following criteria is met:

iv. the offender is granted one-chance statutory release, or

v. the offender is released from custody at warrant expiry date and subject to a long-term supervision order.

b. Level A - A minimum of four face-to-face contacts per month between the Parole Officer and the offender is required when the level of intervention on either static or dynamic factors is assessed as high.

c. Level A - Residency - A minimum of four face-to-face contacts per month between the Parole Officer and the offender is required when the Level I (Intensive Supervision) criteria is met and the offender is residing in one of the following CBRFs: a CCC, a Community Residential Facility (CRF), or a Treatment Centre; this does not include "other location".

d. Level B - A minimum of two face-to-face contacts per month between the Parole Officer and the offender is required when the highest level of intervention on either static or dynamic factors is assessed as medium.

e. Level B - Residency - A minimum of two face-to-face contacts per month between the Parole Officer and the offender is required when the Level A criteria is met and the offender is residing in one of the following CBRFs: a CCC, a CRF, or a Treatment Centre; this does not include "other location". 
f. Level C - A minimum of one face-to-face contact per month between the Parole Officer and the offender is required when the level of intervention on both static and dynamic factors is assessed as low.

g. Level C - Residency - A minimum of one face-to-face contact per month between the Parole Officer and the offender is required when the Level $\mathrm{B}$ criteria is met and the offender is residing in one of the following CBRFs: a $\underline{\mathrm{CCC}}$, a $\underline{\mathrm{CRF}}$, or a Treatment Centre; this does not include "other location".

h. Level D - A minimum of one face-to-face contact every two months between the Parole Officer and the offender may be approved for an offender who meets the following conditions:

i. the offender has been under supervision at level $\mathrm{C}$ for a minimum of one year, not including any time spent on day parole

ii. the offender's Correctional Plan indicates that programming, counselling or other interventions are not required.

i. Level E - A minimum of one face-to-face contact between the Parole Officer and offender every three months may be approved for an offender who has been under level $\mathrm{D}$ supervision for a minimum of one year.

\section{Assessment of the Level of Intervention and Confirmation of Program Referral(s)}

21. All offenders, except those assessed as requiring level I supervision or those offenders in custody on outstanding charges, on immigration hold/removal order, or held in a health facility (dual status offenders), will be supervised at level A until the level of intervention is reviewed. Offenders assessed as requiring level I supervision will be supervised at level I until the level of intervention is reviewed.

22. The level of intervention for offenders in custody on outstanding charges, on immigration hold/removal order or held in a health facility (dual status offenders) will be suspended while the offender is in a secure facility. If required, contact between the Parole Officer and the offender (i.e. face-to-face or by telephone/videoconference) may occur. Contact with the provincial facility and/or Immigration officials will be maintained to obtain the outcome of decisions rendered in their respective areas of authority. The offender's level of intervention will resume once the offender is released back into the community (i.e. bail) following their remand in provincial custody for outstanding charges, their hold by Immigration Canada, or their release from a health facility. At that time, the initial interview will be completed.

23. The Parole Officer will review, with the Parole Officer Supervisor/CCC Manager, the Correctional Plan, Community Strategy, level of intervention, program referrals and offender's adjustment to the community within 30 days of release.

a. If there is no change to the level of intervention, key ratings or program referrals, the results of the review will be recorded in a Casework Record.

b. If there are changes to the level of intervention (e. g. the level of supervision is lowered due to the offender residing in one of the following CBRFs: a CCC, a CRF, or a Treatment Centre) and/or program referral(s), this will be documented in a Correctional Plan Update as outlined in Annex E.

24. For intensive supervision cases, the level of intervention will be reviewed again 90 days following release. Any change to the level of intervention will be documented in a Correctional Plan Update.

25. Offenders released on one-chance statutory release and those subject to long-term supervision orders who had been detained will be supervised at level I for at least 90 days following release. Any exceptions to this standard (e.g. where at the 30-day review, the Parole Officer and Parole Officer Supervisor/CCC Manager assess that intensive supervision is not necessary) require approval by the Area Director and documentation in a Correctional Plan Update.

26. These cases will be reviewed prior to the end of the 90 days. A reduction in supervision will require documentation in a Correctional Plan Update. If there is no change, this review can be documented in a Casework Record.

\section{Monitoring Offender Progress}

27. The Parole Officer must meet with the offender at the required level of intervention, or more often if necessary, to assess progress against the Correctional Plan and monitor special conditions. Contacts with the offender will include community visits to ensure the Parole Officer gathers information about the offender in their environment. The contact 
will be documented in a Casework Record. In the event of a missed contact, the rationale will be documented in a Casework Record.

28. When the level of intervention cannot be met due to exceptional circumstances or those beyond the Parole Officer's control, the level of intervention may be decreased following a case conference with the Parole Officer Supervisor/CCC Manager. When the exception is granted to not meet the level of intervention for a period of less than one month (e.g. hospitalization, illness, natural disaster, weather prohibits meeting with the offender), the case conference will be documented in a Casework Record. Lengthier exceptions will be recorded in a Correctional Plan Update.

29. In cases where the Area Director has authorized a leave of up to a maximum of 15 days per occurrence for emergency medical reasons or up to a maximum of three days per occurrence for compassionate reasons, the Parole Officer will document the information in the next Correctional Plan Update shared with PBC. The Board's authorization is required for leave exceeding 15 days for emergency medical reasons or exceeding three days for compassionate reasons.

30. The Parole Officer will establish a network of collateral contacts to verify offender reported information and to gather information on the behaviour of the offender, throughout the supervision period.

31. When deemed necessary, the Parole Officer will contact police to verify whether the collateral contact is known to police and/or identify the existence of a criminal record, if consent from the collateral contact is obtained as outlined in the Consent CPIC Clearance Request (CSC/SCC 1279 01).

32. Where there are police reporting requirements, these will be verified by the Parole Officer.

33. All relevant offender and collateral contacts will be recorded in Casework Records within five working days. Casework Records will also be completed prior to a transfer of supervision. Any collateral contact with police wherein security or intelligence information is received will be recorded in a Statement/Observation Report (CSC/SCC 0875) and shared as per CD 568-2 - Recording and Sharing of Security Information and Intelligence (https://www.csc-scc.gc.ca/acts-andregulations/568-2-cd-eng.shtml).

34. The Parole Officer will provide the offender with community resource information to facilitate the transition to the community and engagement in the Correctional Plan. Community Employment Centres and mental health services will be utilized where available and appropriate.

35. The Parole Officer will obtain regular progress reports from individuals or agencies providing programming or counselling to the offender, in accordance with the Correctional Plan. This includes as applicable, methadone maintenance treatment, mental health and other program providers.

36. The Parole Officer will promptly inform the police of:
a. suspicion of criminal activities
b. any modifications to release conditions
c. actions taken in response to police information received
d. any travel permits issued to the offender
e. any relevant changes to the offender's circumstances.

37. At any time during the release, the Parole Officer may request assistance and/or a consultation with the Security Intelligence Officer for the following reasons:

a. concerns regarding staff safety have become known

b. the offender is suspected of re-engaging in criminal activity

c. there have been repeated breaches during the supervision period

d. there is a lack of transparency in relation to special conditions

e. the offender is isolated or has special needs

f. there will be a section 810 (http://laws-lois.justice.gc.ca/eng/acts/C-46/section-810.html) Criminal Code order at warrant expiry date and the offender requires monitoring for the final 90 days of the sentence 
g. the offender requires an enhanced level of monitoring due to mental health issues

h. the offender was released from a maximum security institution.

38. At any time during the release, the Parole Officer may make a referral to the Aboriginal Community Liaison Officer, in locations where one is in place, for access to Aboriginal community resources.

\section{Case Conferences}

39. Regular case conferences, which include at a minimum the person supervising the offender and a Parole Officer Supervisor/CCC Manager, will be held:

a. to discuss release plans or a change in the release plan

b. prior to completion of a Correctional Plan Update or an Assessment for Decision

c. to reassess risk and review progress

d. to discuss any required interventions, such as program referrals.

40. All case conferences must be documented in a Casework Record unless the information is contained within a Correctional Plan or an Assessment for Decision.

41. If the initial release plan differs significantly from that approved by PBC, the Parole Officer will submit a

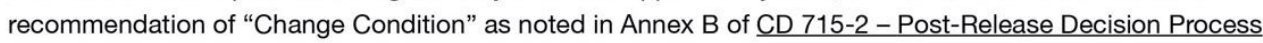
(https://www.csc-scc.gc.ca/acts-and-regulations/715-2-cd-en.shtml).

\section{Updating Offender Progress}

42. Using the Rating Reassessment Framework (Annex C), the Correctional Plan will be updated:

a. to add a program referral when the need/objectives are not already identified in the previous Correctional Plan or remove a program referral pursuant to $\underline{\mathrm{CD}} 726$ - Correctional Programs (https://www.csc-scc.gc.ca/acts-andregulations/726-cd-eng.shtml).

b. when recommending a change in the type of release or day parole is continued

c. where circumstances warrant a reassessment.

\section{Travel Permits}

43. A travel permit is required for all travel outside the established boundaries. Prior to approving travel outside the established boundaries, the Parole Officer will consider case specific factors that can include but are not limited to: purpose and length of travel, offender's current risk level, existence of high risk situations and/or triggers, progress and stability under supervision, security intelligence information, victim concerns, PBC decisions and applicable comments, and strategies to manage risk during the travel period.

44. The decision to approve travel may require consultation with the parole office and/or the police at the destination location.

45. A Community Assessment is normally completed prior to approving travel to a community contact unknown to the Parole Officer. Prior to the offender travelling, the Parole Officer needs to reconfirm the availability of the contact before approving the travel permit. If a Community Assessment is not completed, the rationale for approving the travel permit without a Community Assessment will be documented in a Casework Record.

46. In cases in which the offender has been granted a travel permit to a different supervision area and police reporting is required, the supervising Parole Officer will verify police reporting following the offender's return. In cases where the destination office is actively involved in the supervision of the offender (e.g. travel permits of a long duration), the destination office is responsible for verifying the police reporting. The contact with the police will be documented.

47. The Parole Officer will advise the Security Intelligence Officer of any travel requested by offenders with links to criminal organizations, gangs or security threat groups. 
48. The established levels of intervention will be maintained during periods of travel.

49. The Parole Officer will advise the Victim Services Unit of travel by offenders with victim notification, normally five days prior to the event.

50. Travel will be confirmed by the Parole Officer following completion of the permit. When an offender is travelling to the same destination regularly, confirmation of travel need only occur based on case specific factors.

51. Requests for out-of-country travel require a referral and recommendation to $\mathrm{PBC}$ to receive an exemption from the standard condition requiring the offender to remain in Canada. Refer to PBC Policy Manual (http://publications.gc.ca/collections/collection 2016/clcc-pbc/JS92-43-2013.pdf) and Exchange of Information Agreement Between CSC and Passport Canada, regarding out-of-country travel submissions. This does not apply to those offenders who have been granted a parole reduced status.

52. If there are reasonable grounds to believe the offender is a member of or affiliated with a criminal organization, gang or security threat group, the Parole Officer will forward relevant information to the Security Intelligence Officer, prior to submitting an out-of-country travel recommendation to PBC. The Security Intelligence Officer will advise the Preventive Security and Intelligence branches at Regional and National Headquarters.

53. The Parole Officer will include the results of the security review in the submission to PBC. If travel is approved by PBC, the Security Intelligence Officer will provide the travel itinerary to the Preventive Security and Intelligence Branches at Regional and National Headquarters.

\section{Relocation or Reassignment of Offender's Supervision}

54. Prior to transferring an offender to another supervising location, or reassigning the offender's case to another Parole Officer, the supervising Parole Officer will consider the offender's stability and case specific factors to ensure the transfer process is consistent with the goals of the Correctional Plan. Every effort will be made to avoid the transfer or reassignment of an offender who is in an unstable situation unless this will contribute to improved management of the offender's risk.

55. Prior to approving an offender's request for relocation, the Parole Officer will consult with the destination office regarding supervision requirements and a need for a Community Assessment. A case conference with the receiving Parole Officer will be held and documented prior to a transfer or reassignment.

56. Normally, where documents require translation, the sending office will translate the Criminal Profile Report, the Correctional Plan, the most recent Correctional Plan Update and Assessment for Decision, a current psychological/psychiatric report and any information impacting potential interventions, prior to the transfer of an offender.

\section{High Profile Offenders}

57. If an event involves an offender with a high profile offender flag, the procedures regarding high profile offenders will be followed pursuant to $\underline{\mathrm{CD}} 701$ - Information Sharing_(https://www.csc-scc.gc.ca/acts-and-regulations/701-cdeng.shtml).

Commissioner,

Original signed by:

Anne Kelly 
$11 / 20 / 2019$

Community Supervision

\section{Annex A \\ Cross-References and Definitions}

\section{Cross-References}

CD 001 - Mission, Values and Ethics Framework of the Correctional Service of Canada (https://www.csc-scc.gc.ca/acts-andregulations/001-cd-en.shtml)

CD 568 - Management of Security Information and Intelligence (https://www.csc-scc.gc.ca/acts-and-regulations/568-cdeng.shtml)

CD 568-2 - Recording and Sharing of Security Information and Intelligence (https://www.csc-scc.gc.ca/acts-andregulations/568-2-cd-eng.shtml).

CD 700 - Correctional Interventions (https://www.csc-scc.gc.ca/acts-and-regulations/700-cd-eng.shtml).

CD 701 - Information Sharing_(https://www.csc-scc.gc.ca/acts-and-regulations/701-cd-eng.shtml)

CD 702 - Aboriginal Offenders (https://www.csc-scc.gc.ca/acts-and-regulations/702-cd-eng.shtml).

CD 710-3 - Temporary Absences (https://www.csc-scc.gc.ca/acts-and-regulations/710-3-cd-eng.shtml)

CD 710-7 - Work Releases (https://www.csc-scc.gc.ca/acts-and-regulations/710-7-cd-eng.shtml).

CD 712-1 - Pre-Release Decision Making_(712-1-cd-en.shtml).

CD 712-4 - Release Process (712-4-cd-en.shtml)

CD 712-5 - Pre-Release Case Preparation for Provincial/Territorial Offenders and Federal Offenders Incarcerated in

Provincial/Territorial Facilities (https://www.csc-scc.gc.ca/acts-and-regulations/712-5-cd-eng.shtml)

CD 714 - Community Correctional Centre Standards (https://www.csc-scc.gc.ca/acts-and-regulations/714-cd-eng.shtml).

CD 715 - Community Supervision Framework (715-cd-en.shtml)

CD 715-2 - Post-Release Decision Process (715-2-cd-en.shtml).

CD 715-3 - Community Assessments (715-3-cd-en.shtml).

CD 715-4 - Case Preparation and Supervision of Women Offenders with Children Residing at a Community-Based

Residential Facility_(https://www.csc-scc.gc.ca/acts-and-regulations/715-4-cd-eng.shtml).

CD 719 - Long-Term Supervision Orders (https://www.csc-scc.gc.ca/acts-and-regulations/719-cd-eng.shtml)

CD 726 - Correctional Programs (https://www.csc-scc.gc.ca/acts-and-regulations/726-cd-eng.shtml).

CD 784 - Victim Engagement (https://www.csc-scc.gc.ca/acts-and-regulations/784-cd-en.shtml).

CD 800 - Health Services (https://www.csc-scc.gc.ca/acts-and-regulations/800-cd-eng.shtml)

Specific Guidelines for the Treatment of Opiate Dependence (Methadone/Suboxone)

National Essential Health Services Framework

\section{Definitions}

Case conference: a formal meeting, consultation or discussion about an offender between two or more individuals.

Community-based residential facility: a designated facility that provides accommodation to offenders on parole, statutory release, temporary absence or long-term supervision order. This includes community correctional centres, community residential facilities, hostels, treatment centres, private home placements and other facilities designated as CBRFs.

Community Correctional Centre (CCC): a federally operated community-based residential facility that provides a structured living environment with 24-hour supervision, programs and interventions for the purpose of safely reintegrating offenders into the community. These facilities, which may also have an enhanced programming component, accommodate offenders under federal jurisdiction who have been released to the community on unescorted temporary absences, day parole, full parole, work releases, statutory release, as well as those subject to long-term supervision orders

Community residential facility: a community-based residential facility operated by a non-governmental agency or a provincial entity that provides a structured living environment with 24-hour supervision, programs and interventions for the purpose of safely reintegrating the offender into the community.

Community supervision contact: any supervision contact with the offender in the community.

Contractor: a person providing services of a prescribed class to the Correctional Service of Canada under a contract. 
Day Parole to an other location: a location that provides accommodation to an offender on day parole, other than a penitentiary, community-based residential facility or provincial institution, as set out in subsection 99(1)_https://lawslois.justice.gc.ca/eng/acts/C-44.6/section-99.html) of the CCRA. This includes a private home or private facility, which has not been designated as a community-based residential facility.

Dual status: offenders who are subject to a current federal sentence AND who are also subject to a finding of not criminally responsible pursuant to section 672.34 (https://laws-lois.justice.gc.ca/eng/acts/C-46/section-672.34.html) of the Criminal Code of Canada.

Exception for tandem supervision: the Area Director's authority to suspend the application of tandem supervision for offenders identified as meeting the established tandem supervision criteria, at the recommendation of the Case Management Team.

Parole reduced status: offenders who have had the majority of standard conditions removed by the Parole Board of Canada. Offenders who have been granted parole reduced status are only subject to three standard conditions, namely paragraphs 161(1)(a) and (ㄷ)_(http://laws.justice.gc.ca/eng/regulations/SOR-92-620/section-161.html) and subparagraph 161(1).(g)(i)_(http://laws.justice.gc.ca/eng/regulations/SOR-92-620/section-161.html) of the CCRR (http://laws.justice.gc.ca/eng/regulations/SOR-92-620/index.html), which require them to report to their parole supervisor, obey the law and keep the peace, and notify the parole supervisor of any change in their address of residence.

Tandem supervision: the requirement to conduct community supervision visits with a second authorized individual.

Tandem supervision criteria: tandem supervision is a requirement in cases which meet one (or both) of the following criteria:

a. offenders who have a criminal history involving any sexual offence and/or death and are assessed as high risk at intake (level of intervention based on static factors)

b. offenders who have a criminal history involving any sexual offence and/or death and are classified as maximum security upon release (offender security level).

Treatment centre: a community-based residential facility, which provides a structured living environment with 24-hour onsite supervision, programming, support systems and monitoring for safe reintegration back into the community. The main objective of treatment centres is to address the identified treatment needs (e.g. addictions, mental health) of the offender under their care.

\section{Annex B - Staff Safety Assessment}

Reason for Safety Assessment: Initial Reassessment Reassignment
Offender:

Release Type and Date:

Parole Officer:

Consider Each Factor in Relation to its Impact on Staff Safety

\section{Offender Factors}

\section{History of violence}




11/20/2019
\begin{tabular}{|l|r|}
\hline 5. Previous hostility or assault on staff & Yommity Supervision \\
\hline 6. Instability of intimate relationships & Y/N \\
\hline 7. Mental health issues & Y/N \\
\hline 8. Links to organized crime/gangs, etc. & Y/N \\
\hline 9. Assigned Parole Officer meets the profile of the offender's victim(s) & Y/N \\
\hline 10. Other & Y/N \\
\hline
\end{tabular}

\section{Environmental Factors}

\begin{tabular}{|l|r|}
\hline 11. Remote location & Y/N \\
\hline 12. Availability of police & Y/N \\
\hline 13. Criminal history - at location & Y/N \\
\hline 14. Proximity to criminal/gang activity & Y/N \\
\hline 15. Uncooperative/hostile collateral & Y/N \\
\hline 16. Restricted access to outside intervention & Y/N \\
\hline 17. Restricted cell phone coverage & Y/N \\
\hline 18. Other & Y/N \\
\hline
\end{tabular}

\section{Tandem Supervision Criteria}

19. Tandem supervision is a requirement in cases which meet one (or both) of the following criteria:

a. offenders who have a criminal history involving any sexual offence and/or death and are assessed as high risk at intake (level of intervention based on static factors)

$\mathbf{Y} / \mathbf{N}$

b. offenders who have a criminal history involving any sexual offence and/or death and are classified as maximum security upon release (offender security level)

$\mathrm{Y} / \mathrm{N}$

Community Visit Strategy ( alternate interview location, police notification, emergency protocols, tandem supervision, etc.)

\section{Parole Officer: \\ Parole Officer Supervisor/CCC Manager:}


Case Conference Date:

Exception/Removal (If Applicable)

Case Management Team Recommendation

Rationale

Date:

\section{Annex C - Rating Resssessment Framework}

\section{Level of Intervention Based on Static Factors}

1. A review of static factors (i.e. based on historical information related to risk that is available at the time of the offender's admission to federal custody, such as rating on the Statistical Information on Recidivism Scale, criminal history record, offence severity record, sex offence history, detention criteria) produces a reliable estimate of the probability and severity of re-offending. This estimate, originally determined at intake, appears as a rating of level of intervention based on static factors. The rating is normally accurate throughout the offender's period of incarceration and for the first six months of supervision on conditional release, at which time dynamic factors related to performance on release become increasingly dominant.

2. The predictive accuracy of this rating can be improved in some cases by reviewing the following factors:
a. time since the offender's release
b. existence of collateral contacts that could assist in the supervision
c. significant disciplinary problems, suspensions or police intervention in the last year
d. offender's progress and motivation to participate in their Correctional Plan.

3. Only a significant and sustained change in the offender's performance or situation justifies an increase or a decrease in the level of intervention based on static factors. Guidelines for adjusting the level are as follows:

a. LOW

- If the previous rating was LOW and there have been no significant changes in the above factors.

- If the previous rating was MEDIUM and there have been significant and sustained improvements in the above factors.

b. MEDIUM

- If the previous rating was MEDIUM and there have been no significant changes in the above factors.

- If the previous rating was HIGH and there have been significant and sustained improvements in the above factors. 
- If the previous rating was LOW and there has been significant and sustained deterioration in the above factors.

c. HIGH

- If the previous rating was $\mathrm{HIGH}$ and there have been no significant changes in the above factors.

- If the previous rating was MEDIUM and there has been significant deterioration in the above factors.

\section{Level of Intervention Based on Dynamic Factors}

4. Reassessing the level of intervention based on dynamic factors begins with the reassessment of each of the dynamic factors, by examining each of the following areas:

a. progress related to the Correctional Plan

b. anything else that may affect the intensity of the dynamic factor (e.g. changes in personal situation, health, etc.).

5. The rating for each dynamic factor may be as follows:

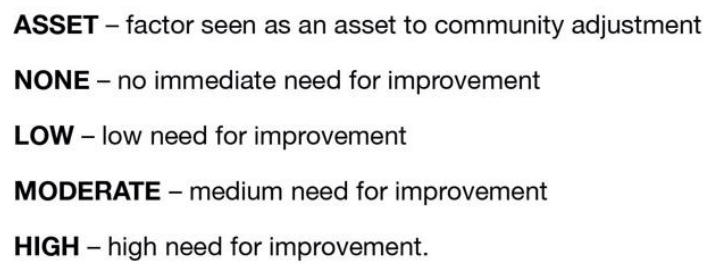

6. Reassessment of the overall rating can then be conducted by examining the number and seriousness of the dynamic factors.

7. The overall rating should only change if there are some changes in the reassessment of the dynamic factors. The overall rating may be:

a. LOW

- No identified dynamic factors (e.g. factors seen as an asset to community adjustment and/or no immediate need for improvement)

- Relatively few identified dynamic factors and rated as "low or medium need for improvement"

b. HIGH

- Few identified dynamic factors but rated as "high need for improvement"

- Multiple dynamic factors identified (regardless of degree or severity of needs)

\section{MEDIUM}

- Any combination of dynamic factor severity and number that lies outside of either the low or high scoring guidelines as identified above.

8. During the reassessment process, it is possible to identify new dynamic factors for which intervention may improve the chances for the offender's eventual reintegration.

\section{Accountability}

9. Accountability is the level of involvement of the offender in their Correctional Plan in relation to the obligation to modify behaviours identified as being problematic. Attitude, behaviour, and insight are critical components to offender accountability.

10. The following criteria are used to assess an offender's level of accountability:

a. level of acceptance of responsibility for their criminal behaviour 
b. level of remorse and victim empathy

c. institutional adjustment and/or behaviour under community supervision

d. conduct that demonstrates respect for other persons and property

e. communication to their Parole Officer of their willingness to engage in their Correctional Plan

f. active participation in setting and achieving the objectives of their Correctional Plan

g. understanding of their offence cycle

h. understanding and commitment to their relapse prevention

i. meeting of court-ordered obligations.

\section{Overall Level of Accountability}

11. The guidelines for establishing the overall level of accountability are as follows:

a. LOW - Offender rejects responsibility for their actions and fails to recognize their problems. Does not disclose emotional states, display guilt or victim empathy with evidence indicating a high level of denial and cognitive distortions.

b. MODERATE - Offender may not fully accept responsibility for their actions but recognizes some of their problems. Displays some guilt and victim empathy with some evidence of denial and cognitive distortions.

c. HIGH - Offender accepts responsibility for their actions and recognizes their problems. Willing to self-disclose, displays guilt and victim empathy with evidence indicating a low level of cognitive distortions.

\section{Level of Motivation}

12. The criteria for reassessing motivation are:

a. recognition that a problem exists with lifestyle, behaviour and resulting consequences

b. level of comfort with problem and its impact on the offender's life

c. level of feeling of personal responsibility for the problem(s)

d. willingness to change, i.e. expression of wish to change, or of intention to fully participate in Correctional Plan

e. possession of skills and knowledge required to effect change in behaviour

f. level of external support from family, friends or other community members

g. past history related to demonstrated change.

13. The level of motivation can be assessed as:

a. LOW

- Offender strongly rejects the need for change or is unwilling to participate in recommended programs or other interventions.

\section{b. MEDIUM}

- Offender may not fully accept overall assessment but will participate in recommended programs or other interventions.

c. HIGH

- Offender is self-motivated and will actively address problem areas.

\section{Responsivity}


14. Responsivity is the presence of a characteristic(s) that influences the offender's capacity to benefit from the targeted intervention(s).

15. Responsivity indicators are identified as "Yes", "No" or "Unknown".

16. The following factors are used to assess an offender's responsivity:
a. language barriers interfere with learning, work or intervention
b. basic reading and/or writing skills are problematic
c. concentration problems are evident
d. introverted/shy
e. displays chronic antisociality
f. may have a learning disability
g. low self-esteem
h. intellectually disabled
i. may have other issues that would interfere with programming
j. suicide attempts/self-injury history
k. grief or loss
I. has unique cultural communication style
$\mathrm{m}$. expresses interest in strengthening culture, or
n. any other factor.

17. Overall responsivity is identified as "Yes" or "No".

\section{Engagement}

18. Engagement is the demonstrated willingness of an offender to:
a. actively participate in their assigned Correctional Plan
b. be free of criminal and gang activity while under sentence
c. display conduct that demonstrates respect
d. obey the penitentiary rules and/or supervision requirements.

19. Determine the offender's engagement in their Correctional Plan. In order to be considered engaged, the offender must obtain a rating of either moderate or high in both accountability and motivation.

20. Engagement is identified as "Yes" or "No".

\section{Reintegration Potential}

21. The reassessment of the reintegration potential is based on the analysis of the offender's progress and the following elements:
a. score on the Statistical Information on Recidivism Scale
b. level of intervention, based on static factors
c. level of intervention, based on dynamic factors
d. level of motivation
e. release history (number, type, success or failure). 
22. The reintegration potential should only change if the above have changed, and should be rated as:

a. LOW

- If the previous rating was LOW and there have been no significant changes in the above factors.

- If the previous rating was MEDIUM and there has been significant deterioration in the above factors.

b. MEDIUM

- If the previous rating was MEDIUM and there have been no significant changes in the above factors.

- If the previous rating was HIGH and there has been significant deterioration in the above factors.

- If the previous rating was LOW and there have been significant improvements in the above factors.

c. HIGH

- If the previous rating was HIGH and there have been no significant changes in the above factors.

- If the previous rating was MEDIUM and there have been significant improvements in the above factors.

\section{Annex D - Exchange of Information Agreement Between CSC and Passport Canada}

1. Under the terms of the Canadian Passport Order, Passport Canada can withhold passports from Canadian citizens who are subject to a term of imprisonment or forbidden to leave Canada or the territorial jurisdiction of a Canadian court by conditions imposed with respect to any temporary absence, work release, parole, statutory release or other similar regime of absence or release from a penitentiary or prison or any other place of confinement granted under the Corrections and Conditional Release Act, the Prison and Reformatories Act or any law made in Canada that contains similar release provisions [subparagraph 9(d)(i) of the Order].

2. Passport Canada will consider issuing a passport to an offender only following a PBC decision allowing the offender to travel internationally. As part of the documentation submitted to Passport Canada, the applicant is required to submit the PBC Decision Sheet. There is no supporting documentation required from the supervising Parole Officer, as it is the applicant's responsibility to provide Passport Canada with all required documentation.

3. In the event that Passport Canada requires confirmation or clarification of information submitted by the applicant, contact will be made with Passport Canada CSC liaison person at National Headquarters. If necessary, further follow-up with the supervising Parole Officer will be initiated by the CSC liaison person.

4. If Passport Canada approves the issuance of a passport, a limited validity passport will be issued for the period of time that the offender is permitted to travel by PBC, or for the minimum duration required to meet entry/exit requirements of the country of travel.

5. Where a limited validity passport is issued, the offender will sign an agreement with Passport Canada to return the passport to Passport Canada's Security Bureau upon return to Canada. The limited validity passport will be cancelled upon receipt by Passport Canada. A new passport will be required for each occasion that PBC allows the offender to travel internationally.

6. Given that limited validity passports will be issued for offenders approved for international travel, it remains important that submissions to PBC for this purpose specify as accurately as possible the duration of the offender's anticipated travel.

7. In cases where travel is approved by PBC for emergency or compassionate reasons, Passport Canada can issue passports within a short timeframe on a case-by-case basis.

8. Unless Passport Canada is advised that the condition requiring an offender to remain at all times in Canada has been relieved by PBC, a passport will be denied or a valid passport will be revoked.

9. Information from Passport Canada pertaining to a decision rendered is electronically communicated to CSC. 
10. The decision is in turn forwarded to the offender's current institutional or community Parole Officer via email. The notification includes the offender's name, FPS, date of decision and description. The description notes the decision rendered by Passport Canada (i.e. revoked, maintained, refused or issued).

11. Upon receipt of a decision by Passport Canada, the Parole Officer will be required to do the following:

a. print the decision

b. discuss the decision and any implications on the offender's risk management with their supervisor

c. discuss this information and Passport Canada's decision with the offender

d. complete a Casework Record under "Case Conference"

e. place the printed decision notification on the offender's Case Management file.

12. Every six months, Parole Officers will receive a report via email that will contain a list of all previous passport application decisions rendered with regard to offenders on their caseload.

13. A Parole Officer will not receive such a report where they do not have any offenders on their current caseload who have had a decision rendered on a passport application since the implementation of this initiative.

14. The foregoing does not apply to offenders with parole reduced status.

15. Offenders who have been granted parole reduced status are only subject to three standard conditions, namely paragraphs 161(1).(a) and (뜨)_(http://laws.justice.gc.ca/eng/regulations/SOR-92-620/section-161.html) and subparagraph 161(1).(g)(i)_(http://laws.justice.gc.ca/eng/regulations/SOR-92-620/section-161.html) of the CCRR (http://laws.justice.gc.ca/eng/regulations/SOR-92-620/index.html), which require them to report to their parole supervisor, obey the law and keep the peace, and notify the parole supervisor of any change in their address of residence. As such, they are not subject to paragraph 161(1)(b).(http://laws.justice.gc.ca/eng/regulations/SOR-92620/section-161.html) of the CCRR and therefore refusal or revocation of passport services would not be undertaken with reference to subparagraph 9(d)(i) of the Canadian Passport Order.

\section{Annex E - Correctional Plan Uptade - Community Progress - Report Guide}

The main purpose of the Correctional Plan Update is to report on the offender's progress in meeting their Correctional Plan objectives. When a Correctional Plan Update is prepared because release is being considered, the report includes the offender's proposed release plan and provides sufficient information to support a request for a Community Strategy.

When an Assessment for Decision is prepared, the Correctional Plan Update becomes a key document that both supports the assessment and recommendation as well as decision-making.

The report contains the following sections:

\section{Section 1 - Objectives/Expected Gains}

Case Status

Provide a brief synopsis of the case, including:

- the purpose of the update

- the offender profile, offence, offence history (which normally is unchanged from the intake Correctional Plan)

- deportation/immigration status (which normally is unchanged from the intake Correctional Plan).

If a referral is being made for cancellation, revocation and/or a change in conditions, or recommending a lay of information for an offender subject to a long-term supervision order:

- summarize the circumstances of the suspension and/or the reason a modification to conditions is recommended

- provide the offender's version if the report is related to a breach and/or increase in risk 
$11 / 20 / 2019$

Community Supervision

- include required additional information if a modification to conditions is recommended

- comment on whether the current circumstances merit a detention review if revocation is recommended

- comment on whether early discretionary release is recommended for a new period of statutory release.

\section{Ratings Reassessment and Correctional Plan Progress}

Using the Key Ratings Reassessment Framework (Annex C), update the relevant ratings, highlighting any changes that have occurred from the beginning of the sentence. Specify what changes, if any, have occurred concerning the Correctional Plan objectives, including court-ordered obligations, obtaining missing pieces of identification, commenting on the impact of programs and interventions, updated mental health information and relevant security information.

- Static Factor Assessment Rating

- Dynamic Factor Assessment Rating

- Accountability Rating

- Motivation Rating

- Responsivity Factor

- Engagement Factor

- Reintegration Potential Rating

- Psychological/Psychiatric Mental Health Information.

\section{Offence Cycle}

Update, if required, the offence cycle, and comment on any changes regarding the offender's understanding of the cycle.

\section{Correctional and Sentence Planning}

In consultation with the offender and other members of the Case Management Team:

- update the Correctional Plan goals and objectives, including the healing components, where required. The objectives will be individualized, structured, measurable, attainable, relevant and time-bound, while setting the framework for managing the sentence

- summarize the overall level of progress since the last review

- indicate the offender's plan for and/or progress in obtaining outstanding pieces of identification.

\section{Section 2 - Analysis of Current Request}

If a new Community Strategy is required, summarize the offender's release plan, including the following:

- the outstanding risk factors requiring intervention

- the community interventions that would be required to target the outstanding risk factors, and in the case of an Aboriginal offender following (or interested in following) a traditional path, also include any community cultural activities/ceremonies that will be undertaken which will help to assist the offender, as well as any interventions noted in a section 84 (http://laws-lois.justice.gc.ca/eng/acts/C-44.6/section-84.html) or section 84.1 (https://lawslois.justice.gc.ca/eng/acts/C-44.6/section-84.1.html) agreement

- specifics of the proposed release plan, including destination (and, if applicable, whether section 84 (http://lawslois.justice.gc.ca/eng/acts/C-44.6/section-84.html) or section 84.1 (https://laws-lois.justice.gc.ca/eng/acts/C44.6/section-84.1.html) of the CCRA applies and any resulting agreement with the offender's home community or alternately another Aboriginal community that engages in a section 84 (http://laws-lois. justice.gc.ca/eng/acts/C44.6/section-84.html) or section 84.1 (https://laws-lois.justice.gc.ca/eng/acts/C-44.6/section-84.1.html) with the offender), employment, accommodation, family support. If the proposed accommodation is to reside at an other location for day parole, confirm: 
- the existence of a Community Assessment of this location. In the event that none exist, a Community Assessment will be required pursuant to $\underline{\mathrm{CD}} 715-3$ - Community Assessment (https://www.csc-scc.gc.ca/acts-andregulations/715-3-cd-eng.shtml).

- if the community resource agrees to house the offender and has an understanding of their role and responsibilities in supporting and facilitating the offender's release

- determine the curfews and time to be spent at the location; this must be established within the context of the offender's progress in meeting the objectives of the Correctional Plan

- victim considerations, including possible restrictions on travel, requests from victims for non-association conditions, sentencing judge comments.

Date modified:

2019-04-04 


\section{Appendix C: CD 715-2- Post-Release Decision Process}

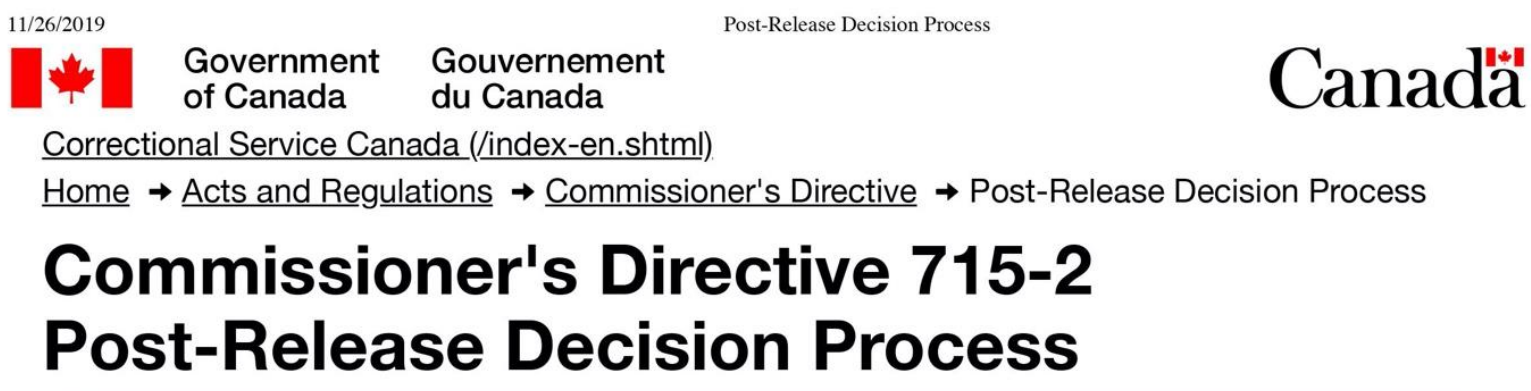

\begin{tabular}{|l|}
\hline Commissioner's Directive \\
Number: $715-2$ \\
In Effect: $2019-04-15$ \\
Related links \\
Policy Bulletin 633 (633-pb-en.shtml) \\
\hline
\end{tabular}

\section{Authorities}

- Corrections and Conditional Release Act (http://laws-lois.justice.gc.ca/eng/acts/C-44.6/) (CCRA), sections 3 (http://laws-lois.justice.gc.ca/eng/acts/C-44.6/section-3.html), 3.1 (http://laws-lois.justice.gc.ca/eng/acts/C-44.6/section-3.1.html), 4 (http://lawslois.justice.gc.ca/eng/acts/C-44.6/section-4.html), 15.1 (http://lawslois.justice.gc.ca/eng/acts/C-44.6/section-15.1.html), 26 (http://lawslois.justice.gc.ca/eng/acts/C-44.6/section-26.html), 81 (https://lawslois.justice.gc.ca/eng/acts/C-44.6/section-81.html), $\underline{84}$ (https://lawslois.justice.gc.ca/eng/acts/C-44.6/section-84.html), 84.1 (https://lawslois.justice.gc.ca/eng/acts/C-44.6/section-84.1.html), 131(4)_(https://lawslois.justice.gc.ca/eng/acts/C-44.6/section-131.html), 133 (http://lawslois.justice.gc.ca/eng/acts/C-44.6/section-133.html), 133(3.1)_(https://lawslois.justice.gc.ca/eng/acts/C-44.6/section-133.html), 133(3.2)_(https://lawslois.justice.gc.ca/eng/acts/C-44.6/section-133.html), 133(4.4)_(https://lawslois.justice.gc.ca/eng/acts/C-44.6/section-133.html), 133(ㄱ)_(https://lawslois.justice.gc.ca/eng/acts/C-44.6/section-133.html) 134.1 (http://lawslois.justice.gc.ca/eng/acts/C-44.6/section-134.1.html), 134.1(2)_(https://lawslois.justice.gc.ca/eng/acts/C-44.6/section-134.1.html), 134.1(5)_(https://lawslois.justice.gc.ca/eng/acts/C-44.6/section-134.1.html), 134.1(2.1)_(https://lawslois.justice.gc.ca/eng/acts/C-44.6/section-134.1.html), 135 (http://lawslois.justice.gc.ca/eng/acts/C-44.6/section-135.html), 135.1, 135(1.1), 135(1.2)_http://lawslois.justice.gc.ca/eng/acts/C-44.6/section-135.1.html)and 137.1 (http://lawslois.justice.gc.ca/eng/acts/C-44.6/section-137.1.html). 


\section{Purpose}

To provide direction for post-release decision making and establish the procedures for the monitoring, intervention and assessment of the offender's progress against the Correctional Plan

\section{Applications}

Applies to staff involved in supervision, case preparation and the post-suspension process

\section{Contents}

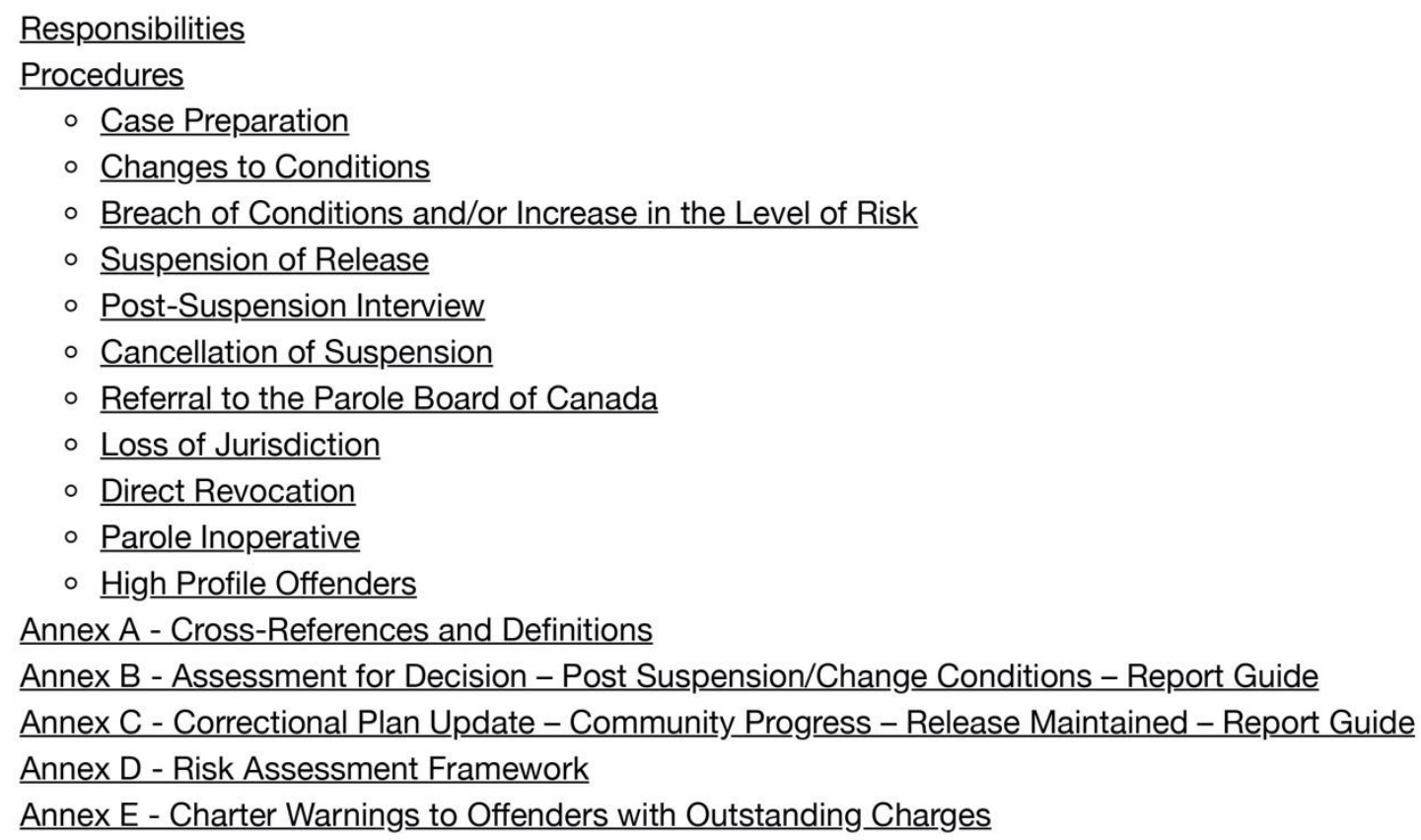

\section{Responsibilities}

1. Following the offender's suspension, the Regional Deputy Commissioner will immediately report a loss of jurisdiction and any subsequent release of the offender to the Assistant Commissioner, Correctional Operations and Programs.

2. The District Director will ensure:

a. procedures for High Profile Offenders are followed pursuant to Commissioner's Directive (CD) 701 - Information Sharing_(https://www.csc-scc.gc.ca/acts-and-regulations/701cd-eng.shtml). 
b. procedures outlined in $\mathrm{CD} 784$ - Victim Engagement (https://www.csc-scc.gc.ca/actsand-regulations/784-cd-en.shtml) are followed.

3. The Area Director will ensure processes are in place to:

a. share information with the Parole Board of Canada (PBC) within timeframes prescribed by policy

b. issue warrants.

4. The Parole Officer will:

a. process offender applications and reviews for conditional release within prescribed timeframes

b. complete post-suspension reviews within legal timeframes

c. ensure that information is provided to the Victim Services Unit pursuant to $\mathrm{CD} 784$ Victim Engaggement (https://www.csc-scc.gc.ca/acts-and-regulations/784-cd-en.shtml).

d. consider victim information, as well as any victim statements provided pursuant to subsections 133(3.1)_http://laws-lois.justice.gc.ca/eng/acts/C-44.6/section133.html)and 134.1(2.1)_(http://laws-lois.justice.gc.ca/eng/acts/C-44.6/section134.1.html) of the CCRA, for the purpose of case preparation for pre-release decisionmaking processes.

\section{Procedures}

5. Following the release of an offender to the community, the decision-making process will be used in the following situations:

a. case preparation

b. changes to conditions

c. breach of conditions or any other situation that gives reason to believe the risk level has increased

d. suspension of conditional release, including automatic suspension

e. direct revocation.

\section{Case Preparation}

6. For case preparation decisions, the Parole Officer will:

a. update the information on the offender's progress as outlined in Annex E of CD 715-1Community Supervision (715-1-cd-en.shtml). 
b. if required, request a Community Strategy and a Community Assessment (if the offender is remaining in the same supervision area, release plans can be presented in the Assessment for Decision)

C. if a day parole to an other location is being considered as a period of transition from a community-based residential facility into the community, confirm the existence of a Community Assessment at the location. In the event that none exist, a Community Assessment will be required pursuant to $\underline{\mathrm{CD}} 715-3$ - Community Assessment (715-3-cden.shtml).

d. complete an Assessment for Decision addressing the new release type pursuant to CD 712-1 - Pre-Release Decision-Making_(712-1-cd-en.shtml).

e. share documentation with the PBC within the following timeframes:

i. six weeks prior to the expiration of day parole

ii. three months prior to warrant expiry for offenders in the community who are subject to a long-term supervision order

f. when a condition to reside in a Community Correctional Centre on statutory release is recommended or imposed, the Parole Officer will request approval from the Assistant Deputy Commissioner, Correctional Operations, using the form Regional Consent Statutory Release with Residency (CSC/SCC 1218) (see subsections 131(4)_(http://lawslois.justice.gc.ca/eng/acts/C-44.6/section-131.html) and 133(4.4)(http://lawslois.justice.gc.ca/eng/acts/C-44.6/section-133.html) of the CCRA. This is not required when recommending residency for offenders subject to a long-term supervision order

g. ensure information pursuant to section 26 (http://laws-lois.justice.gc.ca/eng/acts/C44.6/section-26.html) of the CCRA is provided to the Victim Services Unit (refer to Annex $\mathrm{D}$ of $\mathrm{CD} 784$ - Victim Engagement (https://www.csc-scc.gc.ca/acts-andregulations/784-cd-en.shtml))

h. if there is a victim notification required flag, request victim information from the Victim Services Unit, as well as any victim statements pursuant to subsections $\underline{133}(\underline{3.1})$ (http://laws-lois.justice.gc.ca/eng/acts/C-44.6/section-133.html)and 134.1(2.1) (http://laws-lois.justice.gc.ca/eng/acts/C-44.6/section-134.1.html) of the CCRA.

\section{Changes to Conditions}

7. The Parole Officer may recommend to the PBC that release conditions be imposed, modified or removed when there is a change in the level of risk or upon request of the offender.

8. If a Parole Officer has made a decision to recommend a change to the release conditions, an Assessment for Decision will be completed (see Annex B).

9. The Parole Officer will contact the Victim Services Unit to advise of a recommendation to remove or modify a condition that was imposed to protect the victim, and consider victim's 
concerns, if any, pursuant to subsections 133(7)_(http://laws-lois.justice.gc.ca/eng/acts/C44.6/section-133.html) and 134.1(5)_(http://laws-lois.justice.gc.ca/eng/acts/C-44.6/section134.1.html) of the CCRA.

10. If an offender has requested a change to their release conditions and the Parole Officer has made a decision to not recommend the change, this will be documented in a Casework Record.

11. The Parole Officer will inform the offender that they are entitled to submit written comments to the PBC.

12. If the offender submits written comments to the PBC, the Parole Officer will complete an Assessment for Decision (see Annex B).

\section{Breach of Conditions and/or Increase in the Level of Risk}

13. The Parole Officer must immediately inform a person with designated authority for suspension pursuant to sections 135 (http://laws-lois.justice.gc.ca/eng/acts/C-44.6/section-135.html)and 135.1 (http://laws-lois.justice.gc.ca/eng/acts/C-44.6/section-135.1.html)of the CCRA when:

a. there is a breach of standard or special conditions (this includes arrest without warrant)

b. information indicates a potential increase in risk, or

c. the offender has refused or is unable to provide a required urine sample.

14. The Parole Officer and the person with designated authority will consider the factors outlined in the Risk Assessment Framework (Annex D) in determining the most appropriate intervention among the following:

a. suspension of release

b. additional treatment or programming to address dynamic risk factors

c. additional control measures (e.g. increased reporting, curfews, special instructions or direction)

d. disciplinary interview

e. amendments to special conditions

f. suitable cultural alternatives or interventions.

15. These factors will also be considered in determining whether a warrant of suspension of conditional release or long-term supervision order should be issued if the offender has breached a condition and a police officer has arrested the offender without a warrant, pursuant to section 137.1 (http://laws-lois.justice.gc.ca/eng/acts/C-44.6/section-137.1.html)of the CCRA.

16. If a decision is made to not suspend the offender's release, the Parole Officer will update the Correctional Plan within 14 days, as outlined in Annex C. Reports pertaining to a positive 
urinalysis or inability/refusal to provide a urine sample will be shared with the PBC.

\section{Suspension of Release}

17. A conditional release or a long-term supervision order can be suspended for the following reasons, pursuant to sections 135 (http://laws-lois.justice.gc.ca/eng/acts/C-44.6/section135.html)and 135.1 (http://laws-lois.justice.gc.ca/eng/acts/C-44.6/section-135.1.html)of the CCRA:

a. when a breach of conditions has occurred

b. to prevent a breach of conditions, or

c. to protect society.

18. The suspension process will be initiated when:

a. an offender's risk is assessed as unmanageable in the community, or

b. in the case of parole or statutory release, the offender receives an additional sentence other than a conditional or intermittent sentence (automatic suspension), pursuant to subsections 135(1.1)_(http://laws-lois.justice.gc.ca/eng/acts/C-44.6/section-135.html). and 135 (1.2)_(http://laws-lois.justice.gc.ca/eng/acts/C-44.6/section-135.html) of the CCRA.

19. Offenders who are released from a federal institution directly to other secure custody by way of a court order (e.g., remand, hospital) are not deemed to have benefited from release and are not subject to special or standard conditions of release. There is no authority to issue a suspension warrant for behaviours that did not occur in the community and the provisions of automatic suspension also do not apply.

20. The person with designated authority will ensure that a warrant of suspension of conditional release or long-term supervision order or a warrant of apprehension and recommitment (in the case of automatic suspension) is issued. Significant safety concerns (e.g., suicide risk, family violence, gang affiliation, mental health issues) will be communicated to police.

21. The Parole Officer will contact the police and, if necessary, the Security Intelligence Officer to provide all relevant information to assist in the timely apprehension of the offender.

22. A person with designated authority can withdraw the warrant if the warrant has not been executed. If the PBC directed the suspension, the PBC must approve any withdrawal.

23. The person with designated authority will notify the assigned Sentence Management Officer of the releasing institution when a warrant or order of cancellation is issued/executed within one working day.

24. The District Director or designate of the operational unit will ensure there is a system in place that guarantees ongoing efforts are made to locate an offender unlawfully at large. This may 
include contact with the offender's family, associates and other agencies. These efforts will be documented.

25. Where it is known that a criminal investigation is in progress, agreement from the police will be sought prior to contacting individuals who may be aware of the offender's location.

26. Cases of offenders unlawfully at large may be referred to the Security Intelligence Officer.

27. Following the execution of the warrant, the Parole Officer or, if after hours, the National Monitoring Centre will immediately forward the Notification to Detention Centre Following Execution of a Warrant (CSC/SCC 1338) to the Detention Centre or police authority holding the offender.

28. When the offender is apprehended in an area outside the boundaries of the supervising office, the Parole Officer will ensure file information is up to date within five working days of the execution of the warrant of suspension of conditional release or long-term supervision order or warrant of apprehension and recommitment, including the Correctional Plan. The supervising office will ensure that the office responsible for the area where the offender is apprehended is advised of the apprehension and any need to complete post-suspension documentation.

29. The Parole Officer assuming responsibility for the case in the location where the offender was apprehended will complete any post-suspension documentation. Close communication between both Parole Officers will be maintained.

30. In cases where the offender had a condition to reside in a Community Correctional Centre (CCC) and whose conditional release was suspended within the first 45 days, the case may be reassigned to the closest parole office following a case conference between the respective Parole Officer Supervisors/CCC Managers. This process excludes offenders subject to a longterm supervision order.

\section{Post-Suspension Interview}

31. If the offender is facing new criminal charges, the Parole Officer must provide warnings to the offender (see Annex E).

32. The Parole Officer will conduct a post-suspension interview with the offender to:

a. advise the offender of the details of the suspension, including the reasons for the suspension based on the criteria found in section 135 (http://lawslois.justice.gc.ca/eng/acts/C-44.6/section-135.html) or 135.1 (http://lawslois.justice.gc.ca/eng/acts/C-44.6/section-135.1.html).of the CCRA, and provide them an opportunity to explain their conduct

b. in the case of an automatic suspension pursuant to subsection 135(1.1)_(http://lawslois.justice.gc.ca/eng/acts/C-44.6/section-135.html) of the CCRA, advise the offender that the case must be referred to the PBC 
c. discuss alternatives to a return to custody, including changes to the Correctional Plan

d. inform the offender of their rights, including the right to submit written representations if the case will be referred to the PBC

e. advise the offender of their rights to be informed at least 15 days in advance of the review of the relevant information that the PBC will take into consideration.

33. Following the post-suspension interview, the Parole Officer will assess information related to the offender's supervision performance, circumstances of suspension, risk presented to the community and any realistic new release plans that are consistent with the offender's Correctional Plan.

34. If the offender incurs a new conviction and remains in the community (e.g., receives a noncustodial sentence), the community Parole Officer will update the Criminal Profile and, if necessary, the Statistical Information on Recidivism (SIR), and inform the assigned Sentence Management Officer of the releasing institution. If the offender (including a temporarily detained offender) is returned to the penitentiary, the institutional Parole Officer will update the Criminal Profile.

\section{Cancellation of Suspension}

35. The most common circumstances for cancelling a warrant of suspension of conditional release or long-term supervision order include the following:

a. new information modifies the risk assessment

b. new information modifies the reasons for the suspension

c. a new release plan or new conditions, that are consistent with the offender's Correctional Plan, which reduce the risk to the community to an acceptable level

d. loss of jurisdiction due to late referral.

36. The person with designated authority can cancel the suspension except when:

a. the suspension was issued by the PBC

b. the offender was automatically suspended pursuant to subsection 135(1.1)_(http://lawslois.justice.gc.ca/eng/acts/C-44.6/section-135.html) of the CCRA, or

c. the case has already been referred to the PBC.

37. The person with designated authority can cancel a suspension within the following timeframes (or a shorter period as directed by the PBC):

a. in the case of an offender serving a sentence of two years or more, within 30 days of recommitment

b. in the case of an offender serving a sentence of less than two years, within 14 days of recommitment. This also applies to an offender whose long-term supervision order has 
been interrupted by a sentence of less than two years.

38. The suspension period will be limited to the time required to investigate and prepare alternate release plans.

39. The cancellation order (or a facsimile) will be forwarded to the head of the institution/facility holding the offender to authorize the prompt release of the offender.

40. When the suspension is cancelled by CSC, the Parole Officer will update the Correctional Plan within 14 days (see Annex C). Reports pertaining to a positive urinalysis or inability/refusal to provide a urine sample will be shared with the PBC.

41. When a modification of conditions is being recommended as part of the release plan following a cancellation, the Parole Officer will complete an Assessment for Decision.

\section{Referral to the Parole Board of Canada}

42. If an offender's suspension is not cancelled by CSC, the Parole Officer will refer the case to the PBC within the following timeframes (or a shorter period as directed by the PBC):

a. in the case of an offender serving a sentence of two years or more, within 30 days of recommitment

b. in the case of an offender serving a sentence of less than two years, within 14 days of recommitment. This also applies to an offender whose long-term supervision order has been interrupted by a sentence of less than two years.

43. The referral will include:

a. the Assessment for Decision (as outlined in Annex B)

b. the Reasons for Suspension

c. the most recent Correctional Plan Update (as outlined in Annex E of CD 715-1 Community Supervision (https://www.csc-scc.gc.ca/acts-and-regulations/715-1-cden.shtml))

d. the Community Assessment (if required).

44. The Assessment for Decision will include a statement regarding detention criteria.

45. If a referral for detention is being considered, refer to $\mathrm{CD} 712-2$ - Detention (https://www.cscscc.gc.ca/acts-and-regulations/712-2-cd-eng.shtml).

46. In the case of an automatic suspension where cancellation is being recommended, the Parole Officer will consult Sentence Management to verify the impact on sentence calculation in light of an additional sentence.

47. If a revocation is being recommended and the new statutory release date will be within nine months from the date of the submission to the PBC, the Parole Officer will address new 
release plans, including any need for special conditions and early discretionary release, in the Assessment for Decision.

48. Upon receipt of new information which would change the recommendation, the original completing operational unit will complete a new Assessment for Decision.

49. If the offender has been transferred to a federal institution and the new information does not change the recommendation, the Parole Officer receiving the information will complete an Addendum to the Assessment for Decision, following consultation with their counterpart.

\section{Loss of Jurisdiction}

50. A loss of jurisdiction will occur, making it necessary to release the offender immediately, if:
a. the Assessment for Decision does not include an assessment of the case and a recommendation, and the specified timeframe has expired, or
b. the referral is not submitted to the PBC within the specified timeframes.

51. If a loss of jurisdiction occurs, the Area Director will advise the local police, the PBC (if required), the District Director, and the assigned Sentence Management Officer at the institution where the offender was incarcerated at the time of release.

52. The District Director will immediately advise the Regional Deputy Commissioner of a loss of jurisdiction. The memorandum will include:
a. summary of offender profile and criminal history
b. description of the events leading to the loss of jurisdiction
c. offender's current location and supervision status
d. risk presented by the offender to the community and actions being taken to mitigate the risk
e. media attention
f. decision by the PBC
g. action being taken regarding policy compliance.

\section{Direct Revocation}

53. The PBC may directly revoke a conditional release when:
a. no warrant of suspension of conditional release was issued
b. the issued warrant of suspension of conditional release was not executed
c. CSC is recommending a change of conditions, or
d. CSC is recommending day parole be continued and the PBC disagrees. 
54. If the PBC directly revokes an offender's release when no warrant of suspension of conditional release was issued or executed, the person with designated authority will issue a warrant of apprehension and recommitment on revocation or, when not in custody, a warrant of recommitment on revocation.

55. A post-revocation interview will be held following the apprehension of the offender. If the direct revocation occurred when no recommendation had been submitted to the PBC, the Parole Officer will complete an Assessment for Decision within 30 days and recommend that the revocation be cancelled or confirmed.

56. If the revocation occurred subsequent to a recommendation, the Parole Officer will complete:

a. an Addendum when no information is received or when new information is received (including in the course of the post-revocation interview) which does not alter a previous recommendation submitted to the $\mathrm{PBC}$, or

b. an Assessment for Decision when new information is received which alters a previous recommendation submitted to the PBC.

57. The offender's rights with respect to direct revocation activities are the same as with postsuspension activities.

\section{Parole Inoperative}

58. When parole or statutory release has been made inoperative (the offender is no longer eligible for release), the person with designated authority will issue a warrant of recommittal.

59. Following the execution of the warrant of recommittal, the Parole Officer will advise the PBC of the circumstances of the recommittal by updating the Correctional Plan within 14 days.

60. The offender's release will resume at the new eligibility date unless the PBC cancels or terminates parole.

\section{High Profile Offenders}

61. If a review involves an offender with a high profile offender flag, the procedures regarding high profile offenders will be followed pursuant to $\underline{\mathrm{CD}} 701$ - Information Sharing_(https://www.cscscc.gc.ca/acts-and-regulations/701-cd-eng.shtml).

Commissioner,

Original signed by:

Anne Kelly 
11/26/2019 Post-Release Decision Process

\section{Annex A - Cross-References and Definitions}

\section{Cross-References}

CD 001 - Mission, Values and Ethics Framework of the Correctional Service of Canada (https://www.csc-scc.gc.ca/acts-and-regulations/001-cd-en.shtml). CD 003 - Peace Officer Designations (https://www.csc-scc.gc.ca/acts-and-regulations/003-cdeng.shtml).

CD 701 - Information Sharing_(https://www.csc-scc.gc.ca/acts-and-regulations/701-cd-eng.shtml).

CD 702 - Aboriginal Offenders (https://www.csc-scc.gc.ca/acts-and-regulations/702-cd-eng.shtml).

CD 703 - Sentence Management (https://www.csc-scc.gc.ca/acts-and-regulations/703-cdeng.shtml).

CD 705-6 - Correctional Planning and Criminal Profile (705-6-cd-en.shtml).

CD 712-1 - Pre-Release Decision-Making_(712-1-cd-en.shtml).

GL 712-1-1 - CCRA Sections 84 and 84.1 Release Planning Process (https://www.csc-

scc.gc.ca/acts-and-regulations/712-1-1-gl-en.shtml).

CD 712-2 - Detention (https://www.csc-scc.gc.ca/acts-and-regulations/712-2-cd-eng.shtml).

CD 712-3 - Parole Board of Canada Reviews (https://www.csc-scc.gc.ca/acts-and-

regulations/712-3-cd-eng.shtml).

CD 712-4 - Release Process (712-4-cd-en.shtml).

CD 712-5 - Pre-Release Case Preparation for Provincial/Territorial Offenders and Federal Offenders Incarcerated in Provincial/Territorial Facilities (https://www.csc-scc.gc.ca/acts-and-

regulations/712-5-cd-eng.shtml).

CD 714 - Community Correctional Centre Standards (https://www.csc-scc.gc.ca/acts-andregulations/714-cd-eng.shtml).

CD 715 - Community Supervision Framework (715-cd-en.shtml).

CD 715-1 - Community Supervision (715-1-cd-en.shtml).

CD 715-3 - Community Assessments (715-3-cd-en.shtml).

CD 718 - Designation of Persons with Authority for Suspension (https://www.csc-scc.gc.ca/actsand-regulations/718-cd-eng.shtml).

CD 719 - Long-Term Supervision Orders (https://www.csc-scc.gc.ca/acts-and-regulations/719-cdeng.shtml).

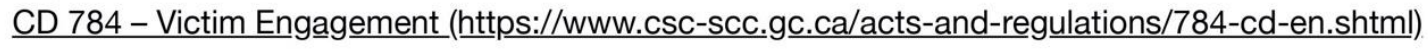

Aboriginal Social History Tool

\section{Definitions}

Aboriginal social history: the various circumstances that have affected the lives of most Aboriginal peoples in Canada. Considering these circumstances may result in alternate options or solutions and applies only to Aboriginal offenders (not to non-Aboriginal offenders who choose to follow the 
Aboriginal way of life). These circumstances include the following (note that this is not an exhaustive list):

- effects of the residential school system

- sixties scoop into the adoption system

- effects of the dislocation and dispossession of Inuit people

- family or community history of suicide

- family or community history of substance abuse

- family or community history of victimization

- family or community fragmentation

- level or lack of formal education

- level of connectivity with family/community

- experience in the child welfare system

- experience with poverty

- loss of or struggle with cultural/spiritual identity.

Day parole to an other location: a location that provides accommodation to an offender on day parole, other than a penitentiary, community-based residential facility or provincial institution, as set out in subsection 99(1) of the CCRA. This includes a private home or private facility, which has not been designated as a community-based residential facility.

Victim information: victim-related information, provided either in writing or verbally, for consideration as part of the overall case management process. This would include information provided by the victim and/or other sources. This also includes the court Victim Impact Statement, when available.

Victim statement: a written statement provided by the victim, pursuant to subsection $133(\underline{3.1})$ (http://laws-lois.justice.gc.ca/eng/acts/C-44.6/section-133.html) or 134.1(2.1)_(http://lawslois.justice.gc.ca/eng/acts/C-44.6/section-134.1.html) of the CCRA, describing the harm done or loss suffered as a result of the commission of an offence and the continuing impact on them including any safety concerns - or commenting on the possible release of the offender. The statement will be considered in the pre-release decision-making process for consideration to impose conditions to protect the victim including a condition that the offender abstain from having any contact with the victim or from going to any specified place.

\section{Annex B - Assessment for Decision - Post- Suspension/Change Conditions - Report Guide}

\section{Preamble}

The Overall Assessmentmust provide the decision-maker with an assessment that supports a recommendation concerning release and/or special conditions. The assessment is based upon information and analysis derived from other key case management documents but, in particular, the 
Criminal Profile, Correctional Plan or Correctional Plan Update and the Community Strategy. Using this information, the assessment must consider the relationship among the various factors as well as their relative weight in formulating and justifying a recommendation.

The assessment must contain information that is up to date, relevant, accurate and complete. It must be balanced, containing both positive and negative aspects of the case. The assessment must reconcile the discordant information while providing a recommendation with a clear rationale and justification based upon the Risk Assessment Framework (Annex D). For Aboriginal offenders, the assessment must be made within the context of their Aboriginal Social History as outlined in Annex H of CD 705-6 - Correctional Planning and Criminal Profile (705-6-cd-en.shtml).

Conceptually, there are two sets of related questions that the assessment must address:

\section{Has the offender's Correctional Plan been successfully implemented and has it been effective?}

In other words, what changes in the offender's attitudes and/or behaviour have occurred since the beginning of the sentence and what effect have these changes had on the offender's risk level? Has the offender been motivated to change and been engaged in the correctional planning process? How does the offender demonstrate their understanding of their crime cycle? In the case of an Aboriginal offender who has been engaged in Pathways or cultural interventions, what changes are observable?

\section{Is the proposed release plan and supervision strategy adequate to address the offender's outstanding risk, support their reintegration and ensure a safe release?}

In other words, how will the available programs and/or interventions mitigate risk? If there is a Healing Plan on file, how has the offender been engaged in the plan? What other positive community supports (including family, friends, Aboriginal community, employers, volunteers, agencies) are available? Are there negative aspects to consider in the release environment? Can the specific areas of risk be effectively managed by the Parole Officer and others in the Case Management Team? How can the offender's behaviour and special conditions be effectively monitored? How do victim concerns impact the release plan?

\section{Assessment for Decision Report Headings}

State the purpose for the assessment and identify any relevant documentation that must be read in conjunction with it, including the Criminal Profile Report, the most recent Correctional Plan Update and the most recent Community Strategy, if applicable.

The following areas must be evaluated as well as their relative weight in formulating and justifying a recommendation. Explain how each of these relevant factors aggravates risk, mitigates risk or has no impact on risk, and discuss the cumulative impact of these factors against the actuarial 
scores/results.

The Pre-/Post-Release Assessment Decision Tool should be consulted for a comprehensive listing of the factors that are relevant when completing the Overall Assessment.

\section{Criminal History and Conditional Release History}

Assess the relevant aspects of the criminal history and conditional release history.

If the offender is Aboriginal, explain how their Aboriginal social history. has impacted their criminal history and how the historical treatment of Aboriginal people has affected the offender's community, the family and the offender. Assess the Aboriginal social history - including effects of the residential school system - to determine what culturally appropriate/restorative measures are available and/or will be put in place in the community to assist the offender.

\section{Institutional/Community Behaviour}

Assess the offender's overall behaviour in the institutional or community setting.

How has the offender's Aboriginal Social History. impacted their overall behaviour in the institution or community setting? Additionally, for Aboriginal offenders, are they working with an Elder or engaging in cultural interventions/pursuits? If so, what are the noted overall impacts of their engagement?

\section{Correctional Plan Progress and Offender Engagement}

Assess the degree of impact of the programs and other interventions that have been provided on each of the targeted dynamic risk factors. The key consideration is whether there has been a reduction in risk.

For Aboriginal offenders, how did programs and interventions take account of the offender's culture and background, including Elder involvement and interest in CCRA section $\underline{81}$ (https://lawslois.justice.gc.ca/eng/acts/C-44.6/section-81.html), 84 (https://laws-lois.justice.gc.ca/eng/acts/C44.6/section-84.html) or 84.1 (https://laws-lois.justice.gc.ca/eng/acts/C-44.6/section-84.1.html). options?

\section{Detention Criteria}

If revocation is recommended, comment on whether the current circumstances of violation merits a detention review.

\section{Release Plan and Supervision Strategy}


11/26/2019 Post-Release Decision Process

Assess the offender's new release plan, highlighting strengths and weaknesses as well as the proposed supervision strategy, if applicable.

For Aboriginal offenders who are interested in following a traditional path, what culturally appropriate programming is available, including involvement of Elders, Aboriginal Community Liaison Officers, home community or different Aboriginal community (sections 81 (https://lawslois.justice.gc.ca/eng/acts/C-44.6/section-81.html), 84 (https://laws-lois.justice.gc.ca/eng/acts/C44.6/section-84.html) and 84.1 (https://laws-lois.justice.gc.ca/eng/acts/C-44.6/section-84.1.html) of the CCRA)? What are the appropriate resources available in the community? If, for any reason, their home community is not considered suitable, how would a different Aboriginal community provide a higher level of support? Is there a section 84 (http://laws-lois.justice.gc.ca/eng/acts/C-44.6/section84.html) or section 84.1 (https://laws-lois.justice.gc.ca/eng/acts/C-44.6/section-84.1.html) in place? Would a plan involving placement at a section 81 (http://laws-lois.justice.gc.ca/eng/acts/C44.6/section-81.html) facility assist in mitigating risk? If a section 84 (http://lawslois.justice.gc.ca/eng/acts/C-44.6/section-84.html) or section 84.1 (https://lawslois.justice.gc.ca/eng/acts/C-44.6/section-84.1.html) is in place, can we leverage existing resources to help mitigate risk? Has consultation been completed with the Elder and ACDO, the offender most recently worked with?

Assess victim information and indicate how the release plan will mitigate any identified risk. Pursuant to subsection 133(3.2) of the CCRA, if a victim statement has been provided pursuant to subsections 133(3.1)_(http://laws-lois.justice.gc.ca/eng/acts/C-44.6/section-133.html) and 134.1(2.1)_(http://laws-lois.justice.gc.ca/eng/acts/C-44.6/section-134.1.html) of the CCRA, consider whether any conditions are reasonable and necessary to protect the victim; the reasons to recommend a condition or not must be documented. If such a statement has not been provided, nothing precludes the author from recommending any conditions pursuant to subsections $\underline{133}(\underline{3})$. (http://laws-lois.justice.gc.ca/eng/acts/C-44.6/section-133.html)and 134.1(2)_(http://lawslois.justice.gc.ca/eng/acts/C-44.6/section-134.1.html) of the CCRA.

If recommending the removal or modification of a condition which was imposed to protect a victim, consider every victim's concerns pursuant to subsections $\underline{133}$ (ㄱ)_(http://lawslois.justice.gc.ca/eng/acts/C-44.6/section-133.html) and 134.1(흐_(http://lawslois.justice.gc.ca/eng/acts/C-44.6/section-134.1.html) of the CCRA.

If a case is made for a residency condition for an offender on statutory release, particular care must be taken to ensure that the legislated criteria are met. It is not enough to state that residency will be beneficial; the Parole Officer must be able to demonstrate that, in the absence of a residency condition, the offender will present an undue risk to society. This requires both establishing how the residency condition will ensure that there is not an undue risk and demonstrating that other possible supervision strategies are insufficient to manage risk.

If a case is made for a residency condition for an offender subject to a long-term supervision order, the Parole Officer must demonstrate that the condition is both reasonable and necessary in order to protect society and to facilitate the successful reintegration into society of the offender. Residency 
conditions for an offender subject to a long-term supervision order may only be imposed for a maximum of 365 days.

For Aboriginal offenders, consider the identified need areas, within the context of the offender's Aboriginal Social History, and how the recommendation will address these needs. When recommending special conditions, make links between the need for a certain condition and the offender's Aboriginal Social History.

\section{Recommendation(s)}

\section{Annex C - Correctional Plan Update-Community Progress - Release Maintained - Report Guide}

The main purpose of the Correctional Plan Update is to report on the offender's progress in meeting their Correctional Plan objectives. When a Correctional Plan Update is prepared because release is being considered, the report includes the offender's proposed release plan and provides sufficient information to support a request for a Community Strategy.

When an Assessment for Decision is prepared, the Correctional Plan Update becomes a key document that both supports the assessment and recommendation as well as decision making.

The report contains the following sections:

\section{Section 1 - Objectives/Expected Gains}

\section{Case Status}

Provide a brief synopsis of the case, including:

- the purpose of the update

- the offender profile, offence, offence history (which normally is unchanged from the intake Correctional Plan)

- deportation/immigration status (which normally is unchanged from the intake Correctional Plan)

- the circumstances of the suspension/increase in risk

- the offender's version if the report is related to a breach and/or increase in risk.

For Aboriginal offenders, consider the above synopsis and circumstances within the context of the offender's Aboriginal Social History.

\section{Ratings Reassessment and Correctional Plan Progress}


Using the Key Ratings Reassessment Framework in Annex C of $\underline{C D} 715-1$ - Community. Supervision (715-1-cd-en.shtml), update the relevant ratings, highlighting any changes that have occurred from the beginning of the sentence. Specify what changes, if any, have occurred concerning the Correctional Plan objectives, including court-ordered obligations, obtaining missing pieces of identification, commenting on the impact of programs and interventions, updated mental health information and relevant security information. For Aboriginal offenders, when providing a description of changes that have occurred, do so within the context of the offender's Aboriginal Social History.

- Static Factor Assessment Rating

- Dynamic Factor Assessment Rating

- Accountability Rating

- Motivation Rating

- Responsivity Factor

- Engagement Factor

- Reintegration Potential Rating

- Psychological/Psychiatric Mental Health Information.

\section{Offence Cycle}

Update, if required, the offence cycle, and comment on any changes regarding the offender's understanding of the cycle. For Aboriginal offenders, explain the offence cycle within the context of their Aboriginal Social History.

\section{Correctional and Sentence Planning}

In consultation with the offender and other members of the Case Management Team:

- update the Correctional Plan goals and objectives, including the healing components, where required. The objectives will be individualized, structured, measurable, attainable, relevant and time-bound, while setting the framework for managing the sentence

- summarize the overall level of progress since the last review

- indicate the offender's plan for and/or progress in obtaining outstanding pieces of identification.

\section{Section 2 - Analysis of Current Request}

If a new Community Strategy is required, summarize the offender's release plan, including the following:

- the outstanding risk factors requiring intervention

- the community interventions that would be required to target the outstanding risk factors, and in the case of an Aboriginal offender following (or interested in following) a traditional path, also include any community cultural activities/ceremonies that will be undertaken which will 
help to assist the offender, as well as any interventions noted in a section 84 (http://lawslois.justice.gc.ca/eng/acts/C-44.6/section-84.html)_or section 84.1 (https://lawslois.justice.gc.ca/eng/acts/C-44.6/section-84.1.html)_agreement

- specifics of the proposed release plan, including destination (and, if applicable, whether section 84 (http://laws-lois.justice.gc.ca/eng/acts/C-44.6/section-84.html) or 84.1 (https://laws-lois.justice.gc.ca/eng/acts/C-44.6/section-84.1.html) of the CCRA applies and any resulting agreement with the offender's home community or alternately another Aboriginal community that engages in a section 84 (http://laws-lois.justice.gc.ca/eng/acts/C44.6/section-84.html) or section 84.1 (https://laws-lois.justice.gc.ca/eng/acts/C-44.6/section84.1.html). with the offender), employment, accommodation, family support. If the proposed accommodation is to reside at an other location for day parole, confirm:

- the existence of a Community Assessment of this location. In the event that none exist, a Community Assessment will be required pursuant to $\mathrm{CD} 715-3$ - Community. Assessment (715-3-cd-en.shtml)

- if the community resource agrees to house the offender and has an understanding of their role and responsibilities in supporting and facilitating the offender's release

- the curfews and time to be spent at the location; this must be established in the context of the offender's progress in meeting the objectives of the Correctional Plan

- victim considerations, including possible restrictions on travel, requests from victims for nonassociation conditions, sentencing judge comments.

\section{Annex D - Risk Assessment Framework}

Following an offender's breach of a condition or an increase in the level of risk, the following factors, where applicable, will be taken into consideration when conducting case conferences. For Aboriginal offenders, these factors must be considered relative to the offender's Aboriginal Social History.

\section{Review of Critical Risk Factors}

a. Current risk to re-offend, including existence of high risk situations/triggers

b. Offence cycle

c. Existence of behavioural patterns in the institution related to the offence cycle

d. PBC decisions and any applicable comments

e. Actuarial/clinical measures of risk and any other information from psychological, psychiatric or supplementary assessments

f. Mental health issues and current risk of suicide.

\section{Circumstance of the Breach/Increase in Risk}


a. Nature of the breach/increase in risk and its relationship to the offence cycle

b. Existence of a pattern of similar breaches during the supervision period

c. Police and preventive security information regarding the breach/increase in risk

d. Intoxicant type, severity of the addiction and its relationship to the offence cycle

e. Victim concerns.

\section{Progress Under Supervision}

a. Progress against case specific dynamic factors

b. Length of time and level of stability in the community

c. Information from collateral sources with special attention to recent breakdown of relationships, domestic problems and family violence

d. Previous response to interventions

e. Demonstrated ability to manage offence cycle

f. Recommendations from supervision team members, e.g., community-based residential facility, program facilitators, police, etc.

g. History of substance abuse, type of intoxicant and its link to criminal behaviour

h. Offender's Aboriginal social history to be taken into consideration when assessing progress.

\section{Strategies to Manage Risk}

a. Availability and suitability of additional treatment or programming including cultural interventions and restorative options, including section 81 (http://lawslois.justice.gc.ca/eng/acts/C-44.6/section-81.html), section 84 (http://lawslois.justice.gc.ca/eng/acts/C-44.6/section-84.html) or section 84.1 (https://lawslois.justice.gc.ca/eng/acts/C-44.6/section-84.1.html) supported release plans to address dynamic risk factors and mitigate risk.

b. Availability and suitability of additional control measures to manage risk, e.g., increased reporting, increased urinalysis, community-based residential facility admission, curfews, etc.

c. Availability of support systems, including family members, friends, employers and volunteers to assist the offender's reintegration efforts.

\section{Annex E - Charter Warnings to Offenders with Outstanding Charges}


11/26/2019

Post-Release Decision Process

"I am here to interview you in relation to the suspension of your conditional release (or long-term supervision order as applicable). I have learned that you have outstanding criminal charges and, therefore, I must inform you that you need not say anything about the charges. You have nothing to hope from any promise or favour and nothing to fear from any threat whether or not you say anything. Anything you do say about the charges may be used against you as evidence.

Furthermore, you have the right to retain and instruct counsel without delay. Do you understand? You have the right to obtain legal advice without charge through a 24-hour telephone service which provides access to legal aid duty counsel. Do you understand? Do you want to call a lawyer before we continue the interview?"

\section{Date modified:}

2019-04-11 


\section{Appendix D: CD 715-3-Community Assessments}

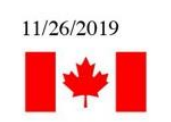

$$
\begin{aligned}
& \text { Government } \\
& \text { of Canada }
\end{aligned} \quad \begin{aligned}
& \text { Gouvernement } \\
& \text { du Canada }
\end{aligned}
$$

Community Assessments

Correctional Service Canada (index-en.shtml).

Home $\rightarrow$ Acts and Regulations $\rightarrow$ Commissioner's Directive $\rightarrow$ Community Assessments

\section{Commissioner's Directive 715-3 Community Assessments}

\begin{tabular}{|l|}
\hline Commissioner's Directive \\
\hline Number: $715-3$ \\
In Effect: $2019-04-15$ \\
Related links \\
Policy Bulletin 633 (633-pb-en.shtml) \\
\hline
\end{tabular}

\section{Authorities}

- Corrections and Conditional Release Act (https://laws-lois.justice.gc.ca/eng/acts/C-44.6/) (CCRA),sections 2 (1)_(https://laws-lois.justice.gc.ca/eng/acts/C-44.6/section-2.html), 3 (http://laws-lois.justice.gc.ca/eng/acts/C-44.6/section-3.html), 3.1 (http://lawslois.justice.gc.ca/eng/acts/C-44.6/section-3.1.html), 4 (http://lawslois.justice.gc.ca/eng/acts/C-44.6/section-4.html), 23 (http://lawslois.justice.gc.ca/eng/acts/C-44.6/section-23.html), 24 (http://lawslois.justice.gc.ca/eng/acts/C-44.6/section-24.html), 71 (http://lawslois.justice.gc.ca/eng/acts/C-44.6/section-71.html), 84 (http://laws-

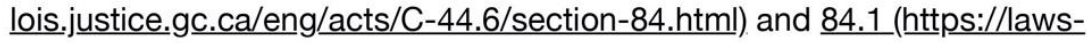
lois.justice.gc.ca/eng/acts/C-44.6/section-84.1.html).

- International Transfer of Offenders Act (http://laws-lois.justice.gc.ca/eng/acts/l20.6/index.html), section 10 (http://laws-lois.justice.gc.ca/eng/acts/l-20.6/section-10.html).

\section{Purpose}

To establish requirements and procedures regarding Community Assessments to assist in the correctional planning process

\section{Applications}

Applies to staff who request and complete Community Assessments 


\title{
Contents
}

\author{
Responsibilities and Procedures \\ - Completion of the Community Assessment Report \\ - Canadian Police Information Centre Checks \\ Annex A - Cross-References and Definitions \\ Annex B - Community Assessment - Report Guide \\ Annex C - Section 84 Community Assessment - Report Guide
}

\section{Responsibilities and Procedures}

1. For procedures regarding Post-Sentence Community Assessment Reports, refer to CD 705-1 - Preliminary Assessments and Post-Sentence Community Assessments (https://www.csc-scc.gc.ca/acts-and-regulations/705-1-cd-eng.shtml).

2. A Community Assessment is required when:

a. there is a new significant source of community information and/or support which needs to be assessed for release planning, including a temporary absence and work release location, or when the offender is in the community

b. existing file information needs to be updated

c. day_parole to an other location is being considered

d. cancellation of the suspension is being considered and the offender's release plan is in another area

e. information is required for an international transfer

f. a victim wishes to provide information which would impact on the management of the case and it is agreed a Community Assessment is required.

3. Information collected from significant contacts will normally be gathered through an in-person interview.

4. The Parole Officer may, in consultation with the Manager, Assessment and Interventions:

a. update or confirm the content of a previous Community Assessment normally through telephone contact, or

b. request or complete a new Community Assessment.

5. When a Community Assessment is required for multiple purposes for the same geographic location, the institutional Parole Officer will request one Community Assessment Report.

6. When multiple contacts are identified in a Community Assessment request for the same geographic location, the community Parole Officer will complete one Community Assessment 
Report which will include all contacts. In cases where this may not be practical, more than one Community Assessment Report may be completed.

7. In the case of private family visits, the Correctional Officer II/Primary Worker will determine if a Community Assessment is required pursuant to $\underline{C D} 710-8$ - Private Family Visits (https://www.csc-scc.gc.ca/acts-and-regulations/710-8-cd-eng.shtml).

8. In all other cases where there is no release to the community (e.g. inter-regional transfer, marriage, transfer of funds), the information gathered can be documented, as applicable, in the Assessment for Decision or in a Casework Record.

\section{Completion of the Community Assessment Report}

9. The Community Assessment Report will be completed as soon as possible but no later than 30 days from the date of request.

10. The Community Assessment Report will be completed as outlined in Annex B or Annex $\mathrm{C}$ in the case of a request made pursuant to section 84 (http://laws-lois.justice.gc.ca/eng/acts/C44.6/section-84.html).

\section{Canadian Police Information Centre Checks}

11. As part of the information gathering process, the decision to conduct a Canadian Police Information Centre (CPIC) check should be made on a case by case basis. When deemed necessary, the Parole Officer will obtain written consent from the community contact using the Consent CPIC Clearance Request (CSC/SCC 1279-01).

12. The contact will be informed of the purpose of the CPIC and that participation is voluntary. However, a refusal could impede the Parole Officer's ability to determine whether the contact is an appropriate support for the offender.

13. The completed Consent CPIC Clearance Request (CSC/SCC 1279-01) will be forwarded to the Security Intelligence Officer and/or police to verify whether the contact is known to police or identify the existence of a criminal record.

14. The existence of a criminal record does not eliminate the individual as a potential source of support. Additional factors need to be taken into consideration such as the nature, number, recency of convictions, and their degree of relevance to the offender's reintegration.

Commissioner,

Original signed by:

Anne Kelly 


\section{Annex A - Cross-References and Definitions}

\section{Cross-References}

CD 001 - Mission, Values and Ethics Framework of the Correctional Service of Canada

(https://www.csc-scc.gc.ca/acts-and-regulations/001-cd-en.shtml).

CD 700 - Correctional Interventions (https://www.csc-scc.gc.ca/acts-and-regulations/700-cdeng.shtml).

CD 701 - Information Sharing_(https://www.csc-scc.gc.ca/acts-and-regulations/701-cd-eng.shtml).

CD 702 - Aboriginal Offenders (https://www.csc-scc.gc.ca/acts-and-regulations/702-cd-eng.shtml)

CD 704 - International Transfers (https://www.csc-scc.gc.ca/acts-and-regulations/704-cd-

eng.shtml).

CD 705-1 - Preliminary Assessments and Post-Sentence Community Assessments

(https://www.csc-scc.gc.ca/acts-and-regulations/705-1-cd-eng.shtml)

CD 710-2 - Transfer of Inmates (https://www.csc-scc.gc.ca/acts-and-regulations/710-2-cden.shtml).

CD 710-3 - Temporary Absences (https://www.csc-scc.gc.ca/acts-and-regulations/710-3-cdeng.shtml).

CD 710-7 - Work Releases (https://www.csc-scc.gc.ca/acts-and-regulations/710-7-cd-eng.shtml).

CD 710-8 - Private Family Visits (https://www.csc-scc.gc.ca/acts-and-regulations/710-8-cdeng.shtml).

CD 712-1 - Pre-Release Decision-Making_(712-1-cd-en.shtml).

GL 712-1-1 - CCRA Sections 84 and 84.1 Release Planning Process (https://www.csc-

scc.gc.ca/acts-and-regulations/712-1-1-gl-en.shtml).

CD 715 - Community Supervision Framework (715-cd-en.shtml).

CD 715-1 - Community Supervision (715-1-cd-en.shtml).

CD 715-2 - Post-Release Decision Process (715-2-cd-en.shtml).

CD 768 - Institutional Mother-Child Program (https://www.csc-scc.gc.ca/acts-and-regulations/768cd-eng.shtml)

CD 784 - Victim Engagement (https://www.csc-scc.gc.ca/acts-and-regulations/784-cd-en.shtml).

Aboriginal Social History Tool

\section{Definitions}

Aboriginal social history: the various circumstances that have affected the lives of most Aboriginal peoples in Canada. Considering these circumstances may result in alternate options or solutions and applies only to Aboriginal offenders (not to non-Aboriginal offenders who choose to follow the 
Aboriginal way of life). These circumstances include the following (note that this is not an exhaustive list):

- effects of the residential school system

- sixties scoop into the adoption system

- effects of the dislocation and dispossession of Inuit people

- family or community history of suicide

- family or community history of substance abuse

- family or community history of victimization

- family or community fragmentation

- level or lack of formal education

- level of connectivity with family/community

- experience in the child welfare system

- experience with poverty

- loss of or struggle with cultural/spiritual identity.

Day parole to an other location: a location that provides accommodation to an offender on day parole, other than a penitentiary, community-based residential facility or provincial institution, as set out in subsection 99(1) of the CCRA. This includes a private home or private facility, which has not been designated as a community-based residential facility.

\section{Annex B - Community Assessment - Report Guide}




\begin{tabular}{|c|c|}
\hline \multicolumn{2}{|r|}{ Community Assessments } \\
\hline & $\begin{array}{l}\text { Reasons for Community Assessment: } \\
\text { - } \text { source of support } \\
\text { - } \text { private family visits (if required) } \\
\text { - work release } \\
\text { - } \text { day_parole to an other location } \\
\text { - community support for leave privileges } \\
\text { - cancellation of suspension } \\
\text { - international transfers. }\end{array}$ \\
\hline $\begin{array}{l}\text { Aboriginal social } \\
\text { history. } \\
\text { (if applicable) }\end{array}$ & $\begin{array}{l}\text { During the interview, discuss and identify any information that can contribute } \\
\text { to the understanding of Aboriginal offenders' social history, including any } \\
\text { culturally specific resources which may contribute to their overall } \\
\text { reintegration. This information is to be presented in heading \# } 7 \text {. }\end{array}$ \\
\hline $\begin{array}{l}\text { 1. Notification to } \\
\text { third party } \\
\text { Complete for all } \\
\text { Community } \\
\text { Assessment } \\
\text { types }\end{array}$ & $\begin{array}{l}\text { Persons contacted to be advised that the information they provide will be } \\
\text { shared with the offender. Should the identity of the contact require } \\
\text { protection, the information will be documented in a Protected Information } \\
\text { Report. The contact will be informed that a summary or "gist" of any } \\
\text { information disclosed will be provided to the offender if this information is to } \\
\text { be used in the decision making process. Refer to CD } 701-\text { Information } \\
\text { Sharing_(https://www.csc-scc.gc.ca/acts-and-regulations/701-cd-eng.shtml). } \\
\text { for the specific procedures regarding the collection of information from } \\
\text { external sources. }\end{array}$ \\
\hline $\begin{array}{l}\text { 2. Source of } \\
\text { information } \\
\text { Complete for all } \\
\text { Community } \\
\text { Assessment } \\
\text { types }\end{array}$ & $\begin{array}{l}\text { For each contact: } \\
\text { - provide a synopsis which includes their name, date of birth, } \\
\text { occupation, relationship to the offender, date of interview, description } \\
\text { of the environment where the interview took place (if relevant), and } \\
\text { other relevant observations about this person } \\
\text { - indicate the contact's criminal history or Canadian Police Information } \\
\text { Centre (CPIC) results, if applicable } \\
\text { - indicate whether the Community Assessment is for a new or existing } \\
\text { contact. }\end{array}$ \\
\hline
\end{tabular}




\begin{tabular}{|c|c|}
\hline 1/26/2019 & Community Assessments \\
\hline $\begin{array}{l}\text { 3. Offender's } \\
\text { relationship with } \\
\text { the contact or } \\
\text { significant } \\
\text { others Complete, } \\
\text { as applicable, to } \\
\text { the Community } \\
\text { Assessment type }\end{array}$ & $\begin{array}{l}\text { Based on information provided by the contact, provide an assessment of : } \\
\text { - the nature of the relationship between the offender and contact } \\
\text { - their ability to provide support to the offender during their sentence } \\
\text { and upon release to the community, where applicable. }\end{array}$ \\
\hline $\begin{array}{l}\text { 4. Contributing } \\
\text { factors } \\
\text { Complete for the } \\
\text { following: } \\
\text { - source of } \\
\text { support } \\
\text { - international } \\
\text { transfer } \\
\text { - private } \\
\text { family visit } \\
\text { (if } \\
\text { applicable) } \\
\text { - Institutional } \\
\text { Mother- } \\
\text { Child } \\
\text { Program } \\
\text { - Day_parole } \\
\underline{\text { to an other }} \\
\text { location }\end{array}$ & $\begin{array}{l}\text { Contact's comments on: } \\
\text { - what contributed to the offender's criminal activity } \\
\text { - awareness or use of social or community services by the offender } \\
\text { - the offender's motivation to engage in their Correctional Plan. } \\
\text { Parole Officer's assessment of: } \\
\text { - all dynamic factors associated with the offender's criminality } \\
\text { - the factors that represent the offender's strengths likely to contribute to } \\
\text { their reintegration } \\
\text { - availability of community resources that could address the offender's } \\
\text { need upon release (if applicable). }\end{array}$ \\
\hline $\begin{array}{l}\text { 5. Information } \\
\text { regarding the } \\
\text { request } \\
\text { - Complete, } \\
\text { as } \\
\text { applicable, } \\
\text { to the } \\
\text { Community } \\
\text { Assessment } \\
\text { type }\end{array}$ & $\begin{array}{l}\text { Work Release } \\
\text { Provide an assessment of: } \\
\text { - the community employer's understanding of the offence cycle and } \\
\text { willingness to accept the offender on work release } \\
\text { - any concerns expressed by the employer. } \\
\text { Include: } \\
\text { - work release plan specifying conditions and level of supervision } \\
\text { required. }\end{array}$ \\
\hline
\end{tabular}




\section{Private Family Visits}

Provide information regarding the contact's eligibility and interest to participate in private family visits, issues related to family violence and concerns regarding child safety.

If not already submitted, obtain completed forms Declaration of Commonlaw Union (CSC/SCC 0530E) and Statement of Voluntary Participation and Consent for Private Family Visits (CSC/SCC 0531) and collect photographs from all participants.

Information regarding the contact's requirements (medication, accommodations, specific goods, etc.) will be collected, but not documented in the Community Assessment. this information will be shared with the institutional Parole Officer to ensure security measures can be initiated as required.

\section{Institutional Mother-Child Program (residential component)}

Provide:

- concerns or comments on relationship with the child and parenting ability of inmate

- any information to indicate if participation is in the best interests of the child and any risk posed to the child.

\section{Day Parole to an other location}

Based on the information provided by the community contact, provide an assessment incorporating the following elements, as applicable:

- the relevance of the offender's release plan, and suggestions for additions or alternatives to the plan with a corresponding rationale

- the unique needs and circumstances of Aboriginal offenders, women offenders, aging offenders or other groups of offenders with specific requirements

- programs accessible in the proposed location to address what seems to be the offender's contributing factors

- employment opportunities and training

- availability of social services for problems with drugs, alcohol, mental health, income support, etc.

- the community contact's ability to assist the offender in their participation in/completion of community programs 
- monitoring the offender's physical presence within the confines of their residence for a set number of hours in each calendar day, as determined by the supervising Parole Officer; and monitoring curfew restrictions

- monitoring the offender's behaviour and provide support services, which will in turn assist offenders in attaining both short and long-term goals, as specified in the offender's Correctional Plan and Community Strategy

- the details of any support needed/provided (financial, social, etc.)

- the agreement of the community contact to participate in the proposed release plan, and an understanding of their role and responsibilities in supporting and facilitating the offender's release.

\section{Cancellation of Suspension}

- Provide an assessment of the new release plan.

\section{International Transfer}

Based on information provided by the contact, in order to satisfy legislative factors outlined in section 10 of the International Transfer of Offenders Act (http://laws-lois.justice.gc.ca/eng/acts/l-20.6/index.html) for the Minister's consideration, assess by discussing and documenting the following information:

\section{Public Safety:}

- Whether the offender's return to Canada will endanger public safety, including:

- the safety of any person in Canada who is a victim, as defined in subsection 2(1)_(http://laws-lois.justice.gc.ca/eng/acts/C44.6/section-2.html) of the CCRA (https://lawslois.justice.gc.ca/eng/acts/C-44.6/), of an offence committed by the offender

- the safety of any member of the offender's family, in the case of an offender who has been convicted of an offence against a family member

- the safety of any child, in the case of an offender who has been convicted of a sexual offence involving a child.

\section{Abandonment/Citizenship}


- Whether the offender left or remained outside Canada with the intention of abandoning Canada as their place of permanent residence

- Place of birth, date citizenship was granted, whether citizenship was renounced in the past, whether offender has dual citizenship with another country other than Canada, place of residence at the time of the offence, time spent living in the foreign country, return visits, period of time spent living in Canada before moving to another country, determination of intention and whether a subsequent citizenship was sought.

\section{Family and Social Ties}

- Whether the offender has social or family ties in Canada

- Nature of the relationship with family or friends. How often was there communication or visits prior to and/or after the present offence? What services or support can be offered? Is this person a positive support? Does the family/contact or Global Affairs Canada have to subsidize the offender's incarceration and provide for their well-being and welfare?

\section{Human Rights}

- Whether the foreign entity or its prison system presents a serious threat to the offender's security or human rights.

\section{Offender's Health}

- Whether the offender has any physical and/or mental health concerns, their nature and level of seriousness

- Does the contact know if the offender is receiving programming and/or treatment in the foreign prison? In the contact's opinion, does this institution or country pose a threat to the offender's health or safety?

\section{Program Participation}

- Whether the offender has refused to participate in a rehabilitation or reintegration program.

\section{Responsibility and Harm to Victims}

- Whether the offender has accepted responsibility for the offence for which they have been convicted, including by acknowledging the harm done to victims and to the community.

\section{Cooperation}

- Whether the offender has cooperated with a law enforcement agency. 


\section{Breach of Trust/Affiliations}

- Is the contact aware whether the offender has, in the past, escaped lawful custody, or breached a court order or probation/parole order? Do they have knowledge whether the offender has links to criminal organizations, gangs or security threat groups and, if so, what was the offender's involvement?

\section{Police or other official information Complete, as required, for the following: \\ - source of support \\ - release to community \\ - cancellation of suspension \\ - work release \\ - international transfers}

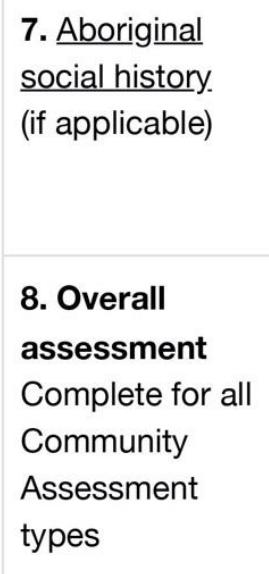

Provide an overview of information obtained from criminal justice partners (Social Services, probation, police, community residential facilities, etc.).

For offenders who are planning a release to an Aboriginal community and do not have an identified plan pursuant to section 84 (http://lawslois.justice.gc.ca/eng/acts/C-44.6/section-84.html) or section 84.1 of the CCRA, consultation with Band members/Council/Justice Committee, etc. should be considered to confirm whether release to the community is supported. The Consent for Disclosure of Personal Information - (Inmate) (CSC/SCC 0487) is required prior to consultation.

In the case of international transfers, include any police information on the offender related but not limited to existing criminal record, outstanding charges, warrants, etc.
Based on the information provided by the contact, provide a summary of any information that can contribute to the understanding of an Aboriginal offender's social history, including availability or past utilization of any Aboriginal community resources which may serve to enhance the offender's eventual reintegration.

Provide an overall assessment of the contact, level of community support available, impact on the offender's reintegration potential and level of engagement.

For international transfers, provide factual and objective information and do not provide opinions, views and recommendations with respect to the application itself. 


\section{1/26/2019 Community Assessments}

\section{Annex C - Section 84 Community Assessment - Report Guide}

\section{Notification to third party}

Persons contacted to be advised that the information they provide will be shared with the offender. Should the identity of the contact require protection, the information will be documented in a Protected Information Report. The contact will be informed that a summary or "gist" of any information disclosed will be provided to the offender if this information is to be used in the decision making process.

Refer to CD 701 - Information Sharing_(https://www.csc-scc.gc.ca/acts-and-regulations/701cd-eng.shtml) for the specific procedures regarding the collection of information from external sources.

\section{Sources of information}

- Name of community

- Organization (e.g. Community Service, Justice Committee, Band Council, Mayor)

- Government structure (i.e., elected or hereditary)

Indicate if the report is completed for an offender's new source of support or a Community Assessment update.

\section{Offender's relationship with the community or significant others}

Based on information provided by the community, provide an assessment of:

- the nature of the relationship between the offender and community (offender is a member of the band/organization)

- the history of criminal behaviour

- the degree of support the community is prepared to offer to the offender regarding their reintegration in the community (in the present and in the future), as well as the reliability of the information obtained

- the offender's social network

- the offender's relationship with peers or significant others

- victim concerns.

\section{The community perspective of contributing factors}

Based on information provided by the community, where relevant, provide an assessment of:

- the criminal behaviour and factors likely to contribute to the safe reintegration of the offender in the community:

- offender's employment history (pattern of employment and job satisfaction)

- offender's substance abuse history 
- offender's attitude towards accepted social values and their views on living a lawabiding lifestyle

- influences associates may have over the offender

- offender's personality (e.g., impulsive, empathetic, sensation seeking, manipulative)

- pattern such as aggression, assertion, coping mechanisms or frustration tolerance

- offender's sexual dysfunction

- offender's mental health

- the offender's childhood, including whether the family unit had a negative or positive influence on the offender

- the offender's experience as a residential school survivor (including whether or not the offender was inter-generationally impacted)

- the factors that represent the offender's strengths likely to contribute to their reintegration

- the interest of the community in participating in a community hearing and/or restorative justice process.

\section{Reintegration plan}

Where relevant, provide an assessment of:

- programs accessible in the community to address what seems to be the offender's contributing factors

- employment opportunities and training

- spiritual resources (e.g. longhouse, sweat lodge, sundance)

- availability of social services and/or traditional approaches to healing for problems with drug, alcohol, mental health, etc.

- the capacity and concerns regarding the supervision and reporting of offender by the community

- the community's ability to assist the offender in the participation/completion of community programs

- the leisure activities and awareness/use of social/community services by the Aboriginal community and the offender

- the relevance of offender's release plan(s), and suggestions for additions or alternatives to the plans with a corresponding rationale

- the dynamic contributing factors to be addressed prior to release (order of priority of the dynamic factors) 
- the agreement of the community to participate pursuant to section 84 (http://lawslois.justice.gc.ca/eng/acts/C-44.6/section-84.html) or section 84.1 (https://lawslois.justice.gc.ca/eng/acts/C-44.6/section-84.1.html).

\section{Overall assessment}

The Aboriginal Community Development Officer must examine all information obtained in the other sections and summarize their opinion on the community support available.

Date modified:

2019-04-25 